EQUITY-BASED RESOURCE ALLOCATION FOR INFRASTRUCTURE DEVELOPMENT 
Examining committee:

Prof.dr.ir. A. Veldkamp

Prof.dr.ir. A. Stein

Prof.dr. A.A. Voinov

Prof.dr. tech. ir. D. Parikesit MSc

Prof.dr. R.W. Künneke
University of Twente

University of Twente

University of Twente

Universitas Gadjah Mada, Indonesia

TU Delft

ITC dissertation number 278

ITC, P.O. Box 217, 7500 AE Enschede, The Netherlands

ISBN 978-90-365-3999-9

DOI 10.3990/1.9789036539999

Cover "W-Curve" designed by Arif Wismadi

Printed by ITC Printing Department

Copyright (C) 2015 by Arif Wismadi 


\title{
EQUITY-BASED RESOURCE ALLOCATION FOR INFRASTRUCTURE DEVELOPMENT
}

\author{
DISSERTATION
}

to obtain

the degree of doctor at the University of Twente, on the authority of the rector magnificus, prof.dr. H. Brinksma, on account of the decision of the graduation committee, to be publicly defended on Wednesday, November 11, 2015 at 14:45 hrs

by

Arif Wismadi

born on 13 June 1968

in Purbalingga, Indonesia 
This thesis is approved by

Prof.dr.ir. M.F.A.M. van Maarseveen, promoter

Dr.ir. M.H.P. Zuidgeest, co-promoter

Dr. J. Flacke, co-promoter 


\section{Acknowledgements}

The research is an integrated activity with Indonesian Facility (INDF) Project, funded by Netherlands Ministry of Economic Affairs that jointly conducted by ITC University of Twente, The Center for Transport and Logistics Studies (PUSTRAL) - Universitas Gadjah Mada, Indonesia and Keypoint Consultancy BV, the Netherland. The project of "Curriculum Development for Integrated Infrastructure Planning and Community Development, Yogyakarta City, Province of DI Yogyakarta, Indonesia" started on 1 October 2007 to 31 May 2011. The project provides 18 months of intermitten stay in ITC. This PhD research also received ITC Research Fund to allow additional quality time of interaction with supervision team in the Netherland. Within several years, many people have been involved, the author acknowledges everyone who have contributed to this work.

First of all, I would like to express my sincere thanks and highest appreciation to my promotor Prof. Dr. Martin van Maarseveen for his valuable advice and assistance which greatly improve the quality of my $\mathrm{PhD}$. His warm support to academic and family life provides the strongest foundation for each step to finalize my study. I wish also to express my sincere thanks to Mr. Mark Brussel who dedicated a lot of his time to support and guide me toward the end. He patiently supervise with each constructive view leading to quality. Without him in the first inner circle of my study, it would be very hard to reach my PhD. When he was assisting me in writing up Samenvatting, I was thinking that he deserves to have it for his own.

I owe my sincere gratitude to Mr. Tom Loran and Dr. Mark Zuidgeest, my co-promotor, who was offering me a great opportunity for pursuing $\mathrm{PhD}$ degree immediately after INDF Project was granted. Their intensive companion in the project and extensive research networks have widely opened my opportunity on academic and professional career. My gratitude goes also to Mr. Leo de Jong of Keypoint Consultancy, without his participation the initiative in INDF will not come to the stage to allow me starting my PhD study.

I wish also to express my sincere gratitude to Dr. Johannes Flacke, my copromotor, who always very helpful in providing the best advise and decision during my difficult time.

I would especially like to thank Dr. Ali Sharifi who opened the world of Spatial Decision Support Systems and Dr. Luc Boerboom for always allow 
me to enjoying experiment in SDSS fields in ITC. I also express my special gratitude to Prof. dr. Alfred Stein for introducing me to my new world of spatial statistics.

My special thanks are to Loes Colenbrander for her continuous facilitation, support, and detailed attention for each aspect of my study, and Petra Weber for all assistance during my stay and showing me to a thousand of nice example on concise writing. I want to thank Marga Koelen for widely opening the access to the bank of knowledge, including the opportunity for outreaching my work to be accessible by all communities though openaccess priviledge. Thanks also to Benno Masselink for finishing touch the production of my thesis.

I would like to thanks Mr. Frans van den Bosch for a wide range of discussion from the field of Geo-informatics to Dutch social life. Special thanks to Fangfang Cheng and Dr. Pu Hao for every detail of warmest oriental hospitalities during my stay in Enschede, and also for Dr. John Carranza, for his warm welcome to scientific and sporty social life in each of my intermittent stay in the Netherland.

Big thanks to all staffs in the Department of Urban and Regional Planning and Geo-information Management (ITC-PGM) who always supportive to serve with friendly environment.

Special gratitude goes to Prof Danang Parikesit for giving a lot of opportunies on career development and courage to work on the field of public infrastructure. He always push me to swim in the bigger ocean of professional challenges. Special thanks and respect to the late Dr. Heru Sutomo for trusting me to work on cutting-edge research areas in Pustral. I am grateful to Prof. Sunyoto Usman for inspiring my scientific excitement to social and political science. I also thank Mr Hengky Purwoto that has been for years accompanying my curiosity on economic and infrastructure interaction, aslo for Dr. Kuncoro Harto Widodo and Dr. Muhammad Pramono Hadi for hosting research enviroment with multi-tasking opportunity. I thanks to Dwi Ardianta Kurniawan for his support to cleaning up the spaghetti of the database for my research, and of course for every individual in my organization who always support me during challenging periods of mutlitasking activities.

Thanks for all INDF project team, Dr. Richard Sliuzias, Emile Dopheide, Dr. Sherif Amer, Dr. Javier Martinez, Liza Groenendijk, Dr. Tumiran, Prof. Achmad Djunaedi, Prof. Djoko Legono, Dr. John Suprihanta, Dr. Trias Aditya, Prof. Aris Marfai, and also Mery Khristanti for her best effort for 
managing any possible slot for my contribution in Management of Infrastructure and Community Development (MICD) course (http://pipm.pasca.ugm.ac.id).

I thank to Department of Architecture and Faculty of Civil Engineering and Planning, Islamic University of Indonesia for all the support and to allow me to take the opportunity to work in inter universities environment.

Although I always stay for very short period of time in Enschede, the life at ITC always supportive, especially from Dr. Wiwin Ambarwulan, Dr. Tyas Mutiara Basuki, Syarif Budhiman, Anas Fauzi, Nasrullah, Nugroho Christanto, Ratna Dewi, Hunggul Yudono, all Indonesian friends and families in Enschede, especially Ibu Dewi Pikaar.

I am and will everlasting be deeply indebted to my parents, my Mother and Father, for enabling me to achieve each level of life through their endless love and prayers.

Finally, thanks a million for Sridayanti, the "Super Mom" of my beloved children Fathin, Tsaqif, Nabila and Dzaki. 


\section{Table of Contents}

Acknowledgements .......................................................................................................

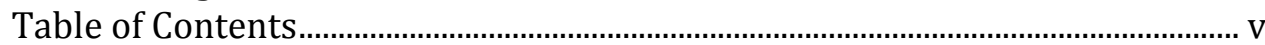

List of figures....................................................................................................................... ix

List of tables.............................................................................................................

Chapter 1 Introduction......................................................................................... 1

1.1 Background ...................................................................................................... 1

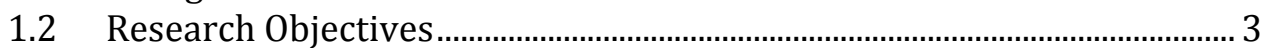

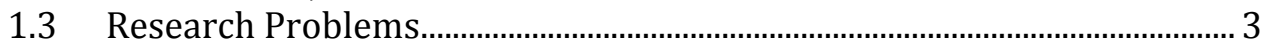

1.4 Research Framework ....................................................................................... 5

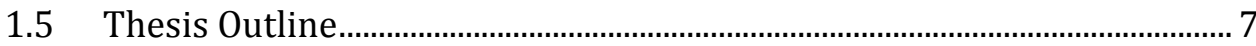

Chapter 2 Equitable infrastructure in economic geography: implication of global policy on specific locality........................................................... 9

2.1 Introduction: inquitable growth in Indonesia, policy or implementation problems?.........................................................................10

2.2 Debate on policy framework for economic geography .............................11

2.3 Politics of distribution and policy to swing the pendulum........................15

2.3.1 Shifting policy on infrastructure service provision.............................16

2.3.2 Multinational firms serve local utility services ...................................16

2.3.3 Options to transform local utility enterprises and inequity risk...18

2.3.4 Universal Service Obligation for equitable public service and

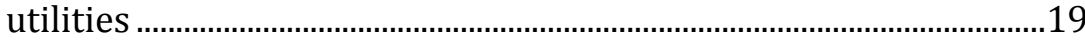

2.3.5 Institutional options to provide equitable public service..................20

2.3.6 Business model of the agency and required planning capacity .....21

2.4 Infrastructure planning capacity toward equitable growth .....................22

2.4.1 Determining indicators for equitable growth......................................22

2.4.2 Demand to accountably decentralize use of resource........................23

2.4.3 Equity assessment for infrastructure policy and planning ..............24

2.4.4 Shortcoming in equity measurement....................................................25

2.5 Understanding interaction and texture before policy ...............................27

2.5.1 Integrated Infrastructure Modelling ………………………………...27

2.5.2 Understanding localities of infrastructure-economy interaction..28

2.5.3 Infrastructure network expansion and the dynamics of spatial

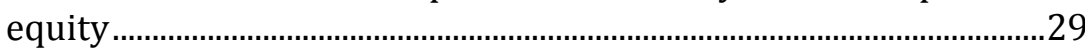

2.5.4 Infrastructure typology which forms texture in geography ............30

2.6 Case Study: WDR policies applied at local context of Yogyakarta,

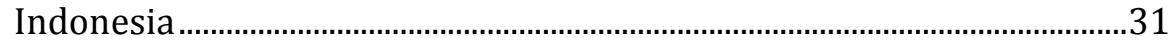

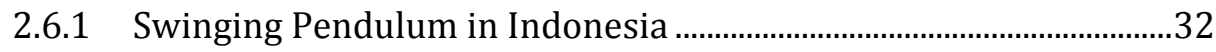

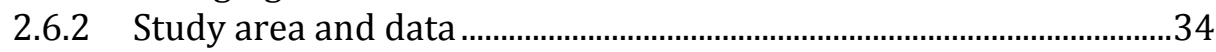

2.6.3 WDR Policy Instruments at different localities...................................37

2.6.4 Discussion on the potential inequity risk and benefit produced

by the implemented policy .........................................................................40 


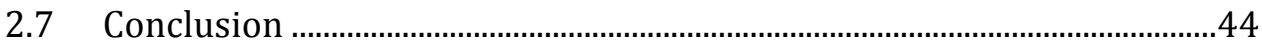

Chapter 3 The Shortcoming of Current Equity Measurements .......................47

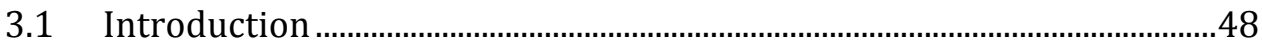

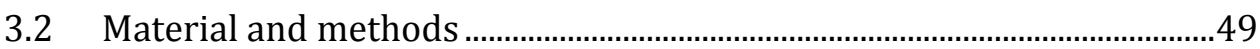

3.2.1 Study Design ....................................................................................... 49

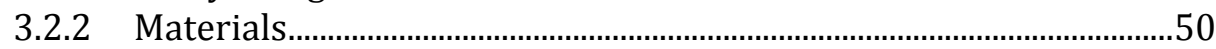

3.2.3 3.2.3 Measurement methods and the framework for analysis ........50

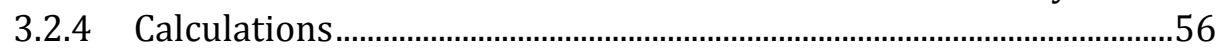

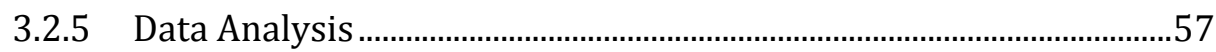

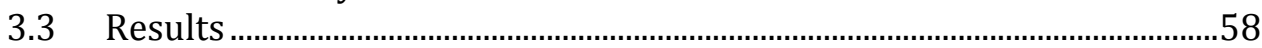

3.3.1 Results of Methods Assessment ........................................................58

3.3.2 Results on Pro-poor Growth Measurement.........................................60

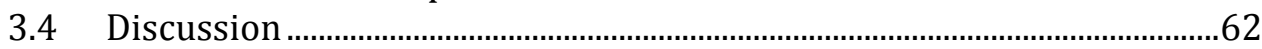

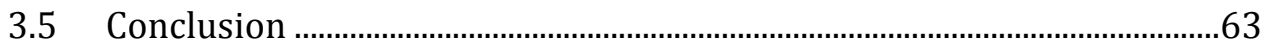

Chapter 4 Spatial Interdependency in Infrastructure Development .............65

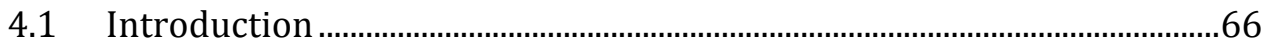

4.2 Concepts of infrastructure and economic opportunity distribution .....69

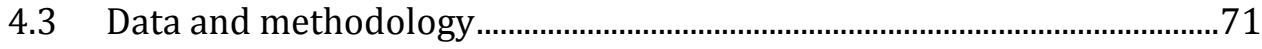

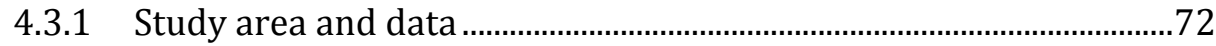

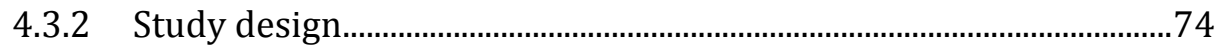

4.3.3 Model specification..............................................................................

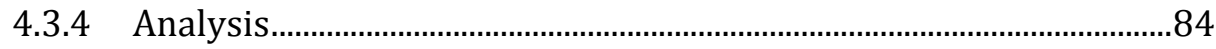

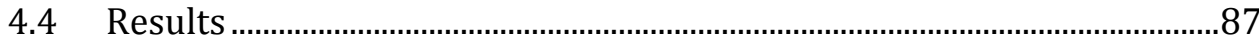

4.4.1 Regression diagnostics and analysis of spatial dependence ...........87

4.4.2 Model parameters and general model fit ..............................................88

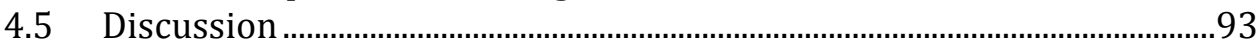

4.6 Conclusions ..........................................................................................96

Chapter 5 Spatial Preference Modelling for Equity Based Resources

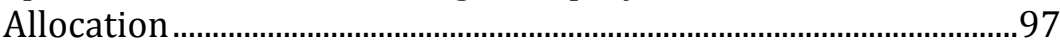

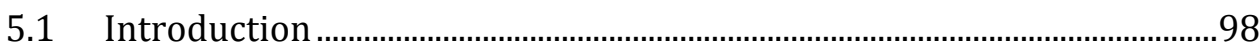

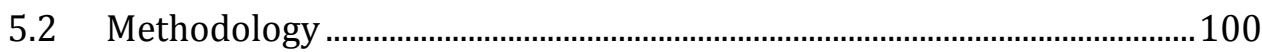

5.2.1 Research Design...................................................................................100

5.2.2 Sen's Capability Approach in Preference Modelling .........................101

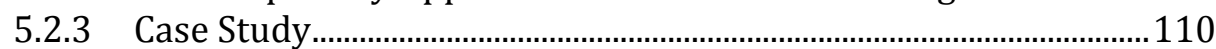

5.2.4 Modelling allocation of transport infrastructure resources.........112

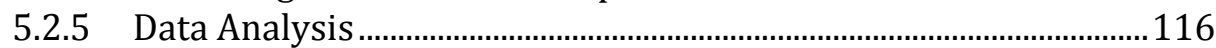

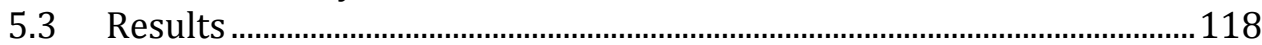

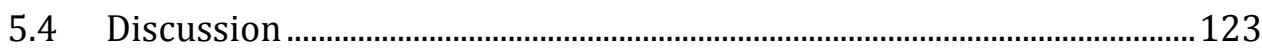

5.5 Conclusions …………………...............................................................126

Chapter 6 Equitable Distribution of Growth for Utilitarian and NonUtilitarian Infrastructure Planning ……………………...............127

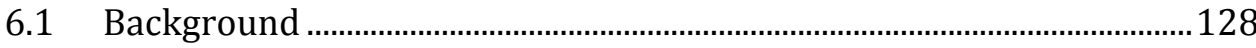

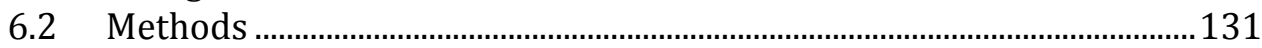


6.2.1 Study area and data ...............................................................................133

6.2.2 Calculations in Preference Modelling.................................................136

6.2.3 Procedure for location-allocation......................................................138

6.2.4 Equity measurement.......................................................................139

6.2.5 Curve dominance analysis for non-utilitarian equality measure140

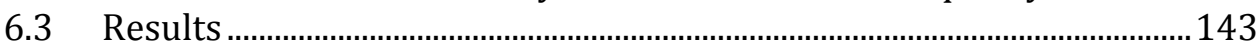

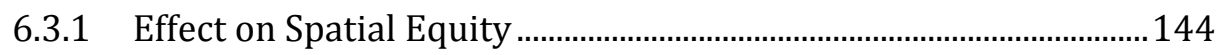

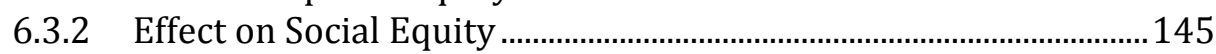

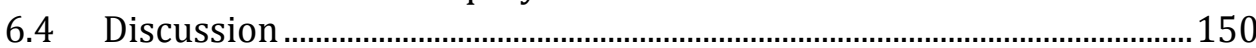

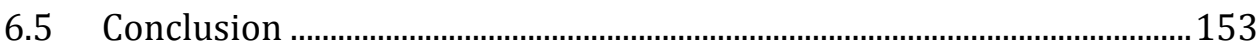

Chapter 7 Equity-based Resource Location-Allocation Simulation (EQLAS): A new SDSS framework for integrated infrastructure

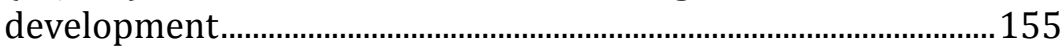

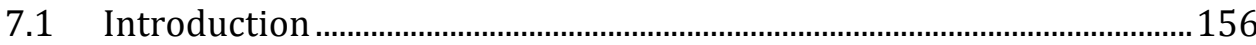

7.2 EQLAS framework ..............................................................................158

7.2.1 Concept: Equality or Equity? .........................................................158

7.2.2 Specific focus of an SDSS on equity-based resource allocation...158

7.2.3 SDSS framework in EQLAS .................................................................159

7.3 EQLAS development process ……………................................................ 163

7.3.1 Analysis in each stage of the decision-making process ..................163

7.3.2 Case study and data set for developing EQLAS ................................165

7.3.3 Lesson learnt from EQLAS development...........................................168

7.4 Implementation in National Infrastructure Programmes.......................168

7.4.1 Transformation of resource allocation decision making in

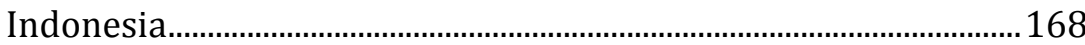

7.4.2 Implications of the transformation for the decision-making process on infrastructure and spatial development......................169

7.4.3 Requirement for information infrastructure and a spatial decision support system for village development. .........................................170

7.5 Case studies of Rural Infrastructure in Indonesia....................................172

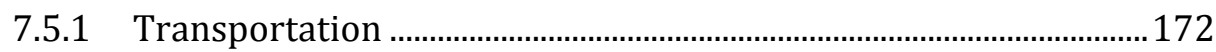

7.5.2 Telecommunications........................................................................... 173

7.5.3 Operationalizing EQLAS in the telecommunications and

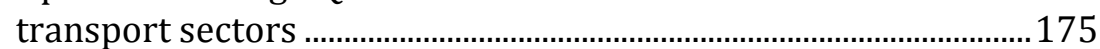

7.6 EQLAS deals with conflicting objectives .................................................. 179

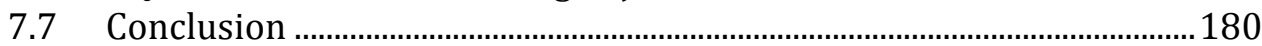

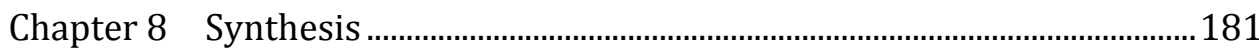

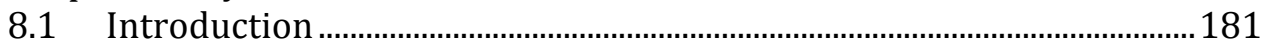

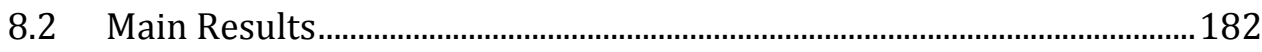

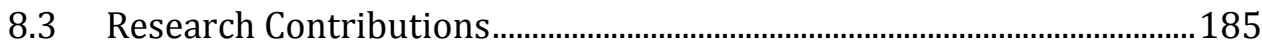

8.3.1 Contributions on the formulation of policy and its implementation of infrastructure resource allocation to address spatial and social inequity..................................................................... 185 
8.3.2 Contributions on the development of Spatial Decision Support Systems (SDSS) ....................................................................................186

8.3.3 Contribution on the multi-disciplinary knowledge of management of infrastructure and community development.....187

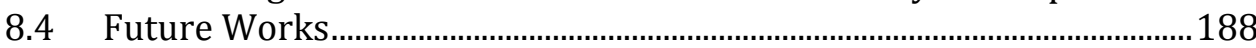

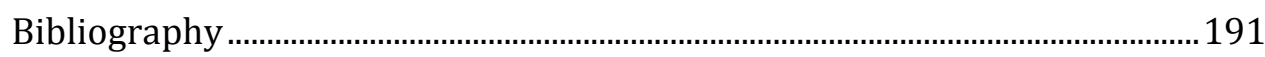

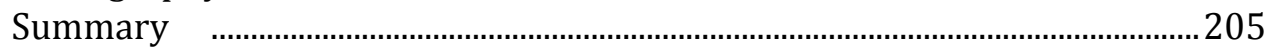

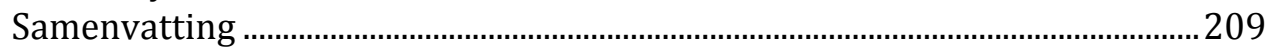

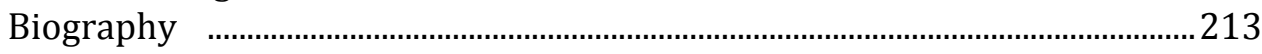

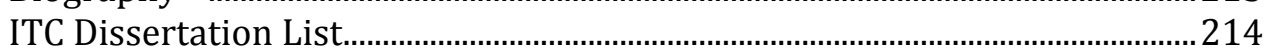




\section{List of figures}

Figure 1.1 Research Framework

Figure 2.1 Models of line patterns. The spatial equity increases along with the increasing connectivity of the networks (Cai, Hirtle et al. 1999)

Figure 2.2 The study area is located in the Special Province of Yogyakarta, Indonesia, with 438 urban and rural villages, urban area at the center of radial road networks.

Figure 2.3 Distribution of infrastructure and economic opportunity in the study area.

Figure 3.1 The framework of methods assessment

Figure 3.3 Graphical representation of the TIP Curve (after UNDP, 2008)

Figure 3.4 Graphical representation of CDF, PDC and PSC (modified from UNDP, 2008)

Figure 3.5 Graphical representation of Pen's Parade (after UNDP, 2008)

Figure 3.6 The calculation procedure from raw data into the indicators of mobility

Figure 3.7 Lorenz Curve

Figure 3.9 Normalized and axes-switched CDF or Pen's Parade

Figure 4.1 The study area is located in the Special Province of Yogyakarta, Indonesia, with 438 urban and rural villages; the study utilises village-level data on demographic, socio-economic and infrastructurerelated issues.

Figure 4.2 Spatial distribution of model's variables. The dark colours represent higher values or better infrastructure performance.

Figure 4.3 Study design

Figure 4.4 OLS for Integrated Infrastructure (Model 1) and Spatial-Lag OLS for Spatial Integrated Infrastructure (Model 2).

Figure 4.5 The shapes of the MFs for the input variables. Each curve estimates the degree of membership for each infrastructure performance to be classified in a certain class. The peak of each curve indicates degree of membership: 1 or $100 \%$. 
Figure 4.6 The architecture for the Sugeno FIS model for SIII (Model 3). Rule-based OLS is implemented in Layer\#4, Defuzzification Layer.

Figure 4.7 Example of FIS calculation for Layers 1, 2 and 3. The example of weighting factor and normalised weighting factor calculation.

Figure 4.8 OLS within Sugeno-FIS procedure in Spatial Integrated Infrastructure Interdependency model (Model 3). It employs OLS and Spatial-Lag OLS for each rule required by FIS.

Figure 4.9 Modelling results. It shows the predicted economic opportunities. Model 1: Integrated Infrastructure (II), Model 2: Spatial Integrated Infrastructure (SII), and Model 3: Spatial Integrated Infrastructure Interdependency (SIII). Blue, yellow and red respectively represent high, medium and low economic opportunities.

Figure 4.10 Spatial data for validation. The modelling results are compared with these Prosperity Level (PL) and the Subjective Well-being (SW).

Figure 5.1 Example of Row Standardisation Method (Source: Feser and Sweeney 2006).

Figure 5.2 The Study Area is located in the Special Province of Yogyakarta, Indonesia, with 438 urban and rural villages. (Source: compiled by the authors based on BPS, 2006)

Figure 5.3 The calculation of raw data for Preference Modelling with mobility as a non-income indicator (Source: compiled by author)

Figure 5.4 Policy Interpretation of simulation results (Source: compiled by author)

Figure 5.5 Initial Data before Simulation (Source: compiled by author).

Figure 5.6 Spatial Priority Targeting, the distribution of allocation preferences in the simulations. (Source: compiled by author).

Figure 5.7 Effect of the Location-Allocation (Source: compiled by author).

Figure 5.8 LISA Maps, the distribution of Spatial Priority Targeting (Source: compiled by author).

Figure 5.9 LISA Maps, before (Initial) and the Effect of LocationAllocation after Simulation (Source: compiled by author). 
Figure 6.1 Research Framework

Figure 6.2 The Special Province of Yogyakarta, Indonesia, consisting of 438 urban and rural villages. Note: The urban area is at the centre of the radial road networks. The dark colours represent villages with higher values or better infrastructure system performance.

Figure 6.3 Procedure for Location-Allocation Mechanism.

Figure 6.4 Original Pen's parade (above) and V-curve parade of gaps (Yp) and surpluses (Yr; below).

Figure 6.5 Spatial equity at the initial level and after allocation with SPM and NSPM. Note: LISA, blue (or black in a b/w colour) represents low-low, red (or dark grey in a b/w colour) represents high-high, and Moran's I discloses that in general, spatial PM is more effective to address spatial equity.

Figure 6.6 Curve dominance analysis, which discloses the similarity of patterns in the telecommunications and water infrastructures.

Figure 7.1 EQLAS Development Process, summarizing the three main stages of the SDSS framework applied in this research.

Figure 7.2 SDSS Framework for Equity-based Resource LocationAllocation Simulation

Figure 7.3 The study area is located in the Special Province of Yogyakarta, Indonesia, with 438 urban and rural villages; the study utilizes village-level data on demographic, socio-economic and infrastructurerelated issues. 


\section{List of tables}

Table 2.1 Typology of infrastructure and examples of real-life representation

Table 2.2 Example of WDR policy instrument applied in localities 38

Table 3.1 Result of methods assessment $\quad 59$

Table 3.2 Summary of Rank between Years 61

Table 3.3 Pro-poor growth analysis $\quad 62$

$\begin{array}{lll}\text { Table 4.1 Variables and the data sources } & 73\end{array}$

Table 4.2 Parameter $\left(\mathrm{c}_{\mathrm{ij}}\right)$ for Gaussian MFs 78

Table 4.3 Number of rules and number of records $\quad 82$

Table 4.4 Diagnostics for Heteroskedasticity 87

Table 4.5 Analysis of spatial dependence 88

Table 4.6 Model parameters in Model 1 and Model $2 \quad 89$

Table 4.7 Reliability of variables in the Rule-Based OLS within FIS for Model $3 \quad 90$

Table 4.8 Summary of Contingency Matrix of Prosperity Level 92

$\begin{array}{ll}\text { Table 4.9 } & \text { Summary of Contingency Matrix of Subjective Well- } \\ \text { being } & 92\end{array}$

Table 4.10 Summary of Kappa Statistics 92

Table 5.1 Variables and data sources 112

Table 6.1 The Data Set 135

Table 6.2 Indices of non-utilitarian equality measure 143

Table 6.3 Minimum Service Level of Domestic Activity as the Poverty Line $\quad 143$

Table 6.4 Evaluation Matrix 144

Table 6.5 Average Redistributed Growth $\quad 144$

Table 6.6 Utilitarian Total Equality 146

Table 6.7 Poverty Incidence 148

$\begin{array}{lll}\text { Table } 6.8 \text { Maximum Severity } & 149\end{array}$

Table 6.9 Poor and Rich Inequality $\quad 149$

Table 6.10 Maximum Prosperity 150

Table 7.1 Variables and the data sources 166

Table 7.2 Minimum Service Level for Domestic Activity as the Poverty Line 168

Table 7.3 Operationalizing EQLAS in the Telecommunications and Transport Sectors $\quad 177$ 


\section{Chapter 1}

\section{Introduction}

\subsection{Background}

Resource allocation for infrastructure development is one of the central issues in many developing countries. Under a limited budget, resource allocation becomes more critical. The budget constraint problem increases the complexity of the decision-making mechanism that includes different policy objectives for development (Liang and Wey 2013). One classical policy trade-off is equity versus efficiency and growth objectives (Castells and Solé-Ollé 2005).

In the decision-making processes for infrastructure development, Indonesia is currently mainstreaming pro-poor (directed at achieving equity and favouring the poor), pro-growth (directed to increase economic growth) and pro-job (directed to increase opportunities to economic opportunities) policies (Essama-Nssah 2005; Bakker 2007). These policies have been on the main development agenda in various countries. Certain attempts to evaluate the impact have occurred (Essama-Nssah 2005; Son and Kakwani 2008); however, a comprehensive and systematic framework for executing (Kraay 2006; Bakker 2007) and evaluating these policies with consistent results does not exist (Essama-Nssah 2005).

In an infrastructure development context, a pro-poor policy's objective is to include equity principles in a resource allocation mechanism to provide opportunities for communities to join economic activities. Economic growth may be called pro-poor if the poor enjoy the benefits of growth proportionally more than the non-poor do. In this situation, inequity declines concurrently during the course of growth (Son and Kakwani 2008). The equity measure includes 'social equity' (striving equity over different socio-economic groups) and 'spatial equity' (striving equity over space to prevent regional disparity).

With regard to regional development, two possible approaches to promote the role of infrastructure and economic interaction are available, placebased policies and people-centred policies. These policy options have been detailed in the publication of the World Development Report (WDR) 2009 (Garretsen, Roberts et al. 2011) and separated into three policy instruments for reshaping economic geography: 1) spatially blind institution, 2) spatially connective infrastructure and 3) spatially targeted 
incentive. The first instrument aims to change the landscape of social and spatial equity through institutional reform disregards its regional position. While the other two always applied with the context of location and space.

Each country or region may have its own desire to adopt these policy options. The EU, for example, chooses the Place-Base Policy to develop Trans-European transport links and key environmental infrastructure projects to support the program for targeting resources at key growth sectors (European Commision 2013), whereas ASEAN, with its ASEAN Master Plan of Connectivity, plans to develop a policy on "physical, institutional and people-to-people connectivity" towards a people-oriented ASEAN with One Vision, One Identity, One Community by 2015 (ASEAN 2011).

Although the WDR policy framework has obtained great acceptance from policy makers, many scholars criticize how choice and implementation are often driven by a pro-growth policy (Maringanti, Sheppard et al. 2009) with less focus on equity (Lawson 2010) because of ignorance of the local context (Maringanti, Sheppard et al. 2009). In addition, a pro-growth policy often ignores critical socio-spatial relations, mobilities and spatialities that shape development processes and outcome distribution, according to Murphy (2011). Moreover, the absence of an equity assessment of the implication of either place-based policies or people-centred policies raises the country's risk of social tension (Lawson 2010). The London Riot (Baudains, Johnson et al. 2013; Till 2013) and the May 1998 Riot in Indonesia (Panggabean and Smith 2011) are examples of outcomes of equity issues associated with policy implications that govern cities and states (Musterd and Ostendorf 2012).

To properly adopt the WDR policy framework, the scholars who criticized (Maringanti, Sheppard et al. 2009; Lawson 2010; Murphy 2011), the neutral readers (Garretsen, Roberts et al. 2011) or the proponents of the WDR (Deichmann, Gill et al. 2010; Deichmann, Gill et al. 2011) suggest that there is a need to refine the policy framework to be more practical and consistent in promoting equitable development in various contexts and localities.

To recraft the WDR policy framework, Indonesia, as the 4th largest country in the world, is a significant choice for a case study. Indonesia is particularly an excellent choice because of its experiences with high growth and its high social and spatial inequity, which resulted in a massive uprising in 1998 by those demanding more equitable distribution of 
resources. Currently, the country continues to transform into more decentralized systems.

\subsection{Research Objectives}

Discourse on place-based policies vs people-centred issues in the context of distributive welfare converges in an attempt to simultaneously address social and spatial equity. Therefore, instead of diverging from those options, this study's objective is to equip policy makers with an understanding of both and the implication for equity in the local context and to provide them with recommendations on where and when those policy options should be applied or combined.

Here, concern for the equity measures is not only focused on providing quantitative description regarding the current level of equity but also strives to systematically address inequity. This intervention requires an equity-based resource location-allocation approach to improve infrastructure performance toward equitable growth.

Therefore, this thesis addresses issues of inequity in infrastructure resource allocation in the context of Indonesia. This is done by, first conducting a thorough analysis of this problem; we investigated whether the two policy options, place-based or people-centred, could distinctly result in effective resource allocation in the infrastructure. Second, to further investigate those policy options, for each, the focus is on a set of models and algorithms to implement the policy into a formal resource allocation operation. These models and algorithms are developed and operationalized for infrastructure development. Third, to analyze the effectiveness of each policy option, a framework for measuring the impact on spatial and social equity is provided, based on social welfare theories. Finally, with these three stages, we provide inputs to the possible development of a Spatial Decision Support Systems (SDSS) tool that could be used for infrastructure allocation in the Indonesia context.

\subsection{Research Problems}

(1) The context: equity and infrastructure development policy

To provide a suitable understanding of the problem, an elaboration of equitable infrastructure development in a global context is provided, as is the implication for a local equity objective. Since the objective deals with converging issue of people and place, the general research question to develop the context paper is "What is the policy discourse in infrastructure development which aims to address social and spatial equity?" 
(2) Background knowledge: equity concern and its measurement

To provide a sufficient understanding on equity issues, the next segment of this study is to assess the applicability of the existing social equity measurement method for infrastructure development. The research question regarding social equity measurement is therefore: "Does the existing social equity measurement satisfactorily evaluate the multiobjectives of pro-poor, pro-growth and pro-job policies?"

\section{(3) Exploring the option for addressing equity}

The next research problem regards the approach to address both social and spatial equity within one intervention or policy action. Social equity compares social units (e.g., individual or household) while disregarding the location of each unit; however, spatial equity should consider the relative position of comparable units. Consequently, social equity involves neighbourhood comparison. For instance, the spatial distance among comparable units may affect the perception of inequity. With this characteristic of inequity perception, it is necessary to include neighbouring comparisons for resource allocation to address both social and spatial equity. However, to determine whether such an approach reflects real life causal mechanisms of infrastructures' effects on the distribution of economic opportunity, an investigation of this mechanism is required. The investigation of this causal mechanism should also involve the interdependency aspect of infrastructures. This issue triggers the next research question of "What is the effect of the inclusion of spatial neighbourhood information and infrastructure interdependency on the distribution of economic opportunity in a region?"

\section{(4) Developing methods for the option to address equity}

Furthermore, to perform an intervention to reduce both social and spatial inequity, a resource location-allocation mechanism should be established; this involves priority setting. In a decision making process, the priority setting requires preference modelling to transform stakeholders' perception into relative priority to improve a location. Traditionally, preference modelling focuses on comparisons among units but disregards neighbourhood comparison. Therefore, such preference modelling will not be able to accommodate location-allocation priority, which requires neighbouring information to be included to respond any inequity over space to enhance the level of spatial equity. Thus, new preference modelling that includes a neighbouring comparison should be developed and compared with the traditional preference modelling. To distinguish both, non-spatial preference modelling (without neighbouring comparison) and spatial preference modelling (with neighbouring comparison) were 
compared. These two models represent people-centred versus place based approaches. The sensitivity of these to the changes in the spatial equity index was investigated. Therefore, the following research question is raised: "Does the inclusion of spatial preference modelling in resource allocation mechanism could improve spatial equity?"

(5) Testing the effectiveness of the proposed equity approach to achieve the planning objective

Moreover, with this new spatial preference modelling, it is necessary to investigate a conformity check with the planning objectives and the preference of community as the beneficiary of infrastructure development. To predict the compliance to the planning objective and to social justice, an assessment derived from planning theories is conducted. Here, the research questions is "Does resource allocation with spatial preference modelling have better agreement with planning objectives and social justice?"

(6) Comprehend the findings into policy framework and decision support tool

After learning from the comparison of non-spatial and spatial preference modelling, which provides knowledge to prioritize place-based versus people-centred policies for regional development, we need to formulate a recommendation for recrafting the policy framework to be practical in various contexts. The formulation is driven by the following research question "When and where should the policy for place-based and peoplecentred resource allocation be applied for more equitable distribution?"

Finally, to each finding from these research questions will be combined in a Spatial Decision Support System framework for equitable resource allocation in infrastructure development.

\subsection{Research Framework}

To produce the framework, four groups of works and its deliverable in a series of papers, these and the associated research questions are outlined as one Context Paper, one Background Paper, three Working Papers and, finally, one Policy Paper (Figure 1.1 Research Framework). 


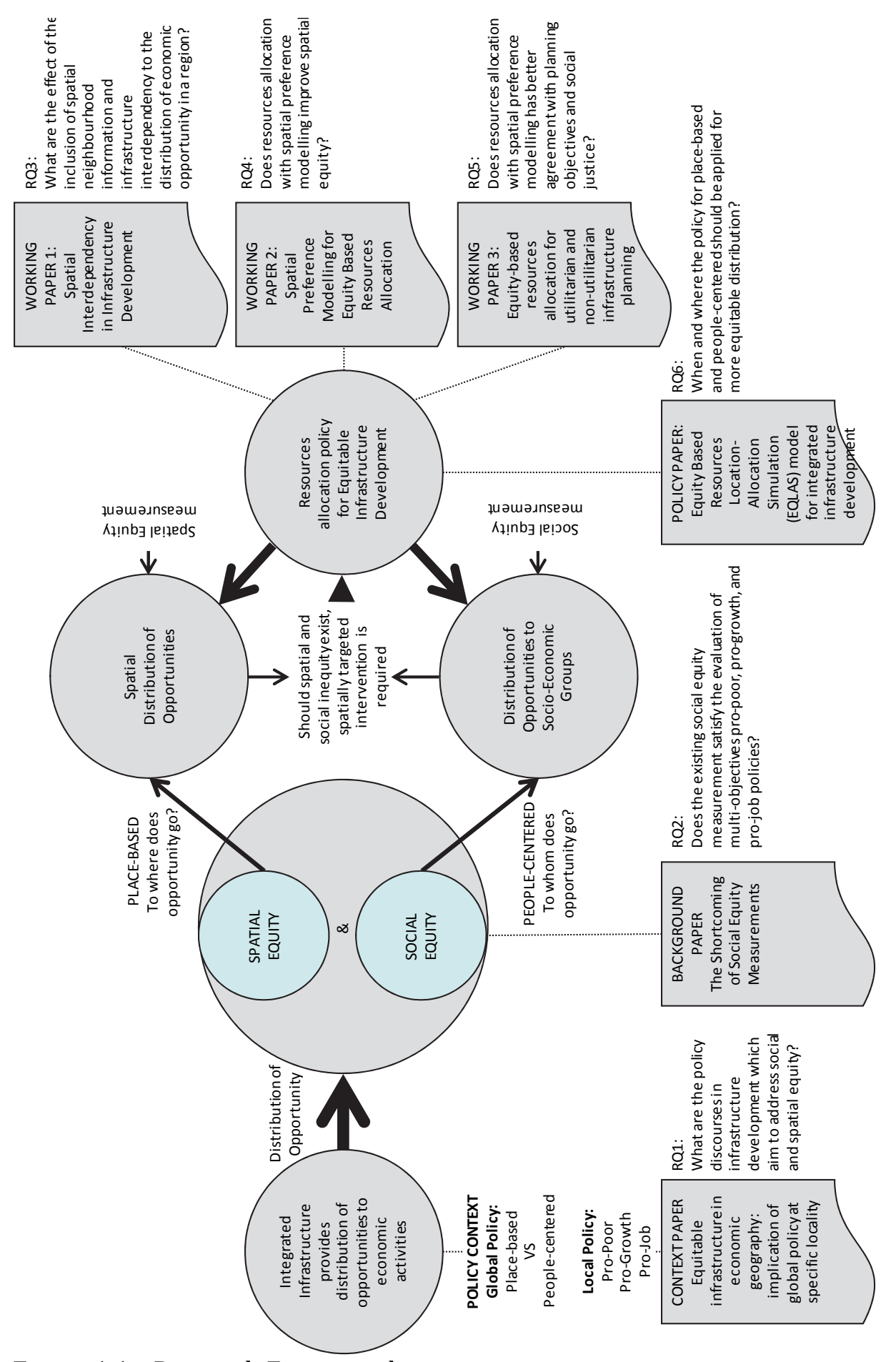

Figure 1.1 Research Framework 


\subsection{Thesis Outline}

Following this introductory chapter Chapter 2 provides the Context Paper and Chapter 3 provides the Background Papers. Chapters 4, 5 and 6 are the series of Working Papers, and Chapter 7 is the Policy paper consisting of recommendations for the planning and decision support systems for an equitable infrastructure. Finally, Chapter 8 concludes the main results and findings from previous chapters and provides suggestions for future works. The summary of each chapter is presented here.

Chapter 1 is the introduction, consisting of the research background, the purpose and objectives, specific research questions and the structure of the thesis and publications.

Chapter 2 discusses the policy context of addressing social and spatial equity for equitable infrastructure. This chapter contributes a debate to prioritize place-based versus people-centred policies for regional development.

Chapter 3 discloses the shortcoming of social equity measurements and describes the existing social equity measurement methods to be applied in infrastructure development.

Chapter 4 examines the effect of place-based policy on infrastructure and economic interaction and serves as a basis to justify the need to establish a formal method to operationalize place-based policy into resource allocation modelling.

Chapter 5 establishes a new approach to implement a place-based resource allocation policy in a Spatial Decision Support Systems and compares its effectiveness to address spatial equity against people-centred policy.

Chapter 6 compares the agreement of a place-based and people-centred policy to planning objectives and social justice with reference to utilitarian and non-utilitarian welfare theories applied in the infrastructure.

Chapter 7 establishes a decision support framework to recommend where and when a "place-based" or "people-centred" policy for equitable infrastructure development should be applied. This chapter synthesizes all finding into a decision support framework, Equity Based Resources Location-Allocation Simulation (EQLAS), for integrated infrastructure development. 
Chapter 8 concludes the main results and findings from the previous chapters; outlines the contribution to scientific, academic and professional fields; and provides suggestions for future works. 


\title{
Chapter 2
}

\section{Equitable infrastructure in economic geography: implication of global policy on specific locality}

\begin{abstract}
Against the background of regional disparity and social inequity problems in Indonesia, this chapter aims to contribute to a debate on prioritizing place-based versus people-centered policies for regional development. This prioritisation of place based policies has been driven by a policy framework promoted in the World Development Report 2009 (WDR) and categorized into three types of interventions i.e. 1) spatially blind institutions 2) spatially connective infrastructure and 3) spatially targeted incentives. Specific attention is given to assessing the implication of this global policy to a specific locality with regards to social justice. On the observation we disclose the construction of politics of distribution and power relations underneath the policy for infrastructure planning and public service provision. Moreover, the lesson learnt serves as knowledge for recrafting the policy framework to be practical in various contexts. From the case study we revealed that, in order to maintain equitable growth, policy makers require planning and decision support tools to help decide where and when place-based or people-centered policies should be applied or combined.
\end{abstract}

Key Words: equitable distribution, infrastructure, economic geography, WDR 


\subsection{Introduction: inquitable growth in Indonesia, policy or implementation problems?}

After more than 30 years of steady growth and a stable political situation which performed under a strong centralistic government regime, in 19971998 Indonesia experienced extreme social and political distress. Prompted by massive riots in many regions triggered by both regional disparity and social equity issues, Indonesia has been conducting governance reform to allocate resources at sub national levels.

A continuous reform process towards a decentralized country has been established through National Act No 22/1999 on Regional Government which has been elaborated into the Government Regulation No 25/2000 and a revised version of the National Act No 32/2004 and Government Regulation No 38/2007 to delegate and distribute authorities from national level directly to district level.

In public service sectors, similar reforms have also been attempted (e.g. Telecommunication Act No 38/1996, Road Transportation Act 22/2009, Electricity Act 30/2009). While the decentralized resource allocation to sub national levels aims to find the best policy and mechanism to allow a proper role sharing between national, provincial, district and village levels, in the public infrastructure sector, the reforms also aim to achieve a proper balance between state centered and market driven infrastructure and service provision. To secure the equitable distribution of service, a National Act on Public Service No 25/2009 has also been issued. It specifies which sectors should be covered, e.g. education and teaching, jobs and business sectors, communication and information, environment, health, social security, energy, banking, transportation, natural resources, tourism and other strategic sectors.

The reforms have been going on for almost two decades through institutional reforms, infrastructure interventions and spatially targeted fiscal incentives; however, the expected equitable growth was not achieved as indicated by a continuous increase of the Gini Index, from 0.308 to 0.350 in the period 1999-2008 and from 0.370 to 0.413 in the sequential government period from 2009-2013 (BPS 2014).

With a focus on infrastructure intervention which allows for basic service distribution as a prerequisite for economic growth we investigated the existing policies, their implementation and possible sources of increasing inequity. 


\subsection{Debate on policy framework for economic geography}

Infrastructure is generally provided to facilitate three main considerations of development, people (social), planet (environment) and profit (economy) (Magar 2010; Tang and Zhou 2012). Disregarding one of them could lead to unsustainable development, incompliance to social justice and increasing risk and uncertainty in achieving development outcomes (Goodman and Hastak 2006).

From an economic point of view infrastructure development can contribute in several ways to economic development, such as through growth in total employment, growth in productivity, economic growth, regional and sectoral transfers, economic welfare and distribution of income (Goodman and Hastak 2006).

With reference to evaluating how spatial distribution of economic activities is evolving, Krugman (1991) introduced a model of new economic geography (NEG). This model could predict the role of infrastructure (e.g. transportation) in economic development, such as the tendency for agglomeration (Tabuchi 2014). This (re-)discovery of geography by economists has promoted the idea of policy making where economic geography is central to be able to understand and influence actual economic development.

NEG is promoted in the publication of the World Development Report (WDR) 2009 by the World Bank (Garretsen, Roberts et al. 2011). In this report, aptly titled Reshaping Economic Geography, the World Bank claims, first, that understanding and shaping economic geography is crucial as a key driver of economic development. Second, as geography is a hindrance to development, policies should be aimed at stimulating economic integration, especially between countries. Within countries, the WDR advises policy makers to focus less on - using their terminology place-based policies and more on people-centered policies.

Specifically the WDR provides a concise framework for understanding the dynamics of infrastructure and economy as a basis for recommending policy options for urban and regional development (Deichmann, Gill et al. 2011). The policy framework advises three instruments for reshaping economic geography; 1) spatially blind institutions (when the result of institutional reforms leads to a people centered resource allocation, irrespective of where they live), as well as 2) spatially connective infrastructure and 3) spatially targeted incentive (where location is the key 
factor in distributing resources). These instruments could be applied stand alone or combined, subject to economic concentration (density and urbanrural convergence), economic disparity (distance of leading and lagging areas, including its migrant and mobility factors), and social and economic division (fragmented by linguistic, political, religious, or ethnic barriers).

This framework makes rigorous spatial policy analysis tractable (Deichmann, Gill et al. 2011). However, while mainly written by economists, this document has also been criticized, by geographers in particular. Maringanti, Sheppard et al. (2009) noted that the report ignores many policies that have been applied in different contexts by drawing mainly on two national experiences, India and China, which are highlighted in the document as global hotspots of growth. Lawson (2010) in addition criticized its narrow view of economic development that is disconnected from place, politics, and society. Especially, given the fact that geography and spatial patterns are constitutive coproducers of political-economic processes, not just outcomes.

Other critics are concerned with the policy impact on social equity. Eventhough the WDR can inform a debate regarding the suitability of 'place-based' versus 'people-centered' policies to address spatial disparities in welfare (Deichmann, Gill et al. 2011), the absence of the assessment of the policy framework to the politics of distribution could lead to increasing inequity (Lawson 2010).

Moreover, Murphy (2011) revealed that the WDR2009 ignores critical relationships, mobilities, spatialities and inequalities that shape development processes and outcomes. He suggests to seriously take into account socio-spatial relationships, local institutions and power asymmetries which influence urban economies, cluster formation, migration patterns and market integration processes, before implementing the WDR2009 policy frameworks.

Within the continuing debate between geography scholars however, the WDR policy framework has obtained great acceptance from policy makers as well as urban economists and regional scientists during two years of consultative process and outreach (Buckley and Buckley 2009; Deichmann, Gill et al. 2010).

Various regions have developed a policy framework associated with the policy options described in the WDR. The EU, for example adopts a placebased approach to develop their Cohesion Policy 2014-2019. With its Place-Base Policy, the EU will invest €325 billion in Europe's Member 
States, their regions and cities to deliver the EU-wide goals of growth and jobs, as well as tackling climate change, energy dependence and social exclusion. This policy includes €66 billion for establishing Trans-European transport links and other key environmental infrastructure projects to support the program for targeting resources at key growth sectors (European Commision 2013).

Meanwhile, ASEAN also applies similar policies to combine three instruments of WDR in their strategy of ASEAN Master Plan of Connectivity with "physical, institutional and people-to-people connectivity" towards a people-oriented ASEAN with One Vision, One Identity, One Community by 2015 (ASEAN 2011).

At the country level, the policy debate between place-based policies and people-centered policies could be more diverse. The controversy is also based on the fact that the WDR policy could be viewed with two contrasting principles of "parsimony" (the term used by the economist) or "oversimplified" - as a critique - by geographers who always work on detailed texture over the geographical landscape (Murphy 2011).

The neutral readers (Garretsen, Roberts et al. 2011) and the proponents of WDR2009 (Deichmann, Gill et al. 2010; Deichmann, Gill et al. 2011) suggest that instead of only critizing, a work for recrafting the proposed policy framework is more beneficial as a constructive input for the policy maker who is the intended user of the framework.

To respond to such invitation, this chapter is intended to provide background information that could be used for re-crafting the provided policy framework. We accomodate the critics by means of outlining relevant overlooked concepts and contexts in specific localities. The context is focused on infrastructure development as the instrument to operationalize the policy. Following the outline, we discuss a possible research agenda to allow more substance in the contribution of applied geography.

As the case study, Indonesia, the fourth largest country on earth in terms of population with 253 million (2014) (behind just China, India, and the US) and the 19th largest country in terms of land mass and natural resources is discussed here. With these figures, Indonesia has the potential to be one of the most promising markets for various commodities and services, and therefore becomes an important subject of global and regional policy implementation. Global policy trends such as trade liberalization have 
created power relations in the country and have influenced the governance and its institutions, infrastructure development and fiscal administration.

Indonesia until the 1990's had experienced decades of high growth which however also resulted in increased social and spatial inequity. In 19971998, the culmination of such contradictory results triggered a reform process from a centralistic into a decentralistic government system. Along with the continuous reform, contrary to global and regional policy trends, which generally aim to reduce division and therefore less demarcation for the global market (e.g. Single Market Entity of ASEAN) Indonesia has experienced more division, disconnection and institutional demarcation due to a decentralistic process in the name of democracy.

In such transforming country, the World Bank's WDR recommendation of place-neutral through spatially blind institutions - which is more pro global free market formation - is therefore questioned with the possible implication to increased inequity, not only within the countries but especially between domestic and international players. A risk of spatial inequity might also arise when a market driven policy with its competitive mechanism leaves commercially unfeasible areas unserved. At the same time, domestic players who generally are not ready for a head-to-head competition with global players express their concern on a protection policy. Under protection policy any infrastructure and institutional development as well as fiscal incentive should favor the local interest to allow them to face a competition in global market interactions.

With consideration to such circumstances, this chapter focuses specifically on providing some perspectives to the evaluation framework, especially the attention to the implication of WDR policies at specific locality to social justice. Here, we organize the discussion by first discussing deliberate politics, power relations and policies for planning and resource allocation for infrastructure, secondly discussing the geography of welfare to find a proper assessment based on social justice, and third by elaborating the policy framework in the WDR into a case study. To address the geographer's requirement to increase texture, a case study at a very low level of adminstration (village) in Yogyakarta, Indonesia is elaborated. Finally, learning from the discussion on customization of WDR policy and its implication to inequity, we recommend an immediate research agenda for recrafting the policy framework to be practical in various contexts. 


\subsection{Politics of distribution and policy to swing the pendulum}

The debate to prioritize place-based versus people-centered policies for regional development is especially important when spatial and social inequity issues are present in the region. Variations in economic concentration, economic disparity as well as social and economic division, which form regional inequity might result from the cumulative long term impact of misleading development policy.

Other possible sources of inequity are the failure to implement ideas of distributive justice into infrastructure and public service operations. In this context, two distinct poles of policy become options, a state monopoly versus a pro-competition market driven policy. A proper state monopoly allows a cross subsidy between the rich and the poor, while the competition could improve the quality of service at a lower price. However, a misconducted policy of state monopoly might fail in providing efficient service at a sufficient economic scale to reach the geographical challenging and economically deprived groups. Meanwhile, a pro competition market driven policy tends to serve only commercially feasible targets.

Those two distinct poles and their dynamic outcomes might determine a country to swing the policy pendulum from state-centered (monopoly) to market driven (pro-competitive) policies or vice versa.

The failure of the first often leads to a transition from state monopoly into a competitive and market driven public service provision. However, the fact that liberal market systems are not really friendly to the poor and remote areas has brought the policy pendulum to swing back from a state monopoly to a market oriented policy, and back to the middle. This middle ground should provide for more equitable infrastructure services provision while maintaining a sufficient level of competition.

To hold the pendulum in the middle requires an establishment of proper policy, regulation, institutional setting and a sound business model for infrastructure and public service operation. This policy will influence infrastructure development and its service to reach the un-served, underserved and the underprivileged group of the poor. Such policy often requires incentives for market driven public service operators to run the business in geographically difficult areas. The incentive might involve a subsidy, hence a robust planning tool to allow the achievement of the expected standard of service while aiming for an optimum use of resources. 
The swinging pendulum could influence the way the policy maker implements WDR policy instruments. Some examples of changing policy and its implication to infrastructure and public service operation is provided in the next sections.

\subsubsection{Shifting policy on infrastructure service provision}

In order to serve the nation in an equitable manner, a state centred approach has been believed to be a proper mechanism to allow distribution and redistribution of resources and welfare among the poor and the rich as well as to reduce inequitable services among regions (Aharoni 1988). Historically, many countries globally often employ state-owned enterprises (SOEs) as a chief instrument of this state economic intervention (Jon 1999).

The state monopoly however is often trapped in inefficient service provision when it is performed in a non competitive and unprofessional business process. This fact is among the reason of a lot of rise and fall of SOEs in the twentieth-century, even in developed countries (Toninelli 2000). When the failure of SOEs was happening, a new era of more competitive and market oriented infrastructure service provision took place. The idea for privatizing or at least to let SOEs run in a competitive environment has then also spread over.

There were pros and cons to this shift, however the fact that under a monopoly it is hard to reach efficiency, the policy for competitive and market oriented become too difficult to be argued (Aharoni 1988). Moreover, a global trend for liberal and free markets to be adopted in each country has been pushed forward by multinational enterprises through multinational organizations such as WTO/GATT (Subramanian and Wei 2007).

\subsubsection{Multinational firms serve local utility services}

In the more liberal and free market policy environments, enterprises in developed countries are commonly better prepared in comparison to their opponents in developing regions. For example, their preparation is conducted through a transformation of utility enterprises from purely domestic into multinational enterprises. In the US, this was triggered with the passage of The Energy Policy Act (EPAct) in 1992. In response to the liberalized regulatory climate, 29 U.S. utilities have diversified their holdings through the acquisition of foreign utilities, many of which are located in emerging markets (Pinto 2003). Multinational enterprises targeting local public service delivery with a competitive tendering also emerged in EU Countries (Augustin and Walter 2010). 
Such policy has given a new shape of service delivery for various infrastructure services at a local level. Many of them are provided by multinational enterprises or their subsidiaries, such as in the telecommunication, transport and energy sectors. The transformation goes through various ways, e.g. by encouraging an agenda for free market environment or the acquisition of a domestic company (Pinto 2003). Even in a sector which is very local in nature, i.e. water, the role of multinational enterprises is identifiable.

In the water sector for example, the role of multinational infrastructure companies is naturally not very extensively penetrated in domestic services delivery. Especially if it is influenced by local decision-makers who have seen that water systems networks are intrinsically tied to geographical location (Hall and Lobina 2007). However, international actors always find their own way to penetrate domestic markets, not via the infrastructure sector but through water commodity trading (e.g. Danone from France in Indonesia). This kind of multinational company intervention to a domestic market, however, is largely done through political strategies rather than competition with rival local companies (Hall and Lobina 2007).

These political strategies applied by a multinational company might vary, and may be subject to the cultural orientation of the country. In general, international investment flows are more friendly in a society that has a cultural orientation toward egalitarianism. In such culture, with its intolerance for abuses of markets by political power, and a desire for protecting less powerful actors (Siegel, Licht et al. 2011), a new (international) player is able to penetrate the market with relative ease.

Similarly, countries which have multinational enterprises also generally retain an egalitarian culture, and allow for symmetric international investment flows from developing or emerging-country firms into their countries. Brazilian, Chinese and Indian multinationals are among examples that operate and even profitably acquire firms in developed countries, chiefly in the United States (Kothari, Kotabe et al. 2013; Fleury and Fleury 2014). The possibility to those Emerging Market Multinational Companies (EMNCs) to do reverse takeovers is part of the dynamic reconfiguration of global production systems. 


\subsubsection{Options to transform local utility enterprises and inequity risk}

Kothari, Kotabe et al. (2013) suggest that for successful EMNCs, the foreign expansion has passed three stages of reform: licking the dirt to carve out the way; taking off with speed and strength; and around the world with excellence. For most of the national and local enterprises which have been in the comfort zone of harvesting the benefits from the domestic market, those three stages of transformation are considerably challenging. Therefore, when liberal market systems are initiated, local players often demand for local enterprise protection.

Pressure for such non-egalitarian position however often is argued by a long list of proof that over protection leads to inefficient service provision. Therefore, the alternative path to encourage transformation to improve local public service provider quality often is performed through the process of corporatization of public sector management by adopting private sector principles (Aharoni 1988; Smith 2004).

This transformation is in fact not an option without a risk. Smith (2004) argues that corporatization is an institutional form emerging from a second wave of neoliberalism, which threatens to undermine the democratic accountability of local authorities by virtue of restructuring the state in ways that are invisible to the public yet with highly negative outcomes for low-income communities.

The risk is brought in by engineers as the key agents in the promotion of cost-recovery policies and 'efficient service', in combination with officials who are highly skilled professionals on the technical side of the production process, but they lack the social training necessary to deal with the politics of distribution and displace politicians in the deliberations over how to deliver services to the poor and un-served areas (Smith 2004).

The requirement for competitive market oriented transformation and its risk to widening the gaps disclose the neccesity for linking utility service programs to be highly visible to the public. As an implication, public officer, politician, decision maker and planner should be exposed to the politics of distribution and equipped with proper equity based planning support tools. 


\subsubsection{Universal Service Obligation for equitable public service and utilities}

The decision to swing the pendulum has been taken by many countries, including Indonesia, in order to move forward with competitive and market driven public service and utilities provision. However, this swing has resulted in an inequitable distribution of service and does not solve the problem of un-served and underserved areas. Also, it does not target the under privileged groups. These shortcomings have triggered the idea of Universal Service Obligation.

Towards more equitable access, the idea of Universal Service Obligation where all citizens should have the right to the same services regardless of where they live- has been established in many countries.

Under such idea, geographical differences in the provision of public services, which are featured as the un-served and underserved areas, requires continuous service improvement (Eliassen and From 2009). The policy to promote network expansion toward more equitable service provision however has been constantly challenged with the global trend towards a market driven approach (Jon 1999; McElhinney 2001). The traditional approach with pricing instruments and cross subsidy under a state monopoly, especially with its nature of inefficient service, is now not relevant within current competitive environment (Estache, Laffont et al. 2006; Parker, Kirkpatrick et al. 2008).

Whether in monopoly or a market driven environment, the urgency to serve the unserved area is part of the obligation of the state. At certain level, this obligation is transfered to a licensed operator of a public service. With a market driven and competitive mechanism however, public service operators are often hesitant to go beyond the commercially feasible areas.

To solve this issue, the idea of sector earmarking through contribution to a Universal Service Obligation Fund (USOF) has been introduced, for example in the Telecommunication industry. It transforms the obligation to "play" in rural area into "pay" contribution for rural network expansion (Mirabel, Poudou et al. 2009). The earmarked fund then is disbursed as incentive for rural expansion through a bidding process in which operators who are willing to "play" in the rural area participate.

A similar concept has been applied in other sectors such as in transportation under the name of Public Service Obligation (PSO), and in the health sector with Universal Health Coverage (UHC). Instead of using an 
earmarked fund, those programs with a "public" term commonly refer to the use of public funding collected from the tax from various sectors as the source of subsidy; it is associated with the obligation from public sectors. Then, through the relevant central government department the PSOs can be awarded, administered and subsidized, either directly or through associated agencies (Williams and Pagliari 2004). Using the budget allocated in the USO and PSO programs, specific service affordable for the target areas and users then could be provided.

The idea of universal service obligation or public service obligation often is interpreted with a sense that government takes back their role in providing public utilities. Of course, it does not mean that the pendulum would swing back, from state monopoly into market driven, and then back to monopoly. Instead, the state attempts to use the market economy to promote more equitable service for the general public. With such objective, certainly a country needs a proper policy, regulation and institutional setting in a way that equitable service is achieved and at the same time the level playing field for fair competition would be kept in place.

\subsubsection{Institutional options to provide equitable public service}

Given the problem of geographically challenged areas, certain countries might consider to bring back the role of SOEs to distribute services in rural or remote areas. However, others might choose as the alternative to use an agency as the extension of government operation and involve the private operator to conduct the service and compete for this specific market.

To provide anillustration of such ideas, an example is given from a developed country, Sweden, that has been challenged with public service provision in geographically difficult rural areas -some of which even witness negative population growth. Sweden is one of the countries that have extensively applied agencies to provide public service, starting with the oldest still existing university founded in 1477 (Uppsala University). Sweden is a good example, not only for the long experience in developing an agency but also for its reforms process to detach political interest and influences in public service provisions. The reform for public administration system aimed to the rationalist ideal that civil servants should function as managers implementing policies efficiently and in a goal- and result-oriented way. This ideal situation has its own challenging requirement of policy autonomy and independency of public agencies to the dominant political and administrative trends. An evaluation of 157 agencies established in Sweden before and after the reforms and comparison of the effects of administrative reforms in different countries 
disclosed that the independency of public agencies requires significant institutional change (Niklasson and Pierre 2012).

Indonesia is one of the countries which have decided to extend the public service through the public agency approach. This option is also considered as the means to address the failure of SOEs in providing equitable services. This diminishing role of SOEs starts when there is a requirement to privatize or when there is a force for public services to operate in a competitive free market driven environment. Such situation is an example of the increasing global trend of privatization in public sector, regardless of political regime (Stolt, Blomqvist et al. 2011).

In Indonesia, the public service agencies, so called Badan Layanan Umum (BLU) at national level, and Badan Layan Umum Daerah (BLUD) if operated at province or district level, are expected to enable national and local government to provide equitable public service. According to Indonesian National Law on Public Service no 25/2009, public service includes education and teaching, jobs and business sectors, communication and information, environment, health, social security, energy, banking, transportation, natural resources, tourism and other strategic sectors.

\subsubsection{Business model of the agency and required planning capacity}

Basically, the agency's business model is conducted by, first, determining the minimum level of service of the infrastructure. Then a plan for equitable distribution is made which considers an optimum revenue at minumum cost to maintain a zero (Glass, Stefanova et al. 2014) or lowest possible level of subsidy, which is provided, executed and monitored. This business model indicates a requirement for an agency to be equipped with a very strong planning capacity.

In Indonesia, after more than 10 years of establishment of BLU, currently there is still no single BLU or BLUD that could show their planning approach to achieve an equitable distribution of service. Even it is more problematic when it has to be confirmed with their financial performances. On the financial issues. they might find difficulties to maintain a low level of subsidy (e.g. BLUs in public transport) or problems to disburse the collected contribution from the industry (e.g. BLU for rural ICT).

A similar situation happened in other Asian countries, e.g. India (Jayakar and Liu 2014). Surprisingly, in a developed region like the US (Berg, Jiang et al. 2011) and the EU, with the case of PSO in air transport, there are also 
major inconsistencies in the approach and commitment to social service provision such as improper focus on fare which undermines mobility and accessibility (Williams and Pagliari 2004).

With a concern to improve planning capacity and equip agencies for public service, it is important to provide an alternative approach for equitable distribution of service, especially when they need to maintain their objective of operating in a pro competitive market environment.

\subsection{Infrastructure planning capacity toward equitable growth}

Among its many intended roles, infrastructure, which firstly aims to provide basic services, has been believed to be a prerequisite of growth as well as a means for equitable distribution of the benefit from economic growth to the whole society. This section elaborates on how the idea of distributive justice, in the context of the swinging pendulum of market orientation and competitiveness -but very much concerned with universal service provision- should be supported with improved infrastructure planning capacity.

\subsubsection{Determining indicators for equitable growth.}

In response to Maringanti, Sheppard et al. (2009) who are concerned that WDR policy is very much oriented to growth and is overlooking the inequity issue, some indicators for equitable infrastructure planning are discussed here.

A macroeconomic indicator, e.g. Gross Domestic Product (GDP), could explain the impact of infrastructure to national economy; however it is not necessarily addressing issues of inequality. Countries in South Asia (e.g. Afghanistan, Bangladesh, Bhutan, India, Maldives, Nepal, Pakistan, and Sri Lanka) and East Asia (Brunei, Cambodia, China, Indonesia, Laos, Malaysia, Myanmar, Philippines, Thailand, and Vietnam), have been growing rapidly around $6 \%$ to $7.5 \%$. However, this growth is still accompanied by an increased poverty and worsened income distribution. At such level of growth, poverty levels on those regions remain very high with more than half of the population still living under the Millennium Development Goal of $\$ 1$ a day (Perera and Lee 2013).

Such aggregated growth indicator, not only overlooked inequality among people but also disparity among regions. At a community level, this GDP is also less informative than a lower-level indicator, such as a change in job 
opportunities (van den Bergh 2009). If villagers are unable to find a job or an economic opportunity, they tend to migrate to urban areas where money is more broadly circulated. In the decentralised context, micro-level indicators, such as infrastructure condition and public service performance are considered as the immediate input for local economic opportunity (e.g. generated by small or medium enterprises). Hence, it is important to include infrastructure performance indicators in any action to address inequity among people and regions.

Beside appropriateness in the selection of growth indicators in the planning process, Perera and Lee (2013) suggests that other sources of ineffective growth are issues of corruption, democratic accountability, and bureaucracy. In such case, an improvement of the level of institutional quality is required. Many facts show that a poor institutional quality and administrative officials influence the level of poverty through market inefficiencies and misallocation of resources (Tebaldi and Mohan 2010) and lead to greater error in administrative decision-making (Keefer and Knack 1997).

\subsubsection{Demand to accountably decentralize use of resource}

With an attention to policy for spatially targeted intervention, currently, the demand for an equitable allocation has also generated increases in the share of spending on infrastructure by local governments (Yu, Zhang et al. 2011). This pattern of increased spending in many countries reveals a new trend in fiscal decentralisation and demand for more interconnecting development of national infrastructure with its sub-national as well as local infrastructure systems.

Surprisingly, however, even though the resource allocation for infrastructure investment aims for decentralized systems, Neyapti (2010) and Kyriacou and Roca-Sagalés (2011) found that the effectiveness of resource allocation decreases in countries with local or regional elections. They argue that local elections result in a decision-bias when the local politicians prefer to distribute the resources mainly only to their constituents.

Moreover, under a decentralised fiscal system, analysis at a lower level, such as at the village level, requires more attention to be given to local conditions and preferences (Thornton 2007). When this occurs, the effect of an investment in infrastructure is more apparent to the general public, in particular to village communities. Hence, this shift requires indicators that reflect the community perspective. 
The sensitivity of constituens reaction to sensible indicators and their vote preferences is very well recognized by politicians. Hence, during the election period government or politicians often declare a national or regional growth target. However, this promise is very often not followed up with a transparency or accountability on how this aggregated growth will be delivered to the lower level administrative units.

The urgent demand to decentralize resources, while maintaining transparency for infrastructure and public service provision indicates a necessity to provide the policy for spatially targeting intervention to be equipped with infrastructure planning tools which enable to accountably distribute a target growth from national into lower level of administration.

\subsubsection{Equity assessment for infrastructure policy and planning}

Discourse on place-based policies vs people-centered policies in the context of distributive welfare converges in an attempt to simultanously address social and spatial equity. This section outlines an elaboration of various concepts related to policy assessment derived from theories of economic geography and social justice.

Inequity is not only an issue in developing countries but also in the developed countries. The London riot (Baudains, Johnson et al. 2013; Till 2013) is among examples of inequity issues that are associated with policy implications to govern cities and states in Europe (Musterd and Ostendorf 2012). While developing countries demand equitable resource allocation for basic opportunities and poverty alleviation, the developed countries aim for establishing democracy and sustaining economic growth (Jung and Sunde 2014).

This course of geography and social welfare has been discussed in many literatures. One of the most comprehensive elaborations has been provided by Smith (1977) in Human Geography: Welfare Approach, which is an extended idea from the book of The Theory of Moral Sentiments by Adam Smith in 1759. This literature provokes interest and debate among planners and geographers in the importance to measure ethical questions of who should get what where, and suggest how spatial reorganization and redistribution towards social justice criteria can be achieved through planning. This literature has provided a foundation of economic, social and political theory, however its practical impementation requires further solid grounding in measurement methods (McConnell 1978). 
Continuing the concerns, Smith (1994) comprehensively elaborated the problem of distributive justice and related issues of morality in a geographical context. He outlined fundamental concepts in moral philosophy and extended a review of theories on social justice including egalitarianism, utilitarianism, libertarianism and contractarianism. Some of his examples emphasize how improper conduct of social justice could lead to social unrest.

With this emerging wave of geography that was devoted to social concerns, Smith (1994) suggested a proposal to address excessive inequality. Some praise fort his approach have been obtained (Harries 1995; Wiegand 1995; Clark 1998), but it is also criticized to be a revival of utopian socialism and at odds with the current worldwide swing to privatization and capitalism (Harries 1995), while from a methodological point of view, a link between theory and application in the field of geography is also barely found. These scholars are concerned that in the absence of quantitative methods which can be formalized into the field of study, the inequality would be assumed as an exceptionally difficult, perhaps unsolvable, issue.

In an attempt to address such inequity, discussions on the concept of fairness of the distribution of resources and welfare have been continuing for decades (Smith 1977; Sen 1980; Dworkin 1981; Dworkin 1981; Nussbaum 2003; Sen 2004; Sudgen 2006; Qizilbash 2011). Such knowledge and understanding of the limits of each equity measure could be one of consideration in evaluating WDR policy framework.

\subsubsection{Shortcoming in equity measurement}

The approach to measure equity implications of place-based or peoplecentered policy should take into account both 'spatial equity' (equitable distribution of economic opportunity over regions) and 'social equity' (distribution of economic opportunity over social groups). Various measurement methods are available. Each has its limits with respect to the appropriateness of measuring equitable growth.

In social equity measurement, several methods are available e.g. the TIP (Three I's of Poverty: Incidence, Intensity and Inequality) curve (Jenkins and Lambert 1997), CDF (Cumulative Distribution Function) Curve, Pen's Parade (Pen 1971) and Lorenz Curve (Son and Kakwani 2008). Most of the assessment on distributional justice is initiated with a graphical approach. It is performed by comparing distribution patterns with curves outlining an increasing level of welfare from the worst-off (poorest) to the better-off (richest). To indicate pro-poorness of distributions a comparison of 
distribution patterns between two (or more) curves using a so called Curve Dominance Analysis is applicable (Kakwani and Silber 2008). Such graphical measure then could also be derived into a quantitative description of distribution such as from Lorenz Curve into a Gini Index of Equality.

In a spatial context a number of efforts to measure equitable distribution are available (Alesina and Angeletos 2005; Tsai 2005; Druckman and Jackson 2008). Most of them are implemented using inequality measurement such us the Gini Index.

Another approach for regional inequality measures applies a formula of dispersion. The Williamson Index (WI) is an example of an index to measure regional inequality (Felsenstein and Portnov 2005). WI implements a population weighted coefficient of variation for dispersion, however it does not include a geographical or spatial feature in the formula.

Moreover, de Smith, Goodchild et al. (2013) imply the importance to include a spatial feature for determining the location of spatially targeted intervention policies. The power of location comes not from location itself, but from the linkages or relationships that it establishes, from relative positions rather than absolute ones. Topological properties, including adjacency, connectivity, and containment are among influencing factors of relative positions. These factors and their occurrences in the real world determine the connectivity matrix in spatial analysis. The result and interpretation of analysis are associated with the matrix. Hence, it is important to consider geographic features of location (e.g. location, shape, size, orientation).

Some scholars have attempted to include Gini into spatial configuration evaluation. For example, Druckman and Jackson (2008) incorporated a Gini coefficient with AR-Gini (Area-based Resources Gini). The A-R Gini can show inequitable use of resources in a spatial context. However, (Tsai 2005) provided an evidence of the limitations of this method. During an attempt to describe quantitatively the spatial distribution of development intensity, he discovered that the Gini is not sensitive to spatial form, distribution and configuration.

In spatial analysis, there are spatial measurement indices associated with multi-group comparison, the so called autocorrelation statistics such as the Getis Index G*, Geary's C, and Moran's I (Lorant, Thomas et al. 2001; Tsou, Hung et al. 2005; Grubesic 2008). The autocorrelation statistics produce 
one value (the Global Index) indicating equitable distribution in a spatial context. For example, Moran's I of 1 indicates a cluster of similarity (equity) and -1 a cluster of dissimilarity (inequity). Moreover, Moran's derivation as Local Index for Spatial Autocorrelation (LISA) is able to indicate the character of spatial inequity (e.g. high-high cluster: an object with a high value surrounded by other objects with high values; as well as low-low, high-low, or low-low). The existing formula of the autocorrelation statistic is applicable to analyse spatial patterns, however it is not applicable to measure social inequity as it is not sensistive to degrees of difference (Tsai 2005).

Based on the advantages and disadvantages of those methods, to assess the WDR policy framework it is critical to explore a combination of the social equity approaches for developing inequity measurement with spatial features of geographic phenomena. More importanly, beside focusing on describing a state of inequity, it is also necessary to find a way to address more equitable distribution. Hence, a possible combination of approaches needs to be explored to propose a new method, not only for evaluating but also for directing growth distribution toward more equitable development.

\subsection{Understanding interaction and texture before policy}

\subsubsection{Integrated Infrastructure Modelling}

To understand the nature of infrastructure-economy interaction, it is necessary to build a simplified real word, a model, of such interaction. As infrastructure systems are often of an interdependent nature, it is important to observe infrastructure as integrated systems which cumulatively interact with the economy.

The knowledge of modelling and simulation for evaluating infrastructure as integrated systems is relatively immature. Most of the previous studies on infrastructure integration focused the analysis in infrastructure interdependency (Rinaldi, Peerenboom et al. 2001; Pederson, Dudenhoeffer et al. 2006; Laprie, Kanoun et al. 2007). Their analysis on interdependency refers to vulnerability. The backgrounds of those studies commonly relate to infrastructure disruption due to terrorism, malfunctioning of critical infrastructures or natural disaster. Therefore, those studies are mainly concerned with measuring the vulnerability or 'the decreasing infrastructure performance' due to perturbation from other infrastructure. 
In order to be able to deal with development that leads to equitable growth, the integration analysis should also discuss interdependency. However, this discussion is more focused on the attempt to 'increase infrastructure performance'. Hence, the analysis for the interdependency shall take into account the performance of other infrastructures to support the intended function of the infrastructure system as a whole. Hence, here the function of infrastructure systems is defined as the enabler and backbone (Little 2005) to provide economic opportunity for the community (Frischmann 2005; Tiffin and Kissling 2007; World Bank 2008).

The idea for enabling a community in engaging in economic actitivies is inline with the concept of the Network Enabling Transport System (NETS) developed by Tiffin and Kissling (2007). This concept provides direction for developing tools for designing, planning and revising infrastructures as system networks. According to these authors 'infra' means 'underneath' therefore an infrastructure is the underlying structure that supports an activity. These infrastructures make the movement, storage and processing of the things that are essential to civilized life possible.

The NETS is originally developed for integrating transport and communication infrastructures. It does not only provide an analytical framework of "network systems" with an infrastructure system, but also an analytical framework for infrastructure as in a "systems networks" (network among various systems), which consists of three actual systems networks (infrastructure, traffic, auxiliary service) and three abstract systems networks (regulatory, communication, and skill).

By taking into account this approach, a response for WDR critics by Murphy (2011) regarding the ignored critical relationships, mobilities, spatialities and inequalities that shape development processes and outcomes could be addressed.

\subsubsection{Understanding localities of infrastructure-economy interaction}

An accountable public investment and resource allocation for infrastructure development is prerequisited by economic impact assessment. At a broader scale the evaluation involves study on its effect to economic development at regional level. Many econometric or spatialeconometric models have been designed to better understand the effect of infrastructure development on the various economic sectors (Cohen 2010; Gutiérrez, Condeço-Melhorado et al. 2010; Yu, Zhang et al. 2011; Elhorst, Lacombe et al. 2012). These tools are commonly applied for analysis at the 
national level and deal mainly with the interaction between infrastructure and the economy in centralised systems.

With reference to macroeconomic models, the analysis of this interaction at specific locality, e.g. village level, requires three types of investigations. The first investigation involves the nature of the contribution to the economy that each type of infrastructure makes in an integrated systems configuration (see the econometric studies by Foley (1992), Nazem, Liu et al. (1996), Mamatzakis (2003), Chandra and Thompson (2000), Gibson and Olivia (2008)). The second investigation is related to the spill-over effect as a result of spatial dependency among neighbouring areas (see the spatialeconometric studies by Ho, Kauffman et al. (2007), Bröcker, Korzhenevych et al. (2010), Flahaut (2004)). The third investigation involves the interdependency among infrastructure types that could determine the various types of economic activity within a region (see the infrastructure interdependency studies by Macaulay (2008), Utne, Hokstad et al. (2011), Zhang and Peeta (2011), Kröger (2008), Johansson and Hassel (2010), Barker and Haimes (2009), Desmedt (2002), Akgun, Kandakoglu et al. (2010). As the relationship between infrastructure and economy is more concrete on the local level, there may also be cumulative effects of those three issues.

Such knowledge will be useful to provide more effective and efficient policies for allocating resources at a specific locality. We need to know, for example, how the variability of the existing infrastructure, the neighbouring factors, and their interdependency influence the distribution of economic opportunity in a region. This knowledge will be useful to improve the effective allocation of resources in a particular location as well as to counter any decision-bias by politicians and decision-makers.

\subsubsection{Infrastructure network expansion and the dynamics of spatial equity}

To extend our understanding of network characteristics of various infrastructures such as transportation, electricity, telecommunication and water supply, a conceptual development of an incremental network of connectivity is presented here.

This knowledge is important especially if a 'spatially targeted intervention policy' will be evaluated on its effectiveness in addressing spatial equity and social equity. A model of line patterns (Cai, Hirtle et al. 1999) was used to depict how the incremental expansion of the network determines network completeness and therefore affects the dynamics of spatial 
inequity. The spatial equity increases along with the increasing connectivity of the networks. Figure 2.1 shows the possible models of line patterns and the family of the models for each graph and sub graphs. While the network of connectivity is expanding (b), inequity occured as characterized by a location with low-surrounded-by-high connectivity or vice versa. At the later stage, an incremental expansion (from $\mathrm{c}$ to e) could form a complete network where all locations have high-surrounded-byhigh network connectivity (f). The later stage then represents equitable distribution of connectivity.

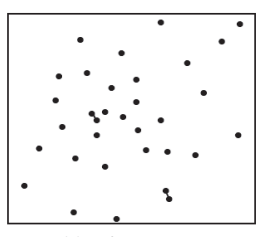

(a) Point Set

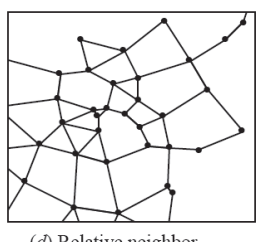

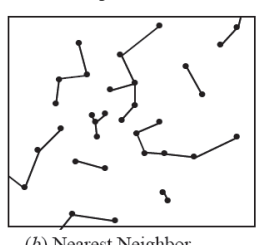

(b) Nearest Neighbor

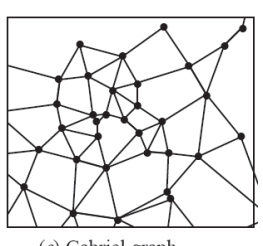

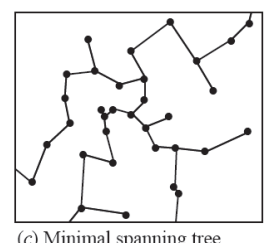

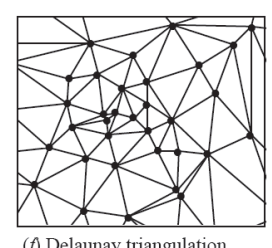

Figure 2.1 Models of line patterns. The spatial equity increases along with the increasing connectivity of the networks (Cai, Hirtle et al. 1999)

To address spatial equity, therefore it is important to recognize the level of network development in the targeted area for resource allocation. We suspect that the initial status of network completeness would influence the effectiveness of resource allocation policy. Hence, this subject should be one of the observed factors for a growth redistribution policy.

\subsubsection{Infrastructure typology which forms texture in geography}

In real life, the above concept of incremental graph models is contructed with various typologies and infrastructure technologies. Several examples of infastructure typology and its real-life representation for the selected types of infrastructure are outlined below (Table 2.1). 
Table 2.1 Typology of infrastructure and examples of real-life representation

\begin{tabular}{lllll}
\hline Typology & & \multicolumn{2}{c}{ Type of Infrastucture } \\
\hline Point & Transportation & Electricity & Telecomunication & Water \\
& Bus Stop, Bus & Off-Grid & Public Phone, & Well, Communal \\
& Station, Train & microhydro- & Internet Point-of- & Water Source \\
& Station, Port, Airport & power & Presence & \\
\hline Linear & Road Networks, Bus & On-Grid power & Copper or Fibre Optic & Water Pipe \\
& Route & lines & Networks & Networks \\
\hline Planar & Private vehicle & Array of Solar or & Terrestial Point-to- & Mobile water \\
& coverage & Wind Powers & point or Point-to- & distribution \\
& & & Multipoint Networks & systems \\
\hline Space & Air transport and & 3D array of Solar & Coverage of Base & Underground \\
& other vertical & and Wind & Transceiver Station & water sources \\
& mobility devices and & Powers & (BTS), Wifi, Very & \\
& infrastructure. & & Small Apperture & \\
& & & Sattelite (VSAT) & \\
\end{tabular}

Similar to the importance of the initial level of network expansion, the typology of infrastructure and technology or type of service could indicate the level of performance and therefore also determines the effectiveness of the policy to address social and spatial equity.

The incremental network of connectivity and these typologies of infrastructure is definitely increasing the complexity of planning toward an equitable distribution. Hence, the inclusion of these factors in planning and decision support is required to enable governments and decision makers to actualize their development objectives.

\subsection{Case Study: WDR policies applied at local context of Yogyakarta, Indonesia}

This discussion aims to elaborate some concepts and considerations deliberated in the previous sections and its implication to policy instruments similar to WDR categories in Indonesia. Using spatial data of infrastructure performance in the study area, background information is provided to better inform the policy context. To generate a potential research agenda, a discussion on the predicted implication of the on-going policy to equity is provided. Attention is given not only to possible role displacement of local players by multinational enterprises due to their acting as a spatially blind institution, but also to potential risks and benefits for equity among society. Finally, a concern on the necessity for planning capacity for policy makers and government agencies to maintan equitable infrastructure is concluded. 


\subsubsection{Swinging Pendulum in Indonesia}

According to the Indonesian Constitution, which was first formulated by the founding fathers in 1945, any resource and its production process that allows the country to support sustainable service for the general public has to be managed by the state. This centralistic approach has been believed as a means to allow an equitable distribution in such big and diverse country like Indonesia, where some remote and commercially unviable areas require sharing between the rich and the poor.

Under such principle, the distribution of resource requires a state-centered nation wide infrastructure to provide an equitable public service. A proper infrastructure development is therefore one of the requirements for national sovereignity. In such policy, the government should manage an equitable distribution of resource and welfare. Historically, many countries globally also rely on state-owned enterprises (SOEs) as a chief instrument of state economic intervention.

However, when such state monopoly runs into an inefficient service and come accross with new competitive business requirement, people started to ask about appropriateness of SOEs for serving the public need. Indonesia is among the countries experienced with this question.

Right after the fall of the authoritarian and centralistic governance system in 1998, when citizens engaged in massive riots in many regions in Indonesia demanded a more equitable distribution of resources, a new policy was started to establish a more decentralistic approach. The distribution mainly involve financial resource (e.g. fiscal transfer to subnational government) and the expansion of infrastructure network to distribute the opportunity to access other national and local resources. Along the democratic reform, the infrastructure provision that previously more state centred and involve monopoly of SOE had been deregulated to allow more private participation operate under pro-competitive policy.

With it, a new era of more competive and market oriented infrastructure service provision begun. The idea for privatizing or at least to let SOEs run on a competitive basis has spread over since.

There were pros and cons. However, the fact that monopoly is hard to reach its efficiency has promoted the policy for competitive and market oriented service. Moreover, a global push towards a liberal and free market to be adopted in a country has also been promoted by multinational enterprises through multinational organizations such as WTO/GATT. 
Indonesia is a country with the fourth largest population on earth, far from being small, Indonesia is in fact is a promising market for various commodities and services. This market includes infrastructure operation that involves various business opportunities. Infrastructure service is a business where every individual continuously demands a service, therefore such huge market formation makes Indonesia is one the largest global business target.

Many countries including Indonesia, which have an objective to provide an equitable public service, started to develop the nation from a state monopoly public service mechanism. Many arguments and facts that monopoly reduces efficenty and requirement for enhancing efficenct to reach economics of scale, have led a state monopoly driven to transform into a market oriented infrastructure service industry. Among four which are discussed here, transportation infrastructure is currently still predominately led by government but allows private companies to compete in mobility service provision. Others have shifted to competition based State Own Enterprises (i.e. electricity which allows a private entity as an alternative energy provider) and Local Government State Enterprise (i.e. water). As an extreme case, Telecommunication even has reformed from a national monopoly, into a duopoly and has been more a decade into a full liberal market for mobile services. In the telecommunication sector, no single infrastructure asset is owned by government, and therefore all the developments have been driven by market oriented private investment.

The fact that market driven infrastructure service has shown its efficiency in providing a more affordable service, the problem of unequal service for non-commercially feasible areas remains. This revealed fact of underserved and un-served areas as well as underprivileged groups, has determined a swing back of the policy pendulum into a more equitable development. This policy has been implemented through Public Service Obligation (PSO), e.g. in transportation service, and Universal Service Obligation (USO) in the telecommunication sector, and other similar schemes in the rural electrification program.

When the pendulum is swinging back, to the middle, the nation needs to learn how to appropriately manage market driven public services in more equitable ways, without any incompliance to the National Constitution.

Learning from the failure of SOEs in providing an equitable service - due to the new nature of competitive basis - there is an idea on public service provision with a role of agency. This agency is expected to distribute the service on a non-profit basis. Any profitable services and regions would 
share their income to the unprofitable units. In case, the revenue could not cover the operation cost, the subsidy could be provided from state budget. In Indonesia various public sectors has been provided with a Badan Layanan Umum (BLU) or Public Service Agency, such as hospitals, universities, public transport and rural telecommunication.

The idea to serve the general public via an agency is in fact not to bring back a state monopoly, instead to provide an improved service in unprofitable areas, with or without subsidy involved. The new type of competitive policy would be to turn from "competition in the market" into "competition for the market". Under such policy, any service provider who is interested to serve the underserved or un-served area would come into a competitive bidding process.

With a great possibility of a subsidy involved in this process a BLU and other type of public service agencies have to be equipped with planning tools to allow the achievement of service standard with optimum resources.

\subsubsection{Study area and data}

Our study area, the Special Province of Yogyakarta, Indonesia (Figure 2.2) is one of the targets of various programs aimed to more equitable development. Besides the development of main national infrastructure networks, to address poverty, various village level programs are also implemented. An example of a village-level program is the rural electrification program, which has been in execution since the 1970s. Nationally this program is valued at more than USD 200 million annually. The most recent village level program is the rural telecommunication provision, executed under the Universal Service Obligation (USO) program to more than 35,000 villages nationwide. It has invested more than USD 500 million annually since 2010 . For other sectors such as roads and water supply, several community-based infrastructure development programs have also been implemented. The most important one is the Kecamatan Development Program (KDP), which is a community infrastructure program financed by the World Bank (USD 1.2 billion), which begun in 1998 with the aim to alleviate poverty and improve local governance in rural communities. The program, covering approximately 28,000 villages, has developed infrastructure such as roads, bridges, irrigation, drainage and clean water supplies. Kecamatan is a sub-district level of administration in Indonesia. There are more than 4,000 sub-districts in the country. On average, a sub-district contains some 20 villages and has a population of over 50,000 people. 
This kind of village level national program would increase its popularity, especially with the newly issued National Law for Village (Undang Undang Desa, No 6, 2014) which requires more national resources to be distributed directly to village level administration.

Our study area is the part of those national programs. Populated with approximately 3.4 million people, it consists of 438 villages, both urban and rural, with an average population of 5,632 inhabitants. The average size of a village is 724.43 ha with a minimum of 26.57 ha in urban areas and a maximum of $2,890.36$ ha in the more rural areas.

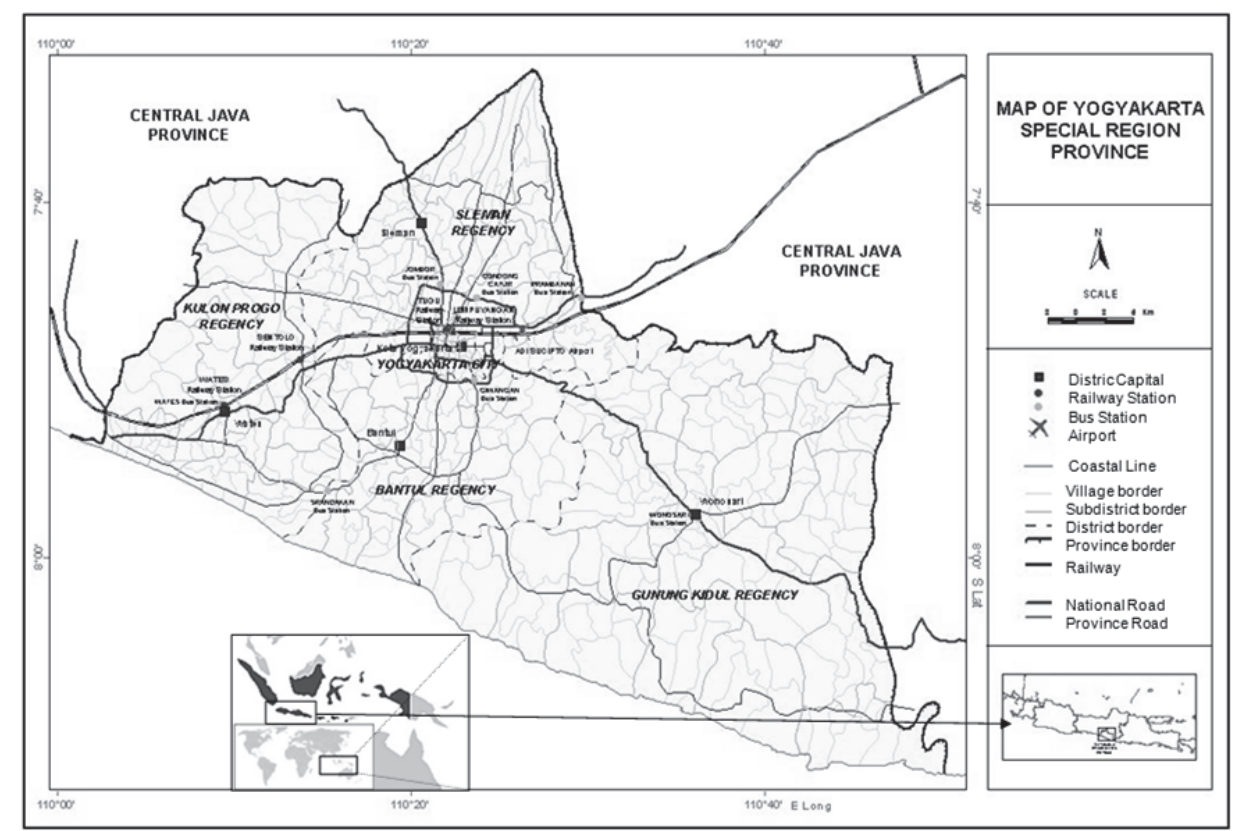

Figure 2.2 The study area is located in the Special Province of Yogyakarta, Indonesia, with 438 urban and rural villages, urban area at the center of radial road networks.

To select the type of infrastructure, with a reference to NETS, focus is given to actual systems networks and the abstract network of communication. Hence, the types of infrastructure included here are transportation, especially road, electricity, telecommunication and water supply networks.

For this study, we use a village-level longitudinal data set from 2005 called PODES - Village Potential series (BPS, 2006), which consists of approximately 400 attributes linked to demographics, socio-economic activities and infrastructure for 438 urban and rural villages in the province. 
The Indonesian Government Central Bureau of Statistics' (BPS) Village Potential series (PODES) is a longstanding tradition of collecting data at the lowest administrative tier of local government. The data are collected by BPS every two or three years along with the context of the periodic censuses (Agriculture, Economy, and Population). PODES contains detailed information on the public infrastructure stock in a surveyed village, along with the village's characteristics, geography and topography. These data have been widely used in national policy and planning formulation, and evaluation of district and village level programs such as the Kecamatan Development Program (KDP) (Montibeller, Franco et al. 2009), and Community Driven Development (CDD) (Perera and Lee 2013) as well as in scientific works (Pinto 2003; Hall and Lobina 2007; Augustin and Walter 2010; Siegel, Licht et al. 2011; Fleury and Fleury 2014).

Detailed information is gathered on a range of characteristics-ranging from infrastructure to village finance-for Indonesia's +/-70,000 rural villages and urban neighborhoods. Sub-district level statistical agents (mantri statistik), who work for BPS, implement the survey. Information is typically gathered from the kepala desa (rural village heads) and lurah (urban neighborhood heads). We use mainly those attributes that are relevant to infrastructure performance.

This village data does not consist of network data of infrastructure, instead, it reflects aggregated information at village level. The transport performance, for example, is recorded in terms of distance and travel time to facilities within the village as well as in neighboring villages. Further information also available such as the information on major inter-village traffic, i.e. if the major traffic is on land. Additionally surveyors ask questions about the type of road construction (i) asphalt/concrete/coneblock or not, (ii) hardened or not, (iii) soil or not, and (iv) others. Another question identifies $(\mathrm{v})$ whether 4-wheel or other vehicles can pass the road all year long.

On electricity, the PODES data consists of the number of households connected to the network grid provided by the State Owned Enterprise of PLN (Perusahaan Listrik Negara). We combined this information with type of costumer indicated by level of economy to estimate the capacity of supply obtained from PLN.

Water supply in PODES is characterized with the source of water, i.e. water pipe from the public network, well with electricifed pump, manual well, 
rain water and other. This data is used to estimate the average supply capacity available for the village.

Telecommunication data in PODES is recorded from the number of households connected to fixed line telephony served with a network of copper wire. Other data is ordinal data of the strength of the mobile signal in the village. Based on that information, we derived average data transfer capacity in the village.

In combination with PODES, we also use the fourth wave of the Indonesian Family Life Survey (IFLS, RAND Corp.) dataset. IFLS is an on-going longitudinal survey in Indonesia. The sample is representative of about $83 \%$ of the Indonesian population and contains over 30,000 individuals living in 13 of the 27 provinces in the country.

The first wave of the IFLS (IFLS1) was conducted in 1993/94 by RAND in collaboration with Lembaga Demografi, University of Indonesia. IFLS2 and IFLS2+ were conducted in 1997 and 1998, respectively, by RAND in collaboration with UCLA and Lembaga Demografi, University of Indonesia. IFLS2+ covered a $25 \%$ sub-sample of the IFLS households. IFLS3, which was fielded in 2000 and covered the full sample, was conducted by RAND in collaboration with the Population Research center, University of Gadjah Mada. The fourth wave of the IFLS (IFLS4), fielded in 2007/2008 covering the full sample, was conducted by RAND, the center for Population and Policy Studies (CPPS) of the University of Gadjah Mada and Survey METRE.

We use the IFLS of $2007 / 2008$ with the variable of subjective well-being on the level of prosperity to verify the level of economic opportunity in the village.

\subsubsection{WDR Policy Instruments at different localities}

To illustrate how the instruments similar to the WDR policy framework are implemented at different localities, three groups of policies are outlined (Table 2.2). Using data described in the previous section, a background information and context of policy instruments similar to the WDR is applied in the study area (Figure 2.3). 
Table 2.2 Example of WDR policy instrument applied in localities

\begin{tabular}{|c|c|c|c|c|}
\hline \multirow[b]{2}{*}{$\begin{array}{c}\text { Types of } \\
\text { Infrastructure }\end{array}$} & \multirow[t]{2}{*}{ Systems Characteristics } & \multicolumn{3}{|c|}{$\begin{array}{l}\text { Example of Policy Instruments similar to WDR applied at } \\
\text { localities }\end{array}$} \\
\hline & & $\begin{array}{l}\text { Spatially Blind } \\
\text { Institution }\end{array}$ & $\begin{array}{c}\text { Spatially } \\
\text { Connective } \\
\text { Infrastructure }\end{array}$ & $\begin{array}{l}\text { Spatially } \\
\text { Targeted } \\
\text { Incentive }\end{array}$ \\
\hline Transportation & $\begin{array}{l}\text { The system is formed } \\
\text { by a linear type of } \\
\text { infrastructure. Mobility } \\
\text { relies on private } \\
\text { vehicles with limited } \\
\text { public transport in the } \\
\text { urban area. Low } \\
\text { performance indicates } \\
\text { traffic jam (urban) and } \\
\text { poor infrastructure } \\
\text { (rural). }\end{array}$ & $\begin{array}{l}\text { Obligation of states } \\
\text { through agency for } \\
\text { providing support for } \\
\text { mobility and } \\
\text { distributing public } \\
\text { transport service. } \\
\text { Country is under } \\
\text { reform to reduce fuel } \\
\text { subsidy and convert } \\
\text { "commodity subsidy" } \\
\text { (fuel) to "systems } \\
\text { subsidy" (public } \\
\text { transport). } \\
\text { Infrastructure owned } \\
\text { by the state and } \\
\text { operated by SOE or } \\
\text { agency. } \\
\text { Rolling stock owned by } \\
\text { SOE and private } \\
\text { enterprise. }\end{array}$ & $\begin{array}{l}\begin{array}{l}\text { PPP for road } \\
\text { (highway) }\end{array} \\
\text { Infrastructure } \\
\text { operation by SOE } \\
\text { for commercially } \\
\text { feasible region. } \\
\text { Infrastructure } \\
\text { operation by } \\
\text { units/agencies for } \\
\text { commercially } \\
\text { unfeasible region. } \\
\text { 100\% Foreign } \\
\text { Direct Investment } \\
\text { for Ports and } \\
\text { Airport. }\end{array}$ & $\begin{array}{l}\text { Public Service } \\
\text { Obligation via } \\
\text { public transport } \\
\text { subsidy at } \\
\text { commercially } \\
\text { unfeasible areas } \\
\text { or target } \\
\text { groups. } \\
\text { Access to credit } \\
\text { for private } \\
\text { vehicle } \\
\text { owership } \\
\text { targeting poor } \\
\text { people to } \\
\text { support } \\
\text { mobility in area } \\
\text { uncovered by } \\
\text { public } \\
\text { transport. }\end{array}$ \\
\hline Electricity & $\begin{array}{l}\text { The system is formed } \\
\text { by a linear type of } \\
\text { infrastructure. The } \\
\text { network is laid along } \\
\text { the road network. High } \\
\text { performance indicates } \\
\text { urban and more } \\
\text { developed villages. }\end{array}$ & $\begin{array}{l}\text { Monopoly for energy } \\
\text { distribution by SOE. } \\
\text { Country is under } \\
\text { reform for liberal } \\
\text { systems for power } \\
\text { source provision, but } \\
\text { the distribution is } \\
\text { under monopoly of } \\
\text { SOE. }\end{array}$ & $\begin{array}{l}\text { On-grid rural } \\
\text { electricity } \\
\text { programs. } \\
\text { Off-grid renewable } \\
\text { energy initiative } \\
\text { programs. }\end{array}$ & $\begin{array}{l}\text { Pricing policy } \\
\text { for growth } \\
\text { (industry and } \\
\text { the rich) and } \\
\text { subsidy for } \\
\text { equity (the } \\
\text { poor). } \\
\text { Payment } \\
\text { systems that is } \\
\text { friendly for the } \\
\text { poor (post- } \\
\text { paid) in the area } \\
\text { covered by data } \\
\text { capable } \\
\text { telecommunicat } \\
\text { ion coverage } \\
\text { (mostly urban } \\
\text { areas). }\end{array}$ \\
\hline
\end{tabular}


Chapter 2

\begin{tabular}{|c|c|c|c|c|}
\hline $\begin{array}{c}\text { Types of } \\
\text { Infrastructure }\end{array}$ & & $\begin{array}{l}\text { Spatially Blind } \\
\text { Institution }\end{array}$ & $\begin{array}{c}\text { Spatially } \\
\text { Connective } \\
\text { Infrastructure }\end{array}$ & $\begin{array}{l}\text { Spatially } \\
\text { Targeted } \\
\text { Incentive }\end{array}$ \\
\hline Telecom & $\begin{array}{l}\text { The system is formed } \\
\text { by a combination of } \\
\text { linear and spatial types } \\
\text { of infrastructure. The } \\
\text { networks of linear } \\
\text { systems rely on fiber } \\
\text { optic (urban center) } \\
\text { and copper (urban to } \\
\text { sub-urban) along the } \\
\text { road networks. The } \\
\text { wireless mobile } \\
\text { networks extend a } \\
\text { space type of network } \\
\text { to reach market in rural } \\
\text { area. }\end{array}$ & $\begin{array}{l}\text { Two decades of } \\
\text { reformed institution } \\
\text { from monoply, to } \\
\text { duopoly between fixed } \\
\text { and local, and } \\
\text { international calls, and } \\
\text { full liberal for mobile. } \\
\text { Established } \\
\text { Independent } \\
\text { Regulatory Body for } \\
\text { Telco and ICT Sector to } \\
\text { equalize level playing } \\
\text { field competition. }\end{array}$ & $\begin{array}{l}\text { Rural ICT } \\
\text { program to extend } \\
\text { last mile } \\
\text { connectivity and } \\
\text { deployment of } \\
\text { Internet Point of } \\
\text { Presence. } \\
\text { National } \\
\text { Backbone } \\
\text { Program of Palapa } \\
\text { Ring Fibre Optics } \\
\text { to connect } \\
\text { financially } \\
\text { unviable areas. }\end{array}$ & $\begin{array}{l}\text { Universal Service } \\
\text { Obligation for } \\
\text { rural and remote } \\
\text { areas (un-served } \\
\text { and underserved } \\
\text { areas). }\end{array}$ \\
\hline Water & $\begin{array}{l}\text { The system is formed } \\
\text { with combination of } \\
\text { point, linear and space } \\
\text { types of infrastructure. } \\
\text { Urban area served by } \\
\text { linear public fresh } \\
\text { water with option to } \\
\text { private wells. } \\
\text { Underground water } \\
\text { forms space type of } \\
\text { infrastructures. Point } \\
\text { infrastructures are } \\
\text { found in drought areas } \\
\text { lacking of water } \\
\text { sources (white cluster } \\
\text { in Figure 2.3). }\end{array}$ & $\begin{array}{l}\text { State centered service } \\
\text { through local } \\
\text { government owned } \\
\text { enteprise (LGOE) to } \\
\text { provide water service. } \\
\text { Corporation and } \\
\text { privatization of LGOE } \\
\text { Unregulated } \\
\text { competition of LGOE } \\
\text { with multinational } \\
\text { fresh (bottled) water } \\
\text { industries/trading. }\end{array}$ & $\begin{array}{l}\text { Communal water } \\
\text { service provision } \\
\text { in drought areas. } \\
\text { Community and } \\
\text { user based water } \\
\text { network } \\
\text { organization. }\end{array}$ & $\begin{array}{l}\text { Government } \\
\text { subsidy for poor } \\
\text { drought areas } \\
\text { through mobile } \\
\text { water } \\
\text { distribution and } \\
\text { communal water } \\
\text { service. }\end{array}$ \\
\hline \multicolumn{5}{|l|}{ Demographic } \\
\hline Population & $\begin{array}{l}\text { Population is } \\
\text { concentratedmostly in } \\
\text { flat areas where } \\
\text { historically fertile soils } \\
\text { are found, bus also } \\
\text { more recently in areas } \\
\text { served with } \\
\text { infrastructure, } \\
\text { especially road } \\
\text { networks and } \\
\text { economically more } \\
\text { developed areas. }\end{array}$ & & & \\
\hline
\end{tabular}




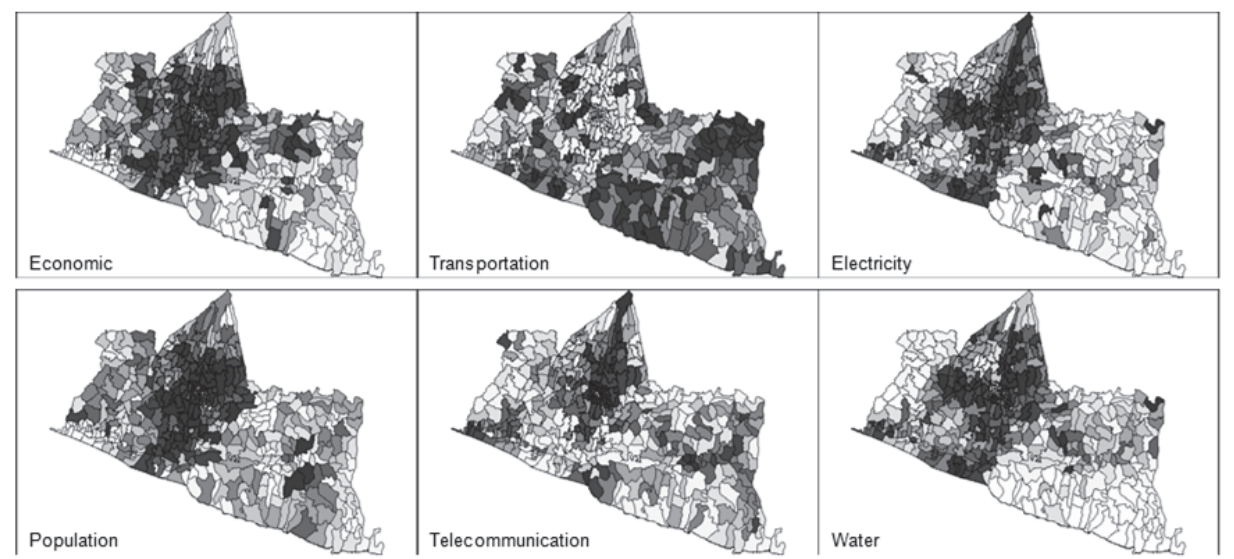

Figure 2.3 Distribution of infrastructure and economic opportunity in the study area.

In this figure the dark colours represent villages with higher values or better infrastructure system performance. Dark colours in Telecommunication also represent more urbanized areas. These variations of infrastructure system performance are produced by the systems described in Table 2.2 .

\subsubsection{Discussion on the potential inequity risk and benefit produced by the implemented policy}

\section{(1) Transportation}

After more than two decades of state absence in public transport service provision - which resulted in market failure leading to low public transport ridership, e.g. in Yogyakarta only 27.22\% (Dirgahayani and Nakamura 2012)- The government released the Transportation Act 22/2009 which mandates the Government to ensure the right to mobility. This spatially blind institutional policy instrument is implemented under the PSO program. The PSO is awarded, administered and subsidized by government through agencies.

The award could go to a private operator or SOEs through a bidding process. Currently, the bidding process only involves local operators. However, in the near future, e.g. as mentioned in ASEAN Free Market 2015, the participation of multinational operators is unavoidable. A Multinational Operator for Local Transport Service (MOLTS) most likely would penetrate and has a level playing field with local operators (Takeru and Hitoshi 2011). Such increasing competitive environment is expected to benefit the public. However, with a very challenging nature of rural transport 
provision, the operators are likely to bid only in urban areas. In this situation, a spatially targeted incentive could be the instrument but it requires a strong financial commitment, otherwise, it may result in increased inequity.

Other challanging aspect on rural transport provision is financing issue. The opportunity to obtain significant amount of financial source is fuel subsidy reduction. After decades of huge fuel subsidy but at same time also there is a fact that the country has very tight fiscal capacity, recently the government decided to reduce the subsidy at about $50 \%$. This policy could obtain to USD20 billion annual saving from fuel subsidy that partly could be provided for PSO programs. Before the subsidy reduction policy, it is difficult for the country to have a full financial commitment for PSOs at national wide mobility service.

The infrastructure budget availability however does not necessarily follow up quickly with new performace of public service. Transformation requires a very long time for implementation. Realizing such burden, a short term solution is given by leting every individual find their own mobility solution with a private vehicle. It is conducted by another spatially blind institution combined with a spatially targeted incentive through a financial credit facility to allow poor people to afford a motorcyle. In reality, this facility is not only used by rural people but mostly by urban people who are also constrained by access to public transport or heavy traffic jams. This situation creates a contraproductive policy with PSOs as it reduces public transport service and its revenue, and therefore also increases the subsidy for public transport.

It seems that without an extraordinary policy measure, this mobility problem will continue to increase, especially given the fact that Foreign Direct Investment for the automotive industry has been committed to produce private vehicles at the level beyond one vehicle for one household.

\section{(2) Electricity}

The energy sector is one of the most lucrative business opportunities where multinationals are desperately urged to participate in providing service. Currently, SOE still has a monopoly for distributing the infrastructure, however, an international lobby has ensured that a liberal market system is getting closer to implementation. This spatially blind policy aims to open a competitive mechanism limited to power source provision (e.g privatization of non petrol power plants). This policy is not easily operated, especially given the fact that the distribution infrastructure is still under a monopoly and therefore only single prospective buyer (PLN) 
for the energy produce by any private company. This monopsony practice reduced the investor interest.

Meanwhile, electricity provision in off-grid areas, that are provided with a renewable source (e.g. solar cells) is still faced with problems of local adaptive capacity to sustain the technology.

\section{(3) Telecom}

This sector is very progressive in implementing liberal policies. A spatially blind institution to diminish the state monopoly has been started with the Telecommunication Act36/1996. The reforms started with an evolvement from a monopoly to a duopoly to let the SOE (TELKOM) to have a competition with other SOE (INDOSAT), that was iniated specific for international calls service. At the later stage this SOE then is privatized. Currently, it has been more than a decade that a full liberal market is operated for mobile services.

At the beginning of the mobile era, the new mobile operators are still dependent on the SOE, the incumbent, which provides connections with fixed lines to public subscribers in the offices and houses. At that time, the incumbent charged an interconnection fee which was intended to extend the network to the rural areas.

However, after the mobile networks reached most of the consumer houses, the mobile operator has become independent from the incumbent. At the time the individual in the house subscribes to a mobile service, a full competition in telecommunication sector is really in place.

In such situation, there is no possibility for the incumbent to charge an interconnection fee or to increase the price for investing in the rural area. Similarly, no single private mobile operator also is willing to "play" in the rural area. At this point a digital divide between the urban and rural areas has created a continuing increase of social and spatial inequity.

In the period when SOEs as well as private operators have no intention to serve the rural area, the government had to intervene by introducing a Universal Service Obligation. This financial intervention is conducted by transforming the obligation to "play" in the rural area into "pay" for the rural area. This USO Fund is then later managed by the Rural Telecommunication Agency to manage the rural service by awarding private operators who are willing to play with a bidding process.

After five years of collecting USO Fund contributions, the program to reduce the digital divide has not reached the expected level of deployment. 
Less then $30 \%$ of the collected fund is disbursed annually due to the challenging rural and remote areas and the limited availability and capacity of the back-bone networks. To address this problem, the country is now aiming to use the USO Fund to not only provide the last mile connectivity but also for deploying a back-bone network in remote and noncommercially viable areas.

After the rural ICT deployment under USO, it is disclosed that the utilization of the facility is very low. This fact shows that addressing the inequity is not only a matter of infrastructure provision, but also should consider the adaptive capacity for the target group to use new ICT technology. Such situation indicated a training program to turn the latent demands into manifest.

\section{(4) Water}

Naturally, the water sector is very much intrinsically tied to geographical location. In such case, local decision making always see that the source and distribution networks should be operated by local operators. However, through the industry and trading sector, a multinational enterprise could penetrate and compete with a local fresh water provider. Through the industry sector, investments in local water bottle factories are made, including long term consessions for springs.

The locally operated and quasi-monopoly systems also show their inefficiency. The water supply provided is not potable, while the network is also very limited. The household that has no connection tends to dig its own wells. The connected one that has experience with unreliable service also prefers to have their own wells. This situation is more complicated when the sewage network is not available to connect households. When each household builds their own infiltration sewer system without sufficient inspection, there is a risk of e-colli pollution to the wells.

A household that is aware of such risk has commonly become a loyal costumer of the multinational fresh water company. Meanwhile, the poor group who can not afford bottled water will use the polluted water. Such inequity is one of the issues triggered by quality of water, not only the quantity.

\section{(5) Inequity risks}

Learning from the above discussion, among four types of infrastructurtures there are some similar issues in the implication of WDR policy to inequity. First is the inequity between domestic players and multinational 
enterprises. A spatially blind institution policy that promotes a competitive free market establishment should be implemented gradually to allow local players to be ready for head-to-head competition with their opponent. Without proper transitition, another type of monopoly (quasi-monopoly) by multinational enterprises could be established creating another source of inequity. Second, if such situation is then supported by a spatially interconnective infrastructure policy, the main beneficiaries could be the multinational enterprises as they will have the dominant market share. Third, with the financial and organizational capacity of the multinationals, the spatially targeted incentive will also benefit this group. For example in telecommunication, where the utilization is low, the multinational group (operators and vendors) who are involved in the USO program will be most likely the direct beneficiaries from the provided incentive.

Hence to avoid an inequitable policy for infrastructure and public service provision, a strong planning and broad understanding of the politics of distribution should be mastered by policy makers. In the end, the evaluation from the perspective of the public, who is the expected beneficiary of the policy, should be performed.

\subsection{Conclusion}

This chapter provides a discussion on of the implications to social justice of appying WDR policies at specific localities. The lessons learnt serve as knowledge to recraft the policy framework to be practical in various contexts.

With the debate introduced by WDR to prioritize place-based versus people-centered policies for regional development we disclose the construction of politics of distribution and power relations underneath the policy for infrastructure planning and public service provision.

Policy makers should be aware that the WDR policy instruments on spatially blind institutions which aim to promote global market integration could change power relations between domestic and multinational infrastructure operators and service providers. Moreover, the associated pro competition environment that potentially increases spatial and social inequity should be managed with proper policy and regulations.

Any program similar to the spatially targeted incentive policy in WDR which is concerned with addressing inequity, such as the Universal Service Obligation or the Public Service Obligation Programs, should be conducted with a proper institutional arrangement. These programs which aim to 
serve geographically difficult and economically challenging target groups require a strong business model to optimize possible subsidy involved. In such case the public service agency should be equipped with proper equity based planning support tools. These tools should also embedded with equity assessment to allow a continuous monitoring on the progress of equitable distribution. With current shortcoming of existing equity measurement a possible combination of approaches needs to be explored to propose a new method, not only for evaluating but also for directing growth distribution toward more equitable development.

Learning from the case study, policy makers should also be equipped with tools to find when and where 1) spatially blind institution 2) spatially connective infrastructure and 3) spatially targeted incentive could properly applied. Finally, the evaluation from the perspective of the public who is the target beneficiary of the policy should be performed with a broad understanding in politics of distribution. 


\title{
Chapter 3
}

\section{The Shortcoming of Current Equity Measurements}

\begin{abstract}
Inequality and poverty issues have been promoting a pro-poor growth policy. To evaluate this policy, we assessed the applicability of several poverty measurement methods. We selected and applied the methods for evaluating transport infrastructure development in Indonesia during the transition period of governance reforms and decentralization. We used mobility as non-income poverty indicators in 1996, 2000 and 2005 to rank the level of compliance with a pro-poor growth policy. Surprisingly, we found that each method produced a different ranking. In general, during the transition period from 1996 to 2005, the transport infrastructure development in Indonesia was compliant with a pro-poor growth policy. However, from 2000 to 2005, the growth became anti-poor. We conclude that an individual measurement method is insufficient to evaluate a propoor growth policy. Therefore, a robust and comprehensive measurement tool is needed. The tool will enable us to maintain the appropriate distribution of development benefit to the poor and the rich.
\end{abstract}

Key Words: pro-poor growth, measurement, inequality, decentralized 


\subsection{Introduction}

Poverty remains a major challenge despite Asia's high growth. More than $60 \%$ of the population in the region is living in poor conditions (ADB 2004) 2004 ), and $75 \%$ of the poor are living in rural areas (World Bank 2008).

Infrastructure development, particularly transportation, is an important means for economic growth and for distributing the benefit of development to different economic groups in the community. Inequalities between urban-rural areas and different economic groups show that the current development of transport infrastructure and services is insufficient for promoting growth and reducing inequality at the same time.

Attempts to reduce spatial inequality inspired countries such as Indonesia to change the means of governing the country from centralized to decentralized systems. Furthermore, to reduce inequalities between different economic-groups as well as to manage growth, Indonesia is currently establishing a pro-poor growth policy for the development. The pro-poor growth policy by one definition is a situation in which any distributional shifts accompanying economic growth favours the poor. The policy focuses on changes in inequality during the growth process (Ravallion 2004).

Although the pro-poor growth policy is currently high on the national agenda, a comprehensive measurement tool for it is not in place. Several methods for measuring the individual properties of poverty, such as the Lorenz or Gini Index for inequality measurement, are available (Son and Kakwani 2008); however, measurement of pro-poor growth should not only consist of an inequality measure, but also include other properties of poverty (i.e., poverty incidence) (Ravallion 2004). In addition, the evaluation of non-poor groups as well as of the nature of the growth is required for the analysis. Therefore, a comprehensive measurement that includes multi-properties of pro-poor growth is important.

While the changes are occurring, the impacts of the governance reform process in Indonesia remain unclear, particularly after the first reform in 1997, the economic crisis in Asia and the decentralized systems implemented in 2001.

This study's objective is to assess the applicability of various poverty measurement methods for measuring the pro-poor growth policy and to evaluate the performance of transport infrastructure development in 
Indonesia during the transition period of governance reforms in the context of compliance with a pro-poor growth policy.

We applied two steps of analysis. The first step was the evaluation of the existing poverty measurement methods, and the second was the testwise application of the methods. We assessed and extended the current graphical methods of poverty measures to evaluate pro-poor growth measurement in transport sectors. We used mobility as non-income poverty indicators from the 1996 to 2000 (first reform and after crisis) and the 2000 to 2005 (after decentralization) periods. Therefore, we analyzed the changes in distributional patterns of opportunity to mobility for the poor and the rich during those periods. The results were rankings of distributional patterns between each periods in terms of compliance with a pro-poor growth policy.

\subsection{Material and methods}

\subsubsection{Study Design}

In the beginning, we assessed and extended current graphical methods of poverty measures to evaluate pro-poor growth measurement in transport sectors. The graphical method of poverty measurement is a common means to evaluate the distribution of income to the poor and to the rich. These methods apply the graphical comparison of curves generated by certain distribution patterns; these are useful for comparing and ranking the distribution patterns from different periods or policies.

First, we evaluated several graphical methods such as the Lorenz Curve, the TIP Curve, the CDF Curve and Pen's Parade for the appropriateness of propoor growth measurements. Then, we derived the properties of the propoor growth measurement (i.e., poverty incidence, severity and inequality) as the criteria for method appropriateness.

Second, to measure infrastructure development performance, we used nonincome indicators instead of income indicators. The non-income indicators are commonly used in poverty measurements when applying a capability approach (Sen 1976). According to Sen's 'capability' approach, individuals are considered poor solely if they lack the capability to achieve essential functioning. An individual may choose a poor diet to indulge an inessential personal weakness. However, if this individual has the capability to achieve the 'adequately nourished' functioning, s/he would not be considered poor. It is the capability that matters. 
Deneulin (2008) presented Sen's capability approach for transport infrastructure and mobility in measuring poverty and justice. He provided an example that the capability to move around in a particular society strongly depends upon the availability of transport infrastructures and their services. Grosse, Harttgen et al. (2008) also applied a non-income indicator for pro-poor growth measures. Moreover, Kakwani and Silber (2008) promoted non-income indicators for pro-poor growth evaluation.

Utilizing the capability approach, we applied the level of mobility as a proxy for a non-income indicator. The mobility as non-income poverty indicators from the 1996 to 2000 (after first reform and crisis in Asia Region) and the 2000 to 2005 (after decentralized system implemented) periods were used for pro-poor growth policy evaluation in the transport sector.

The comparison of distribution patterns of the opportunity to mobility from each period produced the rank of the curves in terms of the pro-poor growth level.

\subsubsection{Materials}

A dataset of infrastructure development in Indonesia from 1996, 2000 and 2005 was used. The dataset was village level data from (BPS 1996; BPS 2000; BPS 2006), which consists of approximately 400 attributes of demographic, social economic and infrastructure data. However, we used transport infrastructure solely in the analysis. In this study, people mobility represented economic opportunity provided by transport infrastructure and services.

The dataset for each year consisted of more than 70.000 villages. For the analysis, we selected villages that contained data completed for all periods. We also removed the outlier with threshold maximum speed of $80 \mathrm{KM} / \mathrm{h}$. Therefore, the quantity of villages was 31,284 ; this is approximately $50 \%$ of the villages in the study area.

\subsection{Measurement methods and the framework for analysis}

The pro-poor growth measurement consists of two groups of properties. The first group includes properties with poverty measurements such as inequality, poverty incidence, poverty intensity or severity. The other group includes properties of growth measurement such as a non-poor group measure (e.g., prosperity) or the growth of measurable indicators (e.g., increasing of total income). 
In the first group, the measurement is closely linked with equity and equality terms. In accordance with the 2006 World Bank report, equity is defined based on two principles. First is equal opportunity, which means the outcome of a person's life, in its many dimensions, should primarily reflect his or her efforts and talents, not his or her background (endowment and process). The second principle of equity is avoidance of absolute deprivation/poverty or people who are unable to command sufficient resources to satisfy basic needs. The term inequality corresponds to the first item of equity; it relates more to the distribution of income/wealth across a population.

Referring to the above definition, the term, equity, includes the poverty line. The term relates to properties of poverty measurement that requires a poverty line such as poverty incidence, poverty deficit, poverty intensity or severity. Properties of growth measurement include the property of nonpoor group (i.e., prosperity as opposed to severity) and increasing the total growth of measurable indicators.

Using various graphical methods, such as the TIP (the Three "I"s of Poverty: Incidence, Intensity and Inequality) curve ((Jenkins and Lambert 1997), CDF (Cumulative Distribution Function) Curve, Pen's Parade (Pen 1971) and Lorenz Curve, we can obtain values of each property of poverty measurement from a distribution pattern. However, before using those methods, we must evaluate the limitation of the methods and the appropriateness of their properties for measuring pro-poor growth. We selected relevant methods and modified the method as deemed necessary.

In addition to properties appropriateness, four criteria for suitable measurement were adopted:

1. Anonymity - permutations or transfers and changes of incomes among individual should not matter for inequality judgments.

2. Scale independence principle (Relative Income Principle) - relative income share solely matters.

3. Population independence principle - population size does not matter, i.e., all that matters are proportions of the population that earn different levels of income.

4. Dalton principle - if one income distribution can be achieved from another by constructing a sequence of regressive transfers (e.g. via cross subsidy), the former distribution must be deemed more unequal than the latter. 
Figure 3.1 presents the framework of the methods assessment and the testwise application. In this figure, three basic properties of pro-poor policy measure, equality, equity and poverty, were derived to analyze the appropriateness of the properties of CDF, TIP, Pen's Parade and Lorenz Curve.

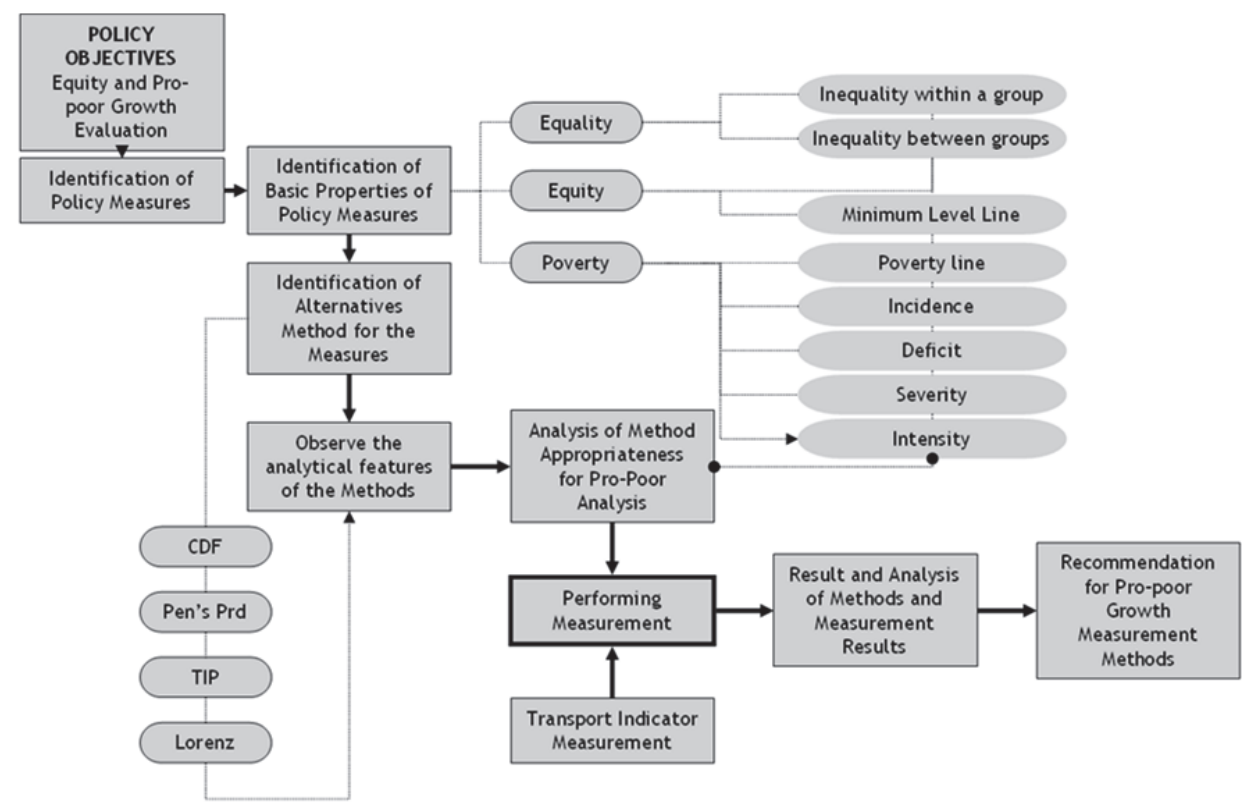

Figure 3.1 The framework of methods assessment

For each graphical measurement method, the description, the step-by-step procedures and associated properties are presented below.

\section{(1) Lorenz Curve Methods}

The system of inequality measurement, although simple and effective for a pair-wise comparison, becomes nearly useless to measure the inequality across more than two units. Max Lorenz previously noticed the computational problems associated with multi-group comparison of income inequality in 1905. The researcher formulated representation of the actual inter-group income distribution as a line, plotting "along one axis cumulated percents of the population from poorest to richest, and along the other the percent of the total wealth held by these percents of the populations". As shown in Figure 3.2, with an unequal distribution, the curves will always begin and end in the same points as with an equal distribution; however, they will be bent in the middle. The rule of interpretation will be, as the bow is bent, concentration [of incomes] increases (Felsenstein and Portnov 2005). 
Furthermore, Corrado Gini moved Lorenz's ideas a step further, suggesting a simple and easy quantitative and comprehensible measure of inequality known as the Gini coefficient. Graphically, the calculation of this coefficient can be interpreted as follows: (Gini coefficient $=$ the area between the Lorenz curve and the diagonal/ total area under the diagonal). Mathematically, the Gini coefficient is calculated as the arithmetic average of the absolute value of differences between all pairs of incomes, divided by the average income. The coefficient takes on values between 0 and 1 , with 0 interpreted as perfect equality.

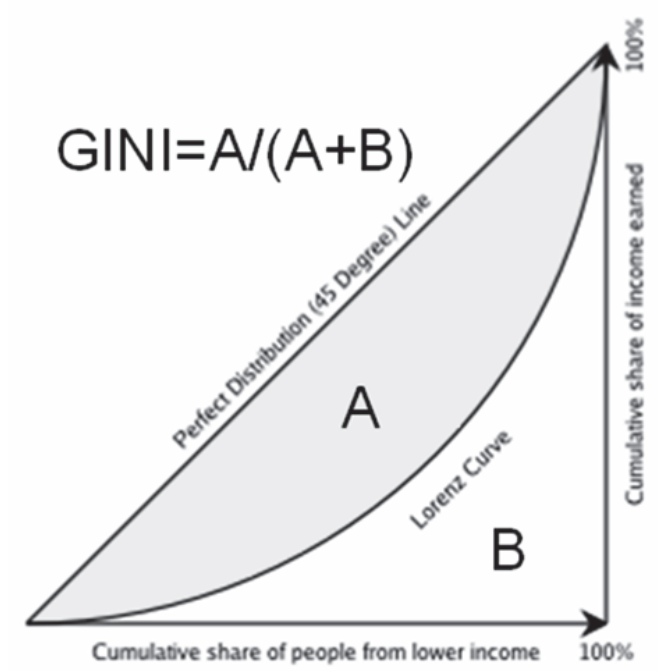

Figure 3.2 Graphical representation of Lorenz Curve and Gini Index

The Lorenz Curve measurement of poverty is widely used; however, it provides a single property measurement, inequality.

\section{(2) TIP Curve}

Jenkins and Lambert (1997) developed a diagram that neatly captures the incidence, intensity and inequality of poverty. The acronym TIP represents the 'Three "I"s of Poverty', which the diagram illustrates. The TIP diagram is formed by first ranking individuals from the poorest to the richest, cumulating their poverty gaps (or normalized gaps) and, finally, plotting the cumulative per capita values against the cumulative share in the population (UNDP 2008). Figure 3.3 is an illustrative TIP diagram.

The formulas for measure the poverty gap are (after UNDP, 2008): 


$$
g\left(y_{i} z\right)=\max \left(z-y_{i}, 0\right)
$$

and the normalized poverty gap is

$$
\mathrm{I}\left(y_{i}, z\right)=\frac{g\left(y_{i}, z\right)}{z}=\max \left(\frac{z-y_{i}}{z}, 0\right)
$$

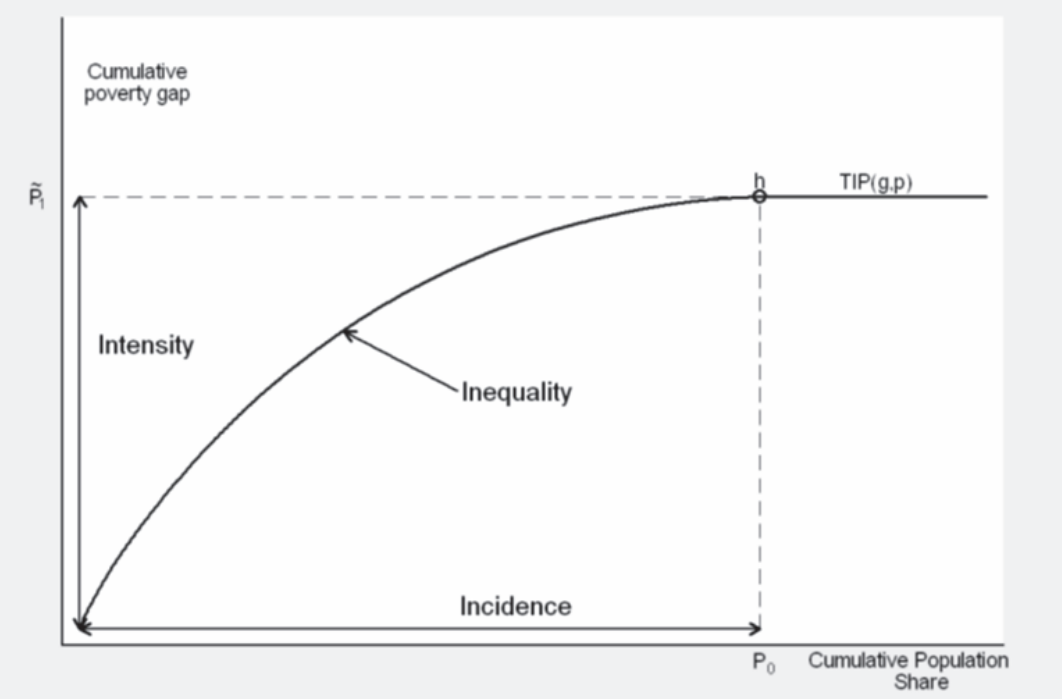

Figure 3.3 Graphical representation of the TIP Curve (after UNDP, 2008)

The quantitative measurement of Poverty Intensity on Poverty Line $\mathrm{Z}$ is the vertical distance from 0 to $\mathrm{P}_{1}$. The Poverty Incidence is the horizontal distance from 0 to $\mathrm{P}_{0}$. For Inequality, we can implement approach to calculate the Gini Index in the Lorenz Curve. The inequality increases if the curve bond is outward. The Inequality in the TIP Curve is actually the inequality within the poor-group.

\section{(3) Cumulative Distribution Function (CDF)}

(UNDP 2008) summarized the cumulative distribution function (CDF) for poverty measurement; it is an obvious method to graph the distribution of income. The CDF simply plots on the vertical axis the proportions of the population with incomes equal to or less than the income level indicated on the horizontal axis. Figure 3.4 presents an illustrative CDF labelled F(y).

For poverty analysis, the CDF focuses solely on the CDF at low levels of income. For any given poverty line, say $\mathrm{z} 1$, the function $\mathrm{F}(\mathrm{y})$ measures the 
headcount ratio (labelled $\mathrm{P}_{0}$ in Figure 3.4): the proportion of the population with incomes equal to or less than the poverty line. The CDF can be considered a plot of the headcount ratio as we vary the poverty line; therefore, it could be called the poverty incidence curve (PIC). The area beneath the CDF has been called the poverty deficit curve (PDC). The area beneath the PDC has been called the 'poverty severity curve' (PSC). Plotting CDFs, PDCs and PSCs provides useful information, particularly in cases where there is doubt regarding the precise location of the poverty line. Such uncertainty may arise when poverty lines are being revised to reflect changing factors, which affect the poverty line. It is important to be aware that, in contrast to Lorenz Curve and TIP, the CDF requires real value for the quantitative analysis.

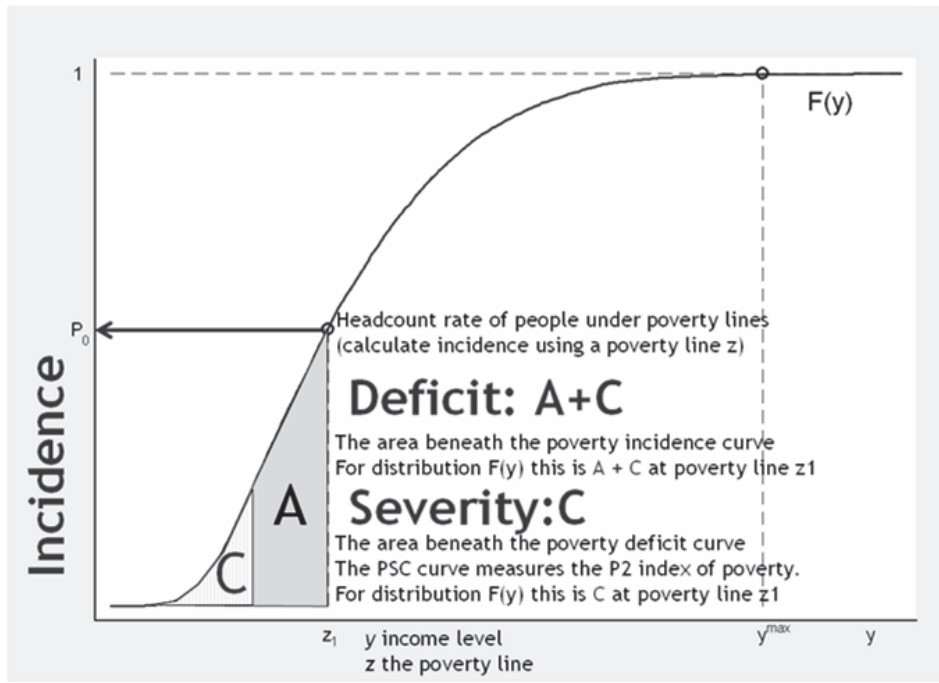

Figure 3.4 Graphical representation of CDF, PDC and PSC (modified from UNDP, 2008)

\section{(4) Pen's Parade}

Pen's Parade is very similar to the CDF, but the axes are switched (Figure 3.5). Imagine that every person in the economy walks by, as if in a parade, a parade that takes exactly an hour to pass. The marchers are arranged in order of income, with the lowest incomes at the front and the highest at the back. Similar to the CDF, Pen's Parade also requires real value for the quantitative analysis.

For the first time in 1971, Jan Pen illustrated the fact that income distributions tend to show more variation at their bottom and top ends: very small dwarves at the start and impressive giants at the end. Not much 
occurs in the middle. The graph can be used to analyze changes in income below the poverty line. If the incomes of the poor are all rising, we would expect Pen's Parade in later years to be everywhere above those for earlier years (UNDP 2008).

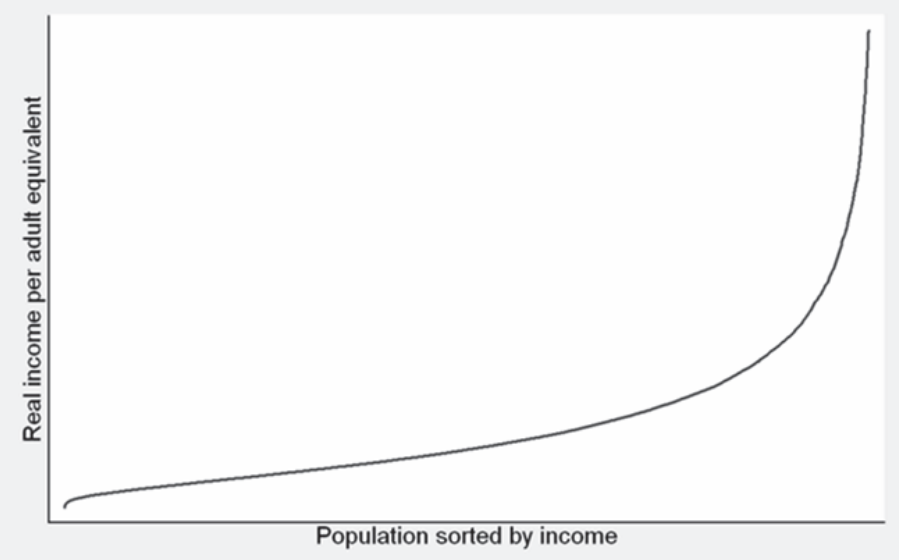

Figure 3.5 Graphical representation of Pen's Parade (after UNDP, 2008)

\subsubsection{Calculations}

To calculate mobility, the main sub-indicators available in the dataset were speed and transport cost. The speed is a proxy to represent the quality of both infrastructure and service. The speed $(\mathrm{KM} / \mathrm{h})$ was calculated by dividing distance from the village centre to facilities with the travel time to the facilities. The travel cost unit (Rp/KM) was calculated by dividing the travel cost to facilities with distance to facilities. The type of facilities for the analysis were education, market, entertainment and administrative centres (Potdes codes: B5R1, B11AR2, B11AR1, B7BR1, B11AR2 and R902)

To determine the poverty line, there are two possible approaches. The first approach was based on the average time available for travelling daily. The second approach was based on the average ability to pay. However, because the data on travel cost are available solely for 2005, in this research, the calculation is based solely on the travel speed and the average time for travelling.

We applied the poverty line at the village level. Villages under the poverty line were determined to be deprived villages. People who live in these villages have a limited opportunity for mobility. To establish the poverty line, the average speed was $25 \mathrm{KM} / \mathrm{h}$, and the travel time was $1 \mathrm{~h}$ per 
person per day; this means the distance of $25 \mathrm{KM}$ was the poverty line used for the calculation. In the other words, people who are unable to travel above $25 \mathrm{KM}$ because of speed constraints were categorized as poor. The assumption for $25 \mathrm{KM} / \mathrm{h}$ was based on a survey of the expected speed on a local road in a mountainous area (TRB 2004). We multiplied the possible travel distance by the number of households in each village and summed to obtain the total number of opportunities for mobility.

Figure 3.6 summarizes the calculation procedure from raw data into the indicators of mobility.

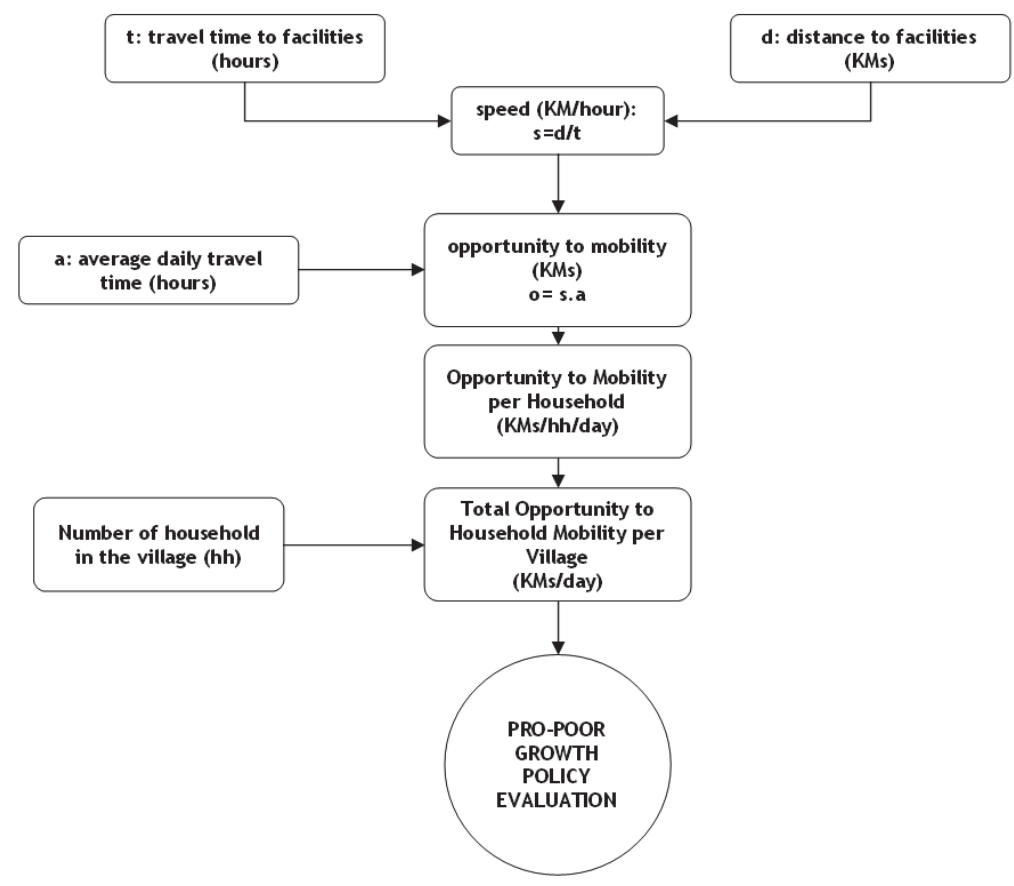

Figure 3.6 The calculation procedure from raw data into the indicators of mobility

\subsubsection{Data Analysis}

To determine the rank of the two distribution patterns in the graphical methods, a curve-dominance-analysis was applied to the selected graphical method. There are two possible situations in a curve comparison. First is first-order dominance, if the curves are not intersecting. The other is second-order dominance, if the curves are intersecting.

In first-order dominance, rank between curves can easily be determined using a visual assessment. For example, with first-order dominance in 
Lorenz Curve, we can conclude that the curve closer to the ideal line has a higher rank, or the growth is unambiguously pro-poor if the entire Lorenz curve shifts upward (Son and Kakwani 2008).

For second-order dominance, we must investigate where and how the curves are intersecting. In this case, we applied both visual assessment and quantitative assessment for each property of measurement.

To summarize the result, we referred to the basic questions in the pro-poor growth analysis. Those are:

- Is poverty decreasing?

- Does economic growth exist?

The first question refers to the objective for reducing poverty incidence, deficit, severity, intensity and inequality. The second relates to growth and non-poor group properties. Therefore, we determined the rule for determining whether the changes of distribution patterns lead to pro-poor or anti-poor growth as follows:

"The growths are pro-poor growth if ALL these properties are reduced (poverty incidence, deficit, severity, intensity AND inequality). The growths are anti-poor if all of the above properties increase."

Using this AND logical operator in the rule-based composing method, we determined whether the changes of distribution lead to pro-poor or antianti poor development. Using an AND logical operator means all of the condition for pro-poor should be accomplished. If one property does not, for example, inequality decreasing but the poverty incidence increases, we cannot categorize it as pro-poor.

\subsection{Results}

\subsubsection{Results of Methods Assessment}

With regards to the framework of method assessment (Figure 3.1), we found that not all basic properties of the pro-poor analysis could be analyzed using each method. Table 3.1 shows that the Lorenz Curve solely has the property of inequality. The TIP Curve has more properties: inequality, poverty incidence and intensity. The result disclosed that since Pen's parade is actually a CDF with axes switched, it has similar properties to a CDF: inequality, incidence, deficit and severity. They, however, have 
different ways for interpretation and providing the quantitative description of the result.

Table 3.1 Result of methods assessment

\begin{tabular}{|c|c|c|c|c|c|}
\hline Measures & Basic Properties & CDF & $\begin{array}{l}\text { Pen's } \\
\text { Parade*) }\end{array}$ & $\begin{array}{ll}\text { TIP } & \text { L } \\
\text { Curve } & \end{array}$ & $\begin{array}{l}\text { Lorenz } \\
\text { Curve }\end{array}$ \\
\hline \multirow[t]{2}{*}{ Equality } & Inequality within a group & No & No & Yes & $\overline{\text { No }}$ \\
\hline & Inequality between groups & No & No & No & Yes \\
\hline Equity & Minimum Level Line & Yes & Yes & Yes & No \\
\hline \multirow[t]{5}{*}{ Poverty } & Poverty Line & Yes & Yes & Yes & No \\
\hline & Incidence & Yes & Yes & Yes & No \\
\hline & Deficit & Yes & Yes & No & No \\
\hline & Severity & Yes & Yes & No & No \\
\hline & Intensity & No & No & Yes & No \\
\hline \multicolumn{6}{|c|}{$=0$} \\
\hline & Inequality reduction between poor groups & No & No & No & Yes \\
\hline & Incidence Reduction & Yes & Yes & Yes & No \\
\hline & Deficit Reduction & Yes & Yes & No & No \\
\hline & Severity Reduction & Yes & Yes & No & No \\
\hline & Intensity Reduction & No & No & Yes & No \\
\hline
\end{tabular}

Note: ${ }^{*}$ ) Pen's Parade is a CDF with the axes switched

Unfortunately, the evaluation of the growth aspect and the non-poor group has been ignored in all of the methods discussed. No single method's objective is to evaluate the non-poor group, which is actually also important for assessing the impact of growth both on poor and non-poor groups. Therefore, in this study, growth was measured using total growth of opportunity to mobility, without assessment of the non-poor group properties.

Based on the result of the methods assessment, we selected the CDF or Pen's Parade, the TIP Curve and the Lorenz Curve. With respect to suitable measurement criteria of the population-independence principle, we applied normalized curves instead of a real-value curve. Consequently, we evaluate the shape of the CDF or Pen's parade instead of quantitatively measuring incidence, deficit and severity reduction, which requires real values for the analysis.

In other words, when we found a second-order dominance curve (the intersecting curves) that requires interpretation using quantitative analysis, we applied the TIP and Lorenz Curves. 


\subsubsection{Results on Pro-poor Growth Measurement}

Figure 3.7 to Figure 3.9 present the curves from the CDF/Pen's Parade, the TIP Curve and the Lorenz Curve from the dataset from 1996, 2000 and 2005. With the Lorenz Curve, the shapes of the curves were not intersecting; therefore, we applied the first-order dominance analysis. With this analysis, the rank, from the highest, was 2005, 1996 and 2000.

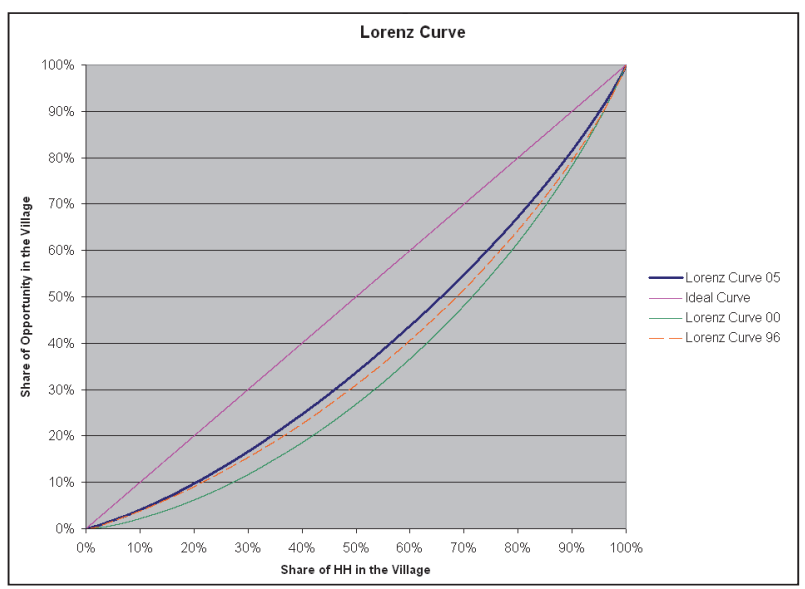

Figure 3.7 Lorenz Curve

With TIP, the curves were also not intersecting (Figure 3.8). Therefore, we also applied the first-order dominance analysis. The result for ranking was 2005, 2000 and 1996.

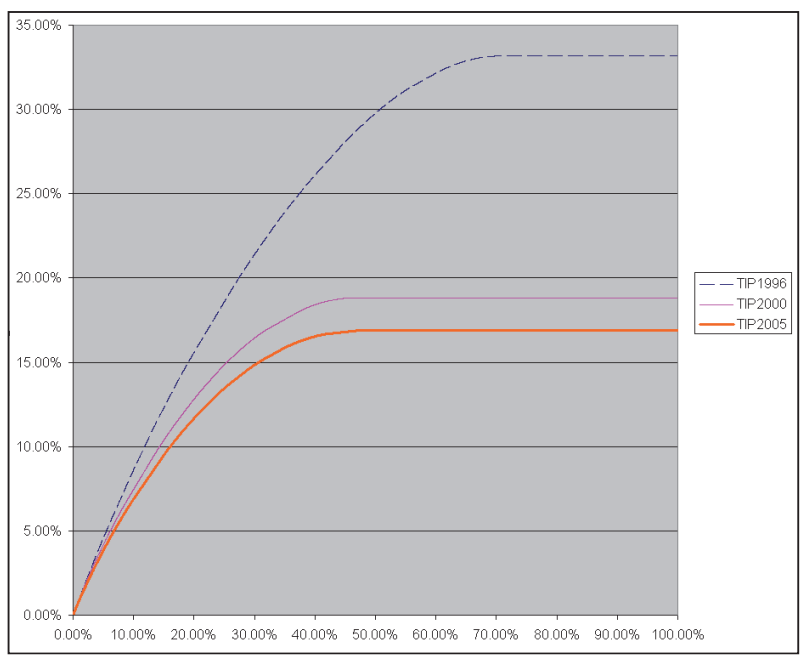

Figure 3.8 TIP Curve 
With a normalized and axes-switched CDF or Pen's Parade, the curves were also not intersecting (Figure 3.9). Therefore, we applied the first-order dominance analysis. Using this analysis, the ranking result was 2000, 2005 and 1996.

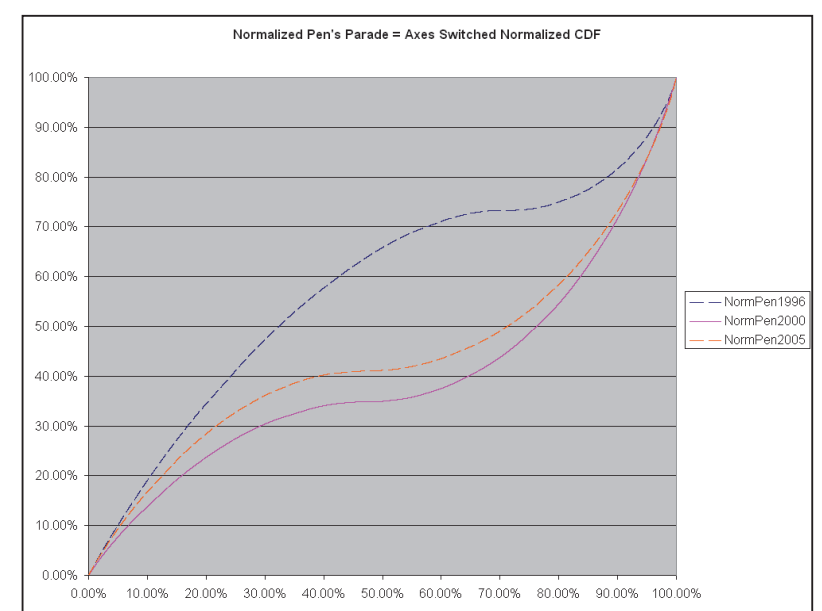

Figure 3.9 Normalized and axes-switched CDF or Pen's Parade

We found that each graphical method produced different ranks, as summarized in Table 3.2. The rank is higher when the inequality, poverty incidence and intensity decrease.

Table 3.2 Summary of Rank between Years

\begin{tabular}{lccc}
\hline Method & Lorenz & TIP & \multicolumn{2}{c}{$\begin{array}{l}\text { Normalized } \\
\text { CDF/Pen's }\end{array}$} \\
\hline RANK I & 2005 & 2005 & 2000 \\
\hline RANK II & 1996 & 2000 & 2005 \\
\hline RANK III & 2000 & 1996 & 1996 \\
\hline
\end{tabular}

Therefore, to summarize the result, it is necessary to review the basic question in pro-poor growth analysis. The answer using the rule-based composing method with an AND logical operator is presented in Table 3.3. 
Table 3.3 Pro-poor growth analysis

\begin{tabular}{|c|c|c|c|c|c|}
\hline $\begin{array}{l}\text { Rules/ } \\
\text { Cases }\end{array}$ & GROWTH & $\begin{array}{l}\text { Poverty } \\
\text { Incidence }\end{array}$ & $\begin{array}{l}\text { Poverty } \\
\text { Intensity }\end{array}$ & Inequality & $\begin{array}{l}\text { Pro/Anti Poor } \\
\text { Growth }\end{array}$ \\
\hline $\begin{array}{l}\text { Rule } 1 \\
\end{array}$ & YES & Decrease & Decrease & Decrease & PRO-POOR \\
\hline Rule 2 & YES & Increase & Increase & Increase & ANTI-POOR \\
\hline $\begin{array}{l}\text { Case: } \\
\text { 1996-2005 }\end{array}$ & $\begin{array}{l}2.54 \mathrm{E}+08- \\
2.86 \mathrm{E}+08 \\
\text { YES }\end{array}$ & $\begin{array}{l}\text { 73.23-48.27\% } \\
\text { Decrease }\end{array}$ & $\begin{array}{l}46.25-37.18 \\
\text { Decrease }\end{array}$ & $\begin{array}{l}0.269-0.231 \\
\text { Decrease }\end{array}$ & PRO-POOR \\
\hline $\begin{array}{l}\text { Case: } \\
1996-2000\end{array}$ & $\begin{array}{l}2.54 \mathrm{E}+08- \\
3.21 \mathrm{E}+08 \text { YES }\end{array}$ & $\begin{array}{l}73.23-46.27 \% \\
\text { Decrease }\end{array}$ & $\begin{array}{l}46.25-36.94 \\
\text { Decrease }\end{array}$ & $\begin{array}{l}0.269-0.234 \\
\text { Decrease }\end{array}$ & PRO-POOR \\
\hline $\begin{array}{l}\text { Case: } \\
\text { 2000-2005 }\end{array}$ & $\begin{array}{l}3.21 \mathrm{E}+08- \\
2.86 \mathrm{E}+08 \mathrm{NO}\end{array}$ & $\begin{array}{l}46.27-48.27 \% \\
\text { Increase }\end{array}$ & $\begin{array}{l}36.94-37.18 \\
\text { Increase }\end{array}$ & $\begin{array}{l}0.324-0.231 \\
\text { Decrease }\end{array}$ & $\begin{array}{l}\text { ANTI-POOR } \\
\text { NO GROWTH }\end{array}$ \\
\hline
\end{tabular}

We found that, during the entire period from 1996 to 2005, the growth was pro-poor. However, if we split these into shorter periods, we found that, during the 2000 to 2005 period, the growth became anti-poor.

\subsection{Discussion}

In this study, we show that an individual measurement method is insufficient for evaluating a pro-poor growth policy. This study also shows that, in general, the performance of transport infrastructure development in Indonesia during the transition period of governance reforms from 1996 to 2005 was compliant with a pro-poor growth policy.

The analysis shows that, in 2005, inequality and poverty incidence and intensity were reduced in comparison with the performance in 1996. Firstorder dominance analysis with each method also shows that the rank of distribution patterns in 2005 is always higher than in 1996.

Surprisingly, if we examine shorter periods (1996, 2000 and 2005), each method produces a different set of ranking. The first rank from Lorenz was 2005, followed by 1996 and 2000. The TIP-Curve produced different sets or ranks; the first was 2005, followed by 2000 and 1996. With normalized CDF/Pen's Parade, we found a different ranking; the first was 2000, 2005 and 1996.

The unexpected result for the 2000-2005 period, which produced anti-poor development, reveals that the decentralized process transition period slows the growth and producing anti-poor development. This result is similar to experiences in other countries such as Russia (Slinko 2003). Firman (2002) also indicated that, in the beginning of a decentralizing process, uncertainty and an unsettled system will negatively affect the development process. Further investigation is required to observe the impact of a crisis combined 
with the challenges of a decentralized system regarding contributions to the slowing growth. The fact that our result shows that inequality also decreased from 0.324-0.231 during this period strengthens the indication that rich people were also becoming poorer.

This fact also clarifies the reason for rank differences. The Lorenz curve, which placed 2005 in the first rank, relies solely on one property of measurement (inequality). The TIP-Curve consists of more properties and therefore provides better measurement. However, the curve ignores the non-poor group's property. Actually, the CDF or Pen's Parade, which includes non-poor properties, has a more comprehensive measure. However, the normalization, which is required for maintaining scaleindependency and the population-independency principle, reduces the possibility to decompose each property. To obtain a more reliable ranking as well as to determine pro/anti-poor growth, we quantified and composed the properties from the Lorenz and TIP Curves with Rule 1 and Rule 2. The result provides more transparent measurements than curve-dominance analysis on the individual graphical method alone.

\subsection{Conclusion}

In this study, we show that an individual measurement method is insufficient to evaluate pro-poor growth policy. All of the methods that focus solely on poor-groups limit the possibility of observing the impact of the development of non-poor groups. Consequently, different methods result in different ranks. In this research, the combination of methods with a rule-based composition approach revealed anti-poor stagnant development from 2000 to 2005. Further investigation to be conducted for this field of research could involve a comparison of the transportation mobility equity with the traditional income distribution. For example, for this mobility measurement we found that the inequality was $0.324-0.231$, while for the income distribution the index at about same period was 0.370 to 0.413 (BPS 2014). This brief comparison indicates while the inequality of income increases, the poor and the rich might have closer experiences on receiving infrastructure service.

Although the combination of several graphical methods in this research is applicable to providing more reliable and transparent measurement, we must consider several limitations. First, we composed a multi-properties value with a Boolean approach (Increase or Decrease) with an AND logical operator. This rule strictly limits the change of distribution-pattern to classification as pro-poor. Therefore, to anticipate a possible increasing number of rules, a Non-Boolean approach for composing properties in Pro- 
poor Growth analysis is necessary. Second, to have a comprehensive measure, we must obtain values of properties from several graphical methods; this increases the computing time. Therefore, it is necessary to develop a single graphical method that includes multi-properties, both for the poor-groups and for the non-poor groups.

In summary, we conclude that a robust measurement tool for pro-poor growth requires more focus for further development. The tool will enable us to maintain the appropriate development benefit distribution to the poor and the rich. 


\title{
Chapter 4
}

\section{Spatial Interdependency in Infrastructure Development ${ }^{1}$}

\begin{abstract}
To determine whether the inclusion of conditions in neighbouring villages and infrastructure interdependency are able to improve the performance of infrastructure-economy interaction models, we compare three related and progressive concepts. The first concept defines economic opportunity in a village as a function of available infrastructure within that village. The second concept includes the effect of economic opportunity in neighbouring villages in addition to available infrastructure within the village. In the third concept, we include the interdependency of infrastructures as another factor affecting the potential level of economic development in the village. We use Ordinary Least Squares (OLS) and a Geographic Information System (GIS) to model the first concept, and we add a spatial-lag model for the second. The third model expands on the second by introducing a Sugeno Fuzzy Inference System (FIS) and a rulebased OLS to capture the nature of infrastructure interdependency. The result of the three models is validated by a known spatial distribution of poverty levels and subjective well-being that serve as proxies for economic opportunity in the Yogyakarta region in Indonesia. The results demonstrate that the third model provides a more accurate prediction of the real conditions and performs consistently better than the other two models. We therefore conclude that conditions in neighbouring villages and infrastructure interdependency influence the economic opportunity of a village and should be considered in policy making regarding resource allocation in infrastructure development.
\end{abstract}

Keywords: Infrastructure interdependency, Sugeno FIS, Economic opportunity, Spatial-lag, Rule-based OLS, village, Indonesia

\footnotetext{
1 Published as:

Wismadi A, Brussel M, Zuidgeest M, Sutomo H, Nugroho LE, van Maarseveen M (2012) Effect of neighbouring village conditions and infrastructure interdependency on economic opportunity: a case study of the Yogyakarta region, Indonesia. Comput Environ Urban Syst 36(5):371-385

doi:10.1016/j.compenvurbsys.2012.02.001
} 


\subsection{Introduction}

Infrastructure is one of the main drivers of economic development (Chandra and Thompson 2000). For this reason, countries spend large amounts of money on infrastructure development.

Along with national development objectives and the diversification of funds among other public sectors (even though the absolute amount of funds might increase), the share of public infrastructure spending decreased from 5 to $2.5 \%$ and 23 to $4 \%$ of GDP for developed and developing countries, respectively (Yu, Zhang et al. 2011). In other words, the infrastructure had to serve more people and their activities with the same amount of public funding, or less. In such a situation the efficiency of allocation becomes a most critical concern.

Concurrently, the demand for an equitable allocation has also generated increases in the share of spending on infrastructure by of local governments (Yu, Zhang et al. 2011). This pattern of increased spending reveals a new trend in fiscal decentralisation and a shift from the development of a single national infrastructure to sub-national or local infrastructure systems.

Indonesia, for example, is one country that has been moving toward a decentralised fiscal system. In the aftermath of the Asian crisis, the infrastructure budget has increased from 0.8 to approximately $1.7 \%$ of GDP (Pisu 2010). With approximately 70,000 diverse villages that have generally been overlooked during more than 30 years of centralised systems, Indonesia now requires large amounts of infrastructure support, but budget constraints have made this difficult, and therefore the country faces a serious challenge with respect to the efficiency of delivery.

Surprisingly, however, even as resource allocation for infrastructure investment in decentralising systems aims to better accommodate local preferences, Neyapti (2010) and Kyriacou and Roca-Sagalés (2011) found that the effectiveness of resource allocation decreases in countries with local or regional elections. They argue that local elections result in a decision-bias on the part of local politicians in the distribution of resources to their constituents.

Neyapti (2010) and Kyriacou and Roca-Sagalés (2011) are among the researchers who have studied infrastructure budget inefficiency. However, they did not take note of nor did they discuss the mechanisms of the 
relationship between infrastructure and economy that lie behind inefficient allocations in a decentralised context.

Resource allocation for infrastructure primarily involves its effect on economic development. Many econometric or spatial-econometric models have been designed to better understand the effect of infrastructure development on the various economic sectors, including its spill-over effect (Cohen 2010; Gutiérrez, Condeço-Melhorado et al. 2010; Yu, Zhang et al. 2011; Elhorst, Lacombe et al. 2012). Such tools allow decision makers to properly establish policies for the allocation of resources for each type of infrastructure to support the economic sectors in a region. These tools are commonly applied for analysis at the national level and deal mainly with the interaction between infrastructure and the economy in centralised systems.

Under a decentralised fiscal system, analysis at a lower level, such as at the village level, requires that more attention be given to local conditions and preferences (Thornton 2007). When this occurs, the effect of an investment in infrastructure is more apparent to the general public, in particular to village communities. Hence, this shift requires indicators that are representative of the community perspective.

For analysis at the national level, a macroeconomic indicator, such as change in Gross Domestic Product (GDP), is sufficient to explain an infrastructure effect. However, at the community level, this GDP is less informative than a lower-level indicator, such as a change in job opportunities (van den Bergh 2009). If villagers are unable to find a job or an economic opportunity, they tend to migrate to urban areas where money is more broadly circulated. In a decentralised context, a micro-level indicator, such as local economic opportunity, is important for an understanding of the interaction between infrastructure and the economy. At the village level, economic opportunity is best represented by the existence of small and medium enterprises, including small business units or home industries that provide opportunities for people in neighbouring areas to be involved in related economic activities.

With reference to macroeconomic models, the analysis of the interaction between infrastructure and the economy at the village level requires three types of investigations. The first investigation involves the nature of the contribution to the economy that each type of infrastructure makes in an integrated systems configuration (see the econometric studies by Foley (1992), Nazem, Liu et al. (1996), Mamatzakis (2003), Chandra and Thompson (2000), Gibson and Olivia (2008)). The second investigation is 
related to the spill-over effect as a result of spatial dependency among neighbouring areas (see the spatial-econometric studies by Ho, Kauffman et al. (2007), Bröcker, Korzhenevych et al. (2010), Flahaut (2004)). The third investigation involves the interdependency among infrastructure types that could determine the various types of economic activity within a region (see the infrastructure interdependency studies by Macaulay (2008), Utne, Hokstad et al. (2011), Zhang and Peeta (2011), Kröger (2008), Johansson and Hassel (2010), Barker and Haimes (2009), Desmedt (2002), Akgun, Kandakoglu et al. (2010)). At the village level, the relationship between infrastructure and economy is more concrete; hence, there may also be the cumulative effect of those three studies. Currently, we do not know whether the combination of those mechanisms improves the performance of models of the interaction between infrastructure and economy.

Such knowledge will be useful to provide more effective and efficient policies for allocating resources at the village level. We need to know, for example, how the variability of the existing infrastructure, the neighbouring factors, and their interdependency influence the distribution of economic opportunity in a region. To date, those aspects have been overlooked in the decision-making process for allocating resources, and they may therefore exert some influence on the effective allocation of resources in a particular village. This possibility should be studied to counter any decision-bias by politicians and decision-makers.

The objective of this research is therefore to determine whether the inclusion of conditions at neighbouring villages and infrastructure interdependency are able to improve the performance of existing infrastructure-economy interaction models in predicting the distribution of economic opportunity at the village level in a region.

This research focuses on the Yogyakarta region, Indonesia, where these issues are extremely relevant. Infrastructure data from four infrastructure sub-sectors are used, i.e., data related to transport, electricity, drinking water, as well as telecommunication and information infrastructures. These infrastructures represent the predominant sectors of government investment. With these datasets and socio-economic, village-level data, we apply three connected explanatory models that are also able to predict economic opportunity distribution as a result of infrastructure development. To evaluate the cumulative effect and to find a best-fit model, the predicted distribution is validated against available secondary data on poverty levels and subjective well-being, used here as a proxy for economic opportunity in the area. 
The paper is organised as follows. Section 2 elaborates the three modelling concepts. Section 3 discusses data, research methodology and the three models. Section 4 presents the results of each model. Section 5 discusses the most important findings, which are followed by conclusions, policy implications and directions for future research in Section 6.

\subsection{Concepts of infrastructure and economic opportunity distribution}

Economic opportunity is a rather broad concept. To enable us to define and later quantify the level of economic opportunity, we adopt the Capability Approach (CA) of Amartya Sen (Sen 1980) which provides a basis for a definition of individual opportunity as the capability to achieve essential functioning. The capability of functioning is generated not only by income indicators but also by non-income indicators. For example, the opportunity or capability to move around in a particular society depends upon the availability of transport infrastructure and its services (Deneulin, Comim et al. 2008). This type of capability, which is made available by the infrastructure, generally provides more opportunity for the community to increase its members' interaction and their capacity to conduct economic transactions. The availability of various types of infrastructure is expected to increase the capability and the opportunity to conduct productive economic activity, such as the development of a small business unit or home industry.

To investigate how infrastructure can provide more opportunity, three concepts of infrastructure-economic interaction are developed.

The first concept is based on the notion that the potential for local economic development is not only a function of the quality of service provision of each type of infrastructure, but also of the combination of the various types of infrastructure in a particular location. The premise here is that the co-existence of various types of infrastructure favours economic development. There has been some research on the contribution of a single type of infrastructure or combined infrastructures within a region to economic growth (Foley 1992; Nazem, Liu et al. 1996; Chandra and Thompson 2000; Mamatzakis 2003; Gibson and Olivia 2008).

The second concept builds on the first, but it recognises that economic potential in a location is not only the result of the characteristics of that location but also of the characteristics of the surrounding area. Ho, Kauffman et al. (2007), for example, found a positive effect of ICT infrastructure in neighbouring regions on a country's e-commerce growth. 
Bröcker, Korzhenevych et al. (2010) identified the spill-over effect of the development of road infrastructure by Trans-European Networks. Most studies, however, have focused on a country-level analysis with spatial macroeconomic models rather than on a similar analysis at the community level. Among the limited studies on lower-level analysis, Flahaut (2004) concluded, with reference to road safety, that there is a strong neighbourhood effect that should be considered when developing infrastructure.

The third concept builds on the first two concepts but also involves the effect that different types of infrastructure have on one another, i.e., the interdependency of the types of infrastructure. One can imagine that the functioning of one type of infrastructure to support a particular economic activity is highly dependent on the performance of another type of infrastructure, e.g., a business entity that requires a certain supply of both water and electricity will not be able to function in the case of a surplus of water but an insufficient supply of electricity. Little research has been conducted regarding the effect of infrastructure interdependency on economic opportunity. Most of the work on infrastructure interdependency has been conducted in the last 10 years and was triggered by the attention paid to natural and manmade disasters, primarily after the 9/11 attacks. Typically, this research entails a vulnerability analysis of critical infrastructure interdependency at the national level (e.g., Macaulay (2008), Utne, Hokstad et al. (2011), Zhang and Peeta (2011), Kröger (2008), Johansson and Hassel (2010), Barker and Haimes (2009), Desmedt (2002), Akgun, Kandakoglu et al. (2010)). The main issue of concern in these studies is the measurement of the 'decreasing infrastructure performance' due to failure or malfunctioning of components of one infrastructure system to the other; this measurement is usually determined by means of physical or input-output interdependency analysis. Even though this knowledge is useful for maintaining the continuous functioning of infrastructure, its direct contribution to infrastructure and spatial planning practices is limited. To understand the relationship between infrastructure and the economic attractiveness of certain locations, the methodology applied in vulnerability studies is not suitable. Moreover, such an approach should focus on infrastructure improvement at the lower, e.g., community level in a regional setting rather at than the national level.

In this study, we develop three models that gradually include the three concepts discussed above. The first model, the so-called Integrated Infrastructure (II) model, predicts economic opportunity in a village as a result of the co-existence of various types of infrastructure. The second model, the Spatial Integrated Infrastructure (SII) model, predicts economic 
opportunity in a village that results from the co-existence of various types of infrastructure in the village itself, as well as from the interaction with the economic development in neighbouring villages. The last model, the Spatial Integrated Infrastructure Interdependency (SIII) model, expands on the second model by also considering the various combinations of infrastructure types and their performance, i.e., the interdependency between various types of infrastructure.

\subsection{Data and methodology}

For over four decades Indonesia has been enacting various infrastructure programmes that target approximately 70,000 villages with the aim to provide more equality in economic opportunity in the various regions of the country. The village is the smallest spatial unit of the administrative system in both rural and urban areas.

An example of a village-level programme is the rural electrification programme, which has been in execution since the 1970s and is valued at more than USD 200 million annually. Another important programme is the rural telecommunication programme, executed under the Universal Service Obligation (USO) programme, and it has invested more than USD 500 million annually in rural areas since 2010.

Several community-based infrastructure development programmes have also been implemented, the most important of which is the Kecamatan Development Programme (KDP). The KDP, which is a community infrastructure programme financed by the World Bank (USD 1.2 billion), was begun in 1998 and seeks to alleviate poverty and improve local governance in rural communities. The programme, covering approximately 28,000 villages, has developed infrastructure such as roads, bridges, irrigation, drainage and clean water supplies. Kecamatan is a sub-district level of administration in Indonesia. There are more than 4,000 subdistricts in the country. On average, a sub-district contains some 20 villages and has a population of over 50,000 people.

The KDP programme is among those that operate on the basis of a direct transfer of funds from the national level to the targeted villages. This system of transfers and disbursement in sub-district and village development plans led to the need for a robust resource allocation model that is able to handle the realisation of policy objectives while maintaining accountability. 
The issue of budget allocation is even more complex in view of the recent decentralisation of administration in Indonesia, which requires a more transparent planning process in a multi-stakeholder environment. In this process, each stakeholder must be able to evaluate how each infrastructure project in his/her region or under his/her responsibility is expected to contribute to the development of economic opportunities in the future.

\subsubsection{Study area and data}

The Special Province of Yogyakarta, Indonesia (Figure 4.1) is one of the targets of various Indonesian development programmes. Our area of study is home to approximately 3.4 million people. It consists of 438 villages, both urban and rural, with an average population of 5,632 inhabitants. The average size of a village is 724.43 ha with a minimum of 26.57 ha in urban areas and a maximum of $2,890.36$ ha in the more rural areas.

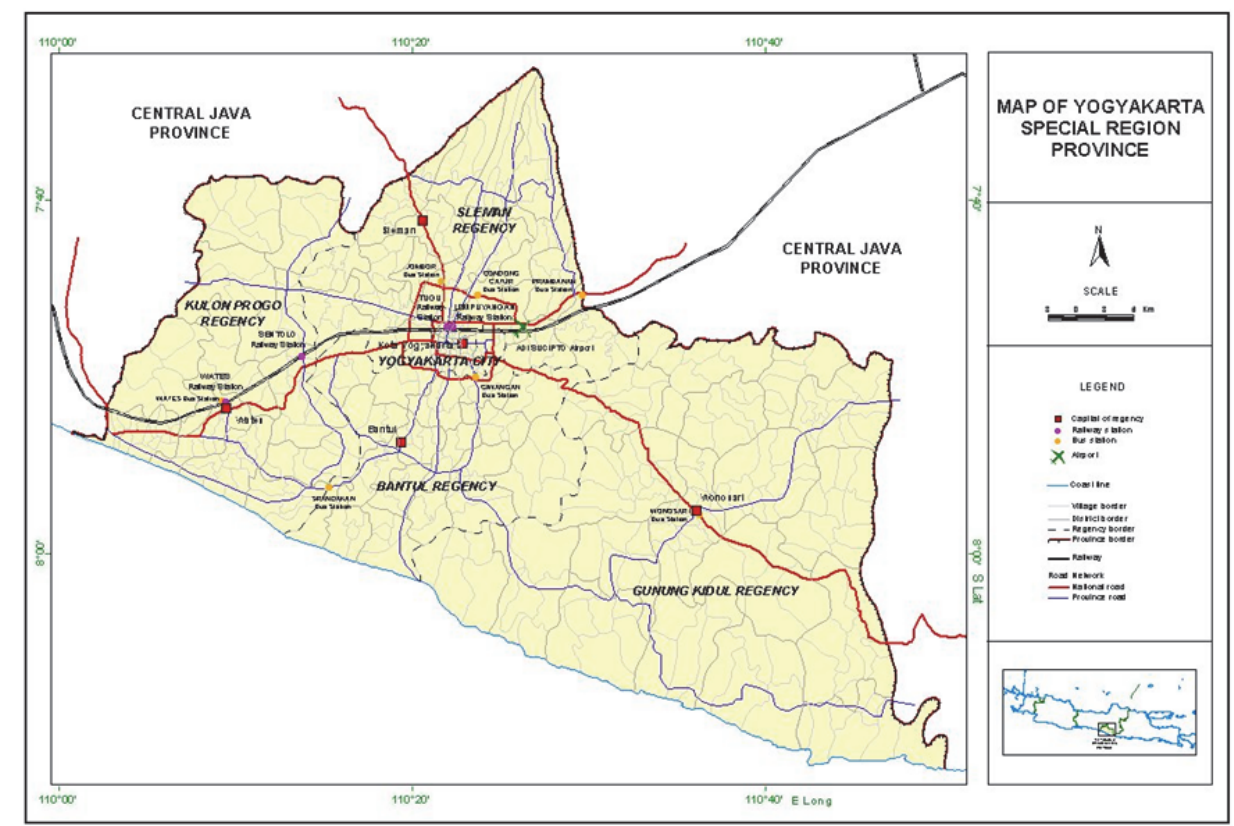

Figure 4.1 The study area is located in the Special Province of Yogyakarta, Indonesia, with 438 urban and rural villages; the study utilises village-level data on demographic, socio-economic and infrastructure-related issues.

For this study, we use a village-level dataset from 2005 called PODES (BPS 2006), which consists of approximately 400 attributes linked to demographics, socio-economic activities and infrastructure for 438 urban and rural villages in the province. We use only those attributes that are relevant to infrastructure performance and economic activity. 
The utilised demographic data concern population and household numbers in each village. The infrastructure data that were used entail transport, electricity, drinking water, and telecommunication and information. These data are the independent variables in the models, and their units of measurement are presented in Table 4.1 and Figure 4.2.

Table 4.1 Variables and the data sources

\begin{tabular}{|c|c|c|c|c|c|}
\hline $\begin{array}{l}\text { Types of } \\
\text { Variable }\end{array}$ & Variables & $\begin{array}{l}\text { Unit of } \\
\text { measurement } \\
\text { for the model }\end{array}$ & Datasources & $\begin{array}{l}\text { Unit of } \\
\text { measurement in } \\
\text { the data source }\end{array}$ & $\begin{array}{l}\text { Data } \\
\text { conversion }\end{array}$ \\
\hline \multirow[t]{7}{*}{ Independent } & Infrastructure: & & & & \\
\hline & Transport & $\begin{array}{l}\text { Average travel } \\
\text { speed }(\mathrm{km} / \mathrm{hr}) .\end{array}$ & $\begin{array}{l}\text { PODES code } \\
9022,9023\end{array}$ & $\begin{array}{l}\text { (distances KM, } \\
\text { travel time HR) }\end{array}$ & $\begin{array}{l}\text { Average travel } \\
\text { speed to } \\
\text { facilities } \\
(9022 / 9023)\end{array}$ \\
\hline & Electricity & $\begin{array}{l}\text { Average } \\
\text { electricity } \\
\text { supply per } \\
\text { household (VA) }\end{array}$ & $\begin{array}{l}\text { PODES code } \\
501\end{array}$ & (Electrified HHs) & $\begin{array}{l}\text { Weighted } \\
\text { average of } \\
\text { electricity } \\
\text { supply for poor } \\
\text { and non-poor. }\end{array}$ \\
\hline & Telecom & $\begin{array}{l}\text { Average data } \\
\text { transfer capacity } \\
(\mathrm{kbps})\end{array}$ & $\begin{array}{l}\text { PODES codes } \\
904,911\end{array}$ & $\begin{array}{l}\text { (Connected HH to } \\
\text { fix line, Mobile } \\
\text { network } \\
\text { coverage) }\end{array}$ & $\begin{array}{l}\text { Weighted } \\
\text { average of data } \\
\text { transfer } \\
\text { capacity of fixed } \\
\text { line and mobile } \\
\text { networks. }\end{array}$ \\
\hline & Water & $\begin{array}{l}\text { Average } \\
\text { discharge } \\
\text { (ltr/day) }\end{array}$ & $\begin{array}{l}\text { PODES code } \\
608\end{array}$ & $\begin{array}{l}\text { (type of source, } \\
\text { electrifiction) }\end{array}$ & $\begin{array}{l}\text { Water discharge } \\
\text { capacity based } \\
\text { on each type of } \\
\text { source. }\end{array}$ \\
\hline & \multicolumn{5}{|l|}{ Demographic: } \\
\hline & Population & $\begin{array}{l}\text { Number of } \\
\text { Population in } \\
\text { the village }\end{array}$ & $\begin{array}{l}\text { PODES code } \\
401 \mathrm{a}, \mathrm{b}\end{array}$ & $\begin{array}{l}\text { (male pop, female } \\
\text { pop) }\end{array}$ & $\begin{array}{l}\text { Total } \\
\text { population } \\
401 \mathrm{a}+401 \mathrm{~b}\end{array}$ \\
\hline Dependent & $\begin{array}{l}\text { Economic } \\
\text { Opportunity }\end{array}$ & $\begin{array}{l}\text { Average annual } \\
\text { income (Mio } \\
\text { IDR) }\end{array}$ & $\begin{array}{l}\text { PODES codes } \\
1101,1102, \\
1103 \text { to } 1132\end{array}$ & $\begin{array}{l}\text { (types and } \\
\text { number of } \\
\text { economic } \\
\text { activities in the } \\
\text { village) }\end{array}$ & $\begin{array}{l}\text { Number of unit } \\
* \text { the average } \\
\text { annual revenue } \\
\text { of each type of } \\
\text { activities }\end{array}$ \\
\hline
\end{tabular}




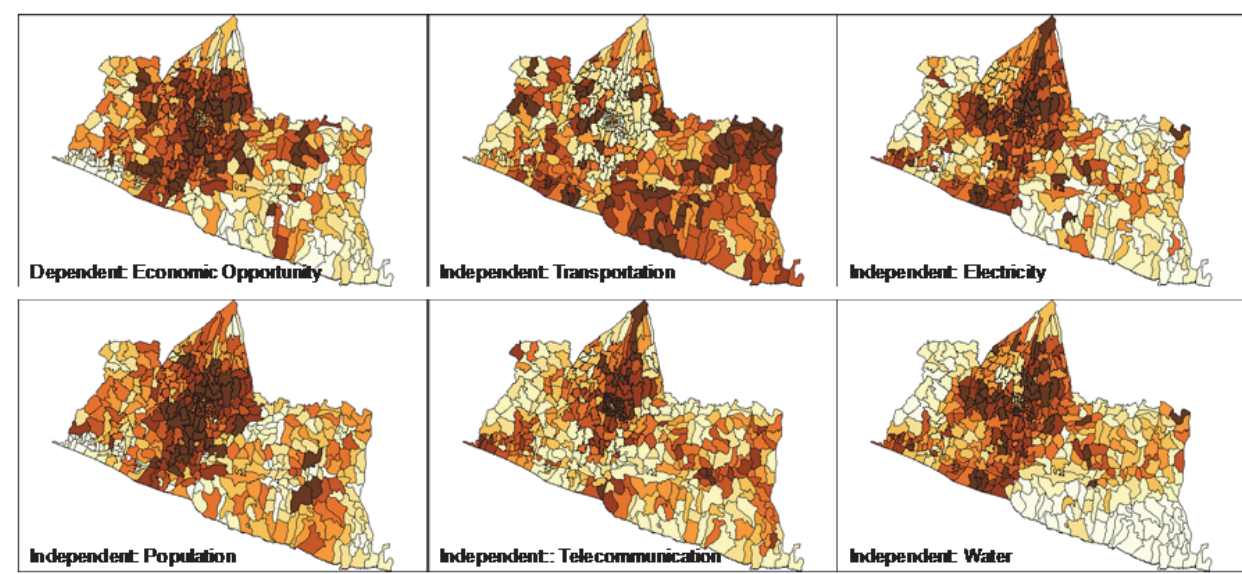

Figure 4.2 Spatial distribution of model's variables. The dark colours represent higher values or better infrastructure performance.

As the dependent variable, i.e., the proxy for economic opportunity, we use economic activity data that encompass 32 types of economic activity for each village. To obtain the monetary value of the economic activity (in millions of Indonesian Rupiahs (IDR)), we multiply the number of units for each type of activity by the corresponding estimated average annual income.

\subsubsection{Study design}

The study has three phases as depicted in Figure 4.3. First, the prediction models are specified. Second, appropriate data on infrastructure, demography and economy in the studied area are collected and used to populate the model and predict economic opportunity for the different villages in the region. Finally, we conduct regression diagnostics and an analysis of spatial dependence, and then we validate the model by comparing the predicted economic opportunity with independent secondary data on poverty levels and subjective well-being. The validation results provide the conclusions and recommendation for future research.

\subsubsection{Model specification}

The three models, with increasing levels of complexity, have been built through stepwise expansion. We use Ordinary Least Squares regression (OLS) because it can be used both as an explanatory as well as a prediction model. All three models have this common base and use the same data. 


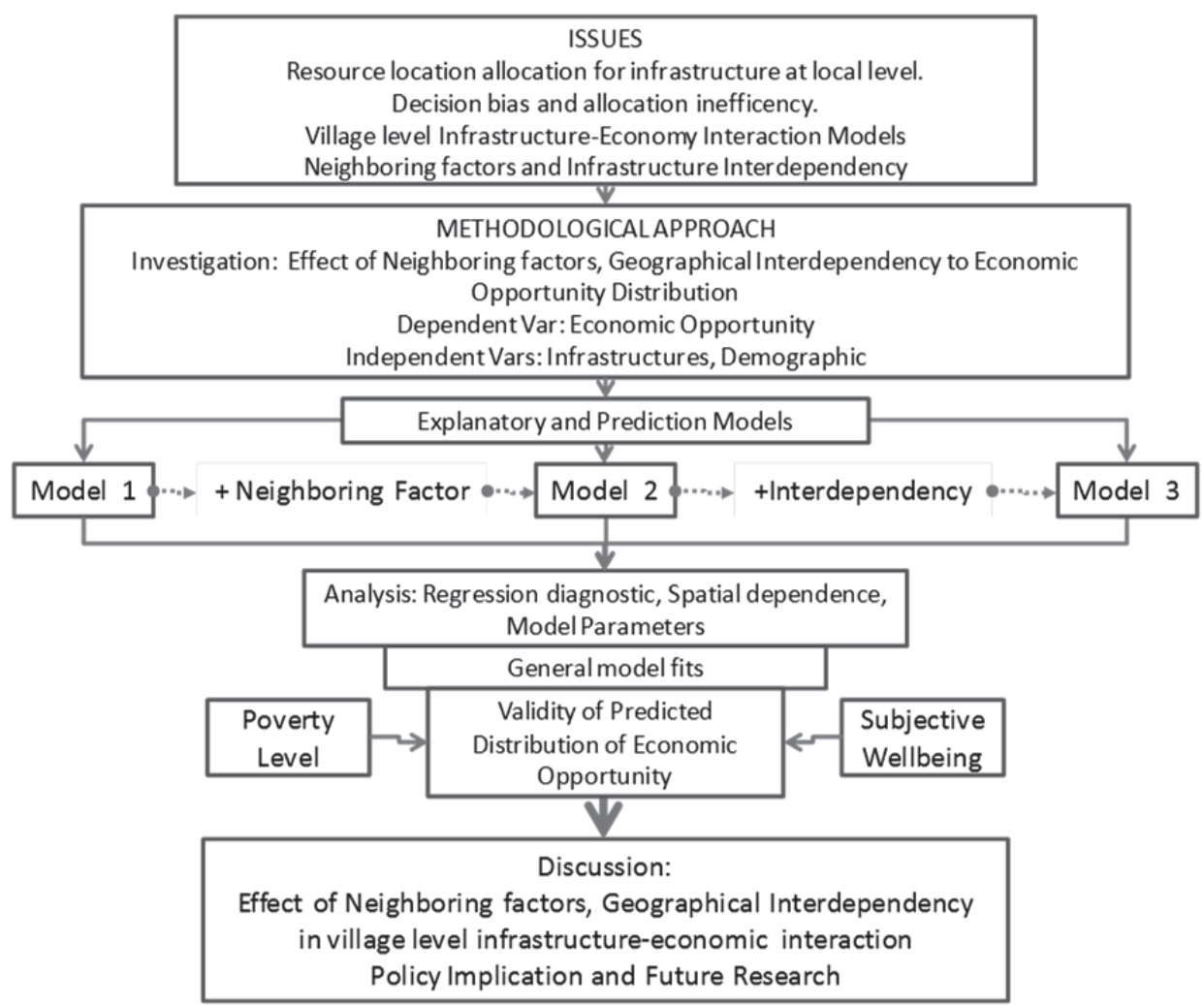

Figure 4.3 Study design

(1) Model 1: The Integrated Infrastructure model (II)

In this model, Ordinary Least Squares regression (OLS) is used to predict the effect of different types of infrastructure in the village on the level of economic opportunity. The basic mathematical model to perform the regression analysis is:

$$
y_{i}=\beta_{0}+\beta_{1} x_{1, i}+\beta_{2} x_{2, i}+\ldots+\beta_{k} x_{k, i}+e_{i}
$$

with $y_{1}$ is the predicted economic opportunity, $x_{1, i}$ infrastructure type 1 (e.g. transport expressed in terms of average travel speed) in location (village) $i$; $\beta_{k}$ explains the role of the type of infrastructure to the predicted economic opportunity; $\beta_{0}$ represents the intercept coefficient, and $e$ is the error term. Figure 4.4, Model 1, illustrates this model's implementation.

\section{(2) Model 2: Spatial Integrated Infrastructure model (SII)}

In Model 2, a mixed regressive, spatial autoregressive model, which incorporates both regression and spatial autocorrelation, is applied. By 
including spatial interdependency in the regression, the model can be classified as a spatial autoregressive model, which is also known as spatiallag OLS (Anselin 2002). Model 2 includes the independent variable of economic opportunity in the neighbouring villages, which is represented by the spatial-lag response-variable $y_{j}$. Coefficient $\rho$ represents this variable. The level of performance indicator for each type of infrastructure is indicated by $x_{k, i}$, i.e. transport, electricity, telecommunication, and water supply at the household level in each village $i$ :

$$
y_{i}=\beta_{0}+\beta_{1} x_{1, i}+\beta_{2} x_{2, i}+\ldots+\beta_{k} x_{k, i}+\rho \sum_{j \in N(i)} y_{j}+e_{i}
$$

The right hand side of Figure 4.4 below illustrates the implementation of Model 2.

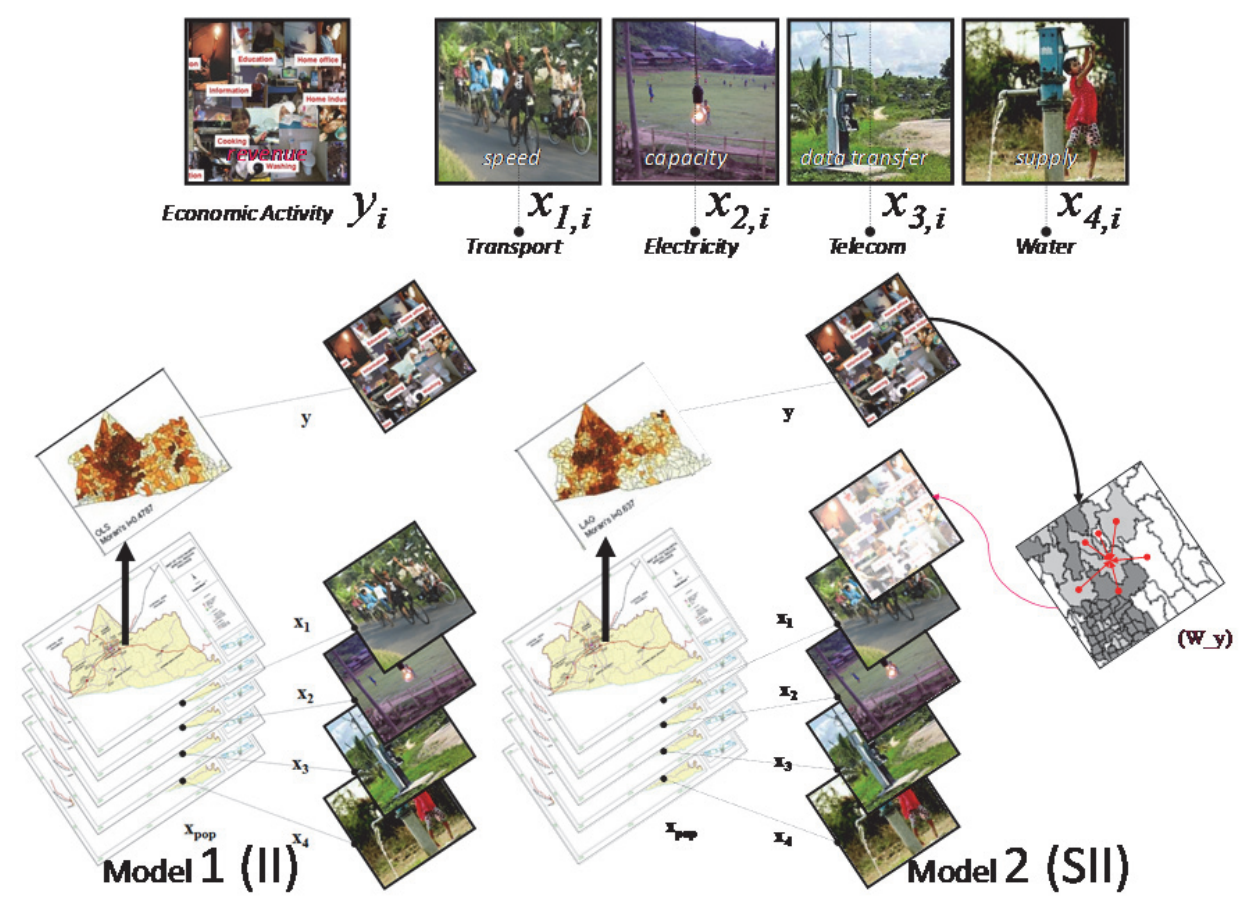

Figure 4.4 OLS for Integrated Infrastructure (Model 1) and Spatial-Lag OLS for Spatial Integrated Infrastructure (Model 2).

(3) Model 3: Spatial Integrated Infrastructure Interdependency model (SIII)

Among the many definitions of interdependency, two possible categories are Physical Interdependency and Geographical Interdependency. Physical Interdependency refers to linkages between input and outputs of two 
agents; for example, a commodity produced or modified by one infrastructure (output) is required by another infrastructure to operate (input), or as engineering reliance between components (e.g., information systems rely on electricity). Geographical Interdependency refers to a local environment event that is able to create changes in a location in close spatial proximity (Rinaldi, Peerenboom et al. 2001; Pederson, Dudenhoeffer et al. 2006). Because we are mainly concerned with local environment conditions that affect economic development, we limit ourselves in this model to Geographical Interdependency.

A fuzzy approach to quantify the impact of infrastructure on economic opportunity

To quantify the level of economic opportunity as a result of infrastructure development, we apply the Capability Approach (CA) of Amartya Sen (Sen 1980). Based on the CA and the relative capacity of the infrastructure to support economic activity, we classify the level-of-service of infrastructure as 'basic service', 'domestic activities' and 'income-generating activities'.

This type of classification reveals types of fuzzy classes that require fuzzy logic modelling. Fuzzy set theory allows us to predict a phenomenon based on fuzzy inputs. Such a predicting function is related to a procedure called Fuzzy Inference Systems (FIS). A FIS is a way of mapping an input to an output using fuzzy logic. There are three common types of FIS: Mamdani, Sugeno and Tsukamoto FIS. In this research, we use Sugeno FIS because of its advantage over other FISs in terms of subjectivity control such as Mamdani FIS (Guney and Sarikaya 2009), the time-consuming defuzzification, and the intransparent process of the Tsukamoto FIS (Siler and Buckley 2005). Sugeno FIS reduces the subjectivity by putting into operation a set of input-output equations in each rule to predict the interdependency between variables (Sivanandam, Sumathi et al. 2006).

The challenge to implementing Sugeno FIS is the development of mathematical input-output equations to predict and explain the relationship between phenomena. Fortunately, it is widely known that linear regression techniques, e.g., OLS, can be applied to obtain such a mathematical model. Therefore, we use a mixed regressive, spatial autoregressive OLS to define the formula for each rule determined in the Sugeno FIS. As such, this model becomes an extension of Models 1 and 2. 


\section{A fuzzy approach to classify the level of infrastructure performance}

In fuzzy logic modelling, a membership function (MF) is required to classify fuzzy objects. For Model 3 there are different levels of capability of the community in developing economic activities connected to the infrastructure service level. Three classes are distinguished: 'basic services', 'domestic activities' and 'income-generating activities'. Each of these requires an MF to be developed. We select a type of MF based on the minimum number of parameters needed to avoid unnecessary justification by decision-makers when they define the value for each parameter. Therefore, a Gaussian MF with only two parameters (Guney and Sarikaya 2009 ) is used to convert the crisp input values $(x)$ into fuzzy values, using:

$$
M_{i j}(x)=\operatorname{Gauss}\left(x ; c_{i j}, \sigma_{i j}\right)=e^{-\frac{1}{2}\left(\frac{x-c_{i j}}{\sigma_{i j}}\right)^{2}}
$$

where $c_{i j}$ and $\sigma_{i j}$ are the premise parameters that characterise the shapes of the input MFs, $c$ is the centre of MF, and $\sigma$ is the width of the MF for infrastructure type $i$ and class $j$.

To set the input variables to the MFs, we use the standard of minimum service level, which the Government of Indonesia (Ministry Decree for Settlement and Regional Infrastructure, 534/KPTS/M/2001) has determined to be $c_{i j}$ (Table 4.2). Figure 4.5 shows the shape of the MF for each input variable.

\begin{tabular}{llllll} 
Table 4.2 & Parameter $\left(\mathrm{c}_{\mathrm{ij}}\right)$ for Gaussian MFS & & \\
\hline Infrastructure & $\begin{array}{l}\text { Performance } \\
\text { Indicators }\end{array}$ & References & $\begin{array}{l}\text { Basic } \\
\text { Service }\end{array}$ & $\begin{array}{l}\text { Domestic } \\
\text { Activity }\end{array}$ & $\begin{array}{l}\text { Income } \\
\text { Generating } \\
\text { Activity }\end{array}$ \\
\hline Transport & $\begin{array}{l}\text { Average travel speed } \\
\text { (km/hr). }\end{array}$ & $534 /$ KPTS/M/2001 & 10 & 15 & 20 \\
\hline Water & Discharge (ltr/day) & $534 /$ KPTS/M/2001 & 30 & 125 & 220 \\
\hline Telecom & $\begin{array}{l}\text { Data transfer capacity } \\
\text { kbps) }\end{array}$ & USO Program BTIP & 14.4 & 28.8 & 56 \\
\hline Electricity & $\begin{array}{l}\text { Electricity supply per } \\
\text { household (VA) }\end{array}$ & TDL PLN & 30 & 450 & 2200 \\
\hline
\end{tabular}

Figure 4.5 presents Gaussian MFs for each type of infrastructure. The horizontal axis represents the range of possible levels of performance as determined by the context of analysis. In this case, the context is the average level of capacity of infrastructure supply for households in each village. 

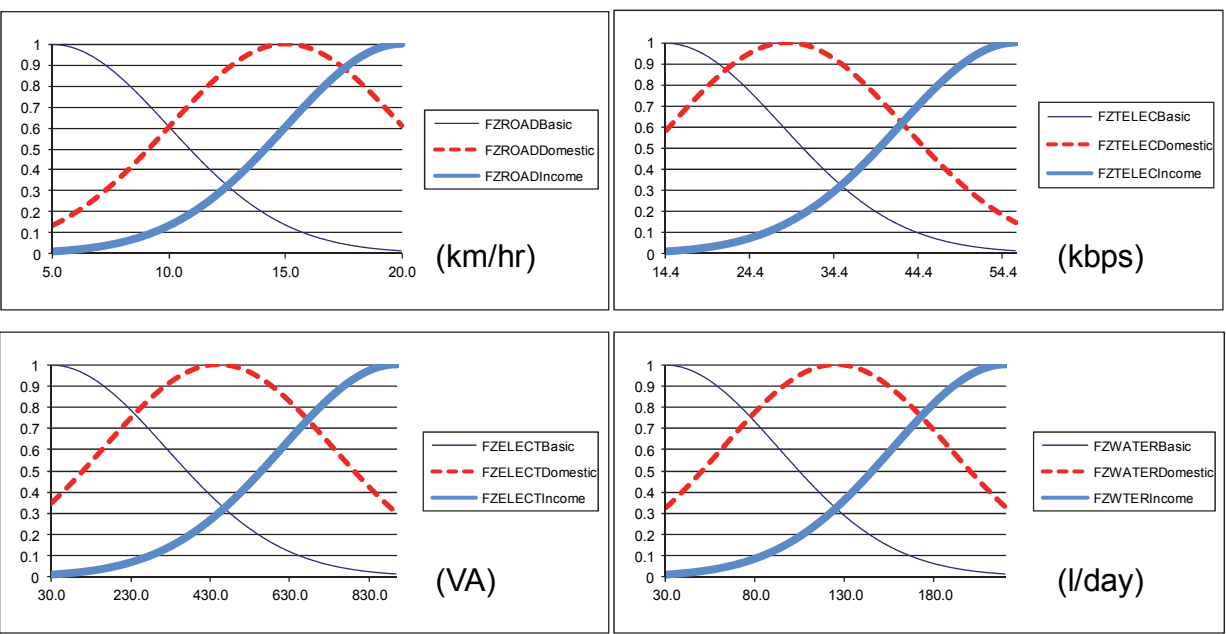

Figure 4.5 The shapes of the MFs for the input variables. Each curve estimates the degree of membership for each infrastructure performance to be classified in a certain class. The peak of each curve indicates degree of membership: 1 or $100 \%$.

Each curve estimates our level of confidence that each level of infrastructure performance can be placed in a certain class. The peak of each curve represents a degree of membership of $100 \%$. For example, in the case of an average travel speed (FZROAD in Figure 4.5) of $5 \mathrm{~km} / \mathrm{hr}$ in a village, the transport infrastructure in this village can be classified as "basic service" with a $100 \%$ degree of membership, while it is only $13 \%$ for classifying it as supporting "domestic activities", and $0 \%$ for classifying it as "income generating". The MFs and the weights attached to each rule are normalised in layer 3, as indicated in Figure 4.6 below.

\section{Sugeno FIS for Infrastructure Interdependency Model}

In Model 3, we extend and apply the architecture for Sugeno FIS (Guney and Sarikaya 2009), which consists of five layers: fuzzy layer, product layer, implication layer, aggregation layer, and the fourth defuzzification layer, wherein the rule-based OLS is implemented (Figure 4.6). 


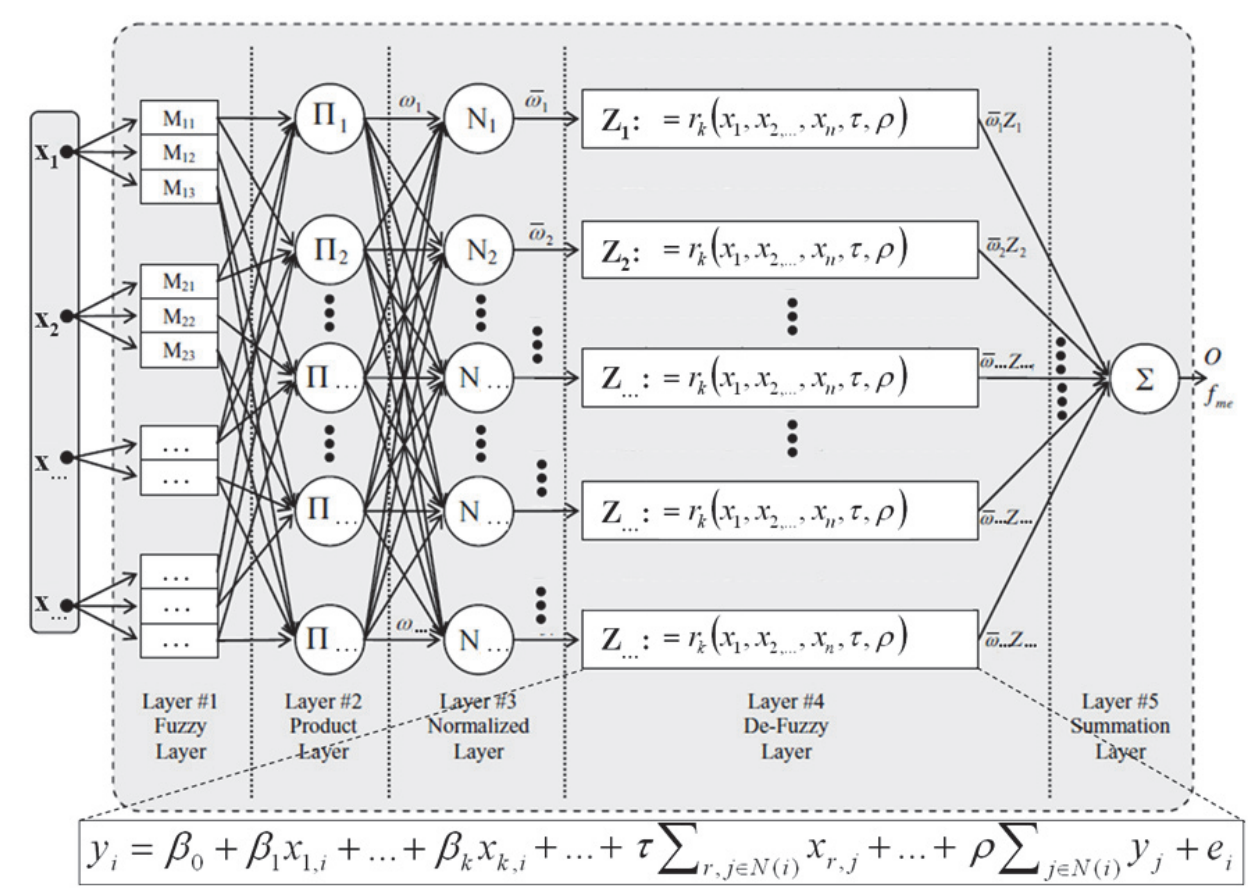

Figure 4.6 The architecture for the Sugeno FIS model for SIII (Model 3). Rule-based OLS is implemented in Layer\#4, Defuzzification Layer.

In Layer 1, the original crisp input values are converted into the fuzzy values through the MFs. We use Gaussian MFs with only two parameters to reduce complexity.

In Layer 2, the weighting factor (firing strength) of each rule can be computed to determine the membership expressions of each rule. The weighting factor represents the degree of fitness of a certain village to a certain rule. This computation is accomplished by first converting the input values into the fuzzy membership values by using the input MFs in layer 1 and then applying the AND operator to these membership values. The AND operator corresponds to the multiplication of input membership values. The weighting factor of each rule is expressed as $\omega_{k}$. This weighting factor indicates the likelihood that the combination of infrastructures in a village fits with each rule in the FIS.

Next, in Layer 3, the normalised weighting factor of each rule, $\varpi_{k}$ is computed by using:

$\varpi_{k}=\frac{\omega_{k}}{\sum_{i=1}^{n} \omega_{i}}$ 
The normalised weighting factor aims to obtain the weight of each rule with a total sum of weights of 1 (or 100\%) (Figure 4.7). A village with a normalised weighting factor of a certain rule close to 0 means that the combination of infrastructure performances in this village is far from the expected combination of the measured rule. For example, a village with low or basic service performances of (transport basic, electricity basic, telecombasic and water $_{\text {basic }}$ ) will be weighted as 0 in the rule of all infrastructures with high performance (transport income, $_{\text {electricity }}$ income, $_{\text {telecom }}$ income and water income).

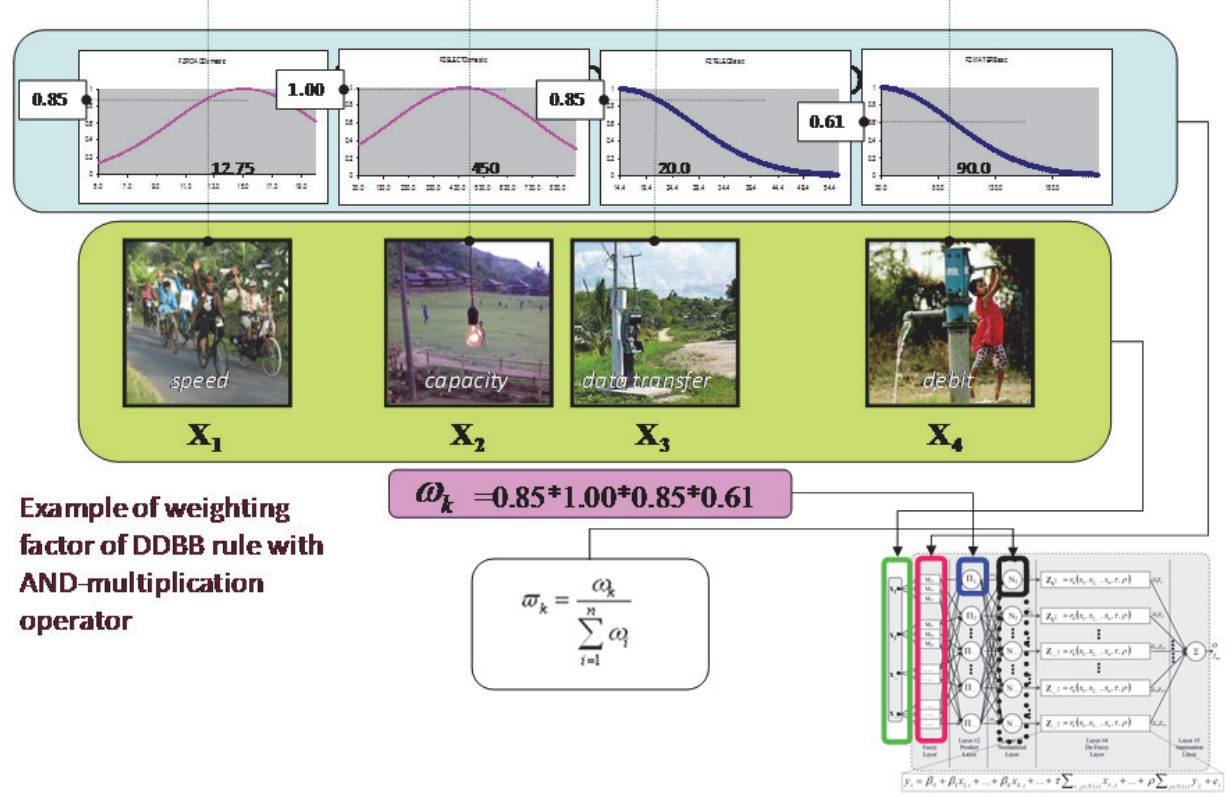

Figure 4.7 Example of FIS calculation for Layers 1, 2 and 3. The example of weighting factor and normalised weighting factor calculation.

In Layer 4, the output rules can be written as:

$\varpi_{k} Z_{k}=\varpi_{k} r_{k}\left(x_{1}, x_{2, \ldots}, x_{n}, \tau, \rho\right)$

where within each rule $r_{k}$ consists of $x_{1 . n}$ as the explanatory variables of each type of infrastructure, $\tau$ is the spatial lag of the $y$ variable, $\rho$ is the spatial lag of the $x$ variable. For each $r_{k}$ we implement OLS to generate an input-output algorithm from the selected dataset that is relevant to the combination of the level of infrastructure performance in the rule. For example, the OLS for the rule of combined infrastructures with all-high performance (transport income, $_{\text {electricity }}$ income, telecom $_{\text {income }}$ and water $_{\text {income }}$ ) the dataset for the OLS is selected for the group of villages that also have 
same characteristics (transport $t_{\text {income, }}$ electricity income, $_{\text {telecom }}$ income and water income). $_{\text {. }}$.

Finally, in Layer 5, each rule is weighted by its own normalised weighting factor and the output of the FIS is calculated by summing all of the rule outputs:

$$
O=\sum_{k=1}^{n} \varpi_{k} Z_{k}=\frac{\sum_{k=1}^{n} \omega_{k} Z_{k}}{\sum_{k=1}^{n} \omega_{k}}
$$

This summation layer thus produces crisp values of predicted economic opportunity in each village.

\section{Rule-based regression modelling for input-output algorithm for Sugeno FIS}

To obtain the best-fit OLS model that is in agreement with Sugeno FIS, we identify all possible rules derived from the combination of inputs and their associated MFs. For each rule, Sugeno FIS requires a set of equations to generate an estimated output. We use 4 types of infrastructure as the input for the equation, which are further classified into 3 levels of service; the possible number of rules, therefore, is $3^{4}=81$.

To generate the equation for each rule of the OLS, we require a sufficient number of records in the dataset so that each rule is represented. To obtain these data, we select the rules that cover at least 3 percent of the total number of records (i.e. total number of villages) in the study area. The resulting combination of rules for generating the equations with OLS is only five sets (Table 4.3). The column of "Number of Records" shows the number of selected villages for each rule. For example, in the area under study, the number of selected villages that have a combination of (transport $_{\text {domestic, }}$ electricity domestic, $_{\text {, }}$ telecom $_{\text {basic }}$ and water basic) $_{\text {(DDBB) is }} 43$ villages out of 438 villages.

Table 4.3 Number of rules and number of records

\begin{tabular}{lllll}
\hline Transport & Electricity & Telecommunication & Water & Number of Records \\
\hline D & D & B & B & 43 \\
\hline D & D & B & I & 153 \\
\hline D & D & D & I & 15 \\
\hline D & I & B & B & 149 \\
\hline I & D & B & I & 17 \\
\hline \multicolumn{5}{c}{ Notes: Level of service available in the village } \\
& (B: Basic Service, D: Domestic, I: Income Generating)
\end{tabular}

Subsequently, we perform several steps to obtain the best possible equation for each rule. First, we perform OLS with all possible models. We prepare all the variables $x$ and $y$, with and without spatial lag. The resulting 
combinations are (1) OLS with all of $x$ but without spatial lag, (2) OLS with $y$ spatial lag, (3) OLS with all of $x$ and spatial lag of $x$ and (4) OLS with all of $x$ and spatial lag of $x$ and $y$. Figure 4.8 portrays Model 3's implementation.

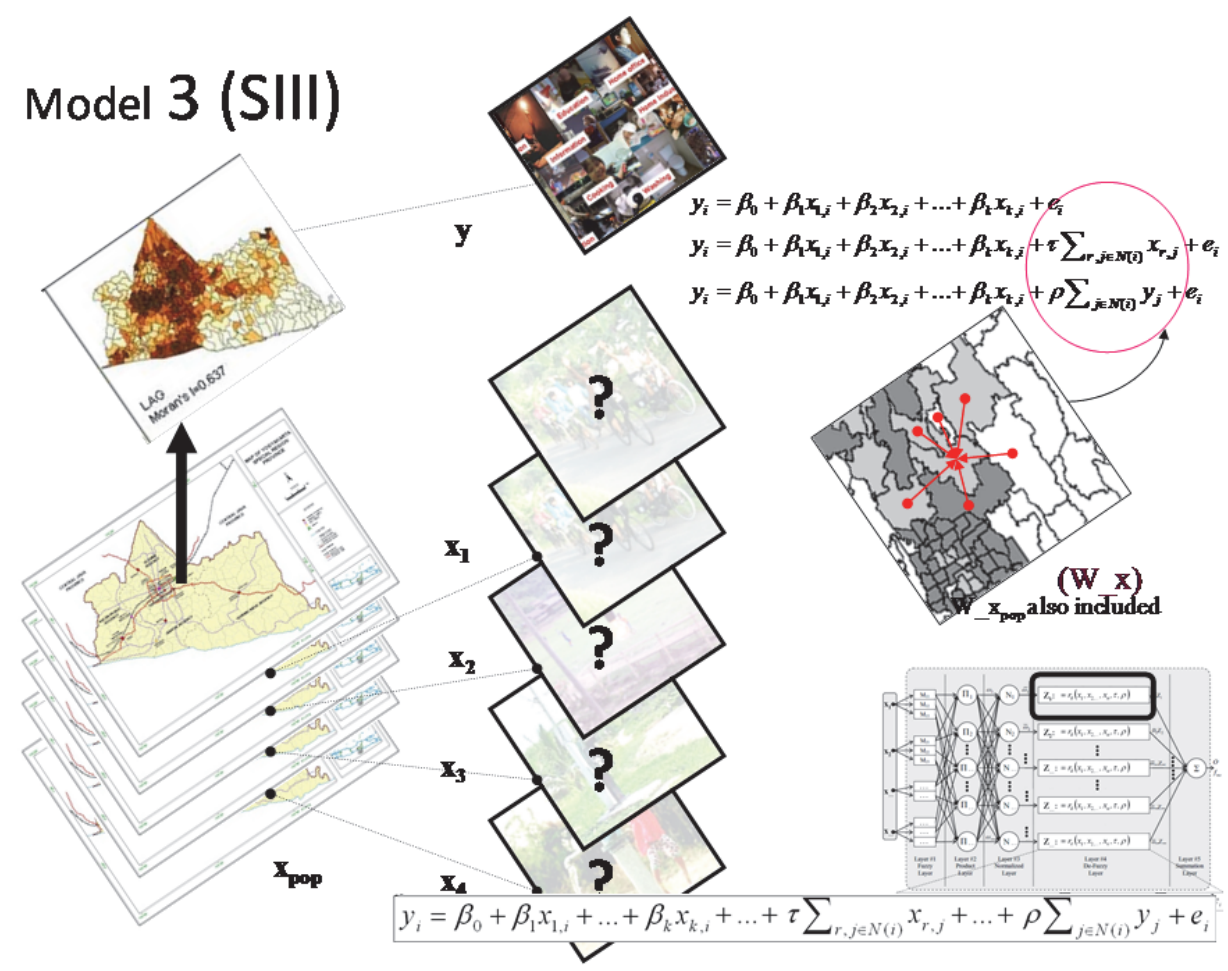

Figure 4.8 OLS within Sugeno-FIS procedure in Spatial Integrated Infrastructure Interdependency model (Model 3). It employs OLS and Spatial-Lag OLS for each rule required by FIS.

Second, we evaluate the reliability of the variables in each rule. For each rule, we perform regression analysis and evaluate the significant level ( $p$ value) of each variable. Third, we omit the unreliable variable for the next OLS computation. For each type of infrastructure that has a significance value $p$ higher than 0.05 , we exclude this infrastructure in the next OLS. In the final step, we repeat steps 1, 2, and 3 for the selected variables. In this step, we expect to obtain the best-fit model for each rule in this step. Otherwise, we repeat all the steps until the best-fit model with the selected variable and $p<0.05$ for all variables is obtained.

To perform Model 3, we use GeoDA to generate the weights matrix and the values of spatial lag of $y$ and $x$. Further calculations and FIS procedure are performed in MS Excel. 


\subsubsection{Analysis}

\section{(1) Regression diagnostics and analysis of spatial dependence}

The OLS estimation is referred to as a Best Linear Unbiased Estimator (BLUE), which is based on several assumptions. Several of these assumptions are related to our purpose: a) the random error has mean zero, and b) the random error terms are uncorrelated, have a constant variance (homoskedastic) and follow a normal distribution. In the case of assumption violation, the estimate is biased and inefficient. The investigation of assumption violation is useful to understand the possible nature of dependence.

Regression diagnostic and spatial dependence analysis aim to determine the existence and the nature of spatial dependence. They can be performed by investigating the source and the type of OLS assumptions violations. The diagnosis for spatial dependence is also performed to test whether the inclusion of spatial variables is able to reduce the OLS assumption violations.

One of the possible sources of assumption violation involves the spatial dependence effect. Two primary types of spatial dependence are: a) Spatial error, i.e. the error terms across different spatial units are correlated, and b) Spatial lag, i.e. the dependent variable $y$ in place $i$ is affected by the independent variables in both place $i$ and $j$.

To detect the above possible assumption violation, we perform a range of diagnostics in the OLS regression: a) multicollinearity to examine any dependencies among variables (in this study this refers to dependency among infrastructures) and the normality of the distribution of the errors, b) heteroskedasticity to test the variance of the error terms as the OLS technique requires constant error variance, and c) diagnostics for spatial dependence. The last two diagnostics aim to find out the effect of the inclusion of neighbouring factor in the model.

Following (Rusinova 2007), we perform six tests to assess the spatial dependence in the model. First, we conduct Moran's I (with a value from -1 to 1) to determine any spatial autocorrelation of the residual. The result indicates whether the inclusion of neighbouring factors represents the actual spatial interaction process. A value toward 1 (positive) indicates a synergic interaction process among neighbouring units, while a negative value indicates competition among neighbouring units. 
Five other statistical tests for spatial dependence aim to determine whether the error dependence exists and whether the inclusion of spatial lag information reduces the error dependence. In addition to the simple test, this process requires that we perform a robust test to help us understand what type of spatial dependence may be at work.

Those tests are: (1) the simple Lagrange Multiplier (LM) test for a missing spatially lagged dependent variable (LM(lag)), (2) the simple LM test for error dependence (LM(error)), and variants of the robust to the presence of the other, (3) Robust LM(lag) and (4) Robust LM(error), which tests for error dependence in the possible presence of a missing lagged dependent variable. Robust RM(lag) is the opposite, while (5) is a portmanteau test (SARMA, which is LM(error) + Robust LM(lag)).

The above diagnostics are applied to Models 1 and 2 using GeoDA software.

\section{(2) Analysis of model parameters and general model fit}

To find the best-fit model among the three models, we compare the model $\mathrm{R}^{2}$ performance parameters. Specifically for Model 1 and 2, we compare Log Likelihood performance parameters using GeoDA. For Model 3, because the model building combines OLS and FIS and the available software cannot perform the Log likelihood under this procedure, we only compare the $\mathrm{R}^{2}$ parameters obtained from a comparison of predicted distribution with known spatial reference data. To produce predicted distribution with Model 2, we apply Spatial Lag instead of Spatial Error. Model 2 with Spatial Error is only used for diagnostic purposes.

Moreover, as we are concerned with spatial distribution of the predicted economic opportunity to find the best-fit model, we compare the result of each model with known spatial reference data. Two sets of reference data that serve as proxies for economic opportunity in the village are: the Prosperity Level (PL) and the Subjective Well-Being (SW). The first is derived from the same PODES dataset. The SW data are derived from the Indonesia Family Life Survey (IFLS), 2007, with the variable of subjective well-being on the level of prosperity, from very poor (scored as 0 ) to very rich (scored as 6). For the analysis, we standardised this range onto a 0 to 1 scale.

We use the contingency matrix (Couto 2003) for measuring the relative validity of the three models as compared to the reference data. Furthermore, the results of the contingency matrix are used to perform the reliability analysis using the Kappa statistic (Couto 2003). This test is performed to determine the consistency of the model. 
The confusion matrix requires a discrete classification. Therefore, we organise the prediction results and the reference data into three classes: Low, Medium and High Economic Opportunity.

The following classes are selected:

1. Low Economic Opportunity (Basic Service) ranging from 0 to 0.125 Mio IDR (20/80 of Regional Minimum Wage in 2007)

2. Medium Economic Opportunity (Domestic Activity) ranging from 0.125 to 0.333 Mio IDR (2/3 of Regional Minimum Wage in 2007: 0.5 Mio IDR).

3. High Economic Opportunity (Income Generating) ranging from 0.333 Mio IDR to maximum value of opportunity (rounded up in Mio IDR)

To have comparable classes, the reference data are also organised into three classes. The basis for classification is the Mean and Standard Deviation (SD) of the dataset.

1. Low Economic Opportunity (Basic Service): from 0 to mean

2. Medium Economic Opportunity (Domestic Activity): from mean to mean +1 SD.

3. High Economic Opportunity (Income Generating): above mean + 1SD

For the Prosperity Level, based on the data of derived poverty incident, we use a mean of 0.54 and SD of 0.2 :

1. Low Economic Opportunity (Basic Service) from 0 to 0.54

2. Medium Economic Opportunity (Domestic Activity) from 0.54 to 0.74

3. High Economic Opportunity (Income Generating) above 0.74

For the Subjective Well-being, we use a mean of 0.35 and SD of 0.13 :

1. Low Economic Opportunity (Basic Service): from 0 to 0.35

2. Medium Economic Opportunity (Domestic Activity): from 0.35 to 0.48

3. High Economic Opportunity (Income Generating): above 0.48 


\subsection{Results}

\subsubsection{Regression diagnostics and analysis of spatial dependence}

(1) Regression diagnostics

The regression diagnostics performs an analysis of multicollinearity and heteroskedasticity. Multicollinearity examines any possible correlation among variables. In this research, these variables are infrastructures. The Multicollinearity Condition Number of Model 1 is 20.5, which is below 30 . This indicates that there is no correlation among infrastructures. The Jarque-Bera test to examine the normality of the distribution of errors indicates a non-normal distribution of the error term with a value of $131,227.5$ and a probability of $1.0 \mathrm{E}-08$. This OLS violation indicates that it is necessary to understand the analysis of other diagnoses to determine whether a possible dependency in the error model exists.

Diagnostics for Heteroskedasticity is applied to Model 1 and Model 2 (both with Spatial Lag and Spatial Error diagnostics). Among the three tests in GeoDA, only the Breusch-Pagan test shows a low probability, which indicates the possible existence of heteroskedasticity. A more robust test (White) indicates that there is no heteroskedasticity (Table 4.4).

Table 4.4 Diagnostics for Heteroskedasticity

\begin{tabular}{|c|c|c|c|c|c|c|}
\hline & \multicolumn{2}{|c|}{ Model 1} & \multicolumn{4}{|c|}{ Model2 } \\
\hline \multirow[t]{2}{*}{ TEST } & & & \multicolumn{2}{|c|}{ Spatial Lag } & \multicolumn{2}{|c|}{ Spatial Error } \\
\hline & VALUE & PROB & VALUE & PROB & VALUE & PROB \\
\hline RANDOM COEFFICIENTS & & & & & & \\
\hline Breusch-Pagan & 41.07 & $\begin{array}{l}1.0 \mathrm{E}-07 \\
* * * *\end{array}$ & 19.68 & $\begin{array}{l}1.4 \mathrm{E}-03 \\
* * * *\end{array}$ & 19.86 & $\begin{array}{l}1.3 \mathrm{E}-03 \\
* * * *\end{array}$ \\
\hline Koenker-Bassett & 0.963 & $9.7 \mathrm{E}-01$ & NA & NA & NA & NA \\
\hline SPECIFICATION ROBUST & & & & & & \\
\hline White & 9.146 & $9.9 \mathrm{E}-01$ & NA & NA & NA & NA \\
\hline
\end{tabular}

\section{(2) Analysis of spatial dependence}

The first test with Moran's I scores 0.167 and is highly significant, indicating a strong spatial autocorrelation of the residual. Moreover, the analysis of spatial dependence with Moran's I and the simple and robust LM tests are significant, indicating the presence of spatial dependency. Both robust LM tests, measuring for error and lag, are insignificant, which means spatial dependency influences error dependence. However, the inclusion of the lagged variable does not remove error dependence (Table 4.5). 
Table 4.5 Analysis of spatial dependence

\begin{tabular}{llll}
\hline TEST & MI/DF & VALUE & PROB \\
\hline Moran's I (error) & 0.166761 & 6.1381014 & $0.0000000^{* * * *}$ \\
\hline Lagrange Multiplier (lag) & 1 & 32.8541094 & $0.0000000^{* * * *}$ \\
\hline Robust LM (lag) & 1 & 0.6326630 & 0.4263802 \\
\hline Lagrange Multiplier (error) & 1 & 33.5906618 & $0.0000000^{* * * *}$ \\
\hline Robust LM (error) & 1 & 1.3692154 & 0.2419467 \\
\hline Lagrange Multiplier (SARMA) & 2 & 34.2233248 & $0.0000000^{* * * *}$ \\
\hline
\end{tabular}

In addition, more specific diagnostics for both Spatial Lag and Spatial Error dependency using the Likelihood Ratio Test show a significant spatial dependence with $p=3.0 \mathrm{E}-07$ and $p=1.0 \mathrm{E}-07$ with values of 26.20711 and 27.82741 , respectively.

The Likelihood Ratio Tests indicate that the introduction of spatial lag and the error terms, which are to be spatially correlated, improves the model fit (see improved $\mathrm{R}^{2}$ and LL in (Table 4.6); however, it did not make the spatial effect disappear.

\subsubsection{Model parameters and general model fit}

\section{(1) Model parameters in Model 1 and 2}

Model 1 represents an OLS regression. The output of the model provides model parameters as presented in Table 4.6. Among the five indicators, only the demographic variable (population) is positively correlated with economic opportunity. However, the infrastructure variables (road, electricity, telecommunication and water) have insignificant effects.

In Model 2, we re-estimate the model using a maximum likelihood approach while controlling for the spatial dependence. In this model, we assign a spatial weight matrix and a spatial lag term of economic opportunity (W_ECON) as additional indicators.

Table 4.6 shows that the spatial lag indicator of W_ECON is insignificant; however, its inclusion makes all other indicators highly significant. Road, water and population are positively correlated with economic opportunity, while electricity and telecommunication are negatively correlated with economic opportunity.

To study the spatial error of Model 2, a coefficient on the spatially correlated errors $(\lambda)$ is introduced as an additional indicator. In the model, $\lambda$ is insignificant. The general model fit and the effect of other independent variables remain virtually the same. 
Chapter 4

Table 4.6 Model parameters in Model 1 and Model 2

\begin{tabular}{|c|c|c|c|c|c|c|c|c|c|c|}
\hline MODELS & Diagnostic & Parameters & $\beta_{0}$ & $\beta_{1}$ & $\beta_{2}$ & $\beta_{3}$ & $\beta_{4}$ & $\beta_{5}$ & $\rho$ & $\lambda$ \\
\hline \multirow{4}{*}{$\begin{array}{l}\text { 1. Integrated } \\
\text { Infrastructure } \\
\text { (II) }\end{array}$} & Classical & $\mathrm{R}^{2}=0.15$ & & & & & & & & \\
\hline & OLS & $\mathrm{Ll}=-10656$ & & & & & & & & \\
\hline & & Vars: & $6.2 \mathrm{E}+08$ & $1.8 \mathrm{E}+07$ & $-1.4 \mathrm{E}+06$ & $-3.6 \mathrm{E}+07$ & $1.7 \mathrm{E}+07$ & $7.0 \mathrm{E}+05$ & & \\
\hline & & P-val: & 8.3E-01 & $6.3 \mathrm{E}-01$ & 7.5E-01 & $9.9 \mathrm{E}-02$ & $1.8 \mathrm{E}-01$ & $\begin{array}{l}0.0 \mathrm{E}-07 \\
* * * *\end{array}$ & & \\
\hline \multirow{6}{*}{$\begin{array}{l}\text { 2. Spatial } \\
\text { Integrated } \\
\text { Infrastructure } \\
\text { model (SII) }\end{array}$} & Spatial Lag & $\begin{array}{l}\mathrm{R}^{2}=0.21 \\
\mathrm{Ll}=-10643\end{array}$ & & & & & & & & \\
\hline & & Vars: & $4.8 \mathrm{E}+08$ & $3.5 \mathrm{E}+07$ & $-2.3 \mathrm{E}+06$ & $-2.8 \mathrm{E}+07$ & $1.1 \mathrm{E}+07$ & $6.1 \mathrm{E}+05$ & $\begin{array}{l}3.3 \mathrm{E}- \\
01 \\
99 \mathrm{~F}\end{array}$ & \\
\hline & & P-val & $\begin{array}{l}0.0 \mathrm{E}-07 \\
* * * *\end{array}$ & $\begin{array}{l}0.0 \mathrm{E}-07 \\
* * * *\end{array}$ & $\begin{array}{l}0.0 \mathrm{E}-07 \\
* * * *\end{array}$ & $\begin{array}{l}0.0 \mathrm{E}-07 \\
* * * *\end{array}$ & $\begin{array}{l}0.0 \mathrm{E}-07 \\
* * * *\end{array}$ & $\begin{array}{l}0.0 \mathrm{E}-07 \\
* * * *\end{array}$ & $\begin{array}{l}9.9 \mathrm{E}- \\
01\end{array}$ & \\
\hline & Spatial Error & $\begin{array}{l}\mathrm{R}^{2}=0.22 \\
\mathrm{Ll}=-10642\end{array}$ & & & & & & & & \\
\hline & & Vars: & $-9.5 \mathrm{E}+07$ & $4.7 \mathrm{E}+07$ & $-1.2 \mathrm{E}+06$ & $-1.1 \mathrm{E}+07$ & $9.0 \mathrm{E}+06$ & $7.1 \mathrm{E}+05$ & & $3.6 \mathrm{E}-01$ \\
\hline & & P-val & $\begin{array}{l}0.0 \mathrm{E}-07 \\
* * * *\end{array}$ & $\begin{array}{l}0.0 \mathrm{E}-07 \\
* * * *\end{array}$ & $\begin{array}{l}0.0 \mathrm{E}-07 \\
* * * *\end{array}$ & $\begin{array}{l}0.0 \mathrm{E}-07 \\
* * * *\end{array}$ & $\begin{array}{l}0.0 \mathrm{E}-07 \\
* * * *\end{array}$ & $\begin{array}{l}0.0 \mathrm{E}-07 \\
* * * *\end{array}$ & & $9.9 \mathrm{E}-01$ \\
\hline
\end{tabular}

Notes: $\mathrm{R}^{2}=\mathrm{R}$-Squared, $\mathrm{Ll}=\mathrm{Log}$ likelihood, $\beta_{0}=$ Intercept Coefficient, $\beta_{1}=$ Transport, $\beta_{2}=$ Electricity, $\beta_{3}=$ Telecommunication, $\beta_{4}=$ Water, $\beta_{5}=$ Population, $\rho=W_{-}$Economic Opportunity, $\lambda=$ Coefficient of the spatially correlated errors. Blank cells: Not applicable

(2) Model parameters in the rule-based OLS for Sugeno FIS in Model 3

For Model 3, we found that only some rules contained reliable variables from the area under study. Only the DDBB and DIBB rules contained variables with a $p<0.05$. The other rules (DDBI, DDII and IDBI) had no variables with a $p<0.05$ in the first iteration. We can therefore exclude those rules in the next iteration. Table 4.7 indicates the level of reliability of each variable in a different set of rules.

In Table 4.7 the "rules" column lists the examined rules. "Steps" refers to the number of the step-wise process used to obtain the reliable variable. "Models" lists the OLS models with and without spatial lag and its goodness-of-fit represented by $\mathrm{R}^{2}$. "Var" consists of $p$ values that indicate the reliability of the variables; the bold text shows the model with the variable at $p<0.05$. The $\beta_{n}$ shows the correlation coefficient of the explanatory variables (e.g. infrastructure). A positive value indicates a positive correlation with economic opportunity. The $\tau_{n}$ shows the correlation coefficient of the spatial lag of $x$; it indicates the extent to which the explanatory variables in the neighbouring village affect the economic opportunity. The $\rho$ represents the correlation coefficient of the spatial lag of $y$. It expresses how the extent to which the economic opportunities in the neighbouring villages affect the economic opportunity within a village.

From the value of $\beta$ in Table 4.7, we found that two reliable variables have negative values. Those variables are road infrastructure $\left(\beta_{1}\right)$ in DDBB (- 
$5.5 \mathrm{E}+07)$ and the spatial lag of telecommunication $\left(\tau_{3}\right)$ in DIBB $(-1.5 \mathrm{E}+08)$. An explanation of this result is provided in the discussion section.

Table 4.7 Reliability of variables in the Rule-Based OLS within FIS for Model 3

\begin{tabular}{|c|c|c|c|c|c|c|c|c|c|c|c|c|c|c|}
\hline Rules & Steps & Models & Var & $\beta_{0}$ & $\beta_{1}$ & $\beta_{2}$ & $\beta_{3}$ & $\beta_{4}$ & $\beta_{5}$ & $\tau_{1}$ & $\tau_{2}$ & $\tau_{3}$ & $\tau_{4}$ & $\rho$ \\
\hline \multirow[t]{12}{*}{ DDBB } & 1st OLS & $x$ Nolag & & $2.5 \mathrm{E}+09$ & $-5.7 E+07$ & $-2.5 \mathrm{E}+06$ & $2.9 \mathrm{E}+08$ & $1.4 \mathrm{E}+07$ & $4.3 \mathrm{E}+05$ & & & & & \\
\hline & & $R^{2}=0.61$ & $P$-val & $4.2 \mathrm{E}-01$ & $1.5 \mathrm{E}-02^{*}$ & $5.4 \mathrm{E}-01$ & $1.4 \mathrm{E}-05 \cdots$ & $2.9 \mathrm{E}-01$ & $4.7 \mathrm{E}-05^{\cdots \cdots}$ & & & & & \\
\hline & & $y$ Lag & & $3.1 \mathrm{E}+09$ & $-4.9 \mathrm{E}+07$ & $-3.8 \mathrm{E}+06$ & $3.0 \mathrm{E}+08$ & $1.0 \mathrm{E}+07$ & $4.0 \mathrm{E}+05$ & & & & & 9.3E-02 \\
\hline & & $R^{2}=0.76$ & $P$-val & $3.0 \mathrm{E}-01$ & 3.4E-02. & 3.4E-01 & 6.1E-06… & $4.5 \mathrm{E}-01$ & $1.1 \mathrm{E}-04^{\cdots \cdots}$ & & & & & $9.1 \mathrm{E}-02$ \\
\hline & & xLag & & 4.5E+09 & & & & & $5.0 \mathrm{E}+05$ & $-1.6 \mathrm{E}+08$ & $1.1 \mathrm{E}+06$ & $-5.1 \mathrm{E}+07$ & $1.9 \mathrm{E}+07$ & \\
\hline & & $R^{2}=0.40$ & $P$-val & $3.1 \mathrm{E}-01$ & & & & & $1.0 \mathrm{E}-04 \cdots$ & $2.0 \mathrm{E}-03^{* *}$ & $8.9 \mathrm{E}-01$ & $2.4 \mathrm{E}-01$ & 4.4E- 01 & \\
\hline & & xylag & & $9.8 \mathrm{E}+09$ & $-1.9 \mathrm{E}+07$ & $-1.0 \mathrm{E}+07$ & $2.7 \mathrm{E}+08$ & $1.6 \mathrm{E}+07$ & $3.8 \mathrm{E}+05$ & $-8.9 \mathrm{E}+07$ & $-1.4 \mathrm{E}+06$ & $3.5 \mathrm{E}+07$ & $-3.7 E+06$ & $1.3 \mathrm{E}-01$ \\
\hline & & $R^{2}=0.80$ & $P$-val & $8.3 \mathrm{E}-02$ & 5.1E-01 & $1.0 \mathrm{E}-01$ & $5.9 \mathrm{E}-05 \cdots$ & $4.2 \mathrm{E}-01$ & $3.1 \mathrm{E}-04 \cdots$ & 8.7E-02 & $8.3 \mathrm{E}-01$ & 4.6E-01 & $8.9 \mathrm{E}-01$ & $3.4 \mathrm{E}-02^{\circ}$ \\
\hline & 2nd oLS & Selected & & $1.0 \mathrm{E}+09$ & $-4.7 E+07$ & & $3.0 \mathrm{E}+08$ & & $4.2 \mathrm{E}+05$ & & & & & $9.1 E-02$ \\
\hline & & $R^{2}=0.75$ & $P$-val & $3.7 \mathrm{E}-01$ & 3.8E-02. & & $5.4 \mathrm{E}-06 \cdots$ & & $4.9 \mathrm{E}-05 \cdots$ & & & & & $8.4 \mathrm{E}-02$ \\
\hline & 3rd oLs & Selected & & $1.6 \mathrm{E}+09$ & $-5.5 \mathrm{E}+07$ & & $2.9 \mathrm{E}+08$ & & $4.5 \mathrm{E}+05$ & & & & & \\
\hline & & $R^{2}=0.73$ & $P$-val & $1.5 \mathrm{E}-01$ & $1.6 \mathrm{E}-02^{\circ}$ & & $1.2 \mathrm{E}-05^{* *}$ & & $1.9 \mathrm{E}-05^{+*}$ & & & & & \\
\hline \multirow[t]{8}{*}{ DDBI } & 1st OLS & xNoLag & & $1.8 \mathrm{E}+09$ & $-2.3 \mathrm{E}+07$ & $2.9 \mathrm{E}+11$ & $2.6 \mathrm{E}+07$ & $-2.0 \mathrm{E}+12$ & $5.5 \mathrm{E}+05$ & & & & & \\
\hline & & $R^{2}=0.51$ & $P$-val & 4.6E-01 & $1.8 \mathrm{E}-01$ & 7.1E-01 & 4.6E- 01 & $7.1 \mathrm{E}-01$ & $1.4 \mathrm{E}-20^{\cdots \cdots}$ & & & & & \\
\hline & & yLag & & $1.2 \mathrm{E}+09$ & $-1.8 \mathrm{E}+07$ & $9.4 \mathrm{E}+10$ & $2.8 \mathrm{E}+07$ & $-6.3 \mathrm{E}+11$ & $5.0 \mathrm{E}+05$ & & & & & 8.4E-02 \\
\hline & & $R^{2}=0.54$ & $P$-val & $6.0 \mathrm{E}-01$ & $2.8 \mathrm{E}-01$ & $9.0 \mathrm{E}-01$ & 4.1E-01 & $9.0 \mathrm{E}-01$ & $2.3 \mathrm{E}-17 \cdots$ & & & & & $1.5 \mathrm{E}-02$ \\
\hline & & xlag & & $-1.2 \mathrm{E}+09$ & & & & & $5.1 \mathrm{E}+05$ & $-4.1 E+07$ & $3.7 E+06$ & $-3.0 \mathrm{E}+07$ & $1.5 \mathrm{E}+07$ & \\
\hline & & $R^{2}=0.54$ & $P$-val & $6.4 \mathrm{E}-01$ & & & & & $3.0 \mathrm{E}-19^{\cdots \cdots \cdot}$ & $1.5 \mathrm{E}-01$ & 3.4E-01 & $9.0 \mathrm{E}-02$ & $2.8 \mathrm{E}-01$ & \\
\hline & & xylag & & $-4.6 \mathrm{E}+08$ & $-4.5 \mathrm{E}+06$ & $-1.5 \mathrm{E}+11$ & $5.2 \mathrm{E}+07$ & $9.9 \mathrm{E}+11$ & $4.8 \mathrm{E}+05$ & $-2.4 \mathrm{E}+07$ & $1.8 \mathrm{E}+06$ & $-3.0 \mathrm{E}+07$ & $2.1 \mathrm{E}+07$ & 7.2E-02 \\
\hline & & $R^{2}=0.57$ & $P$-val & $8.8 \mathrm{E}-01$ & $8.2 \mathrm{E}-01$ & $8.5 \mathrm{E}-01$ & $1.7 \mathrm{E}-01$ & $8.5 \mathrm{E}-01$ & $1.2 \mathrm{E}-15 \cdots$ & $4.8 \mathrm{E}-01$ & $6.7 \mathrm{E}-01$ & $1.2 \mathrm{E}-01$ & $1.3 \mathrm{E}-01$ & $3.9 \mathrm{E}-02$ \\
\hline \multirow[t]{8}{*}{ DDDI } & 1st OLS & xNoLag & & $1.7 \mathrm{E}+09$ & $2.9 \mathrm{E}+08$ & $-2.5 \mathrm{E}+12$ & $-1.8 \mathrm{E}+07$ & $1.7 \mathrm{E}+13$ & $4.8 \mathrm{E}+05$ & & & & & \\
\hline & & $R^{2}=0.36$ & $P$-val & $9.6 \mathrm{E}-01$ & $1.3 \mathrm{E}-01$ & 7.3E-01 & $7.7 \mathrm{E}-01$ & 7.3E-01 & $1.3 \mathrm{E}-01$ & & & & & \\
\hline & & $y$ Lag & & $-1.9 \mathrm{E}+10$ & $3.0 \mathrm{E}+08$ & $-9.3 \mathrm{E}+12$ & $7.7 \mathrm{E}+06$ & $6.2 \mathrm{E}+13$ & $1.3 \mathrm{E}+05$ & & & & & 7.7E-01 \\
\hline & & $R^{2}=0.46$ & $P$-val & $6.0 \mathrm{E}-01$ & $1.2 \mathrm{E}-01$ & 3.5E-01 & $9.1 \mathrm{E}-01$ & 3.5E-01 & $7.8 \mathrm{E}-01$ & & & & & $3.1 \mathrm{E}-01$ \\
\hline & & xLag & & & & & & & $4.4 \mathrm{E}+05$ & $1.5 \mathrm{E}+10$ & $-4.4 \mathrm{E}+07$ & $-1.5 \mathrm{E}+07$ & $-5.6 \mathrm{E}+07$ & \\
\hline & & $R^{2}=0.18$ & $P$-val & & & & & & $3.4 \mathrm{E}-01$ & $6.1 E-01$ & $8.5 \mathrm{E}-01$ & $6.8 \mathrm{E}-01$ & $6.1 \mathrm{E}-01$ & \\
\hline & & $x y$ Lag & & $-4.8 \mathrm{E}+10$ & $3.8 \mathrm{E}+08$ & $-1.4 \mathrm{E}+13$ & $4.6 \mathrm{E}+07$ & $9.3 \mathrm{E}+13$ & $-2.8 \mathrm{E}+05$ & $1.4 \mathrm{E}+08$ & $1.0 \mathrm{E}+07$ & $1.8 \mathrm{E}+07$ & $-5.5 E+07$ & $1.6 \mathrm{E}+00$ \\
\hline & & $R^{2}=0.50$ & $P$-val & $6.8 \mathrm{E}-01$ & $2.9 \mathrm{E}-01$ & $6.5 \mathrm{E}-01$ & $7.5 \mathrm{E}-01$ & $6.5 \mathrm{E}-01$ & $8.6 \mathrm{E}-01$ & $8.1 \mathrm{E}-01$ & $8.7 \mathrm{E}-01$ & $9.4 \mathrm{E}-01$ & $6.9 \mathrm{E}-01$ & $5.3 \mathrm{E}-01$ \\
\hline \multirow[t]{12}{*}{ DIBB } & 1st OLS & $x$ NoLag & & $1.9 \mathrm{E}+09$ & $7.6 \mathrm{E}+06$ & $-2.9 \mathrm{E}+06$ & $-1.9 \mathrm{E}+07$ & $2.9 \mathrm{E}+07$ & $2.7 \mathrm{E}+05$ & & & & & \\
\hline & & $R^{2}=0.15$ & $P$-val & $3.6 \mathrm{E}-01$ & 7.3E-01 & 4.6E-01 & 7.4E-01 & $2.0 \mathrm{E}-03 \cdots$ & $2.2 \mathrm{E}-03^{\cdots} \cdots$ & & & & & \\
\hline & & yLag & & $1.5 \mathrm{E}+09$ & $1.4 \mathrm{E}+07$ & $-2.9 \mathrm{E}+06$ & $-4.2 \mathrm{E}+07$ & $2.2 \mathrm{E}+07$ & $2.5 \mathrm{E}+05$ & & & & & $1.7 \mathrm{E}-01$ \\
\hline & & $R^{2}=0.24$ & $P$-val & 4.7E-01 & $5.2 \mathrm{E}-01$ & 4.3E-01 & 4.4E-01 & $1.6 \mathrm{E}-02$ & $3.0 \mathrm{E}-03^{\cdots} \cdots$ & & & & & 2.3E-04 $\cdots$ \\
\hline & & $x$ Lag & & $2.7 \mathrm{E}+09$ & & & & & $3.2 \mathrm{E}+05$ & $-8.3 \mathrm{E}+06$ & $-3.4 \mathrm{E}+06$ & $-1.7 \mathrm{E}+08$ & $3.7 \mathrm{E}+07$ & \\
\hline & & $R^{2}=0.23$ & $P$-val & $3.1 \mathrm{E}-01$ & & & & & $8.0 \mathrm{E}-05 . \cdots$ & 7.9E-01 & 4.5E-01 & 4.0E-03ㅂ. & $2.2 \mathrm{E}-04 \cdots$ & \\
\hline & & $x y$ Lag & & $2.9 \mathrm{E}+09$ & $3.8 \mathrm{E}+06$ & $-1.9 \mathrm{E}+06$ & $9.8 \mathrm{E}+06$ & $1.1 \mathrm{E}+07$ & $3.0 \mathrm{E}+05$ & $1.0 \mathrm{E}+06$ & $-3.5 \mathrm{E}+06$ & $-1.4 \mathrm{E}+08$ & $2.2 \mathrm{E}+07$ & $1.3 \mathrm{E}-01$ \\
\hline & & $R^{2}=0.28$ & $P$-val & 3.7E-01 & $8.8 \mathrm{E}-01$ & $6.0 \mathrm{E}-01$ & $8.7 \mathrm{E}-01$ & 4.6E-01 & 4.6E- 04 ..... & $9.8 \mathrm{E}-01$ & 4.7E-01 & $3.6 \mathrm{E}-02^{\circ}$ & $1.8 \mathrm{E}-01$ & 8.7E-03 $\cdots$ \\
\hline & 2nd oLS & Selected & & $6.4 \mathrm{E}+08$ & & & & $1.2 \mathrm{E}+07$ & $2.9 \mathrm{E}+05$ & & & $-1.5 \mathrm{E}+08$ & $1.5 \mathrm{E}+07$ & $1.3 \mathrm{E}-01$ \\
\hline & & $R^{2}=0.27$ & $P$-val & $3.6 \mathrm{E}-01$ & & & & $3.8 \mathrm{E}-01$ & 3.3E- $04 \cdots$ & & & $8.9 \mathrm{E}-03^{\cdots \cdots}$ & $2.4 \mathrm{E}-01$ & 8.1E-03* \\
\hline & 3rd oLs & Selected & & $9.1 \mathrm{E}+08$ & & & & $2.5 \mathrm{E}+07$ & $2.8 \mathrm{E}+05$ & & & $-1.5 \mathrm{E}+08$ & & $1.4 \mathrm{E}-01$ \\
\hline & & $R^{2}=0.27$ & $P$-val & $1.7 \mathrm{E}-01$ & & & & $3.5 \mathrm{E}-03^{\cdots} \cdots$ & $5.1 \mathrm{E}-04^{\cdots \cdots}$ & & & 1.1E-02* & & $2.4 \mathrm{E}-03^{\cdots *}$ \\
\hline \multirow[t]{8}{*}{ IDBI } & 1st OLS & $x$ NoLag & & $-3.8 \mathrm{E}+10$ & $2.7 \mathrm{E}+08$ & $-6.9 \mathrm{E}+12$ & $-6.3 E+07$ & $4.6 \mathrm{E}+13$ & $1.5 \mathrm{E}+05$ & & & & & \\
\hline & & $R^{2}=0.29$ & $P$-val & $1.8 \mathrm{E}-01$ & $6.0 \mathrm{E}-01$ & 3.3E-01 & 7.1E-01 & 3.3E-01 & 7.0E-01 & & & & & \\
\hline & & & & $-3.4 \mathrm{E}+10$ & $4.1 \mathrm{E}+08$ & $-6.9 \mathrm{E}+12$ & $-1.5 \mathrm{E}+07$ & $4.6 \mathrm{E}+13$ & $-2.7 \mathrm{E}+04$ & & & & & $1.6 \mathrm{E}-01$ \\
\hline & & $R^{2}=0.36$ & $P$-val & $2.4 \mathrm{E}-01$ & $4.6 \mathrm{E}-01$ & 3.4E-01 & $9.3 \mathrm{E}-01$ & 3.4E-01 & $9.5 \mathrm{E}-01$ & & & & & $3.8 \mathrm{E}-01$ \\
\hline & & & & $4.0 \mathrm{E}+10$ & & & & & $2.3 \mathrm{E}+05$ & $-2.0 \mathrm{E}+08$ & $-5.8 \mathrm{E}+07$ & $9.1 \mathrm{E}+07$ & $9.2 \mathrm{E}+07$ & \\
\hline & & $R^{2}=0.37$ & $P$-val & $1.3 \mathrm{E}-01$ & & & & & $5.4 \mathrm{E}-01$ & $2.6 \mathrm{E}-01$ & $9.0 \mathrm{E}-02$ & 1.4E-01 & $5.9 \mathrm{E}-01$ & \\
\hline & & xylag & & $1.2 \mathrm{E}+10$ & $-6.9 \mathrm{E}+07$ & $-5.8 \mathrm{E}+12$ & $-2.2 \mathrm{E}+07$ & $3.8 \mathrm{E}+13$ & $-3.6 \mathrm{E}+08$ & $-4.8 \mathrm{E}+07$ & $3.4 \mathrm{E}+07$ & $-1.5 \mathrm{E}+08$ & $-3.6 \mathrm{E}+08$ & $6.7 \mathrm{E}-02$ \\
\hline & & $R^{2}=0.60$ & $P$-val & $8.2 \mathrm{E}-01$ & 9.3E-01 & $6.5 \mathrm{E}-01$ & 9.5E-01 & $6.5 \mathrm{E}-01$ & $2.6 \mathrm{E}-01$ & 4.6E-01 & 7.4E-01 & $5.9 \mathrm{E}-01$ & $2.6 \mathrm{E}-01$ & 7.7E-01 \\
\hline
\end{tabular}

\section{(3) General model fit}

The general model fit is indicated by the higher values of $\mathrm{R}^{2}$ and the Log Likelihood. From the spatial lag and spatial error diagnostics, we can see that the inclusion of the spatial factor yields improves Model 1 (Table 4.6). Hence, for the analysis of general model fit using predicted distribution, Model 2 is applied with Spatial Lag OLS. 
A comparison of Models 1 and 2 with Model 3 is performed with a Contingency Matrix and Kappa Statistic to assess the validity and reliability of the predictions. The predicted distribution of economic opportunity from each model is presented in Figure 4.9. For the validation process, these maps are compared with the reference data of Prosperity Level and Subjective Well-being. Figure 4.10 shows the map of Prosperity Level and the map of Subjective Well-being that is also used for the validation.

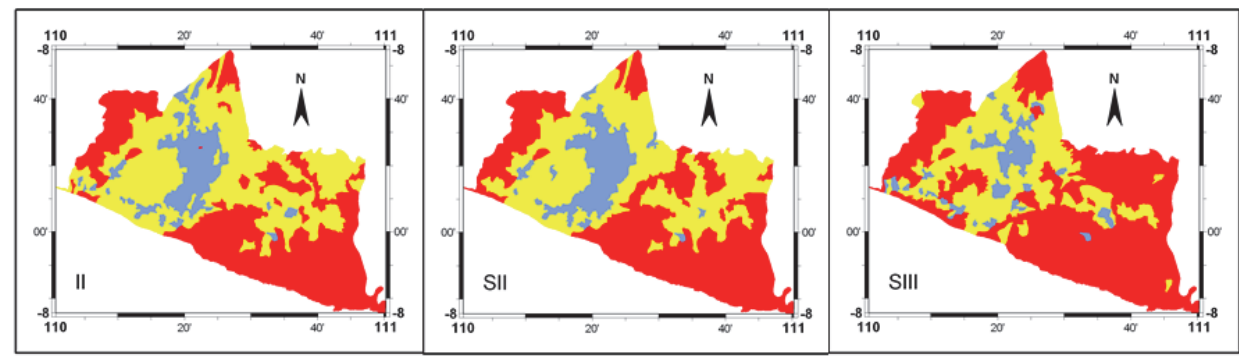

Figure 4.9 Modelling results. It shows the predicted economic opportunities. Model 1: Integrated Infrastructure (II), Model 2: Spatial Integrated Infrastructure (SII), and Model 3: Spatial Integrated Infrastructure Interdependency (SIII). Blue, yellow and red respectively represent high, medium and low economic opportunities.
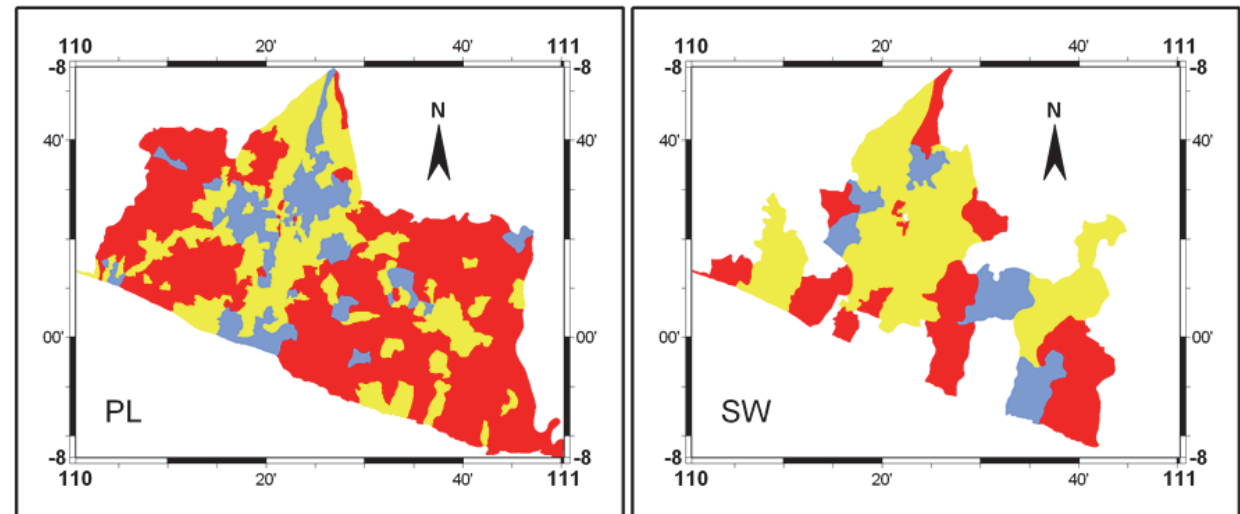

Figure 4.10 Spatial data for validation. The modelling results are compared with these Prosperity Level (PL) and the Subjective Well-being (SW).

PL and SW are used as a proxy for economic opportunity. Prosperity Level (PL) is derived from poverty data in the same dataset for the model (PODES, 2006) therefore depicts the calibration of the model. Subjective Well-being (SW) is derived from a different dataset of IFLS (IFLS, 2007) hence it estimates the ground truth in the validation process. 
In the accuracy assessment with Prosperity Level (Figure 4.10), we found increasing levels of accuracy from model 1 to 3 . Table 4.8 summarises the results of the contingency matrix of each model. Model 1, the Integrated Infrastructure model, had the lowest level of accuracy at 54.23\% followed by Model 2, the Spatial Integrated Infrastructure model that had a slightly higher accuracy at $54.42 \%$. Model 3, the Spatial Integrated Infrastructure Interdependency model, clearly had the highest accuracy at $64.34 \%$.

Table 4.8 Summary of Contingency Matrix of Prosperity Level

\begin{tabular}{llll}
\hline & Model 1 & Model 2 & Model 3 \\
\hline Average Accuracy & $47.57 \%$ & $46.94 \%$ & $51.39 \%$ \\
\hline Average Reliability & $48.62 \%$ & $47.66 \%$ & $54.33 \%$ \\
\hline Overall Accuracy & $54.23 \%$ & $54.42 \%$ & $64.34 \%$ \\
\hline
\end{tabular}

Similarly, the comparison with Subjective Well-being in Table 4.9 shows that Model 1 has the lowest level of accuracy at $50.48 \%$, almost equal to Model 2 at 50.96\%, while Model 3 had the highest accuracy at 51.59\%.

Table 4.9 Summary of Contingency Matrix of Subjective Well-being

\begin{tabular}{llll}
\hline & Model 1 & Model 2 & Model 3 \\
\hline Average Accuracy & $40.62 \%$ & $40.79 \%$ & $43.55 \%$ \\
\hline Average Reliability & $42.70 \%$ & $42.70 \%$ & $42.67 \%$ \\
\hline Overall Accuracy & $50.48 \%$ & $50.96 \%$ & $51.59 \%$ \\
\hline
\end{tabular}

Furthermore, the reliability assessment of each model with the Kappa Statistic in Table 4.10 shows different patterns compared with the accuracy assessment with the Contingency Matrix. The accuracy assessment subsequently provided increasing accuracy from Model 1, Model 2 and Model 3, while the reliability assessment with Kappa Statistic shows that Model 2 had lower reliability than Model 1. Among these models, the Spatial Integrated Infrastructure Interdependency model consistently resulted in the highest score both on accuracy and reliability.

Table 4.10 Summary of Kappa Statistics

\begin{tabular}{llll}
\hline Reference Data & Model 1 & Model 2 & Model 3 \\
\hline PL & $0.237(\mathrm{p}<0.001)$ & $0.230(\mathrm{p}<0.001)$ & $0.340(\mathrm{p}<0.001)$ \\
\hline SW & $0.138(\mathrm{p}<0.001)$ & $0.194(\mathrm{p}<0.001)$ & $0.206(\mathrm{p}<0.001)$ \\
\hline
\end{tabular}

As presented in Table 4.10, the reliability assessment for Model 1 with Prosperity Level is found to be Kappa $=0.237(\mathrm{p}<0.001)$ and with the Subjective Well-being is found to be lower with a Kappa $=0.138(\mathrm{p}<0.001)$. The reliability of Model 2 is almost similar, with a Kappa $=0.230(\mathrm{p}<0.001)$ on the assessment with Prosperity Level and a Kappa $=0.194(\mathrm{p}<0.001)$ for Subjective Well-being. We found that Model 3 has a higher reliability both 
in the comparison with Prosperity Level with Kappa $=0.340(\mathrm{p}<0.001)$ and Subjective Well-being with Kappa $=0.206(\mathrm{p}<0.001)$.

\subsection{Discussion}

In this study, we demonstrate that the inclusion of the conditions in neighbouring villages and infrastructure interdependency are able to improve the performance of infrastructure-economy interaction models in predicting economic opportunity at the village level in a region.

The result of the regression diagnostics and analysis of spatial dependency in Models 1 and 2 with spatial lag and spatial error provides evidence that the inclusion of neighbouring factors improves the general model fit as indicated by $\mathrm{R}^{2}$ and the Log Likelihood (Table 4.6) and also reduces the violation of the OLS assumption of error dependencies and error variance of heteroskedasticity.

With respect to Model 3, the general model fit with $\mathrm{R}^{2}$ indicates that the cumulative effect of infrastructure integration, spatial dependency, and infrastructure interdependency improves the model fit. Using reference data from the Prosperity Level and the Subjective Well-Being, the study finds that the inclusion of neighbouring conditions and infrastructure interdependency in Model 3 increases accuracy by more than $10 \%$, as presented in Table 4.8.

Interestingly, a comparison of Model 1 and 2 reveals that the existence of higher economic development in neighbouring villages does not make a significant contribution to the economic opportunity of a village, as is indicated by the high value of $\rho$. Moreover, the validation results show that the inclusion of a spatial-lag response variable of the economic development of the neighbouring village has no effect on the distribution accuracy of Model 2 (54.42\%) in comparison to Model 1 (54.23\%). This finding is contradictory to the well-known spill-over effect, which postulates that spatial growth of economic opportunities and activities is determined by the spatial proximity of previously existing activities in a neighbourhood area. Our findings suggest that the existence of infrastructure and the expected spill-over effect is insufficient to explain infrastructure-economy interaction. The inclusion of infrastructure interdependency is required for a better analysis.

In Model 3, the results of the Rule-Based OLS in the Sugeno FIS Model also reveal that the specific nature of interdependency is strongly related to the various levels of performance of each infrastructure. We demonstrate that 
some rules might not necessarily hold true in some areas. This means that we can exclude some of the rules in Sugeno FIS. Furthermore, in the course of developing a best-fit OLS, some insignificant variables are excluded. In terms of the interdependency concept, this exclusion implies that in certain areas, the growth of economic activity is insensitive to a particular type of infrastructure.

Our case study has demonstrated that there is variety in the degree of sensitivity of economic opportunity growth to different levels of performance and different types of infrastructure in a given location. For example, in areas where there is a large supply of electricity (DIBB), the telecommunication service $\left(\tau_{3}\right)$ does not necessarily indicate a positive relationship to the growth of economic opportunities. Our finding denotes that telecommunication infrastructure is used for consumption instead of production. It implies, in those areas, that other means of development (e.g. regulatory and or skill networks) might play an important role in increasing the economic opportunity.

Another finding strengthens this argument. Regulatory networks, such as those dealing with the development of infrastructure policy, will affect the nature of the infrastructure development. The results demonstrate this effect in the telecommunication sector. They show that, in general, infrastructure telecommunication $\left(\beta_{3}\right)$ is the best indicator of the distribution of economic activity (Table 4.7). In fact, in certain situations, telecommunication development becomes the dependent variable of economic development. Because policy dealing with infrastructure tends to advance private industry as the driving force of development, businessoriented private telecommunication operators tend to provide infrastructure only in high-density and financially feasible areas. These operators tend not to take rural, remote and poor villages into consideration as areas to be served.

Among other public infrastructures, telecommunications closely reflect the role of infrastructure as "the ship that follows the trade", while other types of infrastructure, especially roads, function as "the trade that follows the ship," which means that infrastructure is provided to promote economic activity. This particular direction is confirmed by the results of the multicollinearity diagnosis, which indicate no correlation among infrastructure variables.

Also of interest is the fact that the assessment, which is based on Rulebased OLS, in areas with transport and electricity infrastructure at the level of domestic activities, while telecommunication and water supply are at the 
level of basic services (DDBB), reveals that increasing the speed of travel does not contribute to the growth of economic opportunity. This situation can be explained by the distinct characteristics of the urban and rural areas in Indonesia. In the area of study, the speed of travel in the rural area is actually higher than in the urban area, although rural areas have less economic activity. In urban areas, travel speeds decrease due to the limited capacity of roads and the levels of congestion, even though the urban area has a higher level of economic activity than the rural area. In this particular situation, it is understandable that the result of OLS shows a negative relationship between the performance of transport and the growth of economic opportunity.

In addition, the reliability assessment using Kappa statistics is only Kappa = $0.340(\mathrm{p}<0.001)$ for Prosperity Level and Kappa $=0.206(\mathrm{p}<0.001)$ for Subjective Well-Being, which is slight to fair in terms of the strength of agreement (Landis and Koch 1977). These results are understandable given the fact that we are dealing with a rather broad concept of economic opportunity, one that is not exactly congruent with the proxy indicators of Prosperity Level and Subjective Well-being. The results, therefore, have only relative validity among the three models. Economic opportunity refers to equality of opportunity and does not necessarily reflect only the equality of income; rather, income is only one of the factors (see Garcia-Valiñas, Fernández-Llera et al. (2008)). Likewise, establishing an infrastructure is but one of the possible ways to improve the equality of economic opportunity in an area; it is not the only way. The real income generated (as reflected in Prosperity Level and Subjective Well-Being) as a result of the provided opportunity depends on the effort of each individual. The Kappa scores may therefore be interpreted as an evaluation of the relative explanatory power of infrastructure for economic development as expressed by the proxy indicators.

The increasing accuracy and reliability of Model 3 also support the combination of Spatial-Lag OLS and Sugeno FIS to provide a plausible tool for modelling infrastructure interdependency. The application of rulebased OLS also enables us to obtain the reliable mathematical equations required in Sugeno FIS, while it helps to exclude unnecessary rules in FIS and therefore reduce computation time. The approach in Model 3 is seen as workable, but of course there is room for improvement; the Infrastructure Interdependency Model, for example, could be improved by more carefully examining the various approaches to defining neighbourhood factors.

Further research will be directed to the implementation of the modelling approach in a resource allocation mechanism. The critical component of 
this mechanism is how allocation priorities will be established. Commonly, the preference modelling in planning and decision support systems is constructed based on an analysis of the decision units in the whole region on a unit by unit basis, which tends to disregard neighbourhood characteristics and infrastructure interdependency. It is therefore necessary to develop a new model of the decision support system that would take these factors into account. This type of modelling, which combines the theoretical construct of Economic Geography as well as its implementation with spatial data computations, could contribute to the recent discussions on New Economic Geography (Behrens and Thisse 2007).

\subsection{Conclusions}

We conclude that the inclusion of conditions of neighbouring village and infrastructure interdependency are able to improve the performance of infrastructure-economy interaction models in predicting economic opportunity distribution at the village level in a region. Hence, these factors need to be considered in the planning and decision making on infrastructure programmes at the village level.

Along with the above conclusion, this research has introduced a new approach for infrastructure interdependency modelling in the form of a combination of an FIS and Rule-based Spatial Lag OLS. This combination provides a means to assess economic opportunity in a given spatial context at a given point in time, but it may also be used to guide decisions on future interventions through its capability to analyse the impact of changes in infrastructure system co-existence and interdependency.

Finally, this approach also provides a basis for a more accountable and transparent planning process. It allows the decision bias in the allocation of resources in decentralised governance systems by planners and policy makers to be addressed and provides an opportunity to consider alternative scenarios that form the basis of effective infrastructure investments. 


\title{
Chapter 5
}

\section{Spatial Preference Modelling for Equity Based Resources Allocation ${ }^{2}$}

\begin{abstract}
To determine whether the inclusion of spatial neighbourhood comparison factors in Preference Modelling allows Spatial Decision Support Systems (SDSS) to better address spatial equity, we introduce Spatial Preference Modelling (SPM). To evaluate the effectiveness of this model in addressing equity, various standardisation functions in both Non-Spatial Preference Modelling (NSPM) and SPM are compared. The evaluation involves applying the model to a resource location-allocation problem for transport infrastructure in the Special Province of Yogyakarta in Indonesia. We apply Amartya Sen's Capability Approach to define opportunity-to-mobility as a non-income indicator. Using the extended Moran's I interpretation for spatial equity, we evaluate the distribution output regarding, first, 'the spatial distribution patterns of priority targeting for allocation' (SPT) and, second, 'the effect of new distribution patterns after location-allocation' (ELA). The Moran's I index of the initial map and its comparison with six patterns for SPT as well as ELA consistently indicates that the SPM is more effective for addressing spatial equity. We conclude that the inclusion of spatial neighbourhood comparison factors in Preference Modelling improves the capability of SDSS to address spatial equity. This study thus proposes a new formal method for SDSS with specific attention on resource location-allocation to address spatial equity.
\end{abstract}

Key Words: Capability Approach, spatial and social equity, locationallocation, Spatial Preference Modelling, Spatial Decision Support System

2 Published as:

Wismadi, A., Zuidgeest, M,H,P., Brussel, M.J.G., van Maarseveen., M.F.A.M., (2013)

Sen's Spatial Preference Modelling for equitable infrastructure provision: an application of Sen's capability approach, Journal of Geographical Systems 


\subsection{Introduction}

In 1968, the theory of social equity was developed as the third pillar of public administration in addition to 'economy' and 'efficiency' (Frederickson 1990). Social equity concerns fair access to resources and livelihood. One of the possible means of governmental interventionism towards social equity is the distribution of public services (e.g., infrastructure provision) based on characteristics such as the age, health, wealth, sex and geographical location of people (Chitwood 1974). Typically, distributional patterns are evaluated in terms of social equity (achieving equity over socio-economic groups of society) or spatial equity (achieving equity over geographical locations).

Decisions leading to an inequitable distribution of public services can result in social tensions. Following protests in Indonesia in 1997 and 1998, government reforms were implemented and resulted in a more decentralised governmental system. This trend of governance and fiscal decentralisation is currently occurring in many other countries (Neyapti 2010). Surprisingly, although such resource allocations for infrastructure investment in decentralising systems aim to better accommodate local preferences, authors such as Neyapti (2010) and Kyriacou and RocaSagalés (2011) note that efficiency decreases in countries with local or regional elections. These authors argue that decentralised systems in conjunction with a system of local elections result in local politicians having decision biases in the distribution of resources to their constituents.

Efforts to counter this decision bias are complicated by the absence of decision support tools that allow for a more balanced allocation of resources in such a decentralised context (bottom-up, reflecting local preferences) but that also consider national processes and requirements (top-down, reflecting national pro-poor, pro-growth and pro-jobs policies, where pro-poor stands for the equity objective). Without such tools, stakeholders cannot effectively evaluate how each infrastructure project in their region or under their responsibility is expected to contribute to equitable development.

Decision Support Systems (DSS) generally incorporate so-called Preference Modelling routines to transform preference values from stakeholders into sets of priorities, such as for location-allocation decisions (Tsoukias 1991; Perny and Roy 1992; Benferhat, Dubois et al. 2006; Piccolo and D'Elia 2008; Roberts and Tsoukiás 2009). Spatial Decision Support Systems (SDSS) aim to assist decision making related to spatial issues such as land use decisions. However, although the priority settings in SDSS are mostly 
presented in maps, the computations often disregard the spatial-equity aspect. For instance, a 'standard' Preference Modelling typically focuses on making global comparisons, whereas, in real life, there may be significant local and neighbourhood effects; e.g., the sense of inequity of an individual is usually stronger in local comparisons than in global comparisons. In addition, the sense of inequity is supposed to decrease with a greater distance between two objects. The implementation of global comparisons in Preference Modelling, which often overlooks local and neighbourhood variations, might therefore negatively affect the effectiveness of resource allocation.

Moreover, infrastructure resource allocation at lower administrative levels (e.g., the village level) requires special attention to the co-existence of infrastructures in a location and infrastructures in its neighbouring areas. Infrastructure systems, particularly networks of linear infrastructures, such as roads, typically exhibit high levels of interconnectivity and therefore require neighbourhood-inclusive analysis techniques in decision making for resource allocation. Disregarding this connectivity jeopardises the function of infrastructure systems in a society and may therefore lead to inefficient location-allocation. Wismadi, Brussel et al. (2012) previously disclosed the importance of adding neighbourhood information to villagelevel infrastructure-economy interaction modelling.

In the context of neighbourhood comparisons, the well-known statistical measure of spatial autocorrelation enables quantification of the degree of difference among values of the same variables of an object with other surrounding objects. One of such measurements is Moran's I index (Shortridge 2007). Although this approach has been widely used to quantify spatial distributions (e.g., Overmars, de Koning et al. (2003); Ping, Green et al. (2004);Tsou, Hung et al. (2005); Tsai (2005)), the inclusion of this concept within a resource-allocation mechanism to address social and spatial equity at a local level cannot be found in the current literature. With the growing number of pro-poor programs and attention to equity issues, knowledge of equity-based resource allocation has become critical, particularly in situations where priority-setting typically faces efficiencyequity trade-offs and/or budget constraint issues (Cho 1998; Bibi and Duclos 2007; Cherchye, De Witte et al. 2010). This budget allocation issue is even more complex in the context of the recent decentralisation of administrations in Indonesia.

The purpose of this study is therefore to determine whether the inclusion of spatial neighbourhood comparison factors in Preference Modelling, i.e., Spatial Preference Modelling, can improve the capability of SDSS in 
resource location-allocation for addressing spatial equity. To this end, we compare Spatial Preference Modelling (SPM) with the more common (NonSpatial) Preference Modelling (NSPM) approach. We develop SPM by extending the Moran's I Scatter Plot formulation and combine it with a linear scale transformation method that is commonly applied in Preference Modelling. This SPM is expected to result in a more equitable allocation. The comparison is performed for the allocation of transport infrastructure resources in Yogyakarta, a region with 438 urban and rural villages in Indonesia. This region is highly diverse in terms of topography, level of urbanisation and modernity, road infrastructure, transport modes and traffic volumes.

The paper is organised as follows. Section 2 discusses the methodology of Preference Modelling, its formulation, the data requirements and the analytical framework. Section 3 presents the results of each Preference Modelling approach. Section 4 discusses the most important findings; conclusions and policy implications follow in Section 5.

\subsection{Methodology}

\subsubsection{Research Design}

We compare two methods of Preference Modelling: first, NSPM, a more common method that disregards spatial features and their neighbourhood effects, and second, SPM, which includes spatial neighbouring objects in the equity measure.

For both methods, we investigate three possible ways for stakeholders to perceive the gaps between object values. First, the gap is defined as the distance between the values and zero as well as between the values and the maximum value within the set. Second, the gap is defined as the interval between the lowest and the highest values. Third, the gap is defined as the distance between the values and a set of pre-determined policy goals. These gaps are operationalised through three common standardisation procedures: maximum standardisation, interval standardisation and goal standardisation (Beedasy and Whyatt 1999; Sharifi and van Herwijnen 2001; Xiang 2001; Phua and Minowa 2005; Ananda and Herath 2009). As such, we evaluate six preference models in terms of their effectiveness in addressing spatial equity for a resource location-allocation problem.

The process is conducted in two stages; we evaluate, first, the effectiveness of the models at addressing 'the spatial distribution patterns of priority targeting for allocation' (SPT) and, second, their 'effect on the new 
distribution patterns after location-allocation' (ELA). The evaluation is performed by comparing the Moran's I index of an initial map with the six mapped patterns from the SPT and ELA analyses. The discussion then focuses on the interpretation of the results and the policy implications with regard to a more equitable resource allocation.

For the case study, we develop and apply a resource location-allocation model for transport infrastructure in the Special Province of Yogyakarta, Indonesia. Specifically, the distributed allocation is framed in terms of 'opportunity-to-mobility' rather than monetary units or construction materials. This notion is derived from the Amartya Sen Capability Approach, which is discussed in the next section.

\subsubsection{Sen's Capability Approach in Preference Modelling}

To achieve an equitable distribution, it is important to define the concept of equity. The notions of equality, equity and redistribution are linked concepts and are strongly related to governmental interventionism. The concept of 'equality' in particular denotes that everyone is at the same level. From an economic perspective, the term implies that incomes are shared in a homogenous way (Garcia-Valiñas, Fernández-Llera et al. 2008). To counter inequality, governments must intervene and reduce strong income differences. For 'equality', not only should poor people be less poor, but the rich should also be less rich. A common 'equality' measurement is the Gini Index.

Equality requires redistribution of resources among groups, which is often problematic to implement. Therefore, the notion of 'equity' replaces the more radical notion of equality. Equity represents fairness, or the equality of outcomes, and involves attention to disadvantaged groups in the system toward accessing equality of outcome. As an analogy, 'equality' involves a 'floor' and a 'ceiling', whereas 'equity' only entails a minimum 'floor' (Garcia-Valiñas, Fernández-Llera et al. 2008). In measuring poverty, the 'floor' is commonly known as the 'poverty line'. As such, the term 'equity' is more reasonable in a practical context. Equity is also very relevant to infrastructure development, which aims to provide minimum service levels so that people can access certain levels of economic opportunity.

In line with the concept of equity, Sen (1980) developed the Capability Approach, which defines individual opportunity as the capability to achieve essential functioning. The approach provides a general way of evaluating social arrangements and a particular way of viewing assessments of equality and inequality (Sen 1992). Hence, one of the central notions in the 
Capability Approach relates to equity aspects or the equality of opportunity (Lelkes 2006; Cabrales and Calvó-Armengol 2008). In the Capability Approach, theLevel of opportunity is measured not only by an income indicator but also by non-income indicators. For example, the performance of transport infrastructure and its services indicate the opportunity or capability of movement (Deneulin 2008).

Although the Capability Approach has been discussed widely in the literature , e.g. (Dworkin 1981; Dworkin 1981; Nussbaum 2003; Sen 2004; Lelkes 2006; Sudgen 2006; Gasper 2007; Qizilbash 2011), its implementation is still limited to social equity assessment, particularly at national levels (e.g., in terms of the Human Development Index). However, when addressing both social and spatial equity issues, a more appropriate level of assessment is usually needed at the local level where communities exist, e.g., in terms of income generating activities in a village.This requirement can be illustrated by looking at national-level development policies, in which a government such as Indonesia - or a politician during election periods - declares a target economic growth of, for example, 10\%. This $10 \%$ growth is cited as a "two-digit" optimistic target (Yuan, Kang et al. 2008; Chen 2010; Ohana 2010) of national development. This target should then be pursued by improving infrastructure performance (among other things), which enables people to engage in economic activities. The distribution of the target growth, however, is often overlooked at the disaggregate level, e.g., the village level. In this study, resource allocation thus refers to the distribution of (targeted) levels of growth or increasing levels of opportunity in each village in the study area.

In addition to the above concept, this study introduces the Capability Approach within Preference Modelling for the allocation of transport infrastructure resources at the village level in Yogyakarta Special Province, Indonesia. Among other types of infrastructure (e.g., water, electricity, telecommunication), transport infrastructure and services provide the opportunity for people to move, meet other people, interact and carry out transactions. Hence, for this research, we derive data on travel time budgets and transport infrastructure performance as an indicator of capability or opportunity for mobility.

To operationalise Sen's Capability Approach, we also include an opportunity benchmark (e.g., a poverty line) in the model. In a standard Preference Modelling, a benchmark is represented through a goal standardisation procedure. The benchmark is also known as the policy achievement target that defines the "floor" or basic capability in the equity concept. Moreover, according to (Sen 1980), the notion of the equality of 
basic capability is very general, whereas any application of it must be culturally dependent. In the field of infrastructure development, this issue of cultural dependency is related to the capability of the community to properly adapt to an increased capacity of new infrastructure, which often involves a new type of technology. In a very diverse region, the idea of applying a single absolute benchmark for the whole population might not be appropriate; therefore, specific benchmarks with reference to each local condition should be introduced. In this research, SPM captures the level of equity among neighbourhoods to define the relative benchmark.

Hence, we introduce two types of benchmarks, the absolute benchmark and the relative benchmark. The absolute benchmark is the minimum level of opportunity required as defined by the policy maker and applied to the whole region, whereas the relative benchmark is derived from gaps in opportunity in relation to the level of opportunities in neighbouring villages. There are two reasons for using the relative benchmark. The first reason is to accommodate efficiency-equity trade-offs and avoid an idle capacity of the provided infrastructure due to a lack of utilisation. Comparison with only one absolute value of benchmark might result in an extreme gap. This gap could result in an overinvestment or underutilised infrastructure. Accordingly, the second reason for the use of the relative benchmark is related to the issue of the adaptive capacity of the community. In an attempt to mend an extreme gap, infrastructure of an inappropriate level may be introduced to which communities will find themselves unable to adapt. This study intends to provide a workable application to operationalise Sen's Capability Approach for an equity-based resource location-allocation problem. In the next section, we discuss the implementation of the NSPM and SPM methods.

\section{(1) Standardisation without spatial neighbouring comparison features}

Preference Models typically include a decision rule based on a difference of ranking between two objects. To compare objects, the common method of linear scale transformation is applied to convert the original criterion scores into standardised scores of utility (Xiang 2001; Malczewski 2004; Ananda and Herath 2009). This method uses two types of preference criteria: benefit criteria, which refer to a stakeholder's preference for the highest raw score (higher scores correspond to greater preference), and cost criteria, which refer to a stakeholder's preference to choose the object with the lowest raw score (lower scores correspond to greater preference). 
With NSPM, the three common sets of standardisation procedures, i.e., maximum, interval and goal standardisations, are considered (Beedasy and Whyatt 1999; Sharifi and van Herwijnen 2001; Xiang 2001; Phua and Minowa 2005; Ananda and Herath 2009).

Maximum standardisation produces scores on a ratio scale with a linear function between 0 and the highest absolute score. For the benefit criteria, the absolute highest score is standardised to 1, whereas for the cost criteria, the lowest score becomes 1 (Eq. (5.1 and (5.2). The advantage of maximum standardisation is that the standardised values are proportional to the original values. However, a small difference between alternatives is not clearly visible.

The following notations are used in equations 1 to 6 :

$P_{i} \quad=\quad$ the priority score for unit $i$; the unit is a spatial target for resource location-allocation

$x_{i}=$ the score of unit $i$

$\max x=\quad$ the highest absolute score in dataset $x$

$\min x=\quad$ the lowest absolute score in dataset $x$

$\min \mathrm{G}=\quad$ a specific goal reference point to the lowest value of a user-

specified range

$\max \mathrm{G}=\quad$ a specific goal reference point to the highest value of a userspecified range

The following equation provides the benefit criteria for maximum standardisation:

$P_{i}=\frac{x_{i}}{\max x}$

The following equation provides the cost criteria for maximum standardisation:

$P_{i}=-\left(\frac{x_{i}-\min x}{\max x}\right)+1$

Interval standardisation produces a score that is normalised with a linear function between the absolute lowest score and the highest score (Eq. (5.3 and Eq. (5.4). For a benefit effect, the absolute highest score is indicated with a value of 1 , and the absolute lowest score is indicated with a value of 0 . For the cost effect, the score indications are opposite. This standardisation implies a relative scale and aims to exaggerate differences. 
The following equation provides the benefit criteria for interval standardisation:

$$
P_{i}=\frac{x_{i}-\min x}{\max x-\min x}
$$

The following equation provides the cost criteria for interval standardisation:

$P_{i}=-\left(\frac{x_{i}-\min x}{\max x-\min x}\right)+1$

Goal standardisation is similar to interval standardisation but assigns specific reference points within the range of unit $i$ scores (Eq. (5.5 and Eq.(5.6). The reference points are an ideal or goal value and a minimum or maximum value that is acceptable for decision makers. Goal standardisation also defines the range of values to standardise, i.e., the goal range $G$. A meaningful minimum value for $G$ is often the score in the noaction alternative or the score of the worst possible alternative. This method produces a clear, real meaning that is independent of the alternatives being evaluated.

The following equation provides the benefit criteria for goal standardisation:

$$
P_{i}=\frac{x_{i}-\min G}{\max G-\min G}
$$

The following equation provides the cost criteria for goal standardisation:

$P_{i}=-\left(\frac{x_{i}-\min G}{\max G-\min G}\right)+1$

For the NSPM calculations, only cost criteria are used, i.e., areas with lower scores (i.e., lower infrastructure performance) should be given preference in allocating resources.

(2) Standardisation including spatial neighbourhood-comparison features

To include spatial neighbourhood-comparison features in the Preference Modelling, we extend the NSPM with a spatial autocorrelation feature, which is achieved through an extension of Moran's I Scatter Plot. Moran's I can be interpreted as the correlation between a spatial variable $X_{i}$ and a spatial lag variable $X_{\operatorname{lag}_{i}}$, which is formed by averaging all the values of 
neighbouring polygons of $X_{i} . X_{\text {lagi }}$ is calculated by using a neighbourhood connectivity rule for the weights $W_{i j}$, which represent the connectivity between neighbouring units of $j$; $W_{i j}$ equals 1 if locations $i$ and $j$ are adjacent or connected and zero otherwise (in addition, $W_{i i}=0$ because a region cannot be adjacent to itself). Two types of neighbourhood connectivity (e.g., Queen and Rook) are commonly applied in spatial statistics software (e.g., GeoDA). A Queen weights matrix defines a location's neighbours as those with either a shared border or vertex (in contrast to a Rook weights matrix, which only includes shared borders). In a regular grid, neighbours according to the Rook criterion would be cells to the north, south, west and east but not those to the northwest or southeast. In the context of Indonesia, the spatial forms of villages and their configurations are more organic and irregular as opposed to the regular forms of rectangular or block systems that are found in some other countries. Hence, we apply the Queen matrix because it better represents the actual village neighbourhood connectivity than the Rook matrix.

In the calculation, weights are row standardised accordingly (Feser and Sweeney 2006; Bivand, Müller et al. 2009). A graphical explanation of the row standardisation method is presented in Figure 5.1 below.

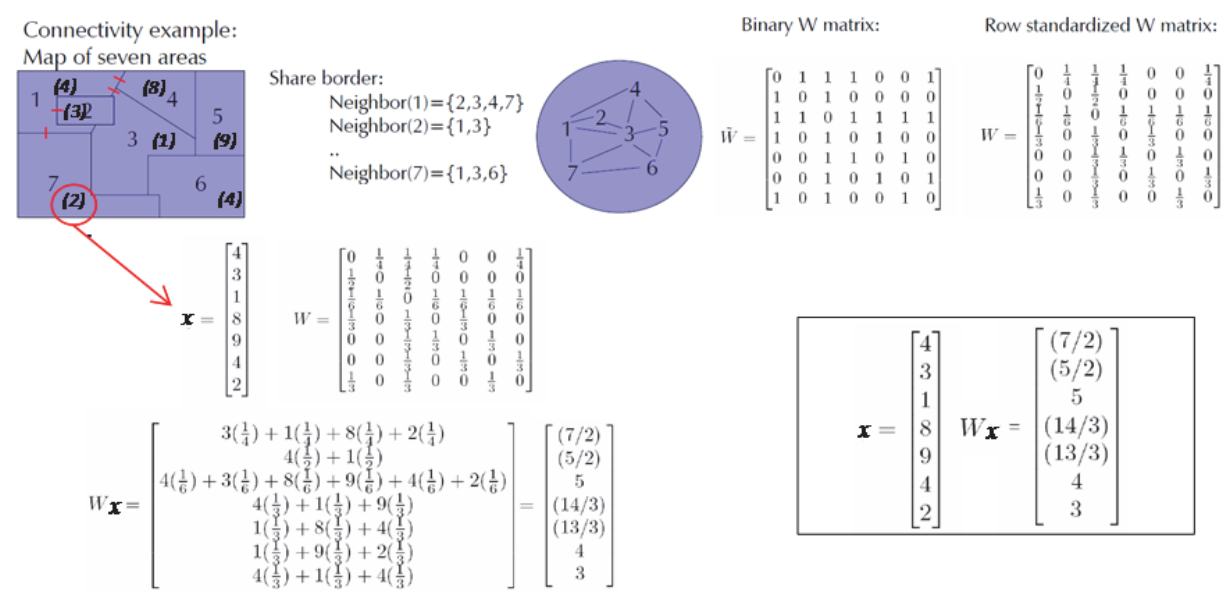

Figure 5.1 Example of Row Standardisation Method (Source: Feser and Sweeney 2006).

Before implementing a linear scale transformation method, we standardise the raw input values of $x, x_{i}$ into $X_{i}$ and $x_{\text {lagi }_{i}}$ into $X_{\text {lag }_{i}}$. For both $x_{i}$ and $x_{\operatorname{lag}_{i}}$, standardisations are based on the raw dataset of $x$; therefore, the mean and 
standard deviation (SD) of $x$ are applied to the following formulae, (Eq.(5.7) and (Eq. (5.8):

$X_{i}=\left(x_{i}-\bar{x}\right) / S D(x)$

$X_{\text {lag }_{i}}=\left(x_{\text {lag }_{i}}-\bar{x}\right) / S D(x)$

with the variables defined as follows:

$x \quad=$ is a set of raw input values of $x$

$\bar{x} \quad=$ mean of $x$

$x_{i} \quad=x$ in the location of $i$

$x_{\text {lagi }}=x_{\text {lag }}$ is the average of $x$ values on the neighbouring polygons of $i$

$S D(x)=$ standard deviation of all $x$

In the Moran's Scatter Plot, a scatter diagram between $X$ and $X_{\text {lag }}$ (also denoted as $W_{-} X$ in a Moran's Scatter Plot) for all locations of $i$ is generated, which is used to obtain the Moran's I index. In our model, we used these values as the spatial feature to be included in the Preference Modelling. As such, the traditional NSPM Preference Modelling becomes a Spatial Preference modelling (SPM). Specifically, we defined the local inequity $g_{i}$, or the gap values between a location $i$, as $X_{i}$, and its neighbouring units as $X_{\text {lag }_{i}}$ (Eq. (5.9), where a positive $g_{i}$ indicates high local inequity, 0 indicates equity and a negative $g_{i}$ indicates that the location $i$ has a better condition and no priority for allocation.

$g_{i}=X_{\operatorname{lag}_{i}}-X_{i}$

We then apply a linear scale transformation method to the local inequity $g_{i}$ in location $i$ to obtain the preference for allocation. Three standardisation procedures similar to NSPM (i.e., maximum, interval, and goal standardisation) are applied as discussed below.

Maximum standardisation in SPM produces a linear function between 0 and the highest score in the neighbouring units (Eq. (5.10 and Eq. (5.11).

We define benefit criteria for maximum standardisation of SPM as follows:

$$
P_{i}=W_{i j}\left[\frac{g_{i}}{\max \hat{g}}\right]
$$

The cost criteria for maximum standardisation of SPM are defined as follows:

$$
P_{i}=W_{i j}\left[\frac{(\min \breve{g})-g_{i}}{\max \hat{g}}+1\right]
$$

with the variables defined as follows: 
$P_{i} \quad=$ the priority score for unit $i$; the unit is a spatial target for resource location-allocation

$W_{i j} \quad=\quad$ the connectivity between $i$ and its neighbouring units of $j$, as in Figure 1

$\min \breve{g} \quad=$ minimum value of $g$ of neighbouring units $j$

$\max \hat{g}=$ maximum value of $g$ of neighbouring units $j$

The symbols ' $N$ ' and ' $"$ ' indicate that the max and min values are only obtained for all $g$ at all $j$ around the unit $i$, not for all $g$ in the dataset.

Interval standardisation in SPM produces a normalised score with a linear function between the absolute lowest score and the highest score in the neighbouring units $j$ (Eq. (5.12 and Eq. (5.13).

We define the benefit criteria of Interval Standardisation in SPM as follows:

$$
P_{i}=W_{i j}\left[\frac{g_{i}-(\min \hat{g})}{(\max \hat{g})-(\min \breve{g})}\right]
$$

The cost criteria of interval standardisation in SPM are defined as follows:

$$
P_{i}=W_{i j}\left[-\left(\frac{g_{i}-(\min \breve{g})}{(\max \hat{g})-(\min \breve{g})}\right)+1\right]
$$

Goal standardisation in SPM implies putting a constraint on the locationallocation process (Eq. (5.14 and Eq. 15). For example, the allocation may be restricted only to locations under the poverty line or within the range of $\min G$ and $\max G$. In the spatial-lag-based calculations, the allocation is restricted only to locations below the average value of neighbouring units, which will act as the poverty line, or the so-called local benchmark $G$. The expected result is that spatial inequity among units in neighbouring groups will decrease.

We define the benefit criteria of goal standardisation in SPM:

$P_{i}=\frac{W_{i j}\left(g_{i}\right)-\min G}{\max G-\min G}$

The cost criteria of goal standardisation in SPM are defined as follows:

$P=-\left(\frac{W_{i j}\left(g_{i}\right)-\min G}{\max G-\min G}\right)+1$ 
In our Preference Modelling, because the input for SPM is the gap calculation $g_{i}$, we apply the benefit criteria. Allocation is expected to target those areas with wider gaps from the benchmark value. If, for example, we set $G=0$, the objective is to obtain a new value that is closer to the average of the neighbouring polygons.

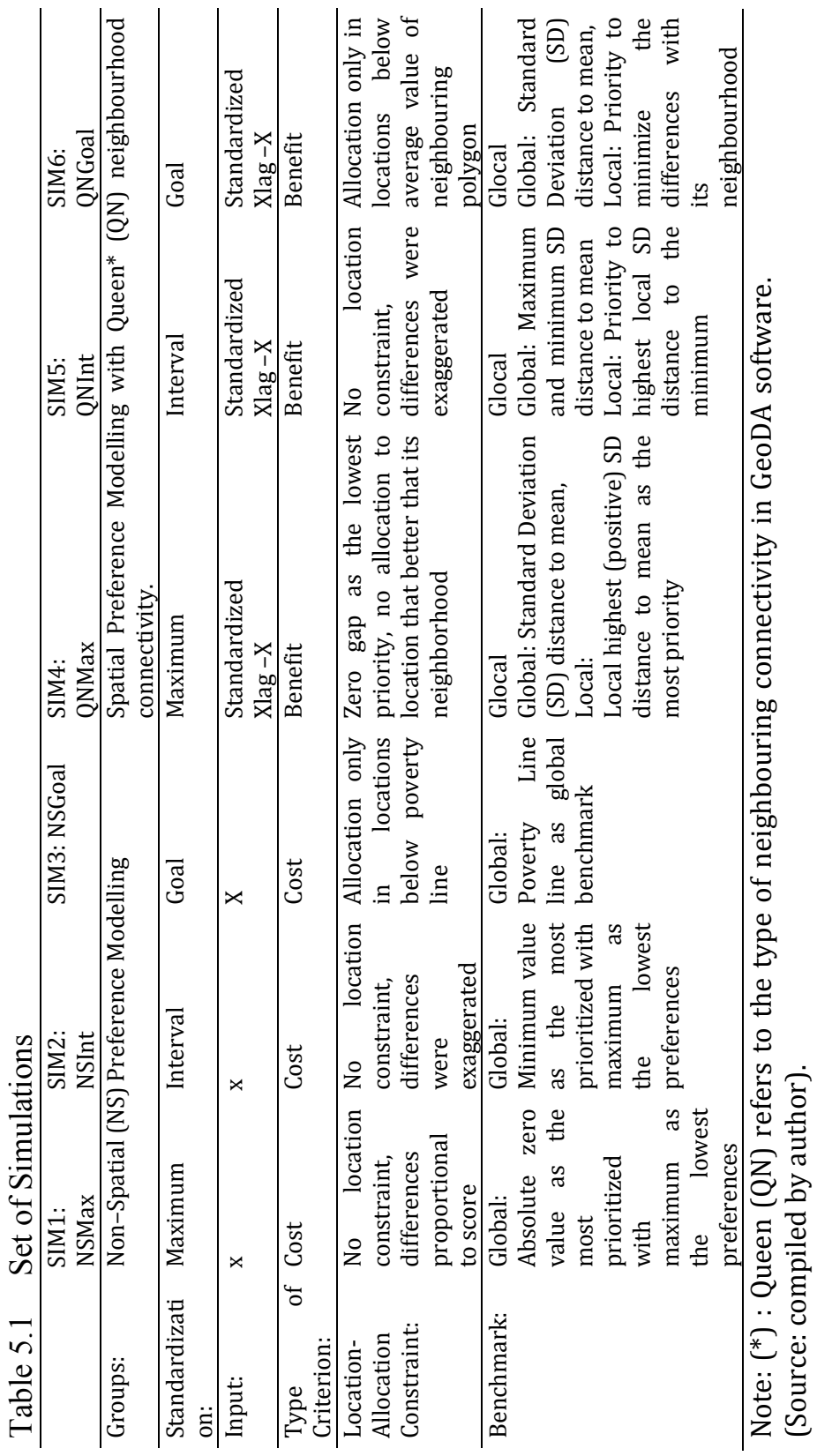


In the next section, we perform six simulations for the different types of Preference Modelling with the various standardisation methods. Table 5.1 Set of Simulations describes the simulations and their settings.

\subsubsection{Case Study}

Attention to local-level resource allocation is common in a country with decentralised fiscal and governance systems, such as Indonesia. To address spatial equity, over the years, Indonesia has executed various infrastructure programmes that target about 70,000 villages. These programmes aim to provide greater equality in economic opportunity in the various regions of the country. The village is the smallest spatial unit of administration in Indonesia.

Implementation of such a large national program that nonetheless targets the very local setting of the village requires a method to reconcile the process and outcome of detailed design of local infrastructure provision with national development objectives. As such, for various rural infrastructure programs, the government of Indonesia limits itself to national overviews of performance of infrastructure provision at the village level; it allows communities to decide on the detailed level of infrastructure planning, engineering and design. In practice, the government allocates funding resources to villages to conduct community-based infrastructure development programmes.

Several community-based infrastructure development programmes have been implemented, the most important being the Kecamatan Development Programme (KDP). The KDP, a community infrastructure programme financed by the World Bank (USD 1.2 billion), started in 1998 and seeks to alleviate poverty and improve local governance in rural communities. The programme, covering approximately 28,000 villages, has resulted in infrastructure developments such as roads, bridges, irrigation, drainage and clean water supplies. Kecamatan is the sub-district level of administration in Indonesia. There are more than 4,000 sub-districts in the country. On average, a sub-district contains some 20 villages and has a population of over 50,000 people. The KDP programme is among those that operate on the basis of a direct transfer of funds from the national level to the targeted villages. This system of transfer and disbursement in subdistrict and village development plans has led to the need for a robust resource allocation model that is able to handle the realisation of policy objectives but maintain accountability. 
The Special Province of Yogyakarta, Indonesia (Figure 5.2) is one of the targets of such development programmes. The study area is populated with approximately 3.4 million people. It consists of 438 villages, both urban and rural, with an average population of 5,632 inhabitants in each village. The average size of a village is about 724 ha, with a minimum of 26.5 ha in urban areas and a maximum of 2,890 ha in the more rural areas.

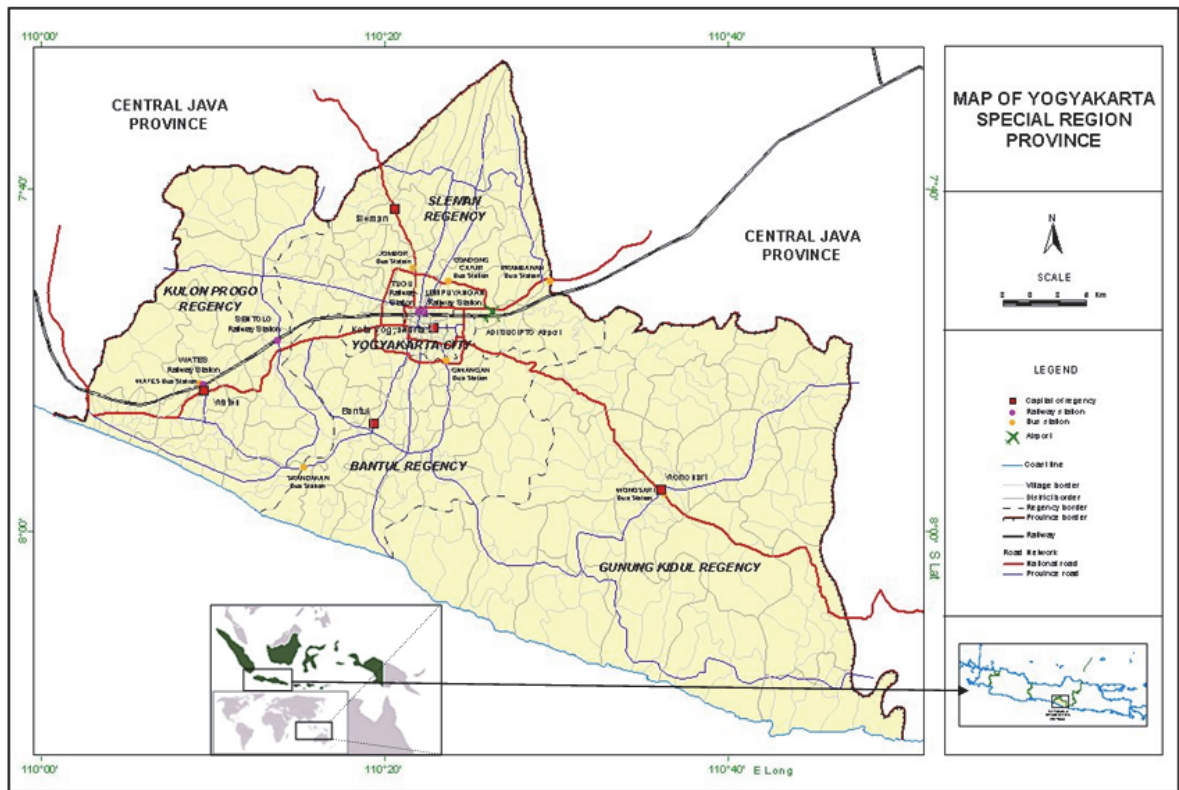

Figure 5.2 The Study Area is located in the Special Province of Yogyakarta, Indonesia, with 438 urban and rural villages. (Source: compiled by the authors based on BPS, 2006)

For this study, we use a village-level dataset from 2005 named PODES (BPS 2006). The dataset consists of approximately 400 attributes describing demographics, socio-economic activities and infrastructures for 438 urban and rural villages in the province. The demographic data used in this study are composed based on the number of households in each village. The infrastructure data that we use relate to transport infrastructure. These variables and their units of measurement are presented in Table 5.1. 
Spatial preference modelling for equity based resources allocation

\begin{tabular}{|c|c|c|c|c|}
\hline Variables & $\begin{array}{l}\text { Unit of } \\
\text { measurement } \\
\text { for the model }\end{array}$ & Data sources & $\begin{array}{l}\text { Unit of } \\
\text { measurement in } \\
\text { the data source }\end{array}$ & Data conversion \\
\hline \multicolumn{5}{|l|}{ Infrastructure: } \\
\hline Transport & $\begin{array}{l}\text { Opportunity to } \\
\text { mobility } \\
\text { (personkm). }\end{array}$ & $\begin{array}{l}\text { PODES code 9022, } \\
9023 \\
\text { Travel Time Budget } \\
\text { (TTB) study }\end{array}$ & $\begin{array}{lr}\text { distances } & \text { KM, } \\
\text { travel } & \text { time } \\
\text { Hour, } & \text { TTB } \\
\text { Hour) } & \\
\end{array}$ & $\begin{array}{l}\text { Average travel speed to } \\
\text { facilities multiplied by } \\
\text { available Travel Time } \\
\text { Budget }\left(9022 / 9023^{*} \text { TTB }\right)\end{array}$ \\
\hline \multicolumn{5}{|l|}{ Demographic: } \\
\hline Population & $\begin{array}{l}\text { Number of } \\
\text { households in } \\
\text { the village }\end{array}$ & PODES code 401c & $\begin{array}{ll}\text { (number } & \text { of } \\
\text { households) }\end{array}$ & Number of HH (401c) \\
\hline
\end{tabular}

(Source: compiled by author).

\subsubsection{Modelling allocation of transport infrastructure resources}

To evaluate the NSPM and SPM models in terms of their effectiveness in assessing spatial equity, we follow Deneulin (2008), Grosse, Harttgen et al. (2008), and Kakwani and Silber (2008) in their interpretations of the meaning and value of Sen's Capability Approach and the use of mobility as a non-income indicator to evaluate poverty and justice.

Capability is defined here as the capability to move around within the available time for travelling and given the prevailing average travel speed in the village'. The time available for daily travel, also referred to as the Travel Time Budget (TTB) (Mokhtarian and Chen 2004), is a concept based on the assumption that individuals have only a limited amount of time to travel per day.

With respect to the capability measure, we do not define the TTB as the actual time spent travelling in one day, as obtained from a travel diary survey, which is usually the case. Instead, we define the TTB as the minimum time budget available for travelling that reflects a basic human need for mobility (Marchetti 1993). Like the time budget that is needed for other activities (e.g., sleep or work), people need at least a one-hour time budget for travelling (Marchetti 1993; Schafer 1998). Those who spend more than one hour because of problems, including congestion, bad roads or poor transport service, are categorised as deprived according to the Capability Approach.

Moreover, in the context of village-level resource allocation, villagers are also categorised as not capable if their village does not have a sufficient level of transport infrastructure and services to reach the minimum level of mobility. This minimum level of mobility is defined here as a travelling 
distance that refers to the poverty line of mobility and is calculated by multiplying the minimum travelling speed by the available TTB. Villages residing under the poverty line can be labelled as deprived and thus merit higher priority in allocating resources.

To define the poverty line, the minimum travelling speed was set at 25 $[\mathrm{km} / \mathrm{h}]$. The decision to use a $25[\mathrm{~km} / \mathrm{h}]$ minimum is based on a survey of expected speeds on local roads in mountainous areas (TRB 2004). This figure is selected on the assumption of minimum capability preferred by the community in the most difficult topographic parts of the study area.

To measure travel speed in each village, we use the average travel speed from the PODES database. Travel speed $[\mathrm{km} / \mathrm{h}]$ for villagers is calculated by dividing the stated distance by the stated travel time from the village centre to (i) the capital of the sub-district, (ii) the capital of the district and (iii) the capital of the nearest district outside their own district. Most facilities (e.g., education, market, entertainment and administrative centres) are located in these capitals.

Again referring to the Capability Approach, to estimate the total opportunity of mobility in a village, we assert that one person in each household should be capable of movement for income-generating activities. This approach is in line with Golob and McNally (1997) and Barrios (2008), who have already suggested that a travel-behaviour analysis of heads of household is important for measuring the impact of transport infrastructure development in rural communities. For this reason, to allocate resource, we use the number of households in the village as a weighting factor. Figure 5.3 summarises the calculation procedure from the raw data into the capability of mobility. 


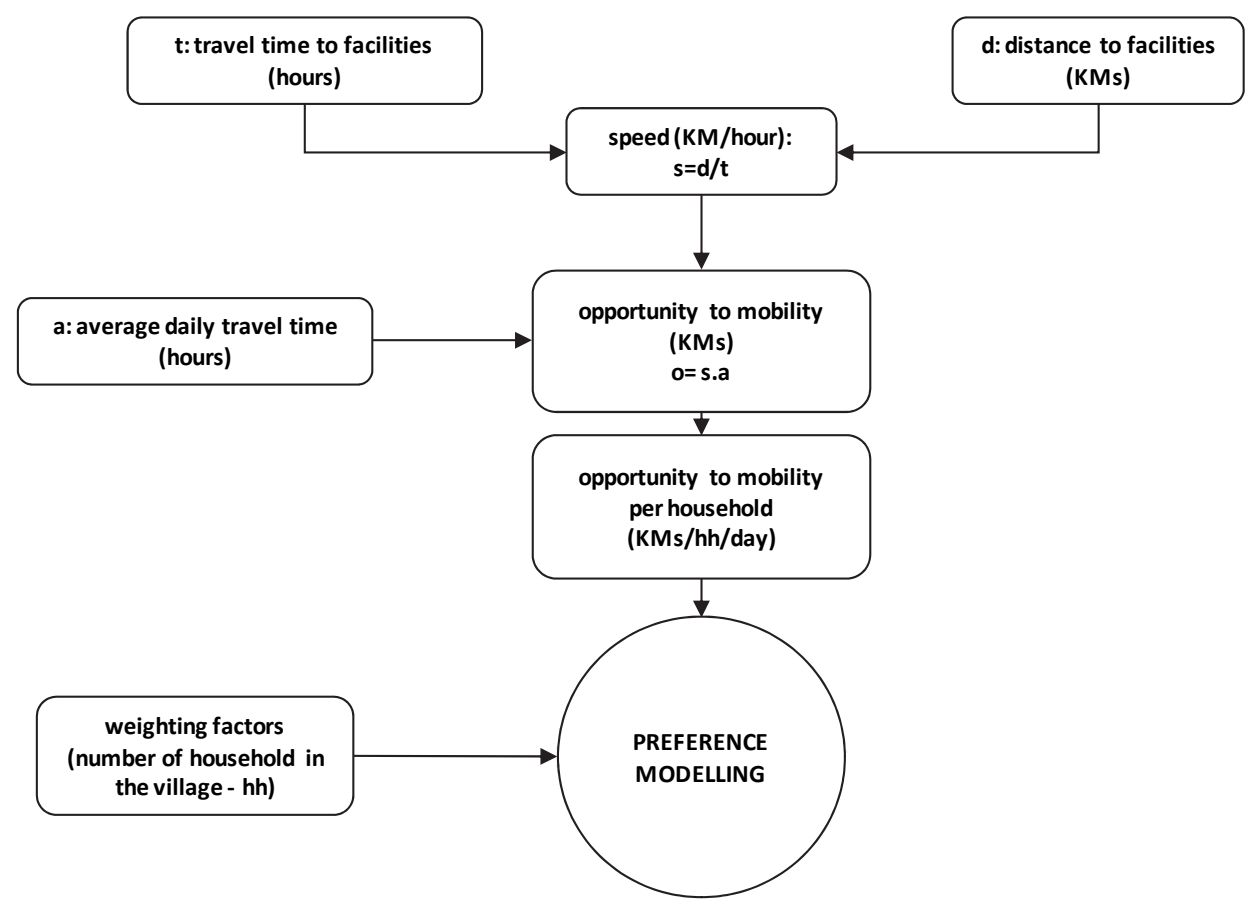

Figure 5.3 The calculation of raw data for Preference Modelling with mobility as a non-income indicator (Source: compiled by author)

\section{Procedure for location-allocation}

To test both the SPM and NSPM models, in combination with the result of the formulas in section 5.2.2, we allocate an additional $10 \%$ of total opportunity to mobility $\left(M_{t o t}\right)$ as compared to the initial condition in the various locations in the study area. A step-by-step procedure for locationallocation is explained below.

\section{Calculation of total daily opportunity to mobility}

The total daily opportunity to mobility is calculated on a household basis using the following equation (Eq. (5.16):

$M_{\text {tot }}=\sum_{i} h_{i} \cdot \bar{v}_{i} \cdot \bar{t}$

$M_{\text {tot }}=$ Total daily opportunity of distance to mobility in the study area [pers. $\mathrm{km}]$

$h_{i}=$ number of household in each village $\mathrm{i}$ from the PODES database

$\bar{v}_{i}=$ average travel speed in village $\mathrm{i}(\mathrm{km})$ from the PODES database

$\bar{t}=$ average daily travel time budget TTB (hours)

Estimating the average travel speed 
The total opportunity to mobility (Eq. (5.16) requires that an average travel speed be calculated for each village (Eq. (5.17):

$\bar{v}_{i}=\frac{\sum_{j=1}^{n}\left(t_{i j} / d_{i j}\right)}{n}$

$\bar{v}_{i}=$ average travel speed in village $\mathrm{i}[\mathrm{km} / \mathrm{h}]$

$t_{i j}=$ travel time in village $\mathrm{i}$ to facility $\mathrm{j}$ from the PODES database $[\mathrm{h}]$

$d_{i j}=$ distance from village $\mathrm{i}$ to facility $\mathrm{j}$ from the PODES database [km]

$\mathrm{n}=$ number of facilities calculated from the PODES database [unit]

\section{Resources to be allocated}

The amount of resources to be allocated is based on the percentage change or growth (or target growth of $\mathrm{T}$ ) in daily opportunity that is required (Eq. (5.18):

$$
A=T \cdot M_{\text {tot }}
$$

$\mathrm{A}=$ resources to be allocated [pers.km]

$\mathrm{T}=$ percentage of expected target growth from initial level of opportunity [\%]

$M_{t o t}=$ the total daily opportunity [pers.km]

\section{Household weighted priority}

To allocate resources, the number of households in each village is used to normalise the scores that resulted from the preference modelling, (Eq. (5.19):

$a_{i}=\frac{P_{i} \cdot H_{i}}{\sum_{i} P_{i} \cdot H_{i}}$

$P_{i}=$ score of priority of village $i$ from the preference modelling [0 to 1$]$, obtained with the formulas in section 2.2.

$H_{i}=$ number of households in village $i[\mathrm{hh}]$

$a_{i}=$ percentage of resources from the total available additional resources in the region to be allocated in village $i[\%]$

\section{Location-allocation at the village level}

Finally, the location-allocation for each village is calculated. The percentage of allocation for village $i$ (Eq.(5.20) is based on the household weighted priority from Eq. 19: 


$$
A_{i}=a_{i} \cdot A
$$

$A_{i}=$ allocated resources for village $i$ [pers.km]

$a_{i}=$ percentage of resource from the total available additional resources in the region to be allocated in village $i[\%]$

$A=$ allocated resources for the region [pers.km]

\subsubsection{Data Analysis}

\section{(1) Spatial equity analysis}

Inequity is often subjective and can generate disputes among stakeholders; therefore, a quantitative approach is required. To provide this quantitative description of the level of spatial equity generated by NSPM and SPM, we apply a spatial autocorrelation approach. Spatial autocorrelation analysis provides both location and attribute information and thus is a powerful analytical technique (Tsou, Hung et al. 2005).

This quantitative description is provided with Moran's I method, which is commonly applied for evaluating spatial equity (Lorant, Thomas et al. 2001; Tsou, Hung et al. 2005; Grubesic 2008). Moran's I is an estimate of Pearson's correlation coefficient among the values in location $i$ or $x_{i}$, with the average values of its neighbourhood $\left(x_{\text {lag }}\right)$ in a Moran Scatter Plot with a horizontal axes of $x_{i}$ and a vertical axes of $x_{\text {lag }}$. When all the $x_{i}$ are equal to $x_{\text {lag, }}$, there is no spatial inequity.

Moran's I provides a global index for spatial equity for the whole study area and does not indicate spatial variation in the subset area. However, a map of Local Indicators of Spatial Autocorrelation/Association (LISA) can be viewed as a direct extension of the Moran Scatter Plot. The resulting map indicates how spatial inequity varies over the study region. For example, a location with low values of $x_{i}$ but high values of $x_{\text {lag }}$ indicates an inequitable situation where the poor are surrounded by the rich. In this study, we use LISA maps to visualise where equity changed as a result of a different allocation model.

\section{(2) Policy interpretation on Moran's I}

The levels of equity as calculated through Moran's I in both the NSPM and SPM models provide a basis for policy interpretation. The interpretation of Moran's I is provided for the distribution of priority scores, as well as for the effect of location-allocation (Figure 5.4). 


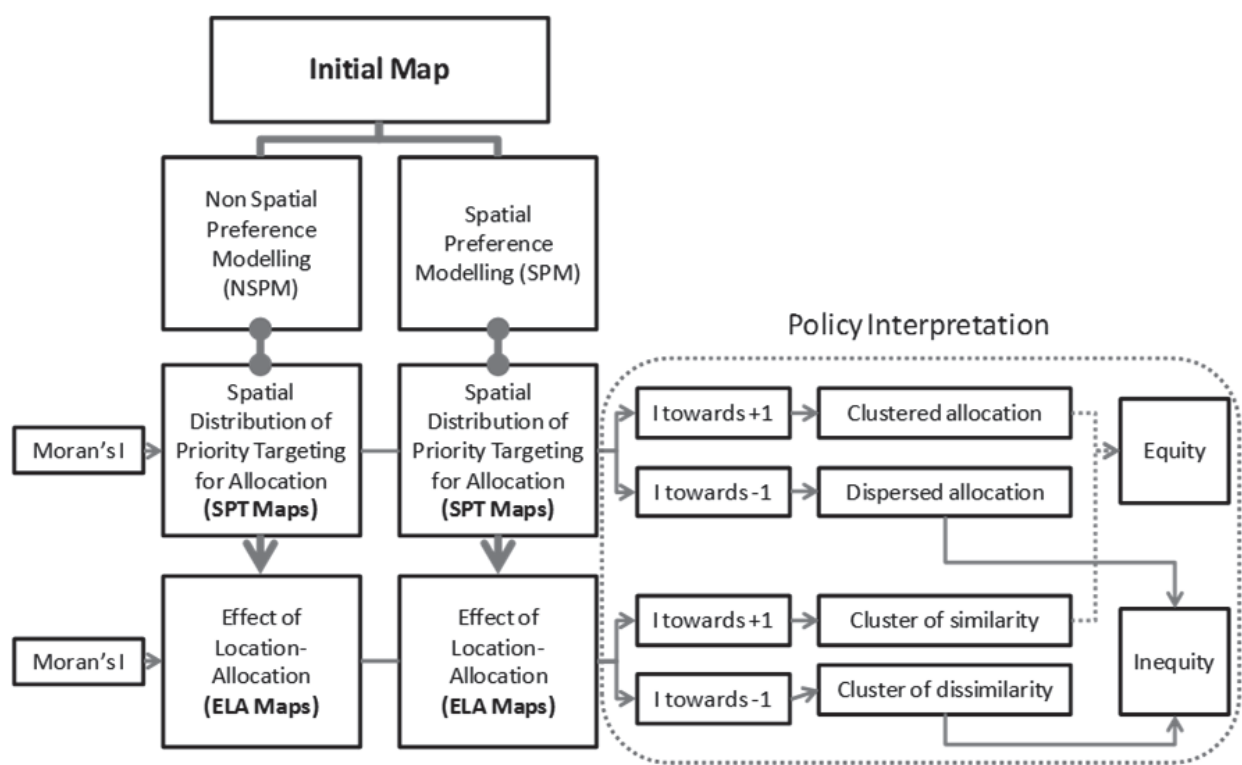

Figure 5.4 Policy Interpretation of simulation results (Source: compiled by author)

Following (Tsou, Hung et al. 2005), Moran's I is positive when nearby objects tend to be similar in attributes; a positive Moran's $I$ suggests an equitable distribution, with Moran's $I=1$ being the best equitable distribution. By contrast, Moran's I is negative when object values tend to be more dissimilar than what is normally expected. With respect to the spatial equity of a public facility, a negative Moran's I suggests an inequitable distribution, with Moran's $I=-1$ being the worst distribution. Moran's $I=0$ when attribute values are arranged randomly and independently in space (Tsou, Hung et al. 2005).

The interpretation of Moran's I for spatial equity can be deducted from two results of the simulation, i.e., the intermediate and end results. The first is the Spatial Priority Targeting (SPT), in which the models are used to prioritise the locations of allocation, whereas in the second result, i.e., the Effect of Location-Allocation (ELA), the new state of equity for the area as a whole is investigated. Both are further discussed below.

Spatial Priority Targeting (SPT) refers to the distribution of priority scores as determined by the Preference Modelling. The distribution of Moran's I scores can be interpreted to create to two general types of distributional patterns. 
1. Positive Moran's I (towards +1 ) of SPT implies a clustered allocation distribution. Spatial priorities are more concentrated in certain areas. This type of distribution provides a less equitable location-allocation in spatial terms.

2. Negative Moran's I (towards -1) of SPT implies a dispersed allocation over the region. The allocation is more spatially dispersed over the region. This type of distribution provides a more equitable allocation in spatial terms.

The Effect of Location-Allocation (ELA) can also be studied using Moran's I, based on the new state of equity after the distribution of resources to the priority locations.

1. Positive Moran's I (towards +1) of ELA implies a more equitable opportunity distribution. Clusters of greater similarity have been generated in the region. The equity among objects and their neighbourhoods is improved. Therefore, the allocation provides better spatial equity. In line with the expected outcome of the Capability Approach, the opportunity is more equally distributed in the region.

2. Negative Moran's I (towards -1) of ELA implies a cluster of dissimilarity. Clusters of greater dissimilarity have been generated. Therefore, the inequity among objects and their neighbourhoods is increased. The location-allocation has reduced the spatial equity of opportunity to mobility in the region.

\subsection{Results}

We find some variations in spatial equity from the NSPM and SPM models for both the Spatial Priority Targeting (SPT) and the Effect of LocationAllocation (ELA). These variations are discussed below.

For NSPMs with maximum and interval standardisations, the Moran's I values for both SPT and ELA are identical to the distribution of the initial maps before the allocation. All the values are identical, with Moran's $\mathrm{I}=0.4218$, which is quite surprising. This result therefore merits a more careful inspection and is further elaborated upon in the discussion section. The results of NSPM are presented in Figure 5.7 and Figure 5.9. The 'NS' in NSMAX and NSINT means 'non-spatial', whereas 'MAX' and 'INT' represent the type of standardisation. The initial maps before allocation are presented in Figure 5.5and Figure 5.9(Initial). 
In the NSPM with goal standardisation, the Moran's I of SPT increases, whereas after allocation, i.e. ELA, the Moran's I decreases. This result indicates a cluster of allocation priority in a certain part of the region and an increased level of cluster of dissimilarity in the region after allocation. See Figure 5.6 (PRNSGOAL) and Figure 5.8 (Goal) for the SPT of NSPM with goal standardisation. The 'PR' in PRNSGOAL means 'priority'. Figure 5.6 shows that NSPMs with maximum and interval standardisations have identical values to the initial map (0.4218) but different scatter plot patterns. The ELA is presented in Figure 5.7 (NSGOAL) and Figure 5.9 (Non-Spatial, Goal).

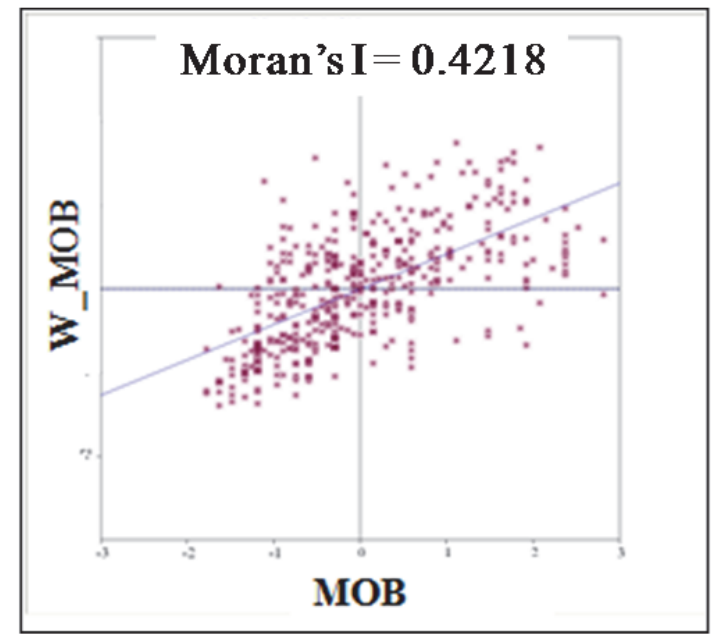

MOB : the standardized value of opportunity to mobility in a village $i$

W_MOB : spatial lag of opportunity to mobility of its neighbouring villages $i j$.

Figure 5.5 Initial Data before Simulation (Source: compiled by author). 


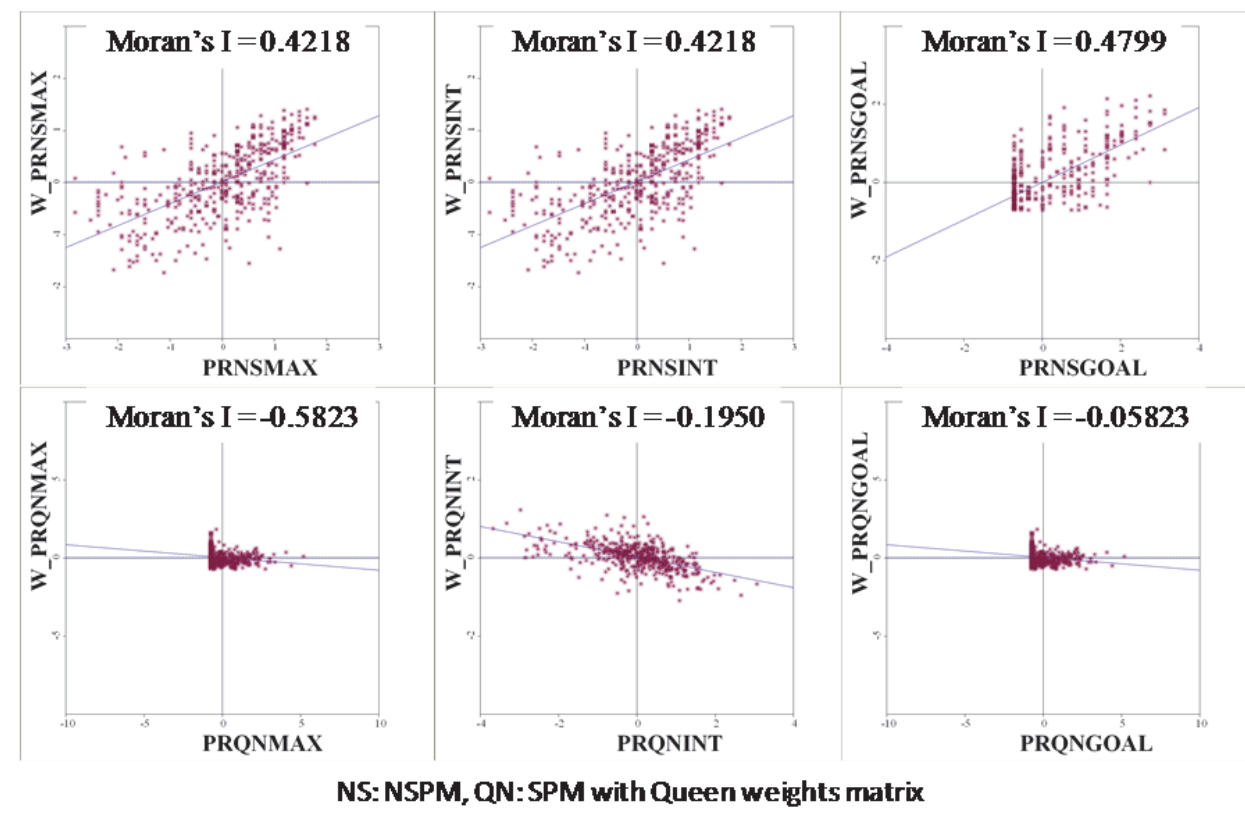

Figure 5.6 Spatial Priority Targeting, the distribution of allocation preferences in the simulations. (Source: compiled by author).

With SPM, we find negative Moran's I values on SPT for all standardisation methods, as shown in Figure 5.6 and Figure 5.8 ((PRQNMAX, I=-0.05823), (PRQNINT, I=-0.1950) and (PRQNGOAL, I=-0.05823)). 'PR' means priority, whereas ' $\mathrm{QN}$ ' represents the Queen neighbourhood connectivity with all adjacent (neighbouring) polygons, as commonly applied in spatial statistics software. After simulation (ELA), the Moran's I values increase (see Figure 5.7 (QNMAX, QNINT, and QNGOAL) and Figure 5.9 (Spatial, Maximum: $\mathrm{I}=0.5992$, Interval: $\mathrm{I}=0.4596$ and Goal: $\mathrm{I}=0.5992)$ ). The ELA for NSPMs with maximum and interval standardisations produce Moran's I values (0.4218) that are identical to the initial map. For both NSPM and SPM, the goal standardisations clearly present the changes of equity status. We also find that the SPMs with maximum and goal standardisations produce identical Moran's I values (Figure 5.6 PRQNMAX, PRQNGOAL). 


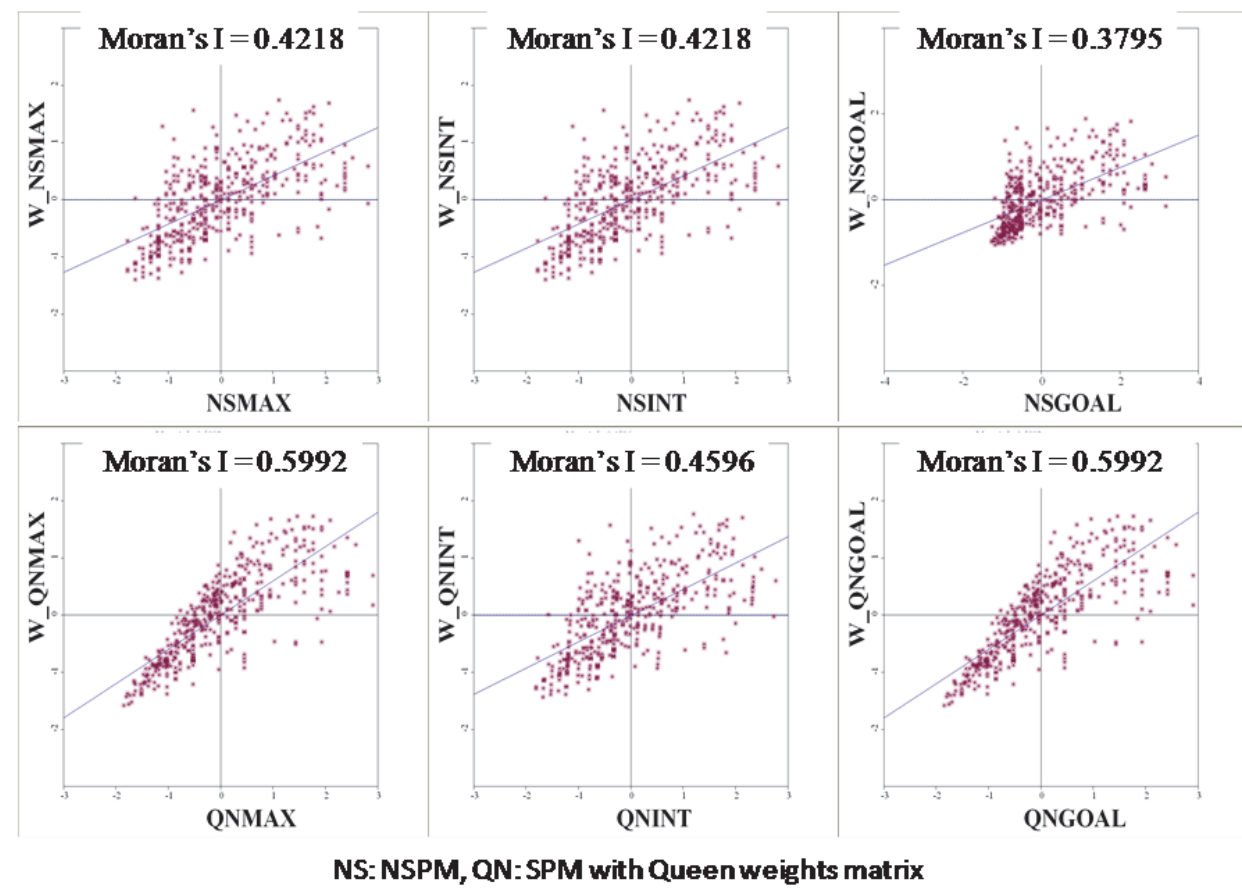

Figure 5.7 Effect of the Location-Allocation (Source: compiled by author).

Figure 5.8 and Figure 5.9 present a direct extension of the Moran's I Scatter Plot, which is visualised as a LISA map and a map showing statistically significant relationships with its neighbours. The map of statistical significance indicates how the neighbourhood variation of a unit forms a cluster of similarity or dissimilarity only for the clusters that are significant. These maps clearly demonstrate the differences between NSPM and SPM and show that the NSPMs with maximum and interval standardisations result in identical maps with Moran's I equal to the initial map.

In the maps of SPT (Figure 5.8), we found that the NSPMs with maximum and interval standardisations produce Moran's I values that are identical to the initial map but produce an inverted version of the initial map. As shown in Figure 5.8, we also found that the SPMs with maximum and goal standardisations produce identical Moran's I values as presented in Figure 5.6 (PRQNMAX, PRQNGOAL). Moreover, the SPMs produce more disbursed targeting over the region, as indicated by the negative Moran's I values. 

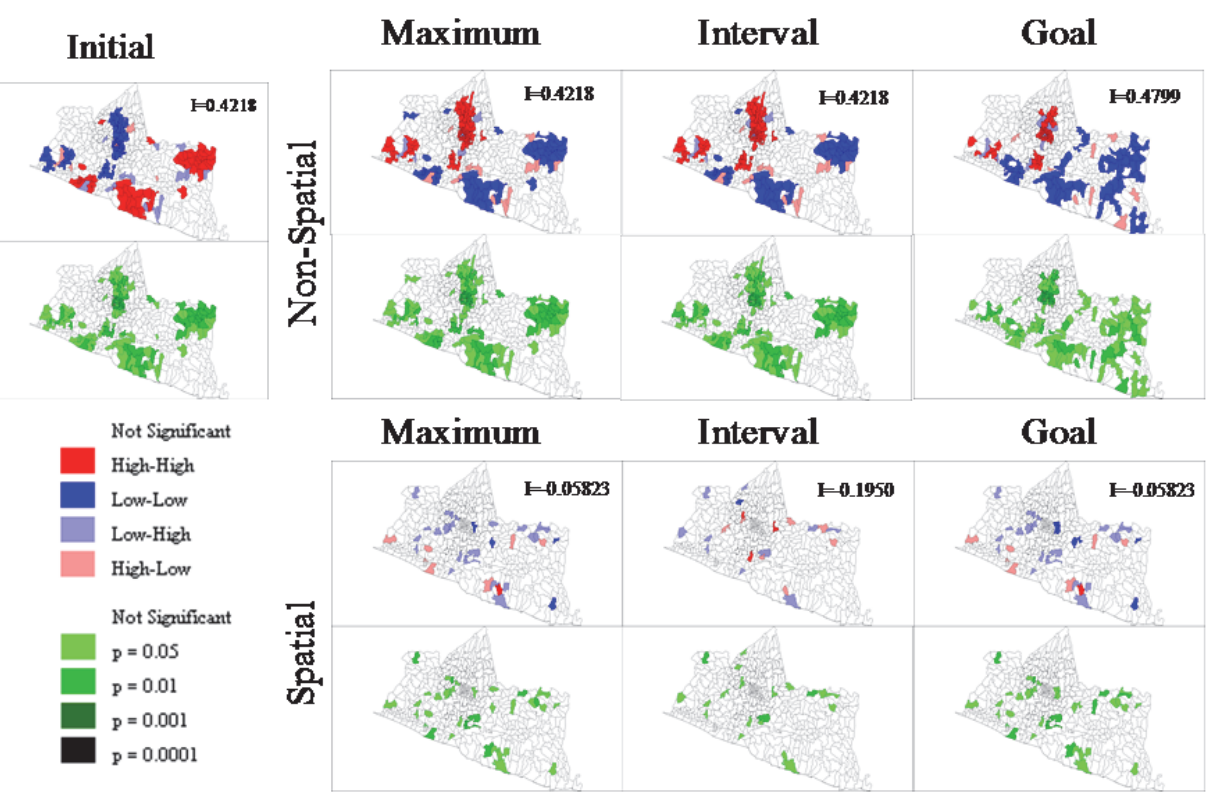

Figure 5.8 LISA Maps, the distribution of Spatial Priority Targeting (Source: compiled by author).
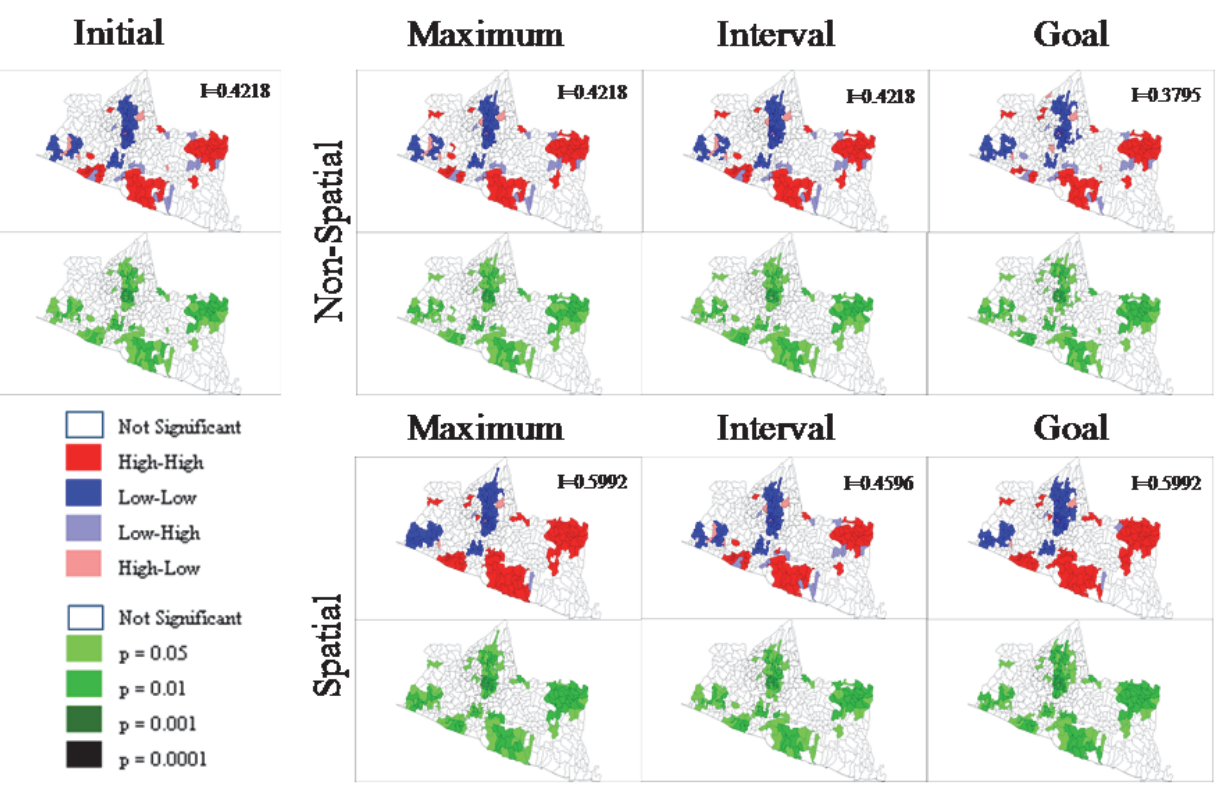

Figure 5.9 LISA Maps, before (Initial) and the Effect of Location-Allocation after Simulation (Source: compiled by author). 
Figure 5.9 clearly shows that the NSPMs with maximum and interval standardisations produce identical maps and identical Moran's I values compared with the initial map. SPM produces more clusters of similarity with positive Moran's I values.

In general, we find that SPM and NSPM and their standardisation procedures result in various degrees of equity, both in the SPT and ELA, and therefore, these results need to be carefully interpreted in the following discussion.

\subsection{Discussion}

In this study, we demonstrate that a new type of Spatial Preference Modelling (SPM) provides more spatially equitable resource allocations compared to a Non-Spatial Preference Modelling (NSPM). This finding is evidenced by the inclusion of a spatial autocorrelation approach within a Spatial Preference Modelling (SPM) that results in a more equitable distribution, as indicated by Moran's I values.

All the simulations with SPM, which include spatial neighbourhood comparisons, produce allocation priorities that are more equally distributed in the region and not only concentrated in certain area. This effect is indicated by negative Moran's I values of Spatial Priority Targeting (Figure 5.8). As a result, the spatial equity of the new distribution also increases, as indicated by increasing Moran's I values in the Effect of Location-Allocation (Figure 5.9). The results systematically and consistently address equity, as indicated quantitatively by the Moran's I values.

The results also indicate that SPM complies well with the equity feature in Sen's Capability Approach. Our conclusion is based on the fact that by allocating the same amount of additional resources, i.e., $10 \%$ of the initial condition, with SPM, the Moran's I changes towards a more equitable distribution (i.e., towards Moran's I=1). Figure 5.8 shows clearly that the Moran's I of the Effect of Location-Allocation changes towards I=1, from $\mathrm{I}=0.4218$ (Initial) to $\mathrm{I}=0.5992$ (SPM-Maximum) and $\mathrm{I}=0.4596$ (SPMInterval), providing evidence that SPM is able to provide a more effective measure for spatial equity.

The Moran's I of Spatial Priority Targeting (Figure 5.8) strengthens this evidence. In contrast to the Maximum and Interval NSPMs, which produce an inverted LISA Map of SPT with Moran's I values that are identical to the initial map and ELA, the maximum and interval standardisations for SPM 
produce distinct Moran's I and LISA Maps from the initial map for both SPT and ELA. Those SPTs in SPMs with negative I values ( $\mathrm{I}=-0.05823$ and 0.1950 ), which produce a dispersed allocation, provide additional evidence of the advantage of SPM in addressing equity.

In addition to demonstrating the advantages of SPM over NSPM, we find an unexpected result; it appears that the Maximum and Interval NSPMs are not sensitive to Moran's I. Figure 5.9 shows that for these NSPMs and 10\% additional opportunity distributed in the region, the Moran's I values of the SPT and ELA are identical to the initial value ( $\mathrm{I}=0.4218)$, indicating that the $10 \%$ allocation may increase opportunity in a region but that it does not elevate opportunity to a level that is equal to neighbouring communities. The NSPMs that do not consider local inequity always prioritise allocation to the most deprived locations and set priorities from highest to least. This behaviour explains why the SPT Moran's I values are identical to the initial value and why the resulting LISA maps are inverted compared to the initial map. In the inverted maps, the highest score in SPT indicates the lowest, or most deprived, location in the initial map. Figure 5.8 clearly reveals that the LISA maps of ELA, both from the Maximum and Interval NSPMs, are inverted versions of the initial map. The figure also demonstrates that the high-scoring villages surrounded by high-scoring villages (High-High areas) have been inverted into Low-Low areas, and vice versa, but these situations result in similar Moran's I values. This result also reveals that Moran's I is not sensitive to the degree of differences in allocation. Our findings imply a necessity to combine Moran's I with an additional measure of equity (e.g., a social equity measure) that is sensitive to the degree of differences among units.

The NSPM with goal standardisation provides the only ELA result that is not indicated by an inverted LISA map with an identical Moran's I value $(I=0.3795)$. This result is understandable given that goal standardisation specifically aims to prioritise target groups below the poverty line. However, the fact that the result provides a lower Moran's I value than the initial value $(\mathrm{I}=0.4218)$ requires further interpretation. The lower I value of 0.3795 (Figure 9, Goal) provides evidence that the Goal NSPM, which applies a global comparison and disregards local neighbourhood comparisons, can address social equity (the deprived village under the poverty line), but it does not systematically resolve spatial equity in the whole region.

The fact that Maximum and Goal SPMs provide identical results (Figure 5.8 and Figure 5.9) can be explained. The Goal SPM aims to minimise the gap among neighbouring units. Hence, we apply the gap to the mean rather 
than to the absolute poverty line. This approach is mainly used to accommodate for the sense of differences among neighbouring units as well as to obtain a sense of the differences within the study region. Similarly, the Maximum SPM also uses the absolute 0 as the reference of the goal, which produces the identical result between the Maximum and Goal SPMs.

The better performance of SPM over NSPM suggests that combining a global comparison with a local comparison in a so-called Glocal model is more effective for addressing equity. As we applied standardised $X$ and $W_{-} X$ scores in SPM (Eq. 8), all the formulae for SPM have been applied to Glocal comparisons. This approach enables us to address social equity and to systematically resolve spatial equity. Moreover, this Glocal modelling actually represents one of the important aspects of the Capability Approach (Sen 1980). The Capability Approach requires the accommodation of ideas of relative importance, which are related to the nature of society. SPM with a Glocal benchmark, which captures relative equity among neighbourhoods as well as the region as a whole, shows a workable application to operationalising Sen's Capability Approach for an equity-based resource location-allocation problem.

An alternative approach that includes a local benchmark, rather than a Glocal or Global one, can be used by applying Goal SPM with raw scores $(x$ and $\left.W_{-} X\right)$, instead of standardised $\left(X\right.$ and $\left.W_{-} X\right)$ scores. With the raw scores, we could apply the average raw values of the neighbouring units as the benchmark in Goal SPM with Benefit Criteria as $\max G$ (Eq. 14) and set the minimum value from neighbouring units as $\min G$ (Eq. 14). This approach allows us to address both social equity and, at the same time, to improve spatial equity in each neighbourhood. Moreover, the effectiveness of SPM might be further evaluated with other types of neighbourhood connectivity matrices (e.g., Rook). Selection of the type of connectivity should also consider the appropriateness to local conditions. Implementation of these ideas and their implication to spatial equity policy should be examined in future research.

We conclude that Spatial Preference Modelling is a reliable method for equitable resource allocation. All the simulations in SPM, which include a spatial relationship by taking into account not only global comparison but also local or neighbourhood comparison produce allocation priorities that give more equally distributed resources in the region. Again, this deduction provides a basis for establishing a new method for implementing Sen's Capability Approach into equity-based resource location-allocation. 


\subsection{Conclusions}

We conclude that the inclusion of a neighbourhood comparison in Spatial Preference Modelling (SPM) provides a more equitable resource locationallocation than NSPM. The SPM also provides an alternative way to accommodate the need of an efficiency-equity trade-off in a diverse region, such as the Special Province of Yogyakarta in Indonesia. This approach allows public officials to apply social and spatial equity criteria for decision making.

Moreover, the derivation of Sen's Capability Approach (CA) into a resource location-allocation procedure provides a new way of addressing the spatial equity of infrastructure provision. The CA in our case study provides the intermediate step towards resource allocation in terms of monetary or fiscal units.

Therefore, this study provides a new systematic approach for resource allocation that can be implemented in a GIS environment to support decision makers in distributing limited resources in an equitable manner. 


\title{
Chapter 6
}

\section{Equitable Distribution of Growth for Utilitarian and Non-Utilitarian Infrastructure Planning ${ }^{3}$}

\begin{abstract}
To simultaneously address social equity and spatial equity, we develop a new type of preference modelling to distribute infrastructure resources that takes into account neighbourhood inequity effects. We compare this so-called spatial preference modelling (SPM) with the more common nonspatial preference modelling (NSPM) in terms of their compliance to two distinct perspectives of welfare theory, i.e., utilitarian and non-utilitarian welfare theory. With respect to utilitarian theory, we apply a total utility equality approach, whereas for non-utilitarian equality, we conduct a curve dominance analysis to evaluate the effect on (1) pro-poor policy, (2) inequity and (3) prosperity. A case study for the Special Region of Yogyakarta in Indonesia is used to show the difference in the effectiveness of SPM and NSPM in resolving resource allocation problems in the fields of transportation, electricity, telecommunication and freshwater infrastructures, four fields of infrastructure that differ in terms of their typology (point, linear, plane and space), initial level of development and spatial inequity. The results confirm that SPM complies better with both welfare theories than NSPM. Moreover, the curve dominance analysis reveals that infrastructure characteristics and the level of development contribute to model effectiveness. Hence, the findings can contribute to a more effective policy for equitable growth.
\end{abstract}

Keywords: $\quad$ Preference Modelling; SDSS; Social Equity; Spatial Equity; Utilitarian; Non-Utilitarian; Infrastructure Planning; Indonesia

\footnotetext{
3 Published as:

Wismadi, A., M.F.A.M., Brussel, M.J.G., Zuidgeest, M,H,P., van Maarseveen., Equitable distribution of growth for utilitarian and non-utilitarian infrastructure planning, Infrastructure Complexity
} 


\subsection{Background}

A long-term inequitable distribution of resources in a country often results in all various social issues (e.g., crimes and social tension). Indonesia has also been challenged by both social and spatial inequality issues. Since 1997-1998, when massive riots demanding political reform led President Suharto to step down, these issues have been driving continuous governance reforms to be more decentralized and aimed at equitable welfare among regions and social groups.

Infrastructure service is one of the instruments for distributing welfare and addressing social and spatial equity (equality of opportunity). Many countries, including Indonesia, have the option to deliver infrastructure service through either a state monopoly or a market-driven procompetitive mechanism. Meanwhile, the global liberalization trend has shifted some public service provision into a more market-driven orientation, allowing private industry to compete.

Among the four infrastructure sectors discussed here, in Indonesia, the provision and management of transportation infrastructure is still led by the government, but the landscape of mobility is determined by private companies and vehicle industries. The electricity sector has been introducing private investment opportunities for energy production, but the monopoly of state-owned enterprises for energy distribution is maintained. Water infrastructure is provided through local government enterprises, but they are operating in a competitive environment with global bottled drinking water industries. Telecommunication has been reformed from a state monopoly into a full liberal market for mobile services. In this case, no single infrastructure asset is owned by government, and development is driven by market-oriented private investment.

The market-driven approach has been shown to be efficient (Zhang 2014), and it has resulted in more affordable services (Yigitcanlar and Lee 2014). However, the infrastructure roll-out tends to go to places where wealthy people or markets are concentrated (Sovacool 2013), thus leaving some areas and social groups unserved or underserved (Sager 2011). Meanwhile, state-owned enterprises, with their mandate for distributing equitable service among people and locations, including non-commercially feasible and remote areas, face difficulties setting cross-subsidy tariffs in a marketdriven environment to allow for rural investment. 
In such a case, market-driven policy has increased the problem of unequal service provision (Araral 2009) across people and spaces. Therefore, the government has reviewed the market-driven approach and applied measures to ensure a more equitable development. Such policies, that are implemented as so-called public service obligation (PSO) programs, e.g., for transportation, or universal service obligation (USO) programs, in the telecommunications and electricity sectors (i.e., the rural electrification program), have been strengthened with the introduction of the National Act No 25/2009 on Public Service to ensure equitable service among social groups and regions. These policy measures are managed by the government with funding support from industry and the state budget.

The attempt to reach an equitable welfare distribution through sector reforms and decentralized actions has been in place for almost two decades. However, inequity has continued to increase, as indicated by a rise in the Gini Index of income distribution from 0.335 to 0.413 between 1996 and 2013 (BPS 2014). This indicates that the implemented policies, being either "people centred" (as in market driven) or "place based" (addressing regional disparity) did not sufficiently address equitable growth. Decades of continuous inequity have also revealed the absence of proper information and decision mechanisms to allocate resources to target groups or locations. Such mechanisms are critical to support a resource distribution under a constrained budget, progress monitoring, and more importantly are a means to formulate effective policy for prioritizing allocation.

The knowledge of addressing equity issues in decision-making requires a theory of social choice and an applicable method of preference modelling that simultaneously addresses equitable social and spatial distributions. In decision support systems (DSS), such preference modelling (PM) refers to a routine that aims to model stakeholder preferences into priority making for selecting certain options, or to locate the allocation of resources (Tsoukias 1991; Perny and Roy 1992; Benferhat, Dubois et al. 2006; Piccolo and D’Elia 2008; Roberts and Tsoukiás 2009).

To address inequity issues, discussions on the concept of fairness in the distribution of resources and welfare have been going on for decades (Smith 1977; Sen 1980; Dworkin 1981; Dworkin 1981; Nussbaum 2003; Sen 2004; Sudgen 2006; Qizilbash 2011). For example, David Marshall Smith and Amartya Sen started the debate in which they questioned the moral philosophy of fairness behind the equality of distribution already in the late 1970s. 
Whereas Smith (1977) questioned the lack of moral concern in the geographical distribution of welfare, Sen (1980) argued that the established concept of equality, which is based on utilitarian theory, has limitations in securing fairness. The most serious limitation, he argued, is the non-compliance to pro-poor policy, particularly if the planner employs equality of marginal utility. This measure attempts to equalize the satisfaction (marginal utility) between the rich and the poor for each unit of additional resources. Naturally, the rich demand more than the poor, and as an implication, more resource goes to the rich.

The alternative measure in utilitarian theory is that of equality of total utility, where the planner aims to maximize the total utility of resource distribution (Maniquet 2004). In such a case, as the poor are more easily satisfied; priority is given to the poor to maximize the total utility.

Sen (1980) also introduced an alternative measure for a non-utilitarian model. He introduced a capability approach that aims to measure additional capability, instead of satisfaction, due to a distributed resource. Hence, a non-utilitarian would focus more on increased capability through the provision of equality of opportunity (Maniquet 2004).

Those approaches have provided a good basis for measuring equality among social groups, but less attention has been given to aspects of spatial inequity, i.e., to the measurement of equality between areas or regions. Most inequality measurements (Eliazar and Sokolov 2012), social welfare functions (Dolan and Tsuchiya 2009) and preference modelling (Domshlak, Hüllermeier et al. 2011) address only social equality, whereas spatial inequality can contribute to large problems for society, e.g., concentrations of crime (Wang and Arnold 2008) or increased health risks (Chandola 2012). Some previous works have tried to include such spatial features in resource allocation (Cloke, Milbourne et al. 2001; Chakhar and Mousseau 2007; Bissonnette, Wilson et al. 2012). However, these methods again do not look at social equity issues. Hence, using only one of these approaches, decisions may overlook the social or spatial dimension of the inequity problem.

To simultaneously address social and spatial equity, Wismadi, Zuidgeest et al. (2013) proposed a new type of preference modelling to allocate resources by explicitly taking neighbourhood inequity into account. Here, this spatial preference modelling (SPM) addresses equity not only among people but also across locations. In accordance with this concept, priority will be given to addressing the inequity of two persons at a closer distance than two others who have a similar level of inequality but live further 
apart. This model has been shown to be able to effectively address spatial equality in the case of transportation infrastructure. However, the compliance of the result to a more general moral philosophy of fairness, i.e., following Sen (1980), still needs to be investigated.

The purpose of this study is therefore to compare spatial preference modelling (SPM) with the more common non-spatial preference modelling (NSPM) for resource allocation in terms of its compliance to two distinct theories of welfare (i.e., utilitarian vs non-utilitarian welfare) and evaluate its practical implication to improve the effectiveness of resource allocation policy for infrastructure development.

The next section explains the methods for resource allocation and equity measurement. The third section reports the results of the simulation, and the fourth section discusses the important findings of this study and discusses the implications for policy implementation. The last section concludes.

\subsection{Methods}

We compare the compliance of SPM and NSPM to the principle of equity, as proposed in both utilitarian and non-utilitarian theories. To learn their practical implications, both preference modelling approaches are applied to resource allocation for four different types of infrastructure (i.e., roads, electricity, telecommunications and water). As shown in Table 6.1, each of them has a different network typology; i.e., roads: linear; electricity: linear; telecommunications: a combination of linear (fibre optic and copper fixed lines) and space (mobile networks); and water: a combination of linear (freshwater pipe) and space (ground water sources) all have different typologies. The simulation is developed for scenario-based rather than optimisation-based applications. Hence, a 'what if' type of question relating to policy objectives, is more appropriate rather than to provide the model user with the 'best' option under given criteria. However, to demonstrate how the algorithm is capable to perform iteration mechanisms toward an optimisation-based applications, a two-step iteration is also demonstrated and observed in this research. Hence, two what-if scenarios of simulation are performed, first by assigning one target growth applied in one simulation, then secondly, by assigning half of the target growth applied in a two-step iterative simulation.

With such purpose, the allocation model in this study aims to distribute a target growth of infrastructure service performance for each location rather than directly determine the amount of distributed resources, such as 
monetary units or construction materials. Resource allocation in this study refers to a percentage of the target growth of performance, which later could be achieved with increasing investment or operational expenditure to reach the targeted performance in the respected location. Here, we do not calculate the actual amount of resources that need to be allocated.

The spatial unit in this study is a village, the lowest administration unit, below a province or a district, for which we set a target of an additional level of service. The target in this experiment is a $10 \%$ growth from the current level of infrastructure performance. With the objective of addressing inequity, some villages receive more priority and an increased service level higher than $10 \%$, whereas others might receive less than $10 \%$ growth compared to the initial service level.

This allocation can be illustrated by looking at national level development policies, where a government-or politicians during election periodsoften declare a target economic growth of, for example, 10\%. This $10 \%$ growth is often cited as the "two-digit" optimistic target of national development (Yuan, Kang et al. 2008; Chen 2010; Ohana 2010). This aggregate target of $10 \%$ at a national or district level must somehow be implemented in lower administrative units. This target growth distribution should not simply be applied with $10 \%$ growth of each village because the poorest village would receive an absolute value that is lower than the $10 \%$ growth of the richest. If more resources are allocated to the rich than to the poor, the allocation would not comply with a sense of fairness.

Spatial preference modelling (both SPM and NSPM) has been formulated to give priority to the poor, and it aims to reduce the inequality amongst them. By introducing spatial proximity as the preference factor in SPM, the spatial patterns of the location of allocated resources will be distinct from NSPM. In SPM, more priority is given to addressing the inequality of two villages at a closer distance than two others at the same levels of inequality but located at a further distance. By contrast, in NSPM, the priority for growth will consider only the inequality level amongst villages and disregard the distance between the compared villages. The variations in the target growth distribution from the two models are the basis for comparing SPM and NSPM with respect to the effectiveness of achieving the objectives of utilitarian and non-utilitarian approaches.

The framework of this research is outlined into the three common stages of decision-making processes (Simon 1960), i.e., the intelligence (specify decision problems and objectives), design (generate an alternative 
solution) and choice stages (evaluate and recommend the solution), as summarized in Figure 6.1.

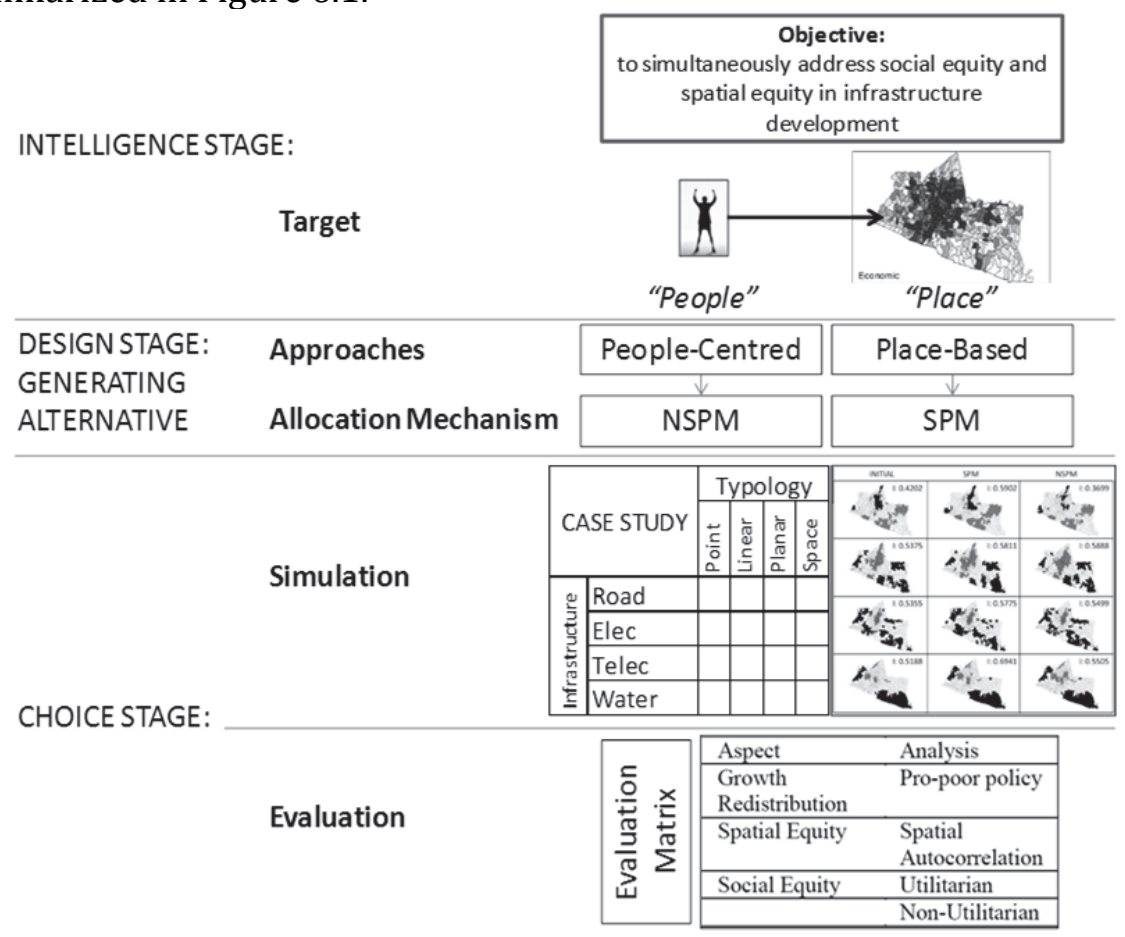

Figure 6.1 Research Framework

\subsubsection{Study area and data}

Indonesia is a vast archipelago that comprises over 17,000 islands form a land mass of 1,919,440 square kilometres populated by 253 million inhabitants (Rowley and Abdul-Rahman 2007). To move towards equitable growth, in addition to focusing on the main national infrastructure networks, various village-level programs are also implemented, e.g., a rural electrification programme (Outhred and Retnanestri 2015); started in the 1970s with more than USD 200 million annually) and a rural telecommunications USO program (since 2010 in more than 35,000 villages with approximately USD 500 million annually, which has been expanded with a Presidential Decree 96/2014 as the Indonesia Broadband Plan). In other sectors, such as roads and water supply, there are community-based infrastructure programmes, i.e., the Kecamatan Development Programme (KDP), which are financed by the World Bank (USD 1.2 billion), which began in 1998 and were aimed at 28,000 villages (Das 2015). Kecamatan is a sub-district administration level in Indonesia. There are more than 4,000 sub-districts in the country. On average, a sub-district contains 20 villages and has a population of over 50,000 people. 
Our study area, the Special Province of Yogyakarta, Indonesia (Figure 6.2), is one of the targets of those programmes. Populated with approximately 3.4 million people, it consists of 438 villages, with an average of 5,632 inhabitants each. The average size of a village is 724.43 ha with a minimum of 26.57 ha in urban areas and a maximum of $2,890.36$ ha in more rural areas (BPS 2006).

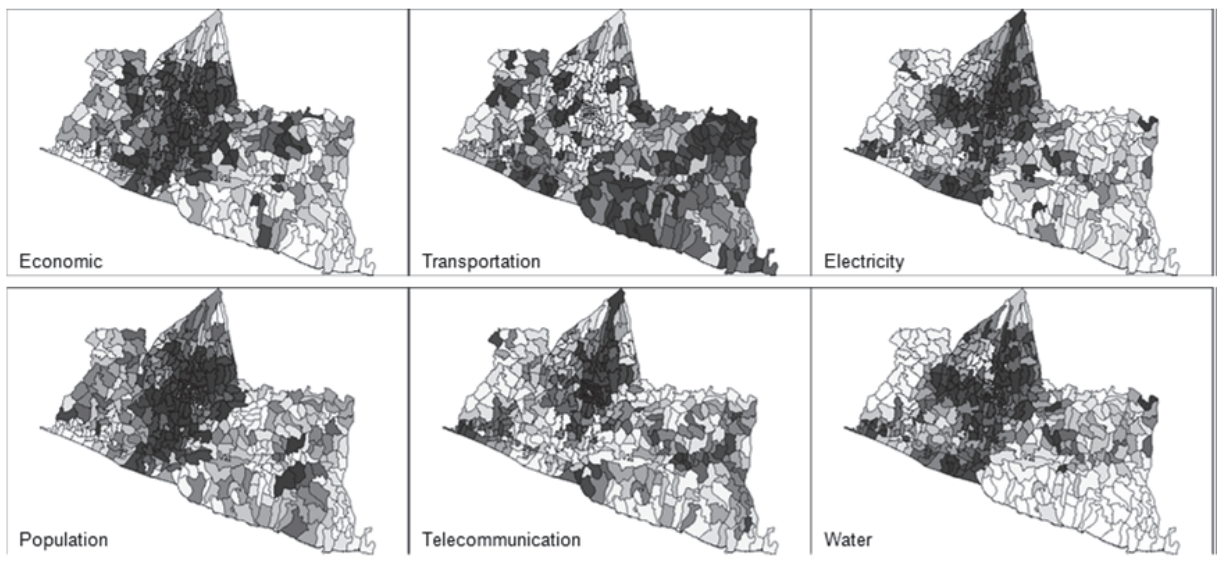

Legend: The dark colours represent villages with higher values or better infrastructure systems performance.

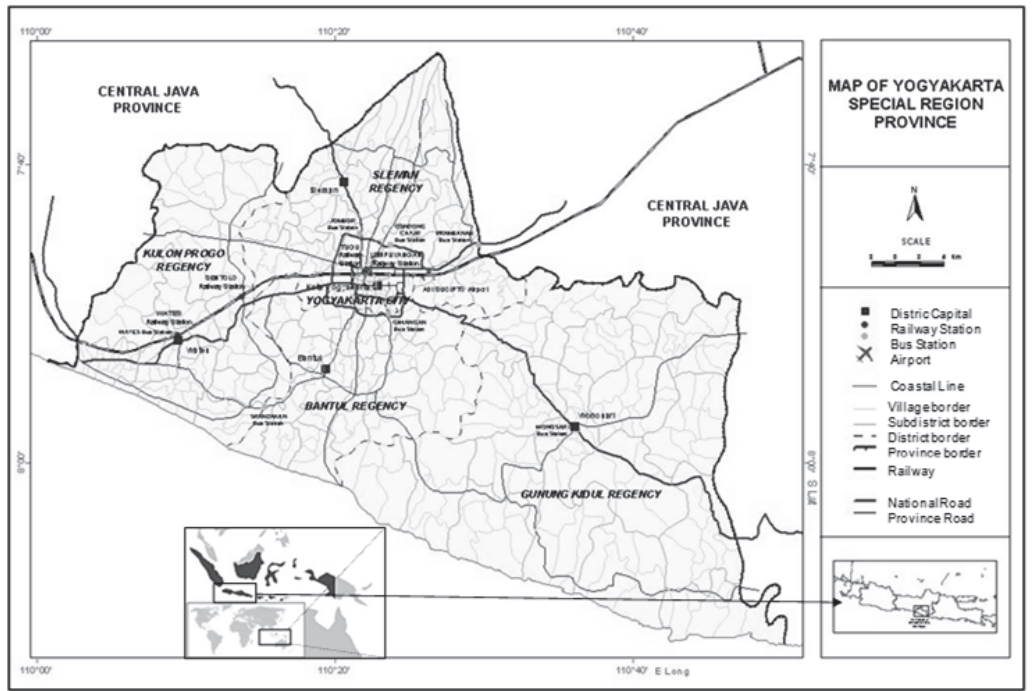

Figure 6.2 The Special Province of Yogyakarta, Indonesia, consisting of 438 urban and rural villages. Note: The urban area is at the centre of the radial road networks. The dark colours represent villages with higher values or better infrastructure system performance. 
We use a village-level dataset from 2005 called PODES (Potensi Desa/Village Potency; (BPS 2006), which consists of approximately 400 attributes linked to demographics, socio-economic activities and infrastructure, but we select only attributes that are relevant to infrastructure. These data and their units of measurement are presented in Table 6.1.

Table 6.1 The Data Set

\begin{tabular}{|c|c|c|c|c|c|}
\hline Types of data & $\begin{array}{l}\text { Unit of } \\
\text { measurement for } \\
\text { the model }\end{array}$ & $\begin{array}{l}\text { Data } \\
\text { sources *) }\end{array}$ & $\begin{array}{l}\text { Unit of } \\
\text { measurement in } \\
\text { the data source }\end{array}$ & $\begin{array}{l}\text { Data } \\
\text { conversion }\end{array}$ & $\begin{array}{l}\text { Systems } \\
\text { Characteristics }\end{array}$ \\
\hline \multicolumn{6}{|l|}{ Infrastructure: } \\
\hline Transport & $\begin{array}{l}\text { Average travel } \\
\text { speed }(\mathrm{km} / \mathrm{hr})\end{array}$ & $\begin{array}{l}\text { PODES } \\
\text { code } \\
9022, \\
9023\end{array}$ & $\begin{array}{l}\text { (distances KM, } \\
\text { travel time } \mathrm{HR} \text { ) }\end{array}$ & $\begin{array}{l}\text { Average } \\
\text { travel speed } \\
\text { to facilities } \\
(9022 / 9023)\end{array}$ & $\begin{array}{l}\text { The system is formed } \\
\text { by a linear type of } \\
\text { infrastructure. } \\
\text { Mobility relies on } \\
\text { private vehicle with } \\
\text { limited public } \\
\text { transport in urban } \\
\text { areas. Low } \\
\text { performance } \\
\text { indicates traffic jam } \\
\text { (urban) and a poor } \\
\text { state of infrastructure } \\
\text { (rural). }\end{array}$ \\
\hline Electricity & $\begin{array}{l}\text { Average } \\
\text { electricity } \\
\text { supply per } \\
\text { household (VA) }\end{array}$ & $\begin{array}{l}\text { PODES } \\
\text { code } 501\end{array}$ & (Electrified HHs) & $\begin{array}{l}\text { Weighted } \\
\text { average of } \\
\text { electricity } \\
\text { supply for } \\
\text { poor and } \\
\text { non-poor. }\end{array}$ & $\begin{array}{l}\text { The system is formed } \\
\text { by a linear type of } \\
\text { infrastructure. The } \\
\text { network is laid along } \\
\text { the road network. } \\
\text { High performance } \\
\text { indicates urban and } \\
\text { more developed } \\
\text { villages. }\end{array}$ \\
\hline Telecom & $\begin{array}{l}\text { Average data } \\
\text { transfer capacity } \\
(\mathrm{kbps})\end{array}$ & $\begin{array}{l}\text { PODES } \\
\text { codes } \\
904,911\end{array}$ & $\begin{array}{l}\text { (Connected HH } \\
\text { to fix line, } \\
\text { Mobile network } \\
\text { coverage) }\end{array}$ & $\begin{array}{l}\text { Weighted } \\
\text { average of } \\
\text { data transfer } \\
\text { capacity of } \\
\text { fixed line and } \\
\text { mobile } \\
\text { networks. }\end{array}$ & $\begin{array}{l}\text { The system is formed } \\
\text { by a combination of } \\
\text { linear and space types } \\
\text { of infrastructure. The } \\
\text { networks of linear } \\
\text { systems rely on fiber } \\
\text { optic (urban center) } \\
\text { and copper (urban to } \\
\text { sub-urban) along the } \\
\text { road networks. The } \\
\text { wireless mobile } \\
\text { networks extend a } \\
\text { space type of network } \\
\text { to reach market in } \\
\text { rural area.. }\end{array}$ \\
\hline Water & $\begin{array}{l}\text { Average } \\
\text { discharge } \\
\text { (litre/day) }\end{array}$ & $\begin{array}{l}\text { PODES } \\
\text { code } 608\end{array}$ & $\begin{array}{l}\text { (type of source, } \\
\text { electrification) }\end{array}$ & $\begin{array}{l}\text { Water } \\
\text { discharge } \\
\text { capacity } \\
\text { based on } \\
\text { each type of } \\
\text { source. }\end{array}$ & $\begin{array}{l}\text { The system is formed } \\
\text { by a combination of } \\
\text { point, linear and } \\
\text { space types of } \\
\text { infrastructure. Urban } \\
\text { area served by linear } \\
\text { public fresh water }\end{array}$ \\
\hline
\end{tabular}


Equitable distribution of growth for utilitarian and non-utilitarian infrastructure

\begin{tabular}{|c|c|c|c|c|c|}
\hline Types of data & $\begin{array}{l}\text { Unit of } \\
\text { measurement for } \\
\text { the model }\end{array}$ & $\begin{array}{l}\text { Data } \\
\text { sources }{ }^{*} \text { ) }\end{array}$ & $\begin{array}{l}\text { Unit of } \\
\text { measurement in } \\
\text { the data source }\end{array}$ & $\begin{array}{l}\text { Data } \\
\text { conversion }\end{array}$ & $\begin{array}{l}\text { Systems } \\
\text { Characteristics }\end{array}$ \\
\hline & & & & & $\begin{array}{l}\text { with option to private } \\
\text { wells as the water } \\
\text { source. Underground } \\
\text { water forms space } \\
\text { type of } \\
\text { infrastructures. Point } \\
\text { infrastructures are } \\
\text { found in dry areas } \\
\text { lacking water sources } \\
\text { (white cluster in } \\
\text { Fig.1). }\end{array}$ \\
\hline \multicolumn{6}{|l|}{ Demographic: } \\
\hline Population & $\begin{array}{l}\text { Number of } \\
\text { Population in } \\
\text { the village }\end{array}$ & $\begin{array}{l}\text { PODES } \\
\text { code } \\
401 a, b\end{array}$ & $\begin{array}{l}\text { (male pop, } \\
\text { female pop) }\end{array}$ & $\begin{array}{l}\text { Total } \\
\text { population } \\
401 \mathrm{a}+401 \mathrm{~b}\end{array}$ & $\begin{array}{l}\text { Population is } \\
\text { distributed in flat } \\
\text { areas which are } \\
\text { historically fertile or } \\
\text { recently served with } \\
\text { infrastructure, } \\
\text { especially road } \\
\text { networks and } \\
\text { economically more } \\
\text { developed areas. }\end{array}$ \\
\hline
\end{tabular}

\subsubsection{Calculations in Preference Modelling}

Preference models typically include a decision rule based on a difference of ranking between two objects. For comparing objects, the common linear scale transformation method is applied to convert the original criterion scores into standardized scores of utility (Xiang 2001; Malczewski 2004; Ananda and Herath 2009).

Such a method uses two types of preference criteria. The first one defines the benefit criteria, which refers to a stakeholder's preference for the highest raw score. (Higher scores are more preferable.) The second defines cost criteria, which refers to a stakeholder's preference to choose the object with the lowest raw score. (Lower scores are more preferable.)

\section{(1) Standardization without spatial neighbouring comparison features}

The three common types of standardization procedures are maximum, interval and goal standardization (Beedasy and Whyatt 1999; Xiang 2001; Phua and Minowa 2005; Ananda and Herath 2009). Maximum standardization ensures that the standardization values are proportional to the original values with the 0 values equal to the absolute 0 in the original score. Interval standardization produces a score that is normalized with a 
linear function between the absolute lowest score and the highest score, which implies a relative scale, and aims to exaggerate the differences. Exaggeration is often required when a slight value of differences is considered critical. Goal standardization is similar to interval standardization; however, it assigns specific reference points within the range of unit $i$ scores as an ideal or goal value and a minimum or maximum value acceptable by decision makers.

While we focus on the pro-poor objective, we want to exaggerate the differences between the poorest and the richest. Hence, we use interval standardization and apply the cost criteria to prioritize the poorest ((6.1).

$P_{i}=-\left(\frac{x_{i}-\min x}{\max x-\min x}\right)+1$

where:

$P_{i}=$ the priority score for unit $i$, the unit is a spatial target for resource location-allocation.

$x_{i}=$ the score of unit $i$

$\max x=$ the highest absolute score in dataset $x$

$\min x=$ the lowest absolute score in dataset $x$

(2) Standardization with inclusion of spatial neighbourhoodcomparison features

To include spatial equity measures, Wismadi et al. (2013) extended the standardization procedures into global, glocal and local spatial standardization. A global spatial standardization compares inequity with the reference of one value within the study region. Accordingly, the glocal spatial standardization measures the inequity with the average value from the region. Local spatial standardization then focuses on addressing inequity among neighbouring units.

Here, we aim to address local inequity. Priority is given to the unit with the highest neighbouring inequality score, with absolute 0 as a reference. When unit $x$ has higher performance than its neighbouring units, we set the level of inequality as 0 , meaning that we will not prioritize the allocation of resources to this unit.

We describe the neighbouring values of $x$ at village $i$ as the spatial lag variable $W_{-} x_{i}$. Spatial lag refers to a lag or value differences of the same variables on its connected neighbouring location. Connectivity is defined by physical connectivity (e.g., the availability of bridges or roads between villages), spatial proximity (distance) or another type defined in the connectivity rule. Hence, spatial lag is calculated by averaging all values of 
neighbouring polygons of $x_{i}$ using a neighbourhood connectivity rule for the weights $W_{i j}$, that represent connectivity between neighbouring units of $j$; i.e., $W_{i j}=1$ if locations $i$ and $j$ are adjacent or connected and zero otherwise (also $W_{i i}=0$ because as a village cannot be adjacent to itself).

Because we prefer to allocate to a unit that has higher gaps than its neighbour, we apply the benefit criteria of local maximum standardization as follows:

$P_{i}=W_{i j}\left[\frac{x_{\operatorname{lag}_{i}}}{\max x_{\text {lag }_{i}}}\right]$

$P_{i}=$ the priority score for unit $i$, the unit is a spatial target for resource location allocation.

$W_{i j}=$ represents the connectivity between $i$ and its neighbouring units of $j$

$x_{\text {lagi }}=$ denotes the local inequity of $W_{-} x_{i}-x_{i}$; however, if $W_{-} x_{i}-x_{i},<0, x_{\text {lagi }}$ will be defined as 0 .

$\max x_{\text {lagi }}=$ denotes the maximum local inequity of $W_{-} x_{i}-x_{i}$.

\subsubsection{Procedure for location-allocation}

We use the priority-score for unit $i, P_{i}$, obtained from preference modelling, to allocate target growth for each respective unit. To locate the allocation, the scores from the preference modelling are weighted with the population in each village $((6.3)$ :

$a_{i}=\frac{P_{i} \cdot Q_{i}}{\sum_{i} P_{i} \cdot Q_{i}}$

$P_{i}=$ score of priority of village $i$ from the preference modelling ( 0 to 1$)$, obtained with equations (1) and (2)

$Q_{i}=$ population of village $i$ (population)

$a_{i}=$ percentage share of the sum of total additional resources in the region allocated to village $i(\%)$

To obtain equitable growth, with the given $10 \%$ growth, we first sum the total additional absolute values from all villages, as $A$, and then, those amounts are redistributed to each village according to the priority score $\left(a_{i}\right)$ from equation (6.3). Generally, some villages (the poorer villages) obtain more than $10 \%$ of the initial allocation, whereas for richer villages, a lower percentage is provided.

Finally, the location-allocation for each village $i$ is provided with: 
$A_{i}=$ allocated absolute value of improved level of service for village $i$ (the units refer to performance indicators in Table 6.3)

$a_{i}=$ percentage share of the sum total additional resources in the region allocated to village $i(\%)$

$A=$ sum total additional absolute values of improved level of service from all villages from the region (the units refer to performance indicators in Table 6.3)

Figure 6.3 summarizes the location-allocation mechanism applied for both NSPM and SPM,

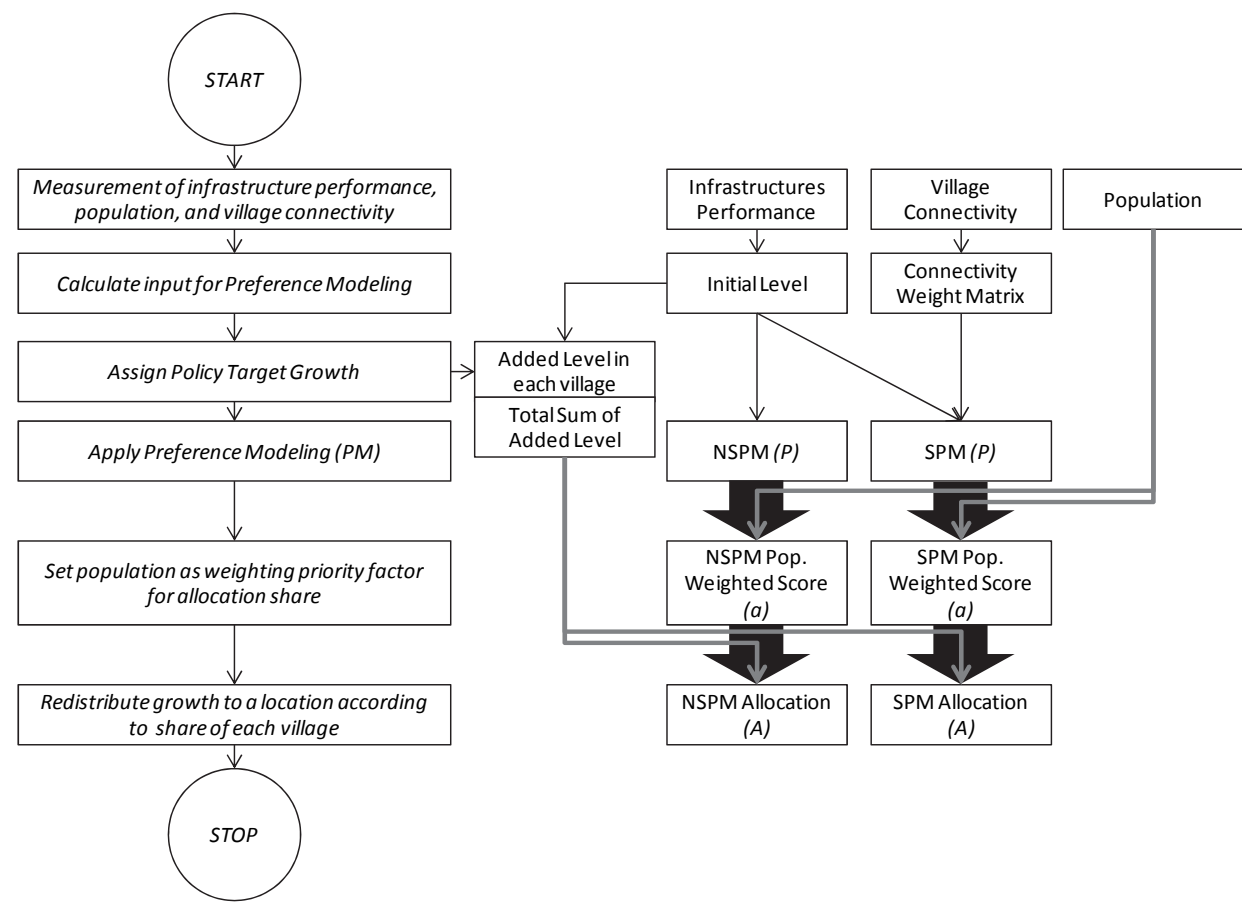

Figure 6.3 Procedure for Location-Allocation Mechanism.

\subsubsection{Equity measurement}

\section{(1) Spatial equity analysis}

We apply a spatial autocorrelation approach to evaluate spatial equity. This approach simultaneously addresses both location and attribute information, thus creating a powerful analytical technique (Tsou, Hung et al. 2005). Here, we use Moran's I method, which is commonly applied for 
evaluating spatial equity (Lorant, Thomas et al. 2001; Tsou, Hung et al. 2005; Grubesic 2008). Moran's $I$ is positive when nearby objects tend to be similar and suggests an equitable distribution, where Moran's $I=1$ is the most equitable distribution. On the contrary, Moran's $I$ is negative when the object values tend to be more dissimilar than what is normally expected, with Moran's $I=-1$ being the most inequitable distribution. Moran's $I=0$ when attribute values are arranged randomly and independently in space.

A direct extension of the Moran scatter plot can be viewed as a map of the Local Index of Spatial Autocorrelation (LISA; (Anselin 1995). The resulting map locates the clusters of similarity (spatial equity) or dissimilarity (spatial inequity).

\section{(2) Total utility to measure utilitarian equality}

With utilitarian theory, the equality objective is to maximize the total utility. Hence, a higher total utility indicates compliance with the objective. This measurement is done by estimating the marginal utility or satisfaction to one additional unit of resource and summing up the total utility generated by the distributed resource.

Referring to the Arrow-Pratt relative risk aversion formula (Damodaran 2008), we apply the first derivative of utility to the wealth of the log utility function of $U=\ln (W), U^{\prime}=1 / W$ to measure how utility changes as wealth $(W)$ changes. Hence, the estimate of marginal utility $U^{\prime}$ or $\mu U$ for an amount of allocated resources $Q$ at village $i$ with an existing level of available resources (wealth) of $X$ is:

$$
\mu U_{i}=Q_{i} / X_{i}
$$

With this formula, the same amount of $Q$ will result in a lower $\mu U$ at a higher level of $X$. The total utility (TU) ((6.6) can then be calculated by summing the product of $\mu U$ and the number of households $(H)$ in village $i$. The total utility for two or more distributions can then be compared.

$$
T U=\sum_{i=1}^{i=n} \mu U_{i} . H_{i}
$$

\subsubsection{Curve dominance analysis for non-utilitarian equality measure}

The non-utilitarian approach evaluates changes in the level of opportunity and the effect on the poor and the rich using curve dominance analysis. The analysis employs a graphical method to compare distributional curves, as 
in (Son and Kakwani 2008), formed by ordering the index from the worst off to the best off (Sen 1980). Curve dominance analysis can visually be interpreted in combination with its quantitative measure, e.g., the Lorenz Curve with the Gini Index (UNDP 2008).

To measure the equality of opportunity, a poverty line is required to indicate the basic capability needed and to decompose distribution patterns into areas below and above the poverty line (Yitzhaki 2002).

Pen's Parade is one graphical method that introduces a poverty line (Pen 1971). The curve represents a parade of every person in the economy walking by, as if in a parade, arranged by order of income, with the lowest incomes (dwarfs) at the front and the highest (giants) at the back (UNDP 2008). With a poverty line, we can calculate the number of poor people (poverty incidence) and the situations of the poor (gaps) and the rich (surpluses).

To accurately measure the sense of equity, with reference to the poverty line, the calculation should recognize the sense of severity of poor people and the enjoyment of surplus by rich people. Recognition of this asymmetric shape of the poverty gap on the poor side versus the prosperity surplus on the wealthy side is important in equity measurement (Berrebi and Silber 1989)

To meet this requirement, we propose a new graphical method: a derivation of Pen's Parade into a parade of gaps and surpluses, as described below.

Let $y_{1}, y_{2}, \ldots, y_{n}$ be the individual incomes of $n$ income-receiving units arranged such that $y_{1} \leq y_{2} \leq \ldots \leq y_{n}$, in which case, rank $\left(r_{y}\right)$ of the lowest income is 1 , and that of the highest income is $n$. Then, graphically, we modify Pen's Parade by applying the translation $y=y_{i}-z$, where $z$ represents the poverty line. Next, for the left part of the curve (with the negative values), we apply the reflection of the curve with the horizontal axis. As a result, we obtain a modification of Pen's parade as a parade of gaps (on the left-hand side) and surpluses (on the right-hand side) in a V-shaped curve.

To enable curve comparison, the rank $\left(r_{y}\right)$ on the horizontal axis is transformed as cumulative share of the population; hence, it shows the percentages of the population below the poverty line (the poor) and above the poverty line (the rich). 
To recognize the asymmetric shape of gaps and surpluses, as suggested by Berrebi and Silber (1989), we then normalize both parts of the V-curve in two different ways. For the left-hand part, i.e., the gaps, we use:

$Y p_{i}=\left(z-y_{i}\right) / y_{i}$ or $Y p_{i}=\left(z / y_{i}\right)-1$

The variable $Y p_{i}$ reflects the effort that "the poor" should exert to reach the poverty line. This normalized value of gaps also reflects the level of severity.

The right-hand side of the $\mathrm{V}$-curve, i.e., the surpluses, are normalized with: $Y r_{i}=\left(y_{i}-z\right) / z$ or $Y r_{i}=\left(y_{i} / z\right)-1$

Here, $Y r_{i}$ reflects the extra opportunities enjoyed by "the rich". This normalized surplus indicates the prosperity level. The original and modified Pen's parade are illustrated in Figure 6.4.
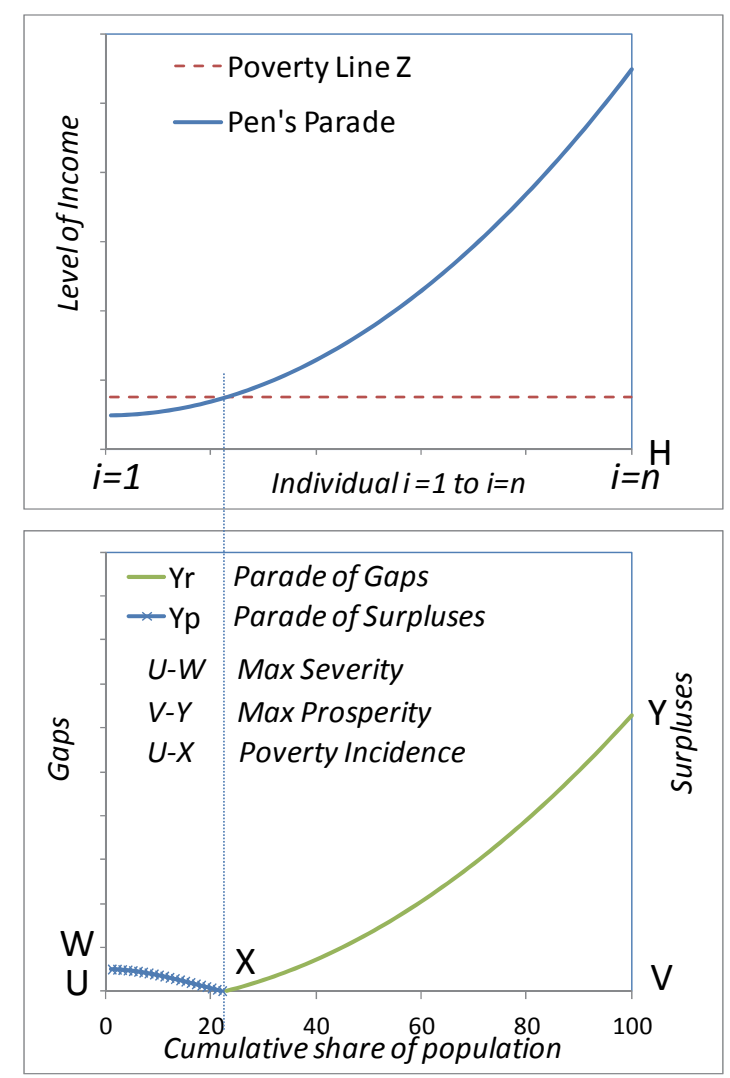

Figure 6.4 Original Pen's parade (above) and V-curve parade of gaps (Yp) and surpluses (Yr; below). 
In this paper, we limit the evaluation of the effect on pro-poor policy, inequity and prosperity. Hence, the selected indicators are poverty incidence, poverty severity, inequality among the poor, inequality among the rich, and prosperity (see Table 6.2).

Table 6.2 Indices of non-utilitarian equality measure

\begin{tabular}{lll}
\hline No & Indices & Descriptions \\
\hline 1 & Poverty Incidence & Percentage of "the poor" (population living under poverty line Z) \\
\hline 2 & Poverty Severity & $\begin{array}{l}\text { Maximum severity burden by the poorest (unit in utils, which is a } \\
\text { hypothetical unit measuring satisfaction), representing the amount of } \\
\text { additional effort for the poorest to reach the poverty line }\end{array}$ \\
\hline 3 & Poor Inequality & Gini inequality among "the poor". \\
\hline 4 & Rich Inequality & Gini inequality among "the rich". \\
\hline 5 & Prosperity & $\begin{array}{l}\text { Maximum prosperity enjoyed by the richest, representing the amount of } \\
\text { benefits for the richest above the level of poverty line. }\end{array}$ \\
\hline
\end{tabular}

To set the poverty line, we use the standard of the minimum service level in the Ministry Decree for Settlement and Regional Infrastructure No 534/KPTS/M/2001, USO Program 2009 and the Pricing Category of Electricity from SOE (PLN; Table 6.3). Toward the capability of incomegenerating activity, we set the poverty line at the service level for domestic activities. We also assume that people living in the same village have equal levels of opportunities.

Table 6.3 Minimum Service Level of Domestic Activity as the Poverty Line

\begin{tabular}{llllll}
\hline Infrastructure & Performance Indicators & References & $\begin{array}{l}\text { Basic } \\
\text { Service }\end{array}$ & $\begin{array}{l}\text { Domestic } \\
\text { Activity }\end{array}$ & $\begin{array}{l}\text { Income } \\
\text { Generating } \\
\text { Activity }\end{array}$ \\
\hline Transport & $\begin{array}{l}\text { Average travel speed } \\
\text { (km/hr) }\end{array}$ & $534 /$ KPTS/M/2001 & 10 & 15 & 20 \\
\hline Water & Discharge (ltr/day) & $534 /$ KPTS/M/2001 & 30 & 125 & 220 \\
\hline Telecom & $\begin{array}{l}\text { Data transfer capacity } \\
\text { (kbps/pop) }\end{array}$ & $\begin{array}{l}\text { USO Program BTIP, } \\
\text { 2009 }\end{array}$ & 14.4 & 28.8 & 56 \\
\hline Electricity & $\begin{array}{l}\text { Electricity supply per } \\
\text { household (VA) }\end{array}$ & TDL PLN & 30 & 450 & 2200 \\
\hline
\end{tabular}

\subsection{Results}

This section reports the comparison of SPM and NSPM to allocate the "10\% growth target" in two what-if scenarios; $(1 \times 10 \%)$ and $(2 \times 5 \%)$ simulations. It reviews the pro-poorness of the growth redistribution, reports the spatial equity evaluation and finally reflects on the compliance of preference modelling to moral philosophy in utilitarian and non-utilitarian welfare theories. The results are outlined using the evaluation matrix in Table 6.4. 
Equitable distribution of growth for utilitarian and non-utilitarian infrastructure

Table 6.4 Evaluation Matrix

\begin{tabular}{llll}
\hline Aspect & Analysis & Measure & Indicators \\
\hline $\begin{array}{l}\text { Growth } \\
\text { Redistribution }\end{array}$ & Pro-poor policy & $\begin{array}{l}\text { Pro poor growth } \\
\text { redistribution }\end{array}$ & $\begin{array}{l}\text { Higher average of redistributed } \\
\text { growth }\end{array}$ \\
\hline Spatial Equity & $\begin{array}{l}\text { Spatial } \\
\text { Autocorrelation }\end{array}$ & $\begin{array}{l}\text { Cluster of similarity or } \\
\text { dissimilarity }\end{array}$ & $\begin{array}{l}\text { Higher Moran's I index that } \\
\text { indicate cluster of similarity }\end{array}$ \\
\hline Social Equity & Utilitarian & $\begin{array}{l}\text { Maximize total utility } \\
\text { equality }\end{array}$ & $\begin{array}{l}\text { Higher summation of marginal } \\
\text { utility }\end{array}$ \\
\hline & Non-Utilitarian & $\begin{array}{l}\text { Effectiveness to } \\
\text { Poverty reduction }\end{array}$ & Lower Poverty Incidence \\
\hline & & Equality of allocation & Lower Poverty Severity \\
\hline & & Lower Rich Inequality \\
\hline & & Effectiveness to & Higher Maximum Prosperity \\
\hline
\end{tabular}

In terms of the pro-poorness of the allocation, the comparison of the level of redistributed growth reveals that with $10 \%$ growth, the SPM indicates a higher level of redistributed growth for all types of infrastructure than with NSPM, as shown in Table 6.5 . The results of both $(1 \times 10 \%)$ and $(2 \times 5 \%)$ based simulations also consistently provide similar finding.

Table 6.5 Average Redistributed Growth

\begin{tabular}{rrrrr}
\hline & Growth: & $1 \times 10 \%$ & Growth: & $2 \times 5 \%$ \\
\hline Sectors & SPM & NSPM & SPM & NSPM \\
\hline ROAD & $17.7 \%$ & $15.0 \%$ & $8.8 \%$ & $7.5 \%$ \\
\hline ELECT & $13.1 \%$ & $11.3 \%$ & $6.6 \%$ & $5.6 \%$ \\
\hline TELEC & $52.2 \%$ & $40.1 \%$ & $26.3 \%$ & $20.1 \%$ \\
\hline WATER & $17.3 \%$ & $14.8 \%$ & $8.7 \%$ & $7.4 \%$ \\
\hline
\end{tabular}

A redistribution of growth, which is much higher than $10 \%$, indicates that the preference model successfully distributes most of the growth to poorer groups. In Table 6.5, the telecommunications and water infrastructures require a redistributed growth much higher than $10 \%$, which indicates a high level of social inequity, and the poorer groups demand more than the regional target growth. The higher value in SPM also indicates that addressing social inequity in a location with a neighbourhood disparity could increase the average of redistributed growth. This result indicates that more attention should be given to spatial inequity.

\subsubsection{Effect on Spatial Equity}

To compare the initial level of spatial equity and the changes due to SPM and NSPM, Figure 6.5 shows LISA maps and its Moran's I values. It indicates the locations of spatial inequity (e.g., low-high, the poor surrounded by the rich, or high-low, the rich surrounded by the poor) and the locations of spatial equity among the rich (high-high) or among the poor (low-low). 
In general, SPM results in higher Moran's I values (closer to 1) than NSPM. The $2 \times 5 \%$ scenario also indicate that SPM systematicaly improve the spatial equity. The improved equity with SPM is logical; it aims to focus more on addressing spatial inequity. On this ground, it can be said that SPM better locates a poor connection or missing link of inter-village infrastructures.

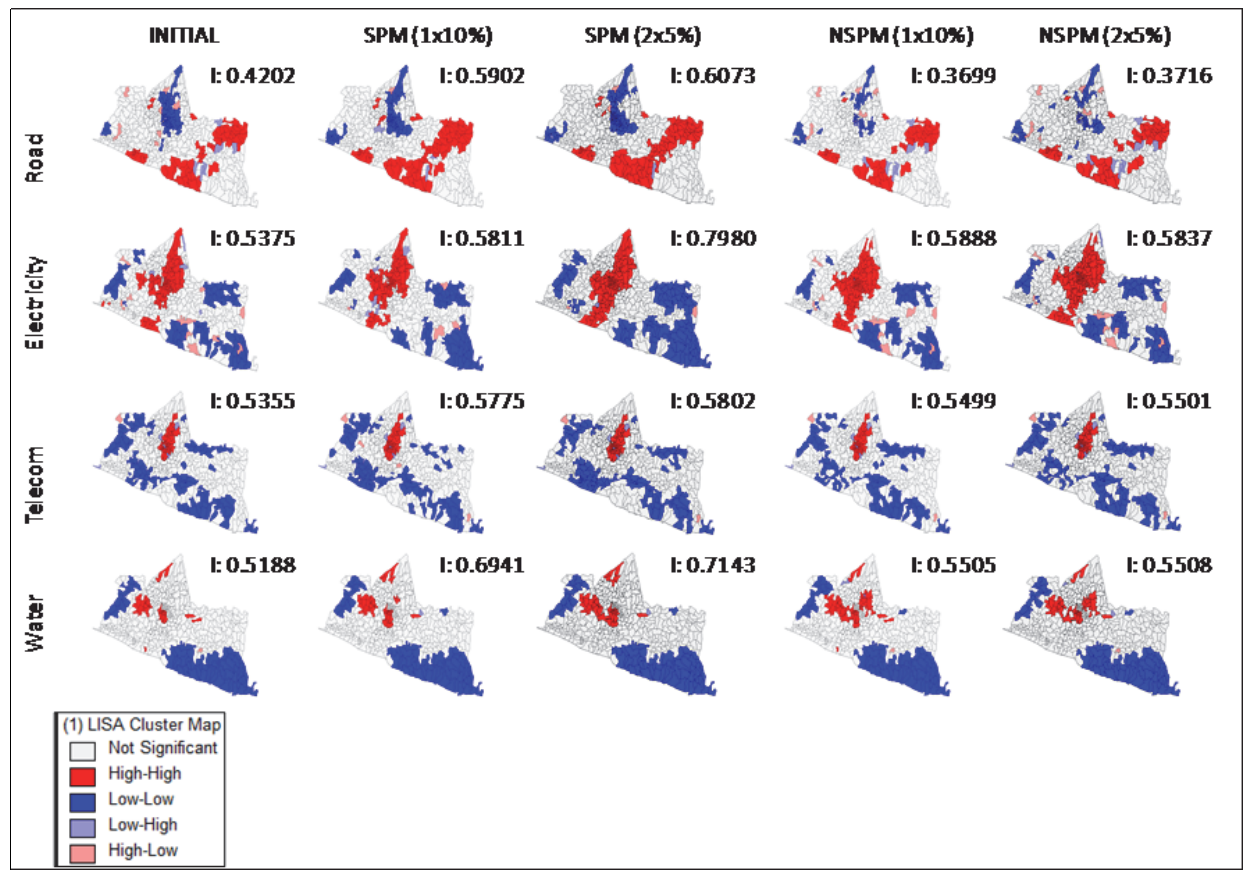

Figure 6.5 Spatial equity at the initial level and after allocation with SPM and NSPM. Note: LISA, blue (or black in a b/w colour) represents low-low, red (or dark grey in a b/w colour) represents high-high, and Moran's I discloses that in general, spatial PM is more effective to address spatial equity.

\subsubsection{Effect on Social Equity}

\section{(1) Utilitarian}

Under utilitarian equity, with a $10 \%$ growth redistribution, the SPM also results in a higher sum total of marginal utility to all types of infrastructure, as shown in Table 6.6. Only a minor variance is found in water sector under $2 \times 5 \%$, which indicates group of villages that severely lacking of water clustered in similar location as shown in LISA map. Such situation makes SPM that seeks for neighborhood inequity is less senstitive than NSPM. Moreover, a lower result on $2 \times 5 \%$ simulation indicates that people 
satisfaction is higher to a distribution which provided in one delivery than two.

Table 6.6 Utilitarian Total Equality

\begin{tabular}{rrrrr}
\hline & Growth : & \multicolumn{2}{c}{$1 \times 10 \%$} & \multicolumn{2}{c}{ Growth: } & \multirow{2}{*}{$2 \times 5 \%$} \\
\hline Sectors & SPM & NSPM & SPM & NSPM \\
\hline ROAD & 222,764 & 201,067 & 184,256 & 183,320 \\
\hline ELECT & 108,390 & 104,879 & 100,323 & 100,042 \\
\hline TELEC & 450,157 & 399,967 & 359,916 & 338,996 \\
\hline WATER & 153,582 & 138,290 & 131,164 & 132,113 \\
\hline
\end{tabular}

With $10 \%$ growth, the SPM generates a higher total utility. Hence, in general, the SPM performs better than the NSPM. This effect corresponds with the result on growth averages. In a utilitarian, context the total utility indicates that SPM is the preferred choice of target beneficiaries.

\section{(2) Non-Utilitarian}

\section{Graphical Result of Curve Dominance Analysis}

The curve comparison (Figure 6.6) shows continuous and discontinuous lines, which, respectively, indicate distinctive patterns of SPM and NSPM. For clarity, the initial situation (before allocation) is not presented in the graph. The results of $1 \times 10 \%$ and $2 \times 5 \%$ show similar patterns. Using the curves, an intuitive interpretation of poverty incidence, its severity and inequality problems can be obtained. 

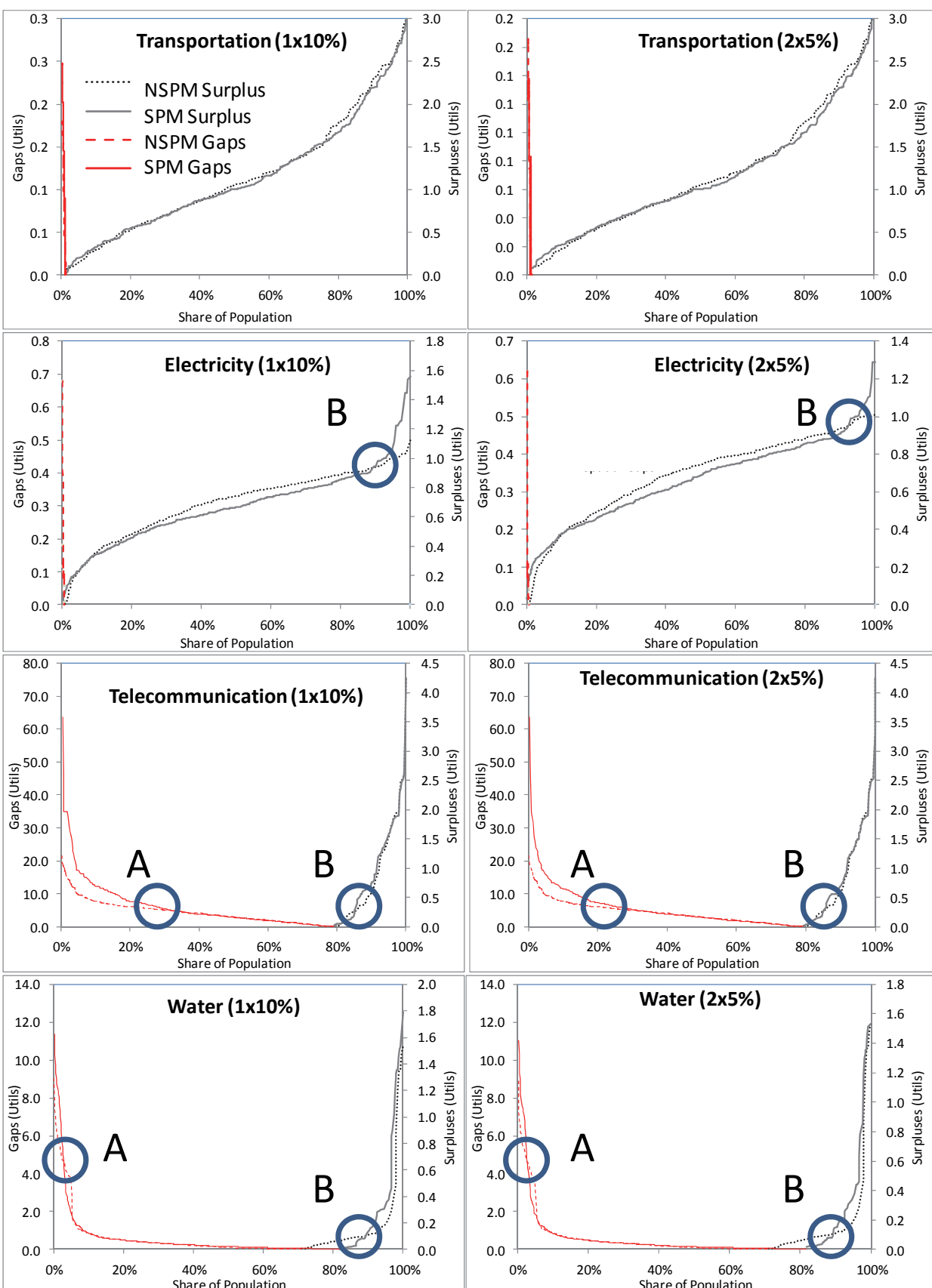

Figure 6.6 Curve dominance analysis, which discloses the similarity of patterns in the telecommunications and water infrastructures.

Among the four types of infrastructures, two of them produce similar patterns (i.e., telecommunications and water in Figure 6.6). Both 
consistently depict that at the beginning of curve, at the left-most side of gaps, NSPM perform better than SPM. Meanwhile, at the right-most side, SPM performs better.

This similar pattern, except for the left side, can also be found for electricity infrastructure. However, a distinct irregular patterns is found for transportation. The possible source of this behaviour is the way infrastructure services are delivered, as explained in the discussion section below.

\section{Quantitative Result of Curve Dominance Analysis}

In addition to pattern observations, a quantitative analysis is provided. Table 6.7 - Table 6.10 present the variation of SPM and NSPM to the level of poverty incidence, severity and inequality among the poor and the rich and its level of prosperity.

In addressing poverty, SPM and NSPM do not always result in similar distributional patterns. For example, SPM is more effective in reducing the poverty incidence in the road and electricity infrastructures but not in the telecommunications and water supply infrastructures, the sectors where a dominant of low-low cluster of severe poverty found.

Table 6.7 Poverty Incidence

\begin{tabular}{|c|c|c|c|c|c|}
\hline & Initial & Growth: & $1 \times 10 \%$ & Growth: & $2 \times 5 \%$ \\
\hline Sectors & & SPM & NSPM & SPM & NSPM \\
\hline ROAD & 9.25 & 1.25 & 1.37 & 1.13 & 1.37 \\
\hline ELECT & 4.13 & 0.19 & 0.7 & 0 & 0.65 \\
\hline TELEC & 82.09 & 79.59 & 79.51 & 79.48 & 79.51 \\
\hline WATER & 91.83 & 81.69 & 70.77 & 80.54 & 69.88 \\
\hline
\end{tabular}

A similar variation is also found in the effect of reducing maximum severity. Except for electricity infrastructure, NSPM is more effective in reducing the severity of the poorest, and it works best for the poorest in telecommunications (Table 6.8). Based on its distribution mechanism, the results in Table 6.7 and Table 6.8 indicate that the poorest are located in approximately the same location and form a cluster of similarity and the local inequality is not recognized. 
Table 6.8 Maximum Severity

\begin{tabular}{rrrrrr}
\hline & Initial & \multicolumn{1}{c}{ Growth: } & \multicolumn{1}{c}{$1 \times 10 \%$} & \multicolumn{1}{c}{ Growth: } & \multicolumn{2}{c}{$2 \times 5 \%$} \\
\hline Sectors & & \multicolumn{1}{c}{ SPM } & NSPM & \multicolumn{1}{c}{ SPM } & NSPM \\
\hline ROAD & 1.24 & 0.25 & 0.18 & 0.14 & 0.16 \\
\hline ELECT & 2.5 & 0.08 & 0.68 & 0 & 0.62 \\
\hline TELEC & 95 & 71 & 21.64 & 71 & 21.4 \\
\hline WATER & 17.38 & 12.2 & 10.2 & 12.0 & 10.11 \\
\hline
\end{tabular}

In terms of addressing equitable allocation, SPM also perform better, there is minor variation where NSPM slightly perform better than SPM to the poor groups (see Table 6.9). Meanwhile, for the rich groups, the SPM consistently performs better than the NSPM for all infrastructure sectors. An unexpected result, however, is found where both SPM and NSPM produce a higher level of inequality in rich groups than the initial condition (Table 6.9). The source of such anomaly is explained in the discussion section.

Table 6.9 Poor and Rich Inequality

\begin{tabular}{lccrrr}
\hline $\begin{array}{l}\text { Poor } \\
\text { Inequality: }\end{array}$ & Initial & Growth: & $1 \times 10 \%$ & Growth: & $2 \times 5 \%$ \\
\hline & \multicolumn{7}{c}{ SPM } & NSPM & SPM & NSPM \\
\hline ROAD & 0.09 & 0.07 & 0.06 & 0.05 & 0.07 \\
\hline ELECT & 0.08 & 0.00 & 0.05 & 0 & 0.04 \\
\hline TELEC & 0.11 & 0.1 & 0.08 & 0.1 & 0.08 \\
\hline WATER & 0.14 & 0.14 & 0.13 & 0.13 & 0.13 \\
\hline & & & & & \\
\hline Rich & & & & & \\
Inequality: & Initial & Growth: & $1 \times 10 \%$ & Growth: & $2 \times 5 \%$ \\
\hline & \multicolumn{7}{c}{ SPM } & NSPM & SPM & NSPM \\
\hline ROAD & 0.09 & 0.07 & 0.08 & 0.07 & 0.08 \\
\hline ELECT & 0.06 & 0.05 & 0.05 & 0 & 0.04 \\
\hline TELEC & 0.12 & 0.13 & 0.14 & 0.14 & 0.14 \\
\hline WATER & 0.18 & 0.21 & 0.3 & 0.21 & 0.3 \\
\hline & & & & & \\
\hline
\end{tabular}

When looking at the effect on the richest groups (Table 6.10), although SPM performs better, less variation is found. However, for the roads and telecommunications infrastructures for both SPM and NSPM, there is no effect on the richest. The fact that SPM affects the richest in the electricity and water infrastructures indicates that not only is the allocation is propoor but it also pays attention to the group that could be promoting growth. 
Table 6.10 Maximum Prosperity

\begin{tabular}{rrrrrr}
\hline \multicolumn{1}{l}{ Sectors } & Initial & \multicolumn{1}{c}{ Growth: } & \multicolumn{1}{c}{ 1x10\% } & Growth: & \multicolumn{2}{c}{ 2x5\% } \\
\hline ROAD & & \multicolumn{1}{c}{ SPM } & NSPM & \multicolumn{1}{c}{ SPM } & NSPM \\
\hline ELECT & 1.4 & 3.4 & 3.4 & 3.4 & 3.4 \\
\hline TELEC & 4.25 & 1.56 & 1.13 & 1.29 & 1.01 \\
\hline WATER & 1.53 & 1.26 & 4.26 & 4.26 & 4.26 \\
\hline
\end{tabular}

Another interesting result is the similarity of patterns among the electricity, telecommunication and water infrastructures, which does not exist for road transportation (see Table 6.10). For these infrastructures, the curves cross each other at Points A and B (Figure 6.6), with the exception of electricity, which crosses only at B. These patterns and their source of variation require careful observation, as is done in the discussion section.

\subsection{Discussion}

With reference to the indicators listed in the evaluation matrix (Table 6.4), the results confirm that in general, spatial preference modelling (SPM) for resource allocation is more in accordance with the theories of welfare than non-spatial preference modelling (NSPM). Some evidence is discussed here.

With regard to utilitarian theory, we found that SPM performs better than NSPM for both the redistribution of growth (Table 6.5) and total utilitarian equality (Table 6.6). This conclusion applies for all types of infrastructure.

The SPM also performs consistently better to serve non-utilitarian perspectives, particularly for infrastructure characterized with a linear type of network (see system characteristics in Table 6.1). For example, in reducing poverty incidence (Table 6.7), SPM works better for the road and electricity infrastructures. These infrastructures that are formed by networks of a linear typology tend to be more sensitive to SPM than infrastructure networks of plane or space typologies. These space typologies occur when the network creates similar level of service between locations in close proximity (e.g., wireless telecommunication and groundwater) and have no issue with local spatial inequity.

Further evidence that SPM works better for linear types of networks is the result of the equality of electricity and telecommunications of the poor groups (Table 6.9, poor section). Here SPM reduced the poor inequality in a place where incomplete network of linear infrastructure found in the cluster of poverty. 
Moreover, in another inequity assessment, particularly for rich groups (Table 6.9, rich section), SPM also works consistently better than NSPM in all types of infrastructure.

More supportive evidence for SPM is obtained from spatial equity assessment, which reveals that generally, SPM performs better than NSPM, as indicated by Moran's I in Figure 6.5. SPM addresses spatial inequity by increasing Moran's I indexes. Even, with two-steps iteration (2x5\%), SPM is much more effective in addressing spatial inequity.

One observable fact where the NSPM performs better that SPM is on Poverty Incidence of Water (Table 6.7). This is another evidence that in the case of water, the poorest group are located in same area, where no water network is available and the water lacking cover a wide area of the region (see the Low-Low cluster of Water in Figure 6.5). In such cases, as no local spatial inequality is detected, SPM with a global or goal standardization (Wismadi, Zuidgeest et al. 2013) might be applied.

This observation also disloses that the typology of infrastructures also determines the effectiveness of certain types of preference modelling. Infrastructures that combine various typologies also require more attention to the implementation of spatial preference modelling. In addition, in an underdeveloping region, the incomplete network of the linear infrastructure tends to generate more spatial inequity. In this case, SPM helps find areas with lower connectivity or an incomplete network structure (e.g., missing links on a road network, underserved urban areas from piped water or fibre optic networks). The curve dominance analysis in Figure 6.6 also enriches this observation. The left-hand side of point $\mathrm{A}$ (Figure 6.6, telecommunications and water) indicates the worst-off groups that live in low-low clusters, whereas on the right-hand side of point B, areas where spatial inequity exists are indicated.

In terms of network development, the right-hand side of B also indicates that incomplete linear networks (e.g., fibre optic or copper networks, electricity grids or water pipe networks) exist and create gaps between spaces. Meanwhile, on the left-hand side of A, the linear networks that have not reached the location result in low-low clusters (e.g., poor wireless network in rural areas, or wells in area with groundwater scarcity). The space between A and B indicates that a combination of systems are in place (i.e., linear network of copper and wireless, or water pipes and wells in each household) and produce an average level of service. 
This A/B pattern is not found for transportation. This irregularity discloses that the road network does not necessarily determine a linear type of network because the predominated private vehicles cover a few public transport routes and turn the linear type into plane. Moreover, a complete road network in urban areas does not guarantee high performance due to traffic congestion.

In addition to the above general conclusion, there are some interesting findings. First, an anomaly is found regarding road infrastructure in the inequality of the poor group (Table 6.9, road), where NSPM works better than SPM. This peculiarity, however, is explainable by the fact that the linear infrastructure of roads does not determine the linearity of the service. The absence of public transport services (which is supposed to be linear in nature) causes the poor groups to have to rely on limited personal mobility and forms a network similar to space typology. A similar observation is found in rural areas, where the poor are mostly located: The issue in electricity and telecommunication could be access to networks, whereas for road and water, the issue is the availability of service. This nature of the problem might determine the type of networks in a specific location.

Therefore, in the case that the poorest are located in the same area and no specific neighbourhood inequality is recognized, the NSPM would work better in addressing the worst-off (the poorest), e.g., roads, telecommunications and water, in Table 6.8. The fact that telecommunication and water infrastructures (Table 6.7) appear more sensitive to NSPM indicates that similar levels of poverty are clustered. Fig 6 confirms this finding, where low-low clusters of telecommunications and water infrastructures are more dominant than the other infrastructures.

Another interesting observation can be found in Table 6.9 regarding the rich, where it is shown that for telecommunications and water, the rich inequality level is initially lower than after allocation. This unexpected finding is explainable: It indicates that some poor people become non-poor due to the allocation. These new near-poor groups, approximately $3 \%$ resp. $20 \%$ in telecommunications and water (see Table 6.7), contribute to inequality among the rich.

In the case of the rich groups (Table 6.10), both types of preference modelling do not affect this group for road and telecommunication, but the SPM in particular increases the level of service performance of the richest in electricity and water infrastructures. These findings indicate that in the 
case of electricity and water with $10 \%$ growth, SPM allows for the rich group to benefit from the growth.

Furthermore, the zero value of poor inequality for electricity (Table 6.9) reveals that with $10 \%$ growth, SPM could reduce more poverty incidences, whereas NSPM leaves more people and villages in poor condition. It also implies that in the case of linear infrastructure has provided sufficient level of service and only left small group of people and villages under poverty line (e.g., electricity), SPM could effectively alleviate deprived villages and poor people to become non-poor, for example, by connecting the villages to its better off neighboorhood.

In conclusion, this discussion outlines a list of evidence that SPM performs better than NSPM not only in satisfying various perspectives of welfare but also in providing new tools to observe infrastructure operational issues on the ground.

\subsection{Conclusion}

We disclose that spatial preference modelling is in compliance with the moral philosophy of both utilitarian and non-utilitarian theories. In general, SPM performs better than NSPM to achieve inequitable growth; however, the combination of both might be necessary with consideration of the level of infrastructure development, the typology of the infrastructure and the initial level of social and spatial equity.

Moreover, this research provides a good basis for generalizing the application of preference modelling for equity-based resource allocation for infrastructure and contributes to the debate of "people-centred" versus "place-base" development (Deichmann, Gill et al. 2011). 
Equitable distribution of growth for utilitarian and non-utilitarian infrastructure 


\title{
Chapter 7
}

\section{Equity-based Resource Location-Allocation Simulation (EQLAS): A new SDSS framework for integrated infrastructure development}

\begin{abstract}
This chapter aims is to integrate the three analyses done in the previous chapters 4-6 in a DSS framework, and to demonstrate in what contexts the SDSS could be applied and what are the requirements and data needs for applying the SDSS, using two case studies. Here we introduces a new spatial decision support system (SDSS) framework for equitable resource location-allocation simulation in infrastructure development. A common three-stage decision-making model for SDSS development that includes intelligence, design and choice is applied to outline the idea, the process and the lessons learnt from each stage of the framework. To develop the framework, a prototype application involving four types of infrastructure in Yogyakarta, Indonesia, is provided. The development process discloses that spatial interdependency in the infrastructure-economy interaction influences the effectiveness of resource allocation. We also found that the spatially linked resource allocation policies could simultaneously address social and spatial equity and also satisfy both Utilitarian and NonUtilitarian perspectives. Moreover, the types of infrastructure typology (e.g., point, linear, and space), the level of performance, and the initial status of spatial equity also influence the effective distribution of growth. To illustrate the potential implementation of this new type of SDSS framework, we compare two case studies of rural infrastructure development. The first is on the Universal Service Obligation Programme in the telecommunications sector, and the second is the Public Service Obligation for the rural transport sector. These case studies outline the general framework and are presented as a demonstration of the institutionalization of an SDSS in a nationwide infrastructure programme.
\end{abstract}

Key Words: SDSS; integrated infrastructure development; equity; resource allocation 


\subsection{Introduction}

The increasing complexity of regional development, driven by social, cultural, economic and environmental factors, creates the need for spatial decision support to manage the trade-offs among various policy objectives (Goosen, Janssen et al. 2007; Bone and Dragićević 2009; Gorsevski and Jankowski 2010). Moreover, decision making might become more complex in a situation in which regional disparity and the demand for growth are constrained by a scarce resource that is to be distributed.

Absent proper support for decision making, such conditions might lead to a decision whereby policy makers invest in locations (e.g., infrastructure and services) that exacerbate inequity and are not necessarily aligned with development objectives (Montibeller, Franco et al. 2009; CoutinhoRodrigues, Simão et al. 2011). The cumulative impact of such a decision raises the country's risk of social tension (Lawson 2010). Indonesia is one of the countries experienced such a situation. After more than 30 years of steady growth and a stable political condition of centralistic government regime, in 1997-1998 Indonesia face an extreme social and political distress and massive riots triggered by issue of social and spatial equity. Its impact on regional disparity led to governance reform to allocate resources at sub national levels. Such a problem is not only an issue in developing countries but also in the developed countries. The London riot (Baudains, Johnson et al. 2013; Till 2013) is among examples of inequity issues that are associated with policy implications to govern cities and states in Europe (Musterd and Ostendorf 2012).

To mitigate such a situation, policy and decision makers should be equipped with a proper decision support tools. A spatial decision support system (SDSS) helps decision makers to structure such a problem, generating possible solutions and selecting the best alternative by applying multiple criteria evaluation (MCE) methods in combination with geographic information systems (GIS) (Malczewski 2006).

There are several Multi-Criteria Decision Analysis (MCDA)-based modelling approaches for analysing resource allocation problems (Archer and Ghasemzadeh 1999; Heidenberger and Stummer 1999; Liesiö, Mild et al. 2007). Montibeller, Franco et al. (2009) also list software packages available to support this type of resource allocation decision-making process (i.e., Equity [www.catalyze.co.uk], HiPriority [www.krysalis.co.uk], and LDW [www.logicaldecisions.com])). Though the task of allocating resources to locations or organizational areas (e.g., departments, regional offices, etc.) has been considered, existing approaches do not account for 
spatial equity issues among locations and only focus on maximizing the total growth under a given budget constraint (Montibeller, Franco et al. 2009). The limited attention devoted to decision tools for addressing spatial equity issues makes the problem of regional disparity difficult to address.

To contribute in the decision tools development, the purpose of this chapter is to integrate the three analyses done in the previous chapters 4-6 in a DSS framework, and to demonstrate in what contexts the SDSS could be applied and what are the requirements and data needs for applying the SDSS, using two case studies. Here, we propose a new type of SDSS framework for equitable resource location-allocation. Specifically, our framework, Equity-based Resource Location-Allocation Simulation (EQLAS), focuses on infrastructure development as a means of simultaneously addressing social and spatial equity and, therefore, regional disparity. We structure the framework into the three common stages of decision-making processes (Simon 1960), i.e., the intelligence, design and choice stages. A simulation involving four types of infrastructure - road, electricity, telecommunications and water - was employed to develop the framework. Based on the lessons learnt from the development process and the case study, we suggest a general framework for guiding the structure of this type of SDSS model.

The remainder of the paper is structured as follows. The next section outlines the SDSS framework applied in the development of EQLAS, followed by a general description of the EQLAS framework, which includes the concept and its specific feature of equity-based resource allocation. A detailed explanation of the EQLAS development process is then structured according to the analysis conducted during each stage of the decisionmaking process. The case study used in the development of EQLAS are also provided in this section. In the subsequent section, we discuss potential implementation of this new SDSS framework in the National Infrastructure Programme in Indonesia, where we address two infrastructure sectors. Finally, the chapter concludes by suggesting potential contributions that EQLAS can make to more equitable infrastructure development.

The following section elaborates the operation of the EQLAS development process. 


\subsection{EQLAS framework}

\subsubsection{Concept: Equality or Equity?}

Equality, equity and redistribution are linked concepts. The concept of equality specifically implies that from an economic perspective, income is shared in a homogenous way (Garcia-Valiñas, Fernández-Llera et al. 2008), i.e., the aim of an intervention to counter inequality is to reduce substantial income differences. Hence, not only should poor people be less poor, but rich people should also be less rich. Consequently, the concept of equality requires a redistribution of resources among groups, which is often problematic in practice. Therefore, the notion of equity has come to replace the more radical notion of equality. As an analogy, "equality" involves a "floor" as well as a "ceiling", while "equity" only entails a minimum "floor" (Garcia-Valiñas, Fernández-Llera et al. 2008). In poverty measurement, the 'floor' is commonly known as the 'poverty line'. Accordingly, equity refers to providing a minimum level of opportunity for the target groups. As such, the term 'equity' is more reasonable in a practical context.

The concept of equity is also highly relevant to infrastructure development, the aim of which is provide minimum service levels to enable people to have access to certain levels of economic opportunity. Making use of the "equity" concept, we study equity-based resource allocation by simultaneously considering both "spatial equity" (the equitable distribution of opportunity across regions) and "social equity" (the distribution of opportunity across economic classes).

\subsubsection{Specific focus of an SDSS on equity-based resource allocation}

A common decision support system is intended to compare competing alternatives to solve an identified decision problem and find the most "satisficing" alternative to be implemented (Mitwasi, Connolly et al. 1989; Yager 1992; Hayakawa 2000). The best alternative in a decision-making process is, therefore, the option that allows one to "satisfy" most of the target groups/stakeholders without entailing excessive "sacrifice" for other interests.

Similarly, a resource allocation decision problem also involves the evaluation of alternatives. The difference from a common SDSS lies in how the resources are allocated. In a common decision-making process, the resources would go only to one, the most satisficing, alternative, whereas, the aim of a resource allocation decision is to distribute the resources to all 
or most of the competing alternatives as the target of the distribution. In this case, a given allocation to a target might reduce or eliminate the allocation to another as long as the best overall value for a given budget is achieved (Montibeller, Franco et al. 2009).

In a resource allocation decision process, therefore, the alternative is not the target of allocation; instead, the alternative is the policies and the associated approaches or the methods for allocating resources to produce the best overall result within the given budget. The policy - which might refer to the preference or eligibility of a target group, an area, or the restriction over a period of disbursement - would affect the impact of distribution. Moreover, the approach, which refers to how a policy should be implemented or regulated, could also influence the benefit of the programme. A consistent implementation will allow for a resource allocation that does not suffer from unnecessary political influences.

Consequently, in the EQLAS, the alternative being evaluated refers to policy as place-based (spatially connective allocation) and people-centred (spatially blind allocation), such that equity could simultaneously be addressed while "satisficing" the beneficiaries defined in the planning objective.

\subsubsection{SDSS framework in EQLAS}

The structure of decision-making process models generally involves the three main stages of intelligence, design and choice (Simon 1960; Turban and Meredith 1991). Each stage involves a body of knowledge and techniques designed to help decision makers in selecting among a set of alternatives in the light of their consequences. In the intelligence stage, we obtain knowledge on how the decision problem - the gap between the policy objective and current conditions - unfolds and what the characteristics of the decision problem are. During the design stage, based on the knowledge obtained during the intelligence stage, alternatives to reduce the gap are generated. Finally, during the choice stage, an evaluation of the consequences of each generated alternative is conducted to find the best alternative.

With the aim of simultaneously addressing social and spatial equity in resource location-allocation, during the intelligence stage, we observe the influence of spatial features in an allocation mechanism and the mechanism's impact on the new equity conditions. This is achieved by using a set of simulations involving spatial econometric models of infrastructure-economy interaction with increasing complexity of 
interaction from spatially independent (integrated infrastructure model), to spatially dependent (spatial integrated infrastructure model), with the final model capturing spatial and sector dependency (spatial integrated infrastructure interdependency model) (see Figure 7.1). During the design stage, we generate resource allocation planning alternatives with reference to two policies, a spatially blind allocation and a spatially linked allocation policy. For both, we provide a preference modelling for distributing growth, namely non-spatial preference modelling (NSPM) and spatial preference modelling (SPM) (see Figure 7.1). Finally, during the choice stage we apply two distinct perspectives on welfare theory, utilitarian and non-utilitarian, to predict the compliance of the allocation policy with community preferences and planning objectives (see Figure 7.1).

\begin{tabular}{|c|c|}
\hline \multirow[b]{3}{*}{$\begin{array}{l}\text { Intelligent Stage: } \\
\text { RQ: Does spatial } \\
\text { neighborhood } \\
\text { matters? }\end{array}$} & \multirow{4}{*}{$\begin{array}{l}\text { Purpose: to understand the role of spatial consideration in the } \\
\text { Infrastructure-Economy interaction } \\
\text { Method: Spatial Econometric Models to compare: } \\
\text { 1. Integrated Infrastructure (II) } \\
\text { 2. Spatial Integrated Infrastructure (SII) } \\
\text { 3. Spatial Integrated Infrastructure Interdependency (SIII) } \\
\text { Analysis: Confusion Matrix between the model and the ground } \\
\text { truth of inverted poverty maps and subjective well-being }\end{array}$} \\
\hline & \\
\hline & \\
\hline & \\
\hline & \multirow{3}{*}{$\begin{array}{l}\text { Purpose: to generate possible option to include social equity } \\
\text { consideration in spatially blind vs spatially linked allocation policy. } \\
\text { Method: Comparison of Preference Modelling in allocation policy: } \\
\text { 1. Non-Spatial Preference Modelling (NSPM) } \\
\text { 2. Spatial Preference Modelling (SPM) } \\
\text { Analysis: Assessment of the effect to Spatial Equity with Moran's I } \\
\quad \text { to measure cluster of dissimilariy (inequity) or cluster of } \\
\quad \text { similariy (equity) }\end{array}$} \\
\hline $\begin{array}{l}\text { Design Stage: } \\
\text { RQ: What are the } \\
\text { options to address } \\
\text { spatial equity? }\end{array}$ & \\
\hline & \\
\hline $\begin{array}{l}\text { Choice Stage: } \\
\text { RQ: Which one is } \\
\text { the preferred } \\
\text { optionsto general } \\
\text { public and } \\
\text { planner? }\end{array}$ & $\begin{array}{l}\text { Purpose: to choose the most effective growth distribution approach } \\
\text { acceptable by general public and planning objectives. } \\
\text { Method: assesment of allocation policy options in compliance to } \\
\text { 1. Utilitarian theory } \\
\text { 2. Non-Utilitarian theory } \\
\text { Analysis: Assessment with Total Utility Equality and Curve } \\
\quad \text { Dominance Analysis }\end{array}$ \\
\hline
\end{tabular}

Figure 7.1 EQLAS Development Process, summarizing the three main stages of the SDSS framework applied in this research.

The generalized framework for EQLAS (see Figure 7.2) provides a conceptual approach following the three stages of the decision-making process. The intelligence stage is developed based on the understanding of the interaction between infrastructure and the economy, implying that it is important to account for neighbouring infrastructure conditions to obtain an effective resource allocation, which is then applied in preference 
modelling to generate alternative methods to allocate resources in the design stage. In the choice stage, the evaluation is based on the theoretical constructs of utilitarian and non-utilitarian welfare to align the allocation with the preferences of targeted communities and general development objectives.

In the design stage, when the equity measurement indicates gaps - either in spatial or social equity - a set of allocation policy alternatives to reduce the gaps will be generated. An example alternative is the option of combining allocation preference modelling (NSPM or SPM) and the equity benchmarks (local, global or glocal). Finally, in the choice stage, the effects of resource distribution are evaluated, again, with respect to spatial and social equity, as well as the perspectives of utilitarian and non-utilitarian theories.

This generalized conceptual framework is developed for scenario-based rather than optimization-based applications. Hence, a 'what if' type of question relating to policy objectives is more appropriate than providing the model's user with the 'best' option given certain criteria. However, with additional iteration mechanisms, optimization-based applications could be developed using the underlying framework (e.g., the optimum allocation to reach the equity threshold) by following the iterative process indicated by the bold lines (outcome optimization) or the dotted lines (impact optimization). 


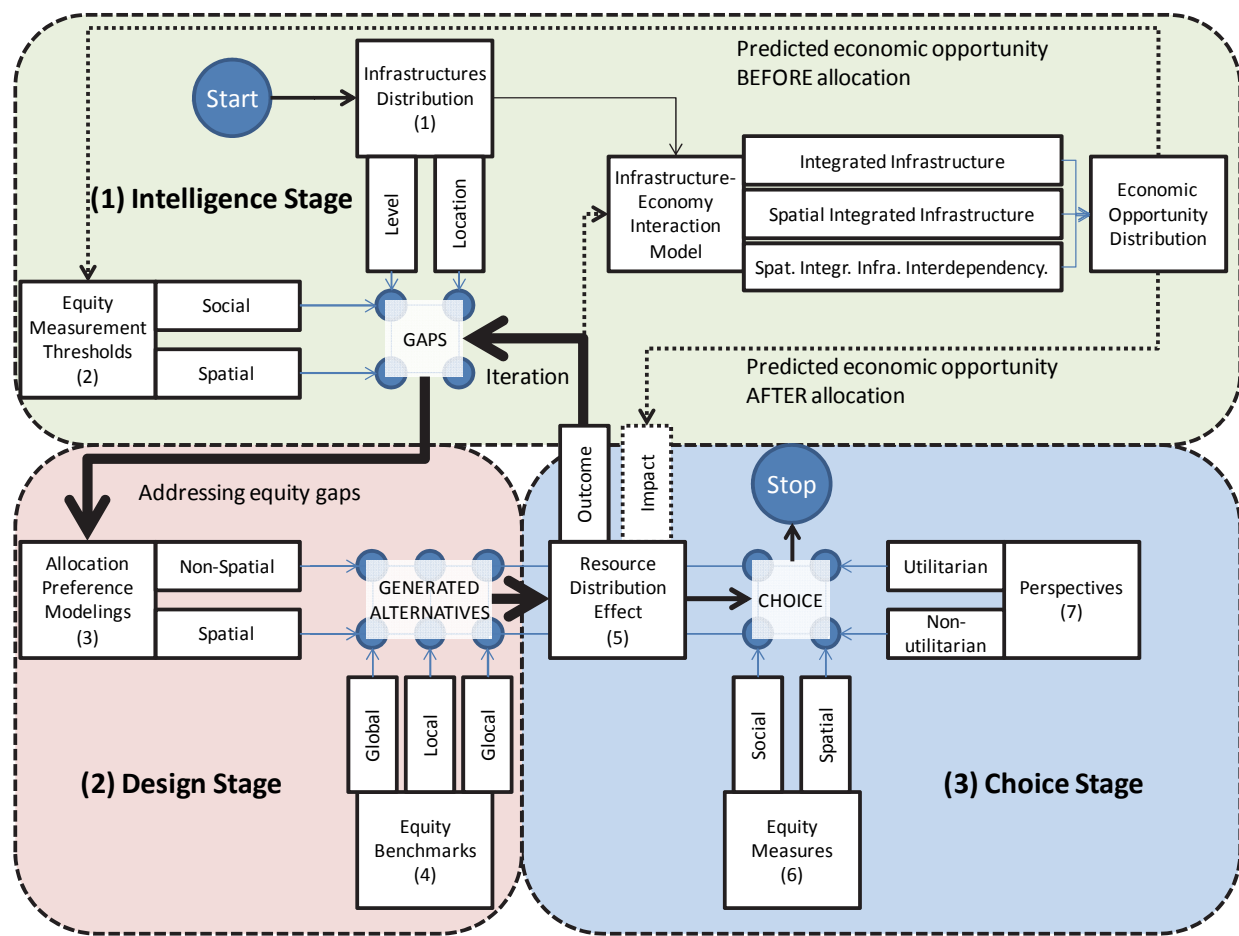

Figure 7.2 SDSS Framework for Equity-based Resource LocationAllocation Simulation

Referring to the subsequence in each stage, the seven steps of EQLAS and the components of each can be outlined as:

Intelligence Stages:

1. Infrastructures Distribution (Level, Location)

2. Equity Measurement (Social, Spatial)

\section{Design Stages}

3. Allocation Preference Modelling (Non-Spatial, Spatial)

4. Equity Benchmark (Global, Local, Glocal)

Choice Stages

5. Resource Distribution Effect (Outcome, Impact)

6. Equity Measurement (Social, Spatial)

7. Perspectives (Utilitarian, Non-Utilitarian)

Each stage is explained in greater detail in the following sections. 


\subsection{EQLAS development process}

\subsubsection{Analysis in each stage of the decision-making process}

(1) Intelligence stage: understanding infrastructure-economy interaction with the aim of achieving an equitable distribution of opportunities

The desire to simultaneously address social and spatial equity is closely related to the debate on place-based vs. people-centred policies. The discussion is based on the need for development policies to be peoplecentred to maximize welfare, while the intervention might also need to take spatial or territorial dimensions into account, thus entailing placebased policies (Banzhaf and Walsh 2013). Interventions for allocating resources to infrastructure could therefore directly target poor people without regard for their location - or distributed at a location where interconnected economic activities could improve growth and welfare for the poor. This nexus is the main foundation for the analysis in the intelligence stage.

Based on the above considerations, the intelligence stage must focus on understanding the interactions between infrastructure and the economy. Such knowledge will be useful to provide more effective and efficient policies for allocating resources to develop infrastructure at a specific location. We need to know, for example, how the variability of the existing infrastructure (level of performance and spatial location), the neighbouring factors, and their interdependency influence the distribution of economic opportunity in a region. The objective at the intelligence stage is, therefore, to determine whether the inclusion of conditions in neighbouring villages or spatial interdependencies in infrastructure are able to improve the performance of existing infrastructure-economy interaction models in predicting the distribution of economic opportunity at the village level in a region. Such knowledge will be useful for improving the effective allocation of resources.

There will be a decision problem during the intelligence stage if a gap is observed between the current status and the expected level of social equity (within the region) and spatial equity in a particular location (e.g., a village or cluster of villages). Hence, an equity measure is required to indicate the necessity of an intervention to address the equity. 
(2) Design: What are the alternative methods to address inequity?

During the design stage, we have to generate alternative methods associated with place-based and people-centred policy options by accounting for spatial inequities in resource allocation. This can be achieved by incorporating a comparison between location units and neighbouring units into the preference modelling.

The purpose of the investigation in the design stage is, therefore, to identify alternatives in preference modelling for resource allocation. Specifically, the aim of the investigation is to determine whether a place-based policy applied while including spatial neighbourhood comparison factors in preference modelling, i.e., spatial preference modelling, can improve the resource location-allocation to address spatial equity. To this end, we compare SPM with the more common NSPM approach, which represents the people-centred policy.

In each preference modelling, there are three possible definitions of "neighbouring": a global benchmark (which refers to a single value that is not necessarily derived from the study area), local benchmark (which refers to the average values from the neighbouring units) or glocal benchmark (which refers to the average values from all of units in the study area).

(3) Choice: concern for regional disparity and assessing alternatives with respect to the utilitarian and non-utilitarian welfare perspectives

Assessing approaches for addressing both social and spatial equity issues in decision making requires a theory of social choice and the measurements of social and spatial equity derived from that theory. The theory is required to predict the compliance of the outcome or impact of the distribution with community preferences and general development objectives.

In the previous intelligence and design stages, the investigation of the interaction between infrastructure and the economy yields a number of alternative approaches for achieving a more equitable allocation of infrastructure resources. The result in the choice stage indicates the most suitable policies and methods to simultaneously and effectively address both social and spatial equality. The equity measurement applied here follows the same concept as in the intelligence stage. 
Hence, in the choice stage, the compliance of the result with a more general moral philosophy of fairness according to the theory of social choice becomes an important aspect of EQLAS. For example, at the practical level, the theory is elaborated into an assessment of the compliance between pro-poor and pro-growth policies. Understanding the behaviour of the model in favouring the poor and the disadvantaged while simultaneously providing a perspective on a reasonable improvement in the prosperity of the rich makes it possible to properly apply the model in various resourceallocation decision-making contexts. As noted above, two distinct welfare theories, utilitarian and non-utilitarian, were applied to predict the compliance of the allocation policy with community preferences and planning objectives.

\subsubsection{Case study and data set for developing EQLAS}

To develop the EQLAS framework, a set of simulations involving four types of infrastructure in Yogyakarta, Indonesia was performed. The Special Province of Yogyakarta, Indonesia (Figure 7.3) is a target of various Indonesian development programmes. The area of study is home to approximately 3.4 million people. It consists of 438 villages, both urban and rural, with an average population of 5,632 inhabitants. The average size of a village is 724.43 ha with a minimum of 26.57 ha in urban areas and a maximum of $2,890.36$ ha in more rural areas.

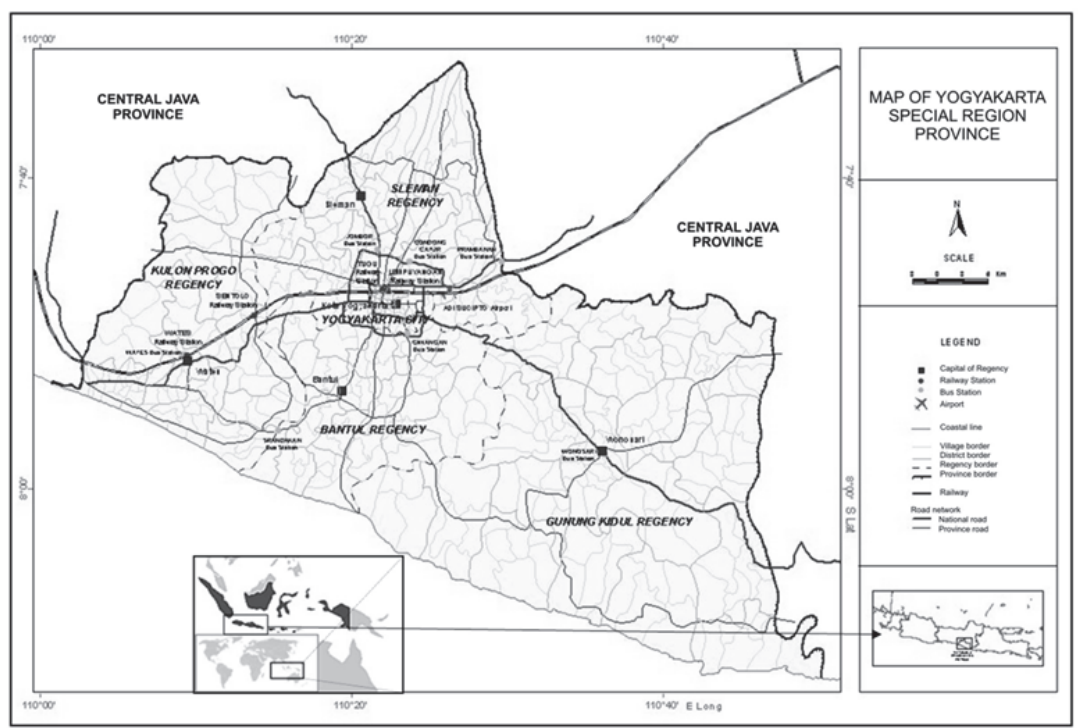

Figure 7.3 The study area is located in the Special Province of Yogyakarta, Indonesia, with 438 urban and rural villages; the study utilizes village-level data on demographic, socio-economic and infrastructure-related issues. 
For this study, we use a village-level dataset from 2005 called PODES (BPS 2006), which consists of approximately 400 attributes linked to demographics, socio-economic activities and infrastructure for 438 urban and rural villages in the province. The demographic data concern population and household numbers in each village. The infrastructure data that were used include information on transport, electricity, drinking water, and telecommunications. As a proxy for economic opportunity, we use economic activity data that encompass 32 types of economic activity for each village (Table 7.1 and Figure 7.4)

Table 7.1 Variables and the data sources

\begin{tabular}{|c|c|c|c|c|c|}
\hline Variables & $\begin{array}{c}\text { Unit of } \\
\text { measurement } \\
\text { for the model }\end{array}$ & $\begin{array}{c}\text { Data } \\
\text { sources }\end{array}$ & $\begin{array}{c}\text { Unit of } \\
\text { measurement }\end{array}$ & $\begin{array}{c}\text { Data } \\
\text { conversion }\end{array}$ & System Characteristics \\
\hline \multicolumn{6}{|l|}{ Infrastructure } \\
\hline Transport & $\begin{array}{l}\text { Average travel } \\
\text { speed }(\mathrm{km} / \mathrm{hr})\end{array}$ & $\begin{array}{l}\text { PODES } \\
\text { code } \\
9022 \\
9023\end{array}$ & $\begin{array}{l}\text { (Distance, KM; } \\
\text { travel time, } \\
\text { HR) }\end{array}$ & $\begin{array}{l}\text { Average } \\
\text { travel speed } \\
\text { to facilities } \\
(9022 / 9023)\end{array}$ & $\begin{array}{l}\text { The system is formed by a } \\
\text { linear type of } \\
\text { infrastructure. Mobility is } \\
\text { reliant on private vehicles, } \\
\text { with limited public } \\
\text { transport in urban areas. } \\
\text { Low performance indicates } \\
\text { traffic jams (urban) and } \\
\text { poor infrastructure (rural). }\end{array}$ \\
\hline Electricity & $\begin{array}{l}\text { Average } \\
\text { electricity } \\
\text { supply per } \\
\text { household } \\
\text { (VA) }\end{array}$ & $\begin{array}{l}\text { PODES } \\
\text { code } 501\end{array}$ & $\begin{array}{l}\text { (Electrified } \\
\text { HHs) }\end{array}$ & $\begin{array}{l}\text { Weighted } \\
\text { average of } \\
\text { electricity } \\
\text { supply for } \\
\text { poor and } \\
\text { non-poor. }\end{array}$ & $\begin{array}{l}\text { The system is formed by a } \\
\text { linear type of } \\
\text { infrastructure. The } \\
\text { network is laid along the } \\
\text { road network. High } \\
\text { performance indicates } \\
\text { urban and more developed } \\
\text { villages. }\end{array}$ \\
\hline Telecom & $\begin{array}{l}\text { Average data } \\
\text { transfer } \\
\text { capacity (kbps) }\end{array}$ & $\begin{array}{l}\text { PODES } \\
\text { codes } \\
904,911\end{array}$ & $\begin{array}{l}\text { (Connected } \mathrm{HH} \\
\text { to fixed line, } \\
\text { mobile } \\
\text { network } \\
\text { coverage) }\end{array}$ & $\begin{array}{l}\text { Weighted } \\
\text { average of } \\
\text { data transfer } \\
\text { capacity of } \\
\text { fixed line and } \\
\text { mobile } \\
\text { networks. }\end{array}$ & $\begin{array}{l}\text { The system is formed by a } \\
\text { combination of linear and } \\
\text { space types of } \\
\text { infrastructure. } \\
\text { networks of linear systems } \\
\text { rely on fibre optic (urban } \\
\text { centre) and copper (urban } \\
\text { to sub-urban) along the } \\
\text { roa networks. The } \\
\text { wireless mobile networks } \\
\text { form a space type of } \\
\text { network to reach markets } \\
\text { in rural areas. }\end{array}$ \\
\hline Water & $\begin{array}{l}\text { Average } \\
\text { discharge } \\
\text { (ltr/day) }\end{array}$ & $\begin{array}{l}\text { PODES } \\
\text { code } 608\end{array}$ & $\begin{array}{l}\text { (Type of } \\
\text { source, } \\
\text { electrification) }\end{array}$ & $\begin{array}{l}\text { Water } \\
\text { discharge } \\
\text { capacity } \\
\text { based on } \\
\text { each type of } \\
\text { source. }\end{array}$ & $\begin{array}{l}\text { The system is formed by a } \\
\text { combination of point, } \\
\text { linear and space types of } \\
\text { infrastructure. Urban areas } \\
\text { served by linear public } \\
\text { freshwater with the option } \\
\text { of using private wells. } \\
\text { Underground water forms } \\
\text { a space type of }\end{array}$ \\
\hline
\end{tabular}




\begin{tabular}{|c|c|c|c|c|c|}
\hline Variables & $\begin{array}{c}\text { Unit of } \\
\text { measurement } \\
\text { for the model }\end{array}$ & $\begin{array}{c}\text { Data } \\
\text { sources }\end{array}$ & $\begin{array}{c}\text { Unit of } \\
\text { measurement }\end{array}$ & $\begin{array}{c}\text { Data } \\
\text { conversion }\end{array}$ & System Characteristics \\
\hline & & & & & $\begin{array}{l}\text { infrastructure. } \\
\text { infrastructures are found } \\
\text { in drought areas lacking } \\
\text { water sources (white } \\
\text { cluster in Fig. 1). }\end{array}$ \\
\hline \multicolumn{6}{|l|}{ Demographic: } \\
\hline Population & $\begin{array}{ll}\text { Number } & \text { of } \\
\text { Population } & \text { in } \\
\text { the village } & \end{array}$ & $\begin{array}{l}\text { PODES } \\
\text { code } \\
401 a, b\end{array}$ & $\begin{array}{l}\text { (Male pop, } \\
\text { female pop) }\end{array}$ & $\begin{array}{l}\text { Total } \\
\text { population } \\
401 \mathrm{a}+401 \mathrm{~b}\end{array}$ & $\begin{array}{l}\text { Population is distributed } \\
\text { on flat areas that are } \\
\text { historically fertile or } \\
\text { recently provided with } \\
\text { infrastructure, especially } \\
\text { road networks, and are } \\
\text { economically more } \\
\text { developed. }\end{array}$ \\
\hline $\begin{array}{l}\text { Economic } \\
\text { Opportunity }\end{array}$ & $\begin{array}{l}\text { Average } \\
\text { annual income } \\
\text { (Mio IDR) }\end{array}$ & $\begin{array}{l}\text { PODES } \\
\text { codes } \\
1101, \\
1102, \\
1103 \\
1132\end{array}$ to & $\begin{array}{l}\text { (Type and } \\
\text { number of } \\
\text { economic } \\
\text { activities in the } \\
\text { village) }\end{array}$ & $\begin{array}{l}\text { Number of } \\
\text { units * the } \\
\text { average } \\
\text { annual } \\
\text { revenue from } \\
\text { each type of } \\
\text { activity }\end{array}$ & $\begin{array}{l}\text { Economic opportunity } \\
\text { distributed in a location } \\
\text { where the market and } \\
\text { supporting infrastructure } \\
\text { are sufficient. }\end{array}$ \\
\hline
\end{tabular}

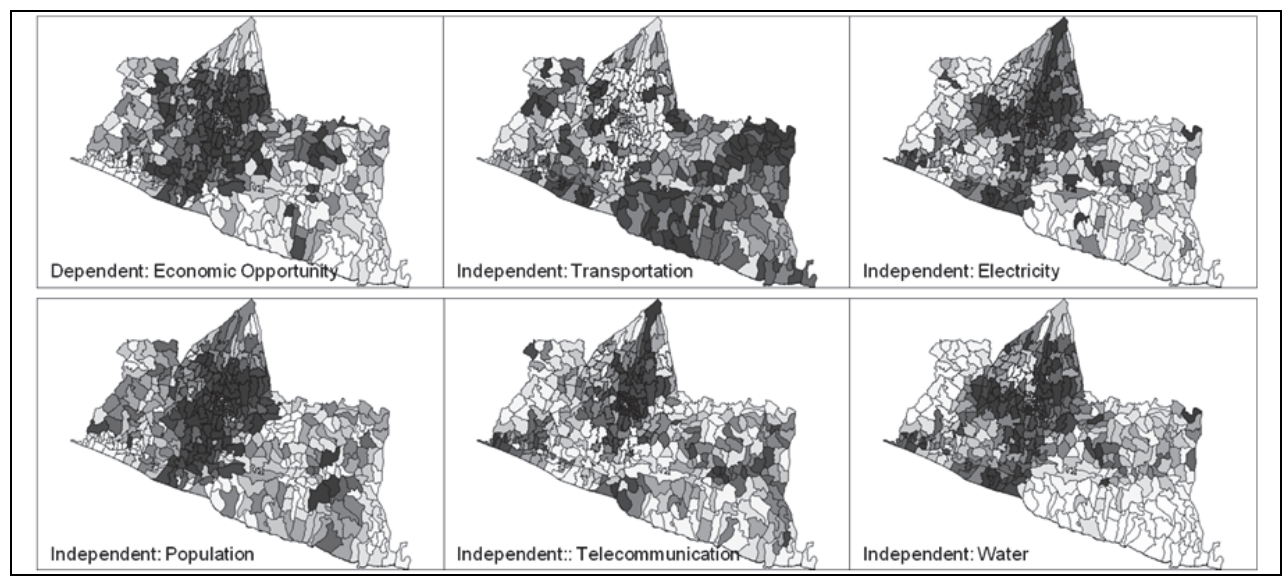

Figure 7.4 Condition of 438 villages in the Special Region of Yogyakarta: Spatial distribution of model variables. The dark colours represent higher values or better infrastructure performance.

To set the poverty line, we use the standard minimum service level that the Government of Indonesia (Ministry Decree for Settlement and Regional Infrastructure, 534/KPTS/M/2001) has determined to be the poverty line (Table 7.2). To provide a strong basis for the capacity for of incomegenerating activity, we set the poverty line at the minimum service level for domestic activities. 
Table 7.2 Minimum Service Level for Domestic Activity as the Poverty Line

\begin{tabular}{lllllll}
\hline Infrastructure & Performance Indicators & References & $\begin{array}{l}\text { Basic } \\
\text { Service }\end{array}$ & $\begin{array}{l}\text { Domestic } \\
\text { Activity }\end{array}$ & $\begin{array}{l}\text { Income- } \\
\text { generating } \\
\text { Activity }\end{array}$ \\
\hline Transport & $\begin{array}{l}\text { Average travel } \\
\text { (km/hr). }\end{array}$ & speed & $534 /$ KPTS/M/2001 & 10 & 15 & 20 \\
\hline Water & Discharge (ltr/day) & $534 /$ KPTS/M/2001 & 30 & 125 & 220 \\
\hline Telecom & $\begin{array}{l}\text { Data transfer capacity } \\
\text { (kbps) }\end{array}$ & $\begin{array}{l}\text { USO Programme } \\
\text { BTIP }\end{array}$ & 14.4 & 28.8 & 56 \\
\hline Electricity & $\begin{array}{l}\text { Electricity supply } \\
\text { household (VA) }\end{array}$ & per & TDL PLN & 30 & 450 & 2200 \\
\hline
\end{tabular}

\subsubsection{Lesson learnt from EQLAS development}

During the intelligence stage we disclosed that spatial interdependency in the infrastructure-economy interaction influences the effectiveness of resource allocation (Wismadi, Brussel et al. 2012). Second, in the design and choice stages, we found that the spatially linked resource allocation policies could best address both social and spatial equity (Wismadi, Zuidgeest et al. 2013) and satisfy both utilitarian and non-utilitarian perspectives. Moreover, the infrastructure typology (e.g., point, linear, and space), the level of performance, and the initial status of spatial equity also influence the effective distribution of growth.

\subsection{Implementation in National Infrastructure Programmes}

To illustrate the implementation of this new type of SDSS framework, we developed two case studies on rural infrastructure development. The first case concerns the Universal Service Obligation Programme in the telecommunications sector, and the second concerns the rural transport sector.

\subsubsection{Transformation of resource allocation decision making in Indonesia}

In the context of regional development, Indonesia has been transitioning from a centralized to a decentralized resource allocation mechanism. After more than 30 years of highly centralized policies, a sudden reform led to a more decentralized fiscal regime, meaning that resource allocation decisions are being taken at the district level (Bennet 2010). The legal framework enabling this decentralization is National Act No 22/1999 on Regional Government, which led to the formulation of Government Regulation No 25/2000 to delegate and distribute responsibilities from the national level directly to the district level. 
Since the introduction of this decentralization mechanism, although the provincial administrations have been recognized as autonomous entities, their actual role has been minimized in such a way that the resource allocation process for national fiscal transfers has resulted in direct allocations to the districts rather than to the provinces. This allocation mechanism generates coordination issues among districts (Firman 2010) and often creates unhealthy competition among local politicians (Sjahrir, Kis-Katos et al. 2014).

This coordination problem often results from differing interpretations of roles, responsibilities and power sharing or distribution reflected by access to resource utilization. Because they are not recognized as serving a resource allocation role, province administrations have been somewhat ignored by district authorities. Learning from these shortcomings in terms of an ignorance of the administrative roles of provinces, in 2004 revised versions of National Act No 32/2004 and Government Regulation No $38 / 2000$ were implemented and returned more power to the provinces in national programme coordination and the allocation of fiscal transfers.

While this revision reinstated a more centralized approach, the demand for resource allocation that takes place at lower level, namely the village level, also emerged. The result of this demand was National Act No 6/2014 on Village (UU Desa), established in 2014, which gives preference in national fiscal transfers directly to the village level.

\subsubsection{Implications of the transformation for the decision- making process on infrastructure and spatial development}

National fiscal transfers to the village level provide greater opportunity for a national programme to be implemented and monitored centrally while ensuring coordination and power distribution at the province and district levels. In such programmes the National Development Planning Agency (Bappenas) and its line ministries define the policy and objectives of various national programmes that should be coordinated by the Ministry of Home Affairs, which is responsible for downstreaming the policy and policy implementation through province and district administrations.

Regarding the evaluation of welfare, this mechanism requires continuous monitoring of the progress made in social and spatial equity. This progress will be one of the critical considerations for regional policy development. 
The national planning system recognizes two possible policy approaches to addressing both social and spatial equity issues and targeting both peoplecentred and place-based policies. The people-centred policy is implemented as a direct transfer from the national budget to poor people through conditional cash transfers (CCT). Examples of such programmes are The Cash Transfers for Poor Students (Bantuan Siswa Miskin/BSM), Conditional Cash Transfers for Poor Households (Program Keluarga Harapan/PKH) and temporary CCT programmes to alleviate the impacts of policy shocks, e.g., fuel subsidy reduction (Bantuan Langsung Sementara Masyarakat /BLSM), on the poorest. Place-based policies are implemented using fiscal transfers through a village-level national programme (e.g., Universal Service Obligation, rural electrification, Program Nasional Pemberdayaan Masyarakat Mandiri Perdesaan/Rural PNPM programmes). Both policy approaches might be combined at a given location. In the people-centred approach, the allocation is based on a head count or household count of those under the poverty line threshold. Combining the people-centred with place-based policy will apply the population as weighting factor in the allocation.

Although many of those equity-oriented programmes are national priorities, a comprehensive programme to monitor and evaluate the progress of both social and spatial equity has not been properly established. If any monitoring is in place, it is focused on aggregate national-level indicators such as ICT penetration level, road network density, electricity levels, etc. With such aggregated indicators, the distribution of resources might not be properly targeted and could increase inequity, as indicated by the increase in the Gini index from 0.335 to 0.413 between 1996 and 2013 (BPS 2014).

This continuous increase over nearly two decades indicates that either people-centred or place-based policy requires a proper information and decision mechanism to allocate resources to target groups or locations. Such systems could serve equity monitoring and evaluation to immediately recognize the impact of allocations and recommend actions to amend the policy or allocation mechanism.

\subsubsection{Requirement for information infrastructure and a spatial decision support system for village development.}

Having recognized the abovementioned insufficiency of information and decision support systems available at present, the government intends to strengthen its information system to realize the capacity for monitoring at the village level. This policy has been mandated to support regional 
development, as described in National Act No: 6/2014 on Villages. Article 86 in Section 3 mandates that national and local governments develop a mechanism called the Information System for Village Spatial Development that is to be shared and used for the benefit of villages.

The conceptual structure for the operation of this information system at each administrative level can be outlined as follows:

1. National level: a policy for resource allocation, to be conducted by the ministry associated with the type of programme at hand.

2. Province level: the allocation and coordination of fiscal transfers, to be facilitated by the Ministry of Home Affairs and the National Planning and Development Board.

3. District level: a spatial development plan, to be conducted by the responsible district or municipality

4. Village level: a village development plan and its implementation, to be conducted by village-level administration with coordination by the Ministry of Villages, Deprived Villages and Transmigration.

At each level, the requirement for the decision support systems for infrastructure development involve the solution for harmonizing 3 conflicting objectives, first is "accessibility" by ensuring physical availability of the infrastructure and its service within a reasonable distance. Second objective is "affordability" by ensuring every individual could afford the service. Third is "utility" by ensuring that a sufficient level of service could satisfy the user.

Accessibility program requires the allocation of resource to expand the existing service to be interconnected toward the most remote and rural areas. Affordability programs involve end-user subsidy, especially in the case of available service is too expensive for the user. Utility program would allocate the resource to set and enhance level of service to satisfy and provide usability for the user.

With a same amount of financial resource, if most of the budget goes to accessibility program, then less resource would be available for end-user subsidy or enhancing quality of service. Similarly, if the resource is allocated mostly for enhancing level of service, less coverage of accessibility and affordability issues would be raised. On the other hand, if an excessive budget is allocated for end user subsidy an inequitable allocation for accessibility and affordability would be the problem.

The data requirement for accessibility program will involve existing infrastructure, its interconnecting hiearchy, and the capacity for expansion. 
The affordability program require information of the capital and operational expenditure against the ability and willingness to pay of the target group and available budget for the end-user subsidy. The utilization program require information of feature of service and demand characteristics of target groups.

The decision support system described in this research (EQLAS) has been provided with Spatial Preference Modelling, therefore it is capable for dealing with connectivity issues in accessibility program. EQLAS also allows to support affordability program that requires allocation of end-user subsidy where interconnected infrastructure is available but price disparity are exist in certain region. Moreover, to support utilization program, EQLAS is capable for what-if scenario or iteration for policy setting on level of increased service and its satisfaction measurement (see Chapter 6). Within EQLAS framework, a Non-Spatial Preference Modelling also available to implement spatially-blind policy where the poor is targeted regardless its spatial location (people-centred approach).

\subsection{Case studies of Rural Infrastructure in Indonesia}

The application of the EQLAS SDSS framework to a real-world decision problem is demonstrated using two case studies of rural infrastructure development and resource allocation prioritization. These case studies represent two distinct requirements for network functionality; the first concerns the transport sector and focuses on the basic functions of rural transport for internal traffic and interaction as well as it connection with main networks. The second case involves telecommunications, where the basic functioning rural network requires global connections.

\subsubsection{Transportation}

After more than two decades of state absence in public transport service provision - resulting in market failure and leading to low public transport ridership, e.g., in Yogyakarta of only $27.22 \%$ of the population on average (Dirgahayani and Nakamura 2012) - the Indonesian government passed Transportation Act 22/2009, which requires the government to ensure the right to mobility. This spatially blind policy instrument is implemented under the Public Service Obligation (PSO) programme. The PSO is awarded, administered and subsidized by the government through agencies.

The awards can go to a private operator or state-owned enterprises (SOEs) through a bidding process. Currently, the bidding process only involves local operators. However, in the near future once ASEAN member countries have formed a single market entity, e.g., as mentioned in ASEAN Free 
Market 2015, the participation of multinational operators from other ASEAN member states or even from the other regions will be unavoidable. A multinational operator for local transport services (MOLTS) is likely to engage in head-to-head competition with local operators (Takeru and Hitoshi 2011). Such an increasingly competitive environment is expected to benefit the public. However, given the exceedingly challenging nature of providing rural transport, the operators are likely to bid only for contracts in urban areas. Thus, a spatially targeting incentive represents a potential instrument to attract the interest of business-oriented operators. This program would combine accessibility, affordability and utility program that requires a strong financial commitment.

One means of obtaining a significant amount of national funding to finance a rural transport system is the savings that would result from reducing fuel subsidies (Dartanto 2013). After decades of considerable fuel subsidies - in a country with extremely constrained fiscal capacity - the government recently decided to reduce the fuel subsidies by approximately $50 \%$. This reduction could yield USD20 billion in annual savings, part of which could be allocated to infrastructure programmes.

Before the reduction in fuel subsidies, it was difficult for the country to make a full financial commitment to PSOs for nationwide mobility services. Realizing this shortcoming, a short-term solution has been implemented: allowing each individual to find his or her own mobility solution through private vehicles. This approach has been implemented using another spatially blind policy, namely, the provision of a financial credit facility that allows poor people to purchase a motorcycle. In practice, this facility is not exclusively used by poor people from rural areas; rather it is primarily used by citizens living in urban areas, who also face limited access to public transport. Absent careful spatial targeting, the policy for allocating credit might be counterproductive with respect to public transport financing. In this case, subsidized public transport will be underutilized as it competes with motorcycles. However, the fact that public service provision would not be provided in the near term means that the need for a spatially blind credit distribution policy remains high. This situation illustrates the need for decision tools to identify the best or combined implementation of people-centred and spatially linked policy into accessibility, affordability and utilization program.

\subsubsection{Telecommunications}

The telecommunications sector in Indonesia is very progressive in implementing liberal policies. A spatially blind institution to reduce the 
state monopoly was created through Telecommunication Act 36/1996. The reform began with a transition from monopoly to duopoly that allowed the SOE (TELKOM) to become a competitor of the other large SOE (INDOSAT). Although INDOSAT was initially specifically established for international telephone service, this SOE was later privatized and became a competitor of TELKOM. After further reforms over the course of over a decade, a fully liberalized was established for mobile service.

At the beginning of the mobile era, the new mobile operators remained dependent on the SOE, the incumbent, which provides connections to fixed lines to public subscribers in offices and homes. At the time, the incumbent charged an interconnection fee that was intended to extend the network to rural areas.

However, after the mobile networks reached most of the SOE's subscribers, the mobile operator ceased to be dependent on the incumbent. After residential customers began to subscribe to the mobile service, full competition in the telecommunications sector was realized.

In this situation, the incumbent is unable to charge an interconnection fee or increase the price to make investments in service in rural areas. Similarly, no single private mobile operator is willing to "play" in rural areas. Thus, a digital divide between urban and rural areas will continuously increase social and spatial inequity.

As the SOEs and private operators had no intention to serve rural areas, the government had to intervene by introducing the USO. This financial intervention is conducted by transforming the obligation to "play" in rural areas into "paying" for rural areas. This funding mechanism, the so-called USO Fund or Universal Service Obligation Fund, was subsequently managed by the Rural Telecommunication Agency (BP3TI) to award any private operator that was willing to play with a bidding process.

After five years of collecting contributions to the USO fund, the programme to reduce the digital divide has failed to achieve the expected level of deployment. Less than $30 \%$ of collected fund is disbursed annually, primarily due to the geographical challenges of operating rural and remote areas and the limited availability and capacity of backbone networks. To address this problem, the country is now seeking to use the USO Fund to not only providing last-mile connectivity but also for deploying backbone networks in remote and non-commercially viable areas. 
To deploy the programme, a poverty line or minimum level of service needed to be determined. The USO programme has also been evolving in terms of the level of service. In 2003, it was intended to provide 'a public phone within walking distance'; therefore, the One Village One Public Phone or Desa Berdering (Ringing Village) programme was initiated and targeted approximately 35,000 villages. An additional programme, called Desa Pinter (Village has Internet), was also implemented. The introduction of the Internet to rural communities then expanded in the form of Subdistrict Internet Service Centres and Mobile Sub-district Internet Service Centres targeting more than 5,000 sub-districts.

Recently, given the increased use of on-line applications, data volumes and traffic demand, a new generation of the USO programme has been implemented. Soon after the establishment of Presidential Decree No $69 / 2014$ on Indonesia Broadband Plan for 2014-2019, a USO programme was inaugurated to provide broadband-capable Internet access for rural communities. Through this redefined programme, the USO fees that are collected are to be distributed using a more robust planning instrument. The redesigned USO programme will begin with a pilot phase involving approximately 800 communities selected from 73,000 villages. The deployment of this programme clearly requires decision support tools to operationalize the new policy and prioritize it among USO programmes. The decision making process for implementing this program also deal with combining objective of accessibility, affordability and utilization. The accessibility program apply a spatially linked policy when connectivity to a main network is required, whereas people-centred policy is needed when affordability is an issue. For example, the IBP policy mandates that the price of broadband be below $5 \%$ of an individual's income. The utilization objective aims to provide the service with at least 1Mbps to $53 \%$ population living in the rural area.

\subsubsection{Operationalizing EQLAS in the telecommunications and transport sectors}

The sectors considered in these case studies face, in some respects, similar decision problems. The general issue is how to effectively address the gaps in infrastructure service provision across regions and people, given budget constraints and the interrelated objectives of accessibility, affordability and utilization programs..

In both cases, the decision process combines a bottom-up and top-down approach. The bottom-up approach is intended to accommodate proposals from lower level administrative units, while the top-down approach is 
intended to ensure an effective implementation of the national programme under the allocated budget.

Proposals can be submitted by various units of local government, line ministries, community groups or service providers. The type of activity is then categorized according to demand and supply characteristics at the proposed sites. To address the budget constraint, it is necessary to determine the priority of each type of activity. The priority ranking of proposals from the bottom-up process is formulated according to the level of commitment stated in the proposal and the appropriateness of the activity to the site's characteristics. The priority established based on the top-down process is formulated using preference modelling in EQLAS (NSPM and SPM). The final priority set is the aggregated score from the bottom-up and top-down preferences.

To address issues concerning the budget constraint, according to each site's characteristics, a budget estimate for providing a certain level of service will be used to simulate the impact of the budget constraint on the distributional impact of the allocation. The aim of the simulation is to provide annual programme targets to incrementally increase infrastructure performance in each village towards the level stated in policy target.

The result of this allocation mechanism is, therefore, a list of priority sites and the budget to be allocated in each year.

To demonstrate the potential application of EQLAS to resource allocation from the national to sub-national and village-level administrations, the variables and operational definitions of each stage of the decision-making process for the telecommunications and transport sectors are elaborated below (Table 7.3). 
Table 7.3 Operationalizing EQLAS in the Telecommunications and Transport Sectors

\begin{tabular}{|c|c|c|c|}
\hline & Programmes: & $\begin{array}{l}\text { Universal Service } \\
\text { Obligation in the } \\
\text { Telecommunications } \\
\text { Sector }\end{array}$ & $\begin{array}{l}\text { Rural/Public Service Obligation in } \\
\text { the Transport Sector }\end{array}$ \\
\hline \multirow[t]{3}{*}{$\begin{array}{l}\text { SEVEN STEPS of } \\
\text { EQLAS: }\end{array}$} & Objectives: & $\begin{array}{l}\text { Addressing the digital } \\
\text { divide and equitable } \\
\text { economic opportunity } \\
\text { through the provision of } \\
\text { broadband access in un- } \\
\text { served and underserved } \\
\text { locations as well as to } \\
\text { underprivileged groups of } \\
\text { people. }\end{array}$ & $\begin{array}{l}\text { Addressing regional disparities in } \\
\text { economic opportunity through the } \\
\text { provision of public transport and } \\
\text { personal mobility services and } \\
\text { urban-rural connectivity }\end{array}$ \\
\hline & $\begin{array}{l}\text { Source of the } \\
\text { Budget: }\end{array}$ & $\begin{array}{l}\text { Universal Service } \\
\text { Obligation Fund (USF) } \\
\text { collected from } 1.25 \% \text { of an } \\
\text { operator's gross revenue. }\end{array}$ & $\begin{array}{l}\text { State budget allocated in the form } \\
\text { of the Transport Special Allocation } \\
\text { Fund (DAK Transport) and Village } \\
\text { Fund (Dana Desa) to be distributed } \\
\text { to village-level administration. }\end{array}$ \\
\hline & Fund Managers: & $\begin{array}{l}\text { Ministry of Communication } \\
\text { and Informatics }\end{array}$ & $\begin{array}{l}\text { Ministry of Villages, Deprived Area } \\
\text { and Transmigration }\end{array}$ \\
\hline $\begin{array}{l}\text { INTELLIGENCE } \\
\text { STAGES }\end{array}$ & ASPECTS: & & \\
\hline \multirow[t]{2}{*}{$\begin{array}{l}\text { Infrastructures } \\
\text { Distributions }\end{array}$} & Level of Service & $\begin{array}{l}\text { Ubiquitous broadband } \\
\text { Internet at a minimum of } \\
\text { 1Mbps speed for mobile } \\
\text { and 2Mbps for fixed } \\
\text { service. }\end{array}$ & $\begin{array}{l}\text { Availability of appropriate formal } \\
\text { or informal transport services to } \\
\text { access local markets and medical } \\
\text { and educational facilities beyond 5- } \\
\mathrm{km} \text { distance at a speed of } 10 \\
\mathrm{~km} / \text { hour. }\end{array}$ \\
\hline & Location & $\begin{array}{l}\text { Urban, rural and remote } \\
\text { areas. }\end{array}$ & Rural and urban-rural linkages \\
\hline \multirow[t]{2}{*}{$\begin{array}{l}\text { Equity } \\
\text { Measurement }\end{array}$} & Social & $\begin{array}{l}\text { Fixed broadband Internet } \\
\text { service to } 49 \% \text { of rural } \\
\text { households and } 6 \% \text { of } \\
\text { individual subscribers, } \\
\text { mobile broadband Internet } \\
\text { service to } 52 \% \text { of the rural } \\
\text { population, both at a } \\
\text { maximum price } 5 \% \text { of } \\
\text { income. }\end{array}$ & $\begin{array}{l}\text { Rural population living within } 30 \\
\text { minutes' walk of appropriate } \\
\text { formal or informal transport } \\
\text { services to access local markets, } \\
\text { medical and educational facilities } \\
\text { beyond 5-km distance. }\end{array}$ \\
\hline & Spatial & 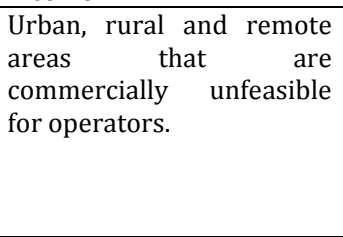 & $\begin{array}{l}\text { Rural populations living within two } \\
\text { kilometres of a road, motorable } \\
\text { trail or other appropriate } \\
\text { infrastructure providing year- } \\
\text { round access connecting the main } \\
\text { village to urban-rural and national } \\
\text { transport networks. }\end{array}$ \\
\hline
\end{tabular}


DESIGN STAGES

\begin{tabular}{|c|c|c|c|}
\hline \multirow[t]{2}{*}{$\begin{array}{l}\text { Allocation } \\
\text { Preference } \\
\text { Modelling }\end{array}$} & Non-Spatial & $\begin{array}{l}\text { Spatially blind policy } \\
\text { prioritization of public } \\
\text { services to r the } \\
\text { underprivileged groups } \\
\text { (e.g., universal health } \\
\text { coverage and insurance } \\
\text { to the poorest that } \\
\text { require on-line/ICT } \\
\text { systems). }\end{array}$ & $\begin{array}{llr}\text { Spatially } & \text { blind } & \text { policy } \\
\text { prioritization in the allocation to } \\
\text { enable individual } & \text { mobility } \\
\text { through sustainable } & \text { transport } \\
\text { systems. } & & \end{array}$ \\
\hline & Spatial & $\begin{array}{l}\text { Spatially connective and } \\
\text { spatial incentive policies } \\
\text { prioritizing the under- } \\
\text { served and un-served } \\
\text { areas with the aim of } \\
\text { reducing the digital } \\
\text { divide. }\end{array}$ & $\begin{array}{l}\text { Spatially connective and spatial } \\
\text { incentive policies to ensure year- } \\
\text { round access and service } \\
\text { connecting main village to urban- } \\
\text { rural and national transport } \\
\text { networks. }\end{array}$ \\
\hline \multirow[t]{3}{*}{ Equity Benchmarks } & Global & $\begin{array}{l}\text { Ubiquitous broadband } \\
\text { Internet at a minimum of } \\
1 \mathrm{Mbps} \text { speed for mobile } \\
\text { and 2Mbps for fixed } \\
\text { service. }\end{array}$ & $\begin{array}{l}\text { Availability of formal or informal } \\
\text { transport services and personal } \\
\text { mobility solutions with a travel } \\
\text { speed of } 10 \mathrm{~km} / \text { hour }\end{array}$ \\
\hline & Local & $\begin{array}{l}\text { Reduced spatial inequity } \\
\text { across locations through } \\
\text { incremental increase of } \\
\text { Internet speed towards } \\
\text { 20Mbps to households ( } 4 \\
\text { Mbps to individuals). }\end{array}$ & $\begin{array}{l}\text { Reduced spatial inequity across } \\
\text { locations through incremental } \\
\text { increases in travel speeds above } \\
20 \mathrm{~km} / \text { hour. }\end{array}$ \\
\hline & Glocal & 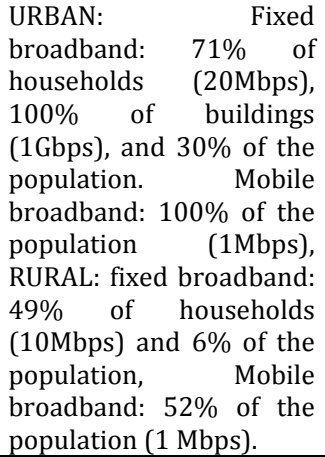 & $\begin{array}{l}\text { Proportion of rural population } \\
\text { living within } 30 \text { minutes' walk of } \\
\text { appropriate formal or informal } \\
\text { transport services to access local } \\
\text { markets and medical and } \\
\text { educational facilities beyond 5- } \\
\text { km distance at } 70 \% \text { (riverbank } \\
\text { areas), } 75 \% \text { (mountainous), } 75 \% \\
\text { (coastal) and } 90 \% \text { (plain). }\end{array}$ \\
\hline
\end{tabular}


Chapter 7

\begin{tabular}{|c|c|c|c|}
\hline \multirow{3}{*}{$\begin{array}{l}\text { Resource } \\
\text { Distribution Effect }\end{array}$} & Outcome & & \\
\hline & & $\begin{array}{l}\text { Infrastructure } \\
\text { performance index (e.g., } \\
\text { broadband penetration) } \\
\text { achieves the policy } \\
\text { targets. }\end{array}$ & $\begin{array}{l}\text { Infrastructure performance index } \\
\text { (e.g., travel speed) achieves the } \\
\text { policy targets. }\end{array}$ \\
\hline & Impact & $\begin{array}{l}\text { Economic Development } \\
\text { Index (e.g., poverty } \\
\text { incidence) achieves the } \\
\text { policy targets. }\end{array}$ & $\begin{array}{l}\text { Economic Development Index } \\
\text { (e.g., poverty incidence) achieves } \\
\text { the policy targets. }\end{array}$ \\
\hline \multirow[t]{2}{*}{ Equity Measures } & Social & $\begin{array}{l}\text { Social equity index (e.g., } \\
\text { Gini) reaches the policy } \\
\text { targets. }\end{array}$ & $\begin{array}{l}\text { Social Equity Index (e.g., Gini) } \\
\text { reaches the policy targets. }\end{array}$ \\
\hline & Spatial & $\begin{array}{l}\text { Spatial equity index (e.g., } \\
\text { Moran I) achieves the } \\
\text { policy targets. }\end{array}$ & $\begin{array}{l}\text { Spatial equity index (e.g., Moran I) } \\
\text { achieves the policy targets. }\end{array}$ \\
\hline \multirow[t]{2}{*}{ Perspectives } & Utilitarian & $\begin{array}{l}\text { Highest total utility of } \\
\text { community satisfaction in } \\
\text { experiencing high speed } \\
\text { Internet. }\end{array}$ & $\begin{array}{l}\text { Increased access for rural people } \\
\text { to job opportunities, poverty } \\
\text { alleviation, health facilities, and } \\
\text { food security }\end{array}$ \\
\hline & Non-Utilitarian & $\begin{array}{l}\text { Highest level of } \\
\text { community capability as } \\
\text { the result of Internet. }\end{array}$ & $\begin{array}{l}\text { Highest level of individual } \\
\text { mobility as a result of } \\
\text { infrastructure and service to } \\
\text { achieve universal mobility. }\end{array}$ \\
\hline
\end{tabular}

\subsection{EQLAS deals with conflicting objectives}

Aforementioned, the decision problem in infrastructure development consist of conflicting objective of accessibility, affordability and utilization. In EQLAS framework, the accessibility objective is addressed with Allocation Preference in Design Stage, particularly the application on Spatial Preference Modelling. This allocation seeks for under connected or missing link, therefor allows for systematics annual program to expand the existing network from backbone (in telecommunication) to the last mile in rural area or from the main transport network to the local transport services, with coverage targeted in the Intelligence Stage in Table 7.3.

To achieve the affordability objective, with refers ot affodability objective (e.g. $5 \%$ of average income) the available budget for end-user could be distributed with EQLAS based on the input of existing affordability gaps data. Beside using this budget contrained decision, this budget requirement for affordability program could be estimate based on the quota of service. For example, on the telecommunication program this end-user subsidy is only limited to certain volume of data (e.g. 100MB/capita/years or $15 \mathrm{~GB} /$ user/month). After reaching the quota, the commercial based price is applied. Similarly, the end-user subsidy for rural mobility program could be based on the amount of daily trips per person (e.g. 2 trips for work or school), the additional trips will be applied with cost-based price. 
EQLAS could address utility objective with its capability for what-if simulation or iteration involving various level of performance. The input for simulation could refer to Equity Bechmark in Table 7.3.

The above capability of EQLAS framework to address overarching and conflicting policy objectives discloses a wide applicability in other domains of infrastructure.

\subsection{Conclusion}

This chapter proposes a new type of SDSS framework for equitable resource location-allocation. Our model of Equity-based Resources Location-Allocation Simulation (EQLAS) provides a decision support framework to simultaneously address social and spatial equity in infrastructure development.

The case study used for the development of EQLAS and the case studies of potential applications to the National Infrastructure Programme in Indonesia offer a practical guideline for institutionalizing this new type of SDSS into a nationwide infrastructure programme. 


\section{Chapter 8}

\section{Synthesis}

\subsection{Introduction}

Infrastructure is a main driver of economic development. Toward an equitable distribution of development benefits, public spending for infrastructure is generally provided to distribute economic opportunity throughout a region. Often, an inequitable distribution of infrastructure limits the availability of economic opportunities in certain areas and causes migration to more developed or urban areas.

Triggered by national and regional disparity, many countries tend to shift their approach towards governance and public spending from centralized to decentralized systems. This trend implies a fiscal decentralization and moves the decision-making governance closer to the people or community at a lower level of administration, such as the village. In an infrastructure development context, the implementation of such systems requires a combination of the interdependence of the coexistence of infrastructure and the accommodation of local preferences in resource allocation for infrastructure. The consequences of involving the community in resource allocation are not only related to the local condition and needs but also the perception of any unequal allocation among people (social equity) as well as among neighbouring units (spatial equity).

Interestingly, although the decentralizing system's objective is to accommodate local preference, the efficiency of public spending decreases in countries that apply local elections. The source of inefficiency is a decision bias from local politicians and decision makers that have an interest in distributing resources to their constituents and future voters. Although this issue has been recognized, the actual mechanism of the infrastructure-economy interaction beyond such an inefficient allocation in a decentralized context can rarely be found in the current literature. The absence of research in this field limits the availability of a robust framework to counter the decision bias and to provide an alternative method to allocate resources for infrastructure. Such a situation not only results in inefficient public spending and a slowdown of economic growth but also creates social tensions because of its implication to the inequity of opportunity among neighbouring units and socio-economic groups. 
To address such inequity, two general policies for reshaping the economic geography of welfare are available: Place-based and People-centred policies. With various initial states of a location, each policy has its own implication on welfare's future equity.

With the intention of assisting policy makers in deciding when and where Place-based and People-centred policies should be implemented for the equitable distribution of infrastructure, the general purpose of our research is to propose a new type of SDSS framework for equitable resource location-allocation. Specifically, we focus on infrastructure development as a means for simultaneously addressing social and spatial equity and therefore for addressing the regional disparity.

This chapter reports the results of this research in a step-by-step manner; it discusses research objectives and the associated research questions as stated in Chapter 1 and discusses the findings of each investigation.

\subsection{Main Results}

The result of this research is presented in the first part of the report in the Context Paper (Chapter 2) and Background Paper (Chapter 3), with the main result outlined as a series of working Papers in Chapter 4, 5 and 6. Furthermore, Chapter 7 summarizes all of the main results into a policy paper.

As an introduction to the context of the research, Chapter 2 presents a debate to prioritize place-based versus people-centred policies for regional development, which has been driven by a policy framework that was promoted in the World Development Report 2009 (WDR). Focus is provided to assess the implications of this global policy on a specific locality for social justice. Here, we disclose the construction of distribution politics and the power relations underlying the policy for infrastructure planning and public service provision. The lesson learned serves as knowledge for recrafting the policy framework to be practical in various contexts. From the case study, we reveal that to maintain equitable growth, the policy maker requires planning and decision support tools to determine where and when the 1) spatially blind institution, 2) spatially connective infrastructure and 3) spatially targeted incentive can be properly applied.

As a background paper, Chapter 3 describes the existing social equity measurement methods to be applied in infrastructure development. The results reveal certain advantages and disadvantages of these methods. 
The detailed description of the main results of this research are outlined below.

1. Consideration for place-based policy: the inclusion of neighbouring village conditions and the infrastructure interdependency improves the performance of the infrastructure-economy interaction model.

With concern for simultaneously addressing social and spatial equity, we discussed the global policies of "place-based" and "people-centred" regional programs and their implication on equity issues at the local level. While contributing to the debate to prioritize place-based versus peoplecentred policies, in Chapter 2, we disclose that the construction of distribution politics and power relations underlying the policy for infrastructure planning and public service provision could result in an unexpected inequity state. The implication of choice between place-based or people-centred policies is very much influenced by the local context; therefore, to maintain equitable growth, the policy maker requires planning and decision support tools to determine where and when "placebased" and "people-centred" policies can be properly applied.

To examine the effect of place-based policy in infrastructure and economic interactions and to serve as a basis to justify the need to establish a formal method to operationalize place-based policy into resource allocation modelling, Chapter 4 reports an investigation of the necessity of including the neighbouring factors and infrastructure interdependency for allocating resources into specific localities. By comparing three connected concepts and the associated models of infrastructure-economy interactions that gradually include neighbouring factors and infrastructure interdependency, we disclosed that both neighbouring factors and infrastructure interdependency are critically important and should be included in the decision making process and for allocating resources in infrastructure development. Therefore, the findings emphasize the importance of considering the neighbouring information and infrastructure interdependency in the implementation of a place-based policy for allocating resources for infrastructure development.

2. Impact of place-based policy: Spatial Preference Modelling in a resource allocation reduces spatial inequity.

In an attempt to further examine place-based policy, in Chapter 5, we develop a new approach to implement a place-based resource allocation policy in a Spatial Decision Support System and compare its effectiveness to address spatial equity against a people-centred policy. 
In a Spatial Decision Support System (SDSS), one main component that is related to policy implementation is Preference Modelling (PM). PM provides a means to transform stakeholder value into priority and allocation. In traditional PM, the preference is calculated by considering the value of decision units and their differences with all of the other units in the region; however, this procedure ignores the specific differences among neighbouring units. With these limits, traditional PM that ignores the neighbourhood gaps is not suited to solve the resource allocation problem in a decentralized context. Traditional PM is close to the non-spatial people-centred policy.

To address this issue, in Chapter 5, we discuss a new approach considering the degree of differences among spatial neighbouring units in a new type of Preference Modelling. This is done by introducing Spatial Preference Modelling (SPM), which enables us to operationalize Place-based Policy in a DSS for allocating resources.

In the comparison between the traditional Preference Model and Spatial Preference Model, we found that, by considering the neighbouring unit differences, resource allocation performs better in addressing spatial equity issues.

3. Place-based and people-centred policies compliance on social justice: Spatial Preference Modelling is closer to planning objectives with an exception for local variances.

To generalize our findings, we compare the agreement of place-based and people-centred policies on planning objectives and social justice, with reference to utilitarian and non-utilitarian welfare theories applied in infrastructure. Learning from the limits of existing social equity measurements as discussed in Chapter 3, in Chapter 6 we propose a new method for measuring social equity, the so called W-curve, which includes an observation for poor as well as non-poor groups. Moreover, to measure its compliance to utilitarian equality theory, we apply the Total Utility Equality approach. However, for non-utilitarian equality, we conduct a curve dominance analysis to evaluate the degree of the pro-poorness of the allocation, its effectiveness to address inequity, and its impact on prosperity.

In Chapter 6, a case study demonstrates the modelling by presenting a resource allocation problem for infrastructure development that includes roads, electricity, telecommunication and fresh water infrastructure in the Special Region of Yogyakarta in Indonesia. The results confirm that Spatial 
Preference Modelling generally better satisfies both utilitarian and nonutilitarian welfare theory than Aspatial Preference Modelling. However, we found variance in which People-centred Policy may be more effective for equitable resource allocation than Place-based Policy. This variance is influenced by the level of development, the typology of infrastructure, and the initial contribution level of inequality. This finding could help both utilitarian as well as non-utilitarian infrastructure planners achieve a more equitable allocation of resources.

4. Equity Based Resources Location-Allocation Simulation (EQLAS) SDSS Framework assists policy makers to determine when and where to implement "place-based" over "people-centred" policy.

Learning from the variance of the effectiveness of "place-based" over "people-centred" policies for equitable infrastructure, in Chapter 7, we establish a decision support framework to recommend where and when "place-based" or "people-centred" policies for equitable infrastructure development should be applied. This framework synthesizes all of the findings into a decision support framework of Equity Based Resources Location-Allocation Simulation (EQLAS) for integrated infrastructure development.

The EQLAS Model is a framework to operationalize measures of well-being and equity in resource location-allocation modelling. This framework includes two types of preference modelling to operationalize both Placebased and People-centred policies, evaluating their impacts and recommend which policy needs to be applied, as well as when and where, according to specific localities.

\subsection{Research Contributions}

\subsubsection{Contributions on the formulation of policy and its implementation of infrastructure resource allocation to address spatial and social inequity.}

With the background of regional disparity and social inequity problems in Indonesia, we contribute to the global discourse on place-based vs peoplecentred policies for reshaping the welfare geography. We merge those two policy options in the context of distributive welfare in an attempt to simultaneously address social and spatial equity. The findings of this research can equip policy makers with the ability to understand both options and their implications for equity in the local context and provide 
recommendations on where and when those policy options should be applied or combined.

Moreover, in addition to evaluating the impact of each policy option, this research also contributes by providing a formal method to apply the policy option into a resource allocation approach in a GIS-based Decision Support System. Hence, this research allows policy and decision makers to systematically address inequity by means of improving infrastructure performance toward equitable growth.

\subsubsection{Contributions on the development of Spatial Decision Support Systems (SDSS)}

Learning from the stages and findings in each chapter, we provide inputs to the possible development of a Spatial Decision Support System (SDSS) tool that can be used for infrastructure allocation in the Indonesian context. The framework for a SDSS can generally be structured into three main stages: a) the intelligence phase, to determine the decision problem and boundary of the system; b) the design phase, to generate alternatives to address decision problems; and c) the choice phase, to find the best alternative under different perspectives, criteria and scenarios. The contribution of this research, through categories for each of these three SDSS framework stages, is described below:

Intelligence: Understanding the infrastructure-economy interaction towards an equitable distribution of opportunities. The intention to simultaneously address social and spatial equity is closely related to a debate on place-based vs. people-centred policies. The discussion is based on the necessity of economic policies to be people-centred to maximize welfare, whereas the intervention may need to consider the spatial or territorial dimensions, which refer to place-based policies (Banzhaf and Walsh 2013). Therefore, the intervention by means of allocating resources for infrastructure could be targeted to poor people directly or distributed at a location where the interconnected economic activities could aggregate growth and welfare for the poor. This debate is the main foundation of the discussion in the intelligence stage. To contribute to this debate, Chapter 4 explores the Place-based policy option by exploring the nature of the infrastructure-economic interaction. Chapter 4 concludes with the importance of considering neighbouring factors and infrastructure interdependency in a decision making process for allocating resources for village level infrastructure development. This understanding is essential as a basis for proper resource allocation and forms the basis for an improved decision mechanism for infrastructure development. 
Design: What are the alternative methods to address inequity? In the intelligence stage, we search for the possibility of including spatial considerations and their influence on both social and spatial inequity. Here, we have generated alternative methods derived from the policy and approach to consider spatial inequity in resource allocation. The so-called Spatial Preference Modelling (SPM) method is provided to consider the infrastructure-economy interaction established in the intelligence phase by introducing neighbourhood inequity as one important consideration for allocating resources. The SPM also represents a Place-Based policy. Chapter 5 explains how the SPM was developed, tested and proven as a new preference model that is useful for addressing spatial inequity in the targeted region. The implementation of Spatial Preference Modelling in a SDSS provides a new means of transforming stakeholder value into priority and allocation and provides a better decision mechanism to address spatial inequity.

Choice: Concern of regional disparity and social welfare perspectives. The Choice stage intensively involves the perspective of the general public and social or infrastructure planners. In the equity context, the interest of the general public reflects the expected moral sense of fairness, whereas the interest of the planner is the achievement of the theoretical or philosophical reasoning behind the planning. In Chapter 6, we used a real world empirical application for four types of infrastructure: roads, electricity, telecommunication and water; we learned from the development process and the case-study and suggest a general framework for equitable infrastructure development policies. Chapter 7 provides a detailed explanation of the Equity Based Resources Location-Allocation Simulation (EQLAS-Model). This model has become the first comprehensive framework to evaluate pro-poor, pro-growth and pro-job policies and programs.

\subsubsection{Contribution on the multi-disciplinary knowledge of management of infrastructure and community development}

This research is part of a joint course development program between ITC University of Twente, Keypoint Consultant in The Netherland and Universitas Gadjah Mada in Indonesia. The development activity was funded by the NL based EVD agency under their INDF project, which aimed to develop a curriculum and to establish a new master course on Management of Infrastructure and Community Development in Universitas Gadjah Mada (http://www.pipm.pasca.ugm.ac.id). The course combines various disciplines, such as Engineering, Social Science, Economy, and 
Development Studies, and the subject matters of Integrated Infrastructures, Spatial Planning, Environment, GIS and RS as well as Governance.

This PhD research is one deliverable in this project with the objective of establishing a new state of the art presence in the new field of Management of Infrastructure and Community Development. Internationally, this research is the first academic study that successfully includes a multidisciplinary approach with various subjects required in the field of Management of Infrastructure and Community Development.

\subsection{Future Works}

This research has combined all of the findings into a decision support framework of an Equity Based Resources Location-Allocation Simulation (EQLAS) for integrated infrastructure development to recommend where and when a "place-based" or "people-centred" policy for equitable infrastructure development should be applied.

During the development process, we learned that certain works could be performed in the near future to refine the current results:

\section{EQLAS as a new software application of SDSS}

This research has provided a working example of the implementation of a framework for equity based resources allocation. The framework has been implemented with various software environments (GeoDA, MSExcell, ArcGIS and Ilwis). For further implementation, new dedicated application software needs to be developed to scale the framework's use and to make it suitable for application by planners.

2. Neighbouring matrix and data requirement for EQLAS variant

In this research, we determine the neighbouring matrix mainly based on the adjacent geographical position. Analysis using the adjacent geographical position may not require network data. Other possible means to generate a neighbourhood matrix (e.g., physical network connectivity and distance based relation) can be implemented as a variant in the EQLAS Model. This model will allow the concept of equitable infrastructure resource allocation at a lower connectivity level, such as road network development.

3. Transform the proportion of allocation into monetary units of allocation 
This research is focused on resource allocation, but is limited to the proportion of the allocation (percentage of growth, increased performance, and percentage of allocation) instead of monetary units of investment (e.g., USD, EUR, and IDR). To transform this research into monetary value, further research is required to estimate the value investment while considering the variability of cost factors, such as the local conditions, the existing policies and regulations, the price of construction services, or geographical and topographical features.

4. Reverse engineering of the infrastructure-economy interaction model.

EQLAS has provided a simulation environment to estimate the resources location-allocation of infrastructure for supporting economic distribution. EQLAS resources location-allocation can be performed by incrementally increasing the allocation target for each type of infrastructure until the expected policy target has been achieved (e.g., the growth of economic opportunity and the acceptable level of social and spatial equity). Often, decision maker wants to know directly what resources are needed for each type of infrastructure in every village. Although the current version of EQLAS allows us to obtain this result, the calculation process cannot be performed backwards. This type of reverse estimate is not provided, and it requires more investigation and the development of a new algorithm. Hence, future work that can be related to reverse engineering an algorithm to derive the expected economic opportunity growth to directly estimate the required infrastructure investment in each village while maintaining the pro-poor, pro-growth and pro-job policy achievement. 


\section{Bibliography}

ADB (2004). Key Indicators 2004: Poverty in Asia: Measurement, Estimates, and Prospects Key Indicator of Developing Asia and Pacific Countries, Asian Development Bank.

Aharoni, Y. (1988). "Why do governments privatize?" Technovation 8(1-3): 7-23.

Akgun, I., A. Kandakoglu, et al. (2010). "Fuzzy integrated vulnerability assessment model for critical facilities in combating the terrorism." Expert Systems with Applications 37(5): 3561-3573.

Alesina, A. and G.-M. Angeletos (2005). "Fairness and Redistribution." American Economic Review 95(4): 960-980.

Ananda, J. and G. Herath (2009). "A critical review of multi-criteria decision making methods with special reference to forest management and planning." Ecological Economics 68(10): 2535-2548.

Anselin, L. (1995). "Local Indicators of Spatial Association-LISA." Geographical Analysis 27(2): 93-115.

Anselin, L. (2002). "Under the hood : Issues in the specification and interpretation of spatial regression models." Agricultural Economics 27(3): 247-267.

Araral, E. (2009). "Privatization and regulation of public services: A framework for institutional analysis." Policy and Society 27(3): 175-180.

Archer, N. P. and F. Ghasemzadeh (1999). "An integrated framework for project portfolio selection." International Journal of Project Management 17(4): 207-216.

ASEAN (2011). Master Plan on ASEAN Connectivity: One Vision, One Identity, One Community. Jakarta, The ASEAN Secretariat: 80.

Augustin, K. and M. Walter (2010). "Operator changes through competitive tendering: Empirical evidence from German local bus transport." Research in Transportation Economics 29(1): 36-44.

Bakker, K. (2007). "Trickle Down? Private sector participation and the propoor water supply debate in Jakarta, Indonesia." Geoforum 38(5): 855-868.

Banzhaf, H. S. and R. P. Walsh (2013). "Segregation and Tiebout sorting: The link between place-based investments and neighborhood tipping." Journal of Urban Economics 74(0): 83-98.

Barker, K. and Y. Y. Haimes (2009). "Assessing uncertainty in extreme events: Applications to risk-based decision making in interdependent infrastructure sectors." Reliability Engineering \& System Safety 94(4): 819-829. 
Barrios, E. B. (2008). "Infrastructure and rural development: Household perceptions on rural development." Progress in Planning 70(1): 144.

Baudains, P., S. D. Johnson, et al. (2013). "Geographic patterns of diffusion in the 2011 London riots." Applied Geography 45(0): 211-219.

Beedasy, J. and D. Whyatt (1999). "Diverting the tourists: a spatial decisionsupport system for tourism planning on a developing island." International Journal of Applied Earth Observation and Geoinformation 1(3-4): 163-174.

Behrens, K. and J.-F. Thisse (2007). "Regional economics: A new economic geography perspective." Regional Science and Urban Economics 37(4): 457-465.

Benferhat, S., D. Dubois, et al. (2006). "Bipolar possibility theory in preference modeling: Representation, fusion and optimal solutions." Information Fusion 7(1): 135-150.

Bennet, R. (2010). "Decentralizing Authority After Suharto: Indonesia's 'Big Bang,' 1998 - 2010." Innovations for Successful Societies Retrieved July 23rd, 2015, from http://successfulsocieties.princeton.edu/sites/successfulsocieties/ files/Policy Note ID132.pdf.

Berg, S. V., L. Jiang, et al. (2011). "Universal service subsidies and cost overstatement: Evidence from the U.S. telecommunications sector." Telecommunications Policy 35(7): 583-591.

Berrebi, Z. M. and J. Silber (1989). "Deprivation, the Gini index of inequality and the flatness of an income distribution." Mathematical Social Sciences 18(3): 229-237.

Bibi, S. and J.-Y. Duclos (2007). "Equity and policy effectiveness with imperfect targeting." Journal of Development Economics 83(1): 109-140.

Bissonnette, L., K. Wilson, et al. (2012). "Neighbourhoods and potential access to health care: The role of spatial and aspatial factors." Health \& Place 18(4): 841-853.

Bivand, R., W. G. Müller, et al. (2009). "Power calculations for global and local Moran's." Computational Statistics \&amp; Data Analysis 53(8): 2859-2872.

Bone, C. and S. Dragićević (2009). "Evaluating Spatio-temporal Complexities of Forest Management: An Integrated Agent-based Modeling and GIS Approach." Environmental Modeling \& Assessment 14(4): 481-496.

BPS (1996). PODES (Potensi Desa). Jakarta, BPS-Statistics Indonesia. BPS (2000). PODES (Potensi Desa). Jakarta, BPS-Statistics Indonesia. BPS (2006). PODES (Potensi Desa). Jakarta, BPS-Statistics Indonesia. 
BPS (2014). Gini Ratio Menurut Provinsi Tahun 1996, 1999, 2002, 2005, 2007-2013. 1996-2013. Jakarta, Biro Pusat Statistik.

Bröcker, J., A. Korzhenevych, et al. (2010). "Assessing spatial equity and efficiency impacts of transport infrastructure projects." Transportation Research Part B: Methodological 44(7): 795-811.

Buckley, R. M. and T. D. Buckley (2009). "Discontent with the World Bank's excursion into economic geography: lions and butterflies once more?" Environment and Planning A 41(12): 2806-2815.

Cabrales, A. and A. Calvó-Armengol (2008). "Interdependent preferences and segregating equilibria." \ournal of Economic Theory 139(1): 99-113.

Cai, G., S. Hirtle, et al. (1999). Mapping the Geography of Cyberspace Using Telecommunications Infrastructure Information. TeleGeo'99 Fist International Workshop on Telegeoprocessing, 6-7th May 1999. Lyon-Villeurbanne, France.

Castells, A. and A. Solé-Ollé (2005). "The regional allocation of infrastructure investment: The role of equity, efficiency and political factors." European Economic Review 49(5): 1165-1205.

Chakhar, S. and V. Mousseau (2007). "An algebra for multicriteria spatial modeling." Computers, Environment and Urban Systems 31(5): 572-596.

Chandola, T. (2012). "Spatial and social determinants of urban health in low-, middle- and high-income countries." Public Health 126(3): 259-261.

Chandra, A. and E. Thompson (2000). "Does public infrastructure affect economic activity?: Evidence from the rural interstate highway system." Regional Science and Urban Economics 30(4): 457-490.

Chen, A. (2010). "Reducing China's regional disparities: Is there a growth cost?" China Economic Review 21(1): 2-13.

Cherchye, L., K. De Witte, et al. (2010). "Efficiency and equity in private and public education: A nonparametric comparison." European Journal of Operational Research 202(2): 563-573.

Chitwood, S. R. (1974). "Social Equity and Social Service Productivity." Public Administration Review 34(1): 29-35.

Cho, C.-J. (1998). "An equity-efficiency trade-off model for the optimum location of medical care facilities." Socio-Economic Planning Sciences 32(2): 99-112.

Clark, G. L. (1998). "Geography and Social Justice. David M. Smith." Urban Geography 19(1): 88-94.

Cloke, P., P. Milbourne, et al. (2001). "The local spaces of welfare provision: responding to homelessness in rural England." Political Geography 20(4): 493-512. 
Cohen, J. P. (2010). "The broader effects of transportation infrastructure: Spatial econometrics and productivity approaches." Transportation Research Part E: Logistics and Transportation Review 46(3): 317326.

Coutinho-Rodrigues, J., A. Simão, et al. (2011). "A GIS-based multicriteria spatial decision support system for planning urban infrastructures." Decision Support Systems 51(3): 720-726.

Couto, P. (2003). "Assessing the accuracy of spatial simulation models." Ecological Modelling 167(1-2): 181-198.

Damodaran, A. (2008). Strategic Risk Taking: A Framework for Risk Management, Wharton School Pub.

Dartanto, T. (2013). "Reducing fuel subsidies and the implication on fiscal balance and poverty in Indonesia: A simulation analysis." Energy Policy 58: 117-134.

Das, A. (2015). "Autonomous but constrained: CBOs and urban upgrading in Indonesia." Cities 48: 8-20.

de Smith, M., M. F. Goodchild, et al. (2013). Geospatial Analysis. A Comprehensive Guide to Principles, Techniques and Software Tools. M. d. Smith, M. F. Goodchild and P. A. Longley. Winchelsea, UK, The Winchelsea Press. Fourth Edition.

Deichmann, U., I. Gill, et al. (2011). "Texture and tractability: the framework for spatial policy analysis in the World Development Report 2009." Cambridge Journal of Regions, Economy and Society 4(2): 163-174.

Deichmann, U., I. Gill, et al. (2010). "World Development Report 2009: A Practical Economic Geography." Economic Geography 86(4): 371380.

Deneulin, S. (2008). Beyond Individual Freedom and Agency: Structures of Living Together in Sen's Capability Approach to Development. The Capability Approach: Concepts, Measures and Application. S. Alkire, F. Comim and M. Qizilbash. Cambridge, Cambridge University Press: 105-124.

Deneulin, S., F. Comim, et al. (2008). Beyond individual freedom and agency: structures of living together in the capability approach: The Capability Approach, Cambridge University Press.

Desmedt, Y. (2002). "Is there a Need for Survivable Computation in Critical Infrastructures?" Information Security Technical Report 7(2): 1121.

Dirgahayani, P. and F. Nakamura (2012). "Fostering partnerships towards sustainable urban mobility from the national to local level: Matsuyama, Japan and Yogyakarta, Indonesia." IATSS Research 36(1): 48-55. 
Dolan, P. and A. Tsuchiya (2009). "The social welfare function and individual responsibility: Some theoretical issues and empirical evidence." Џournal of Health Economics 28(1): 210-220.

Domshlak, C., E. Hüllermeier, et al. (2011). "Preferences in AI: An overview." Artificial Intelligence 175(7-8): 1037-1052.

Druckman, A. and T. Jackson (2008). "Measuring resource inequalities: The concepts and methodology for an area-based Gini coefficient." Ecological Economics 65(2): 242-252.

Dworkin, R. (1981). "What is equality? Part 1: Equality of welfare." Philosophy and Public Affairs 10(3): 185-246.

Dworkin, R. (1981). "What is Equality? Part 2: Equality of Resources." Philosophy and Public Affairs 10(4): 283-345.

Elhorst, J. P., D. J. Lacombe, et al. (2012). "On model specification and parameter space definitions in higher order spatial econometric models." Regional Science and Urban Economics 42(1-2): 211-220.

Eliassen, K. A. and J. From (2009). "Deregulation, privatisation and public service delivery: Universal service in telecommunications in Europe." Policy and Society 27(3): 239-248.

Eliazar, I. I. and I. M. Sokolov (2012). "Measuring statistical evenness: A panoramic overview." Physica A: Statistical Mechanics and its Applications 391(4): 1323-1353.

Essama-Nssah, B. (2005). "A unified framework for pro-poor growth analysis." Economics Letters 89(2): 216-221.

Estache, A., J.-J. Laffont, et al. (2006). "Universal service obligations in LDCs: The effect of uniform pricing on infrastructure access." Lournal of Public Economics 90(6-7): 1155-1179.

European Commision. (2013). "Refocusing EU Cohesion Policy for Maximum Impact on Growth and Jobs: The Reform in 10 points." European Commision Memo MEMO/13/878 Retrieved 22 June, 2014, from http://europa.eu/rapid/press-release MEMO-131011 en.pdf.

Felsenstein, D. and B. A. Portnov (2005). Regional Disparities in Small Countries, Springer.

Feser, E. and S. Sweeney (2006). Regional industry cluster analysis using spatial concepts, space as indicator. Pre-Conference Training, ACCRA 46th Annual Conference, Charlotte, NC.

Firman, T. (2002). "Urban development in Indonesia, 1990-2001: from the boom to the early reform era through the crisis." Habitat International 26(2): 229-249.

Firman, T. (2010). "Multi local-government under Indonesia's decentralization reform: The case of Kartamantul (The Greater Yogyakarta)." Habitat International 34(4): 400-405. 
Flahaut, B. t. (2004). "Impact of infrastructure and local environment on road unsafety: Logistic modeling with spatial autocorrelation." Accident Analysis \&amp; Prevention 36(6): 1055-1066.

Fleury, A. and M. T. L. Fleury (2014). "Local enablers of business models: The experience of Brazilian multinationals acquiring in North America." Journal of Business Research 67(4): 516-526.

Foley, G. (1992). "Rural electrification in the developing world." Energy Policy 20(2): 145-152.

Frederickson, H. G. (1990). "Public-administration and social equity." Public Administration Review 50(2): 228-237.

Frischmann , B. M. (2005). "An Economic Theory of Infrastructure and Commons Management." Minnesota Law Review 89: 917-1030.

Garcia-Valiñas, M. A., R. Fernández-Llera, et al. (2008). More Income Equality or Not? An Empirical Analysis of Individuals' Preferences for Redistribution. CREMA Working Paper Series, School of Economics and Finance, Queensland University of Technology.

Garretsen, H., M. Roberts, et al. (2011). "Geography and development." Cambridge Journal of Regions, Economy and Society 4(2): 157-162.

Gasper, D. (2007). "What is the capability approach?: Its core, rationale, partners and dangers." The Journal of Socio-Economics 36(3): 335359.

Gibson, J. and S. Olivia (2008). The Effect of Infrastructure Access and Quality on Non-Farm Enterprises in Rural Indonesia, University of Waikato, Department of Economics.

Glass, V., S. Stefanova, et al. (2014). "Zero-based budgeting: Does it make sense for universal service reform?" Government Information Quarterly 31(1): 84-89.

Golob, T. F. and M. G. McNally (1997). "A model of activity participation and travel interactions between household heads." Transportation Research Part B: Methodological 31(3): 177-194.

Goodman, A. S. and M. Hastak (2006). Infrastructure Planning Handbook: Planning, Engineering, and Economics, McGraw-Hill Education.

Goosen, H., R. Janssen, et al. (2007). "Decision support for participatory wetland decision-making." Ecological Engineering 30(2): 187-199.

Gorsevski, P. V. and P. Jankowski (2010). "An optimized solution of multicriteria evaluation analysis of landslide susceptibility using fuzzy sets and Kalman filter." Computers \& Geosciences 36(8): 10051020.

Grosse, M., K. Harttgen, et al. (2008). "Measuring Pro-Poor Growth in NonIncome Dimensions." World Development 36(6): 1021-1047.

Grubesic, T. H. (2008). "The spatial distribution of broadband providers in the United States: 1999-2004." Telecommunications Policy 32(34): 212-233. 
Guney, K. and N. Sarikaya (2009). "Comparison of Mamdani and Sugeno Fuzzy Inference System Models for Resonant Frequency Calculation of Rectangular Microstrip Antennas." Progress in Electromagnetics Research B 12: 81.

Gutiérrez, J., A. Condeço-Melhorado, et al. (2010). "Using accessibility indicators and GIS to assess spatial spillovers of transport infrastructure investment." Џournal of Transport Geography 18(1): 141-152.

Hall, D. and E. Lobina (2007). "International actors and multinational water company strategies in Europe, 1990-2003." Utilities Policy 15(2): 64-77.

Harries, K. (1995). Geographical Review 85(3): 402-403.

Hayakawa, H. (2000). "Bounded rationality, social and cultural norms, and interdependence via reference groups." Џournal of Economic Behavior \& Organization 43(1): 1-34.

Heidenberger, K. and C. Stummer (1999). "Research and development project selection and resource allocation: a review of quantitative modelling approaches." International Journal of Management Reviews 1(2): 197-224.

Ho, S.-C., R. J. Kauffman, et al. (2007). "A growth theory perspective on B2C e-commerce growth in Europe: An exploratory study." Electronic Commerce Research and Applications 6(3): 237-259.

Jayakar, K. and C. Liu (2014). "Universal service in China and India: Legitimating the state?" Telecommunications Policy 38(2): 186199.

Jenkins, S. P. and P. J. Lambert (1997). "Three 'I's of poverty curves, with an analysis of UK poverty trends." Oxford Economic Papers 49(3): 317-327.

Johansson, J. and H. Hassel (2010). "An approach for modelling interdependent infrastructures in the context of vulnerability analysis." Reliability Engineering \&amp; System Safety 95(12): 1335-1344.

Jon, M. (1999). "Tradable universal service obligations." Telecommunications Policy 23(5): 363-374.

Jung, F. and U. Sunde (2014). "Income, inequality, and the stability of democracy - Another look at the Lipset hypothesis." European Lournal of Political Economy 35(0): 52-74.

Kakwani, N. and J. Silber (2008). "Introduction: Multidimensional Poverty Analysis: Conceptual Issues, Empirical Illustrations and Policy Implications." World Development 36(6): 987-991.

Keefer, P. and S. Knack (1997). "WHY DON'T POOR COUNTRIES CATCH UP? A CROSS-NATIONAL TEST OF AN INSTITUTIONAL EXPLANATION." Economic Inquiry 35(3): 590-602. 
Kothari, T., M. Kotabe, et al. (2013). "Rules of the Game for Emerging Market Multinational Companies from China and India." Journal of International Management 19(3): 276-299.

Kraay, A. (2006). "When is growth pro-poor? Evidence from a panel of countries." \ournal of Development Economics 80(1): 198-227.

Kröger, W. (2008). "Critical infrastructures at risk: A need for a new conceptual approach and extended analytical tools." Reliability Engineering \&amp; System Safety 93(12): 1781-1787.

Krugman, P. (1991). "Increasing Returns and Economic Geography." Journal of Political Economy 99(3): 483-499.

Kyriacou, A. P. and 0. Roca-Sagalés (2011). "Fiscal decentralization and government quality in the OECD." Economics Letters 111(3): 191193.

Landis, J. R. and G. G. Koch (1977). "The Measurement of Observer Agreement for Categorical Data." Biometrics 33(1): 159-174.

Laprie, J.-C., K. Kanoun, et al. (2007). Modelling Interdependencies Between the Electricity and Information Infrastructures. Computer Safety, Reliability, and Security. F. Saglietti and N. Oster, Springer Berlin Heidelberg. 4680: 54-67.

Lawson, V. (2010). "Reshaping Economic Geography? Producing Spaces of Inclusive Development." Economic Geography 86(4): 351-360.

Lelkes, 0. (2006). "Knowing what is good for you: Empirical analysis of personal preferences and the "objective good"." The Journal of Socio-Economics 35(2): 285-307.

Liang, S. and W.-M. Wey (2013). "Resource allocation and uncertainty in transportation infrastructure planning: A study of highway improvement program in Taiwan." Habitat International 39(0): 128-136.

Liesiö, J., P. Mild, et al. (2007). "Preference programming for robust portfolio modeling and project selection." European Journal of Operational Research 181(3): 1488-1505.

Little, R. G. (2005). "Tending the infrastructure commons: Ensuring the sustainability of our vital public systems." Structure and Infrastructure Engineering 1(4): 263-270.

Lorant, V., I. Thomas, et al. (2001). "Deprivation and mortality: the implications of spatial autocorrelation for health resources allocation." Social Science \& Medicine 53(12): 1711-1719.

Macaulay, T. (2008). Critical Infrastructure: Understanding Its Component Parts, Vulnerabilities, Operating Risks, and Interdependencies, Taylor \& Francis.

Magar, C. S. E. (2010). Chapter 10 - Seven Principles for Interconnectivity: Achieving Sustainability in Design and Construction. Sustainable 
Communities Design Handbook. W. W. Clark. Boston, ButterworthHeinemann: 165-179.

Malczewski, J. (2004). "GIS-based land-use suitability analysis: a critical overview." Progress in Planning 62(1): 3-65.

Malczewski, J. (2006). "Ordered weighted averaging with fuzzy quantifiers: GIS-based multicriteria evaluation for land-use suitability analysis." International Journal of Applied Earth Observation and Geoinformation 8(4): 270-277.

Mamatzakis, E. C. (2003). "Public infrastructure and productivity growth in Greek agriculture." Agricultural Economics 29(2): 169-180.

Maniquet, F. (2004). "On the equivalence between welfarism and equality of opportunity." Social Choice and Welfare 23(1): 127-147.

Marchetti, C. (1993). On Mobility. Final Status Report. Laxenburg, Austria, International Institute for Applied Systems Analysis (IIASA).

Maringanti, A., E. Sheppard, et al. (2009). Where Is the Geography? World Bank's WDR 2009.

McConnell, B. (1978). "Human Geography-A welfare approach by David M. Smith, Edword Arnold." New Zealand Journal of Geography 65(1): 36-37.

McElhinney, S. (2001). "Telecommunications liberalisation and the quest for universal service in Australia." Telecommunications Policy 25(4): 233-248.

Mirabel, F., J. C. Poudou, et al. (2009). "Universal service obligations: The role of subsidization schemes." Information Economics and Policy 21(1): 1-9.

Mitwasi, M., A.-M. Connolly, et al. (1989). "Applying multicriteria decision making techniques for planning machining operations." Applied Mathematics and Computation 29(3): 197-218.

Mokhtarian, P. L. and C. Chen (2004). "TTB or not TTB, that is the question: a review and analysis of the empirical literature on travel time (and money) budgets." Transportation Research Part A: Policy and Practice 38(9-10): 643-675.

Montibeller, G., L. A. Franco, et al. (2009). "Structuring resource allocation decisions: A framework for building multi-criteria portfolio models with area-grouped options." European Journal of Operational Research 199(3): 846-856.

Murphy, J. T. (2011). "The socio-spatial dynamics of development: geographical insights beyond the 2009 World Development Report." Cambridge Journal of Regions, Economy and Society 4(2): 175-188.

Musterd, S. and W. Ostendorf (2012). Inequalities in European Cities. International Encyclopedia of Housing and Home. S. J. Smith. San Diego, Elsevier: 49-55. 
Nazem, S. M., Y.-H. Liu, et al. (1996). "Implementing telecommunications infrastructure: A rural America case." Telematics and Informatics 13(1): 23-31.

Neyapti, B. (2010). "Fiscal decentralization and deficits: International evidence." European Journal of Political Economy 26(2): 155-166.

Niklasson, B. and J. Pierre (2012). "Does agency age matter in administrative reform?: Policy autonomy and public management in Swedish agencies." Policy and Society 31(3): 195-210.

Nussbaum, M. (2003). "Capabilities as fundamental entitlements: Sen and social justice." Feminist Economics 9(2-3): 33-59.

Ohana, S. (2010). "Modeling global and local dependence in a pair of commodity forward curves with an application to the US natural gas and heating oil markets." Energy Economics 32(2): 373-388.

Outhred, H. and M. Retnanestri (2015). "Insights from the Experience with Solar Photovoltaic Systems in Australia and Indonesia." Energy Procedia 65: 121-130.

Overmars, K. P., G. H. J. de Koning, et al. (2003). "Spatial autocorrelation in multi-scale land use models." Ecological Modelling 164(2-3): 257270.

Panggabean, S. R. and B. Smith (2011). "Explaining Anti-Chinese Riots in Late 20th Century Indonesia." World Development 39(2): 231-242.

Parker, D., C. Kirkpatrick, et al. (2008). "Infrastructure regulation and poverty reduction in developing countries: A review of the evidence and a research agenda." The Quarterly Review of Economics and Finance 48(2): 177-188.

Pederson, P., D. Dudenhoeffer, et al. (2006). Critical Infrastructure and Interdependency Modeling: A Survey of US and International Research.

Pen, J. (1971). Income distribution: facts, theories, policies, Praeger.

Perera, L. D. H. and G. H. Y. Lee (2013). "Have economic growth and institutional quality contributed to poverty and inequality reduction in Asia?" Џournal of Asian Economics 27(0): 71-86.

Perny, P. and B. Roy (1992). "The use of fuzzy outranking relations in preference modelling." Fuzzy Sets and Systems 49(1): 33-53.

Phua, M.-H. and M. Minowa (2005). "A GIS-based multi-criteria decision making approach to forest conservation planning at a landscape scale: a case study in the Kinabalu Area, Sabah, Malaysia." Landscape and Urban Planning 71(2-4): 207-222.

Piccolo, D. and A. D'Elia (2008). "A new approach for modelling consumers' preferences." Food Quality and Preference 19(3): 247-259.

Ping, J. L., C. J. Green, et al. (2004). "Exploring spatial dependence of cotton yield using global and local autocorrelation statistics." Field Crops Research 89(2-3): 219-236. 
Pinto, J. A. M. (2003). "Equity valuation in a changing institutional climate: evidence from multinational utilities." \ournal of International Accounting, Auditing and Taxation 12(1): 23-43.

Pisu, M. (2010). Tackling the Infrastructure Challenge in Indonesia, OECD Publishing.

Qizilbash, M. (2011). "Sugden's critique of Sen's capability approach and the dangers of libertarian paternalism." International Review of Economics 58(1): 21-42.

Ravallion, M. (2004). Pro-poor growth : A primer, The World Bank.

Rinaldi, S. M., J. P. Peerenboom, et al. (2001). "Identifying, Understanding, and Analyzing Critical Infrastructure Interdependencies." IEEE control systems magazine. 21: 11-25.

Roberts, F. and A. Tsoukiás (2009). "Voting theory and preference modeling." Mathematical Social Sciences 57(3): 289-291.

Rowley, C. and S. Abdul-Rahman (2007). The Changing Face of Management in South East Asia, Taylor \& Francis.

Rusinova, D. (2007). "Growth in transition: Reexamining the roles of factor inputs and geography." Economic Systems 31(3): 233-255.

Sager, T. (2011). "Neo-liberal urban planning policies: A literature survey 1990-2010." Progress in Planning 76(4): 147-199.

Schafer, A. (1998). "The global demand for motorized mobility." Transportation Research Part A: Policy and Practice 32(6): 455477.

Sen, A. (1980). Equality of What? Tanner Lectures on Human Values. Choice, Welfare and Measurement. S. McMurrin. Cambridge.

Sen, A. (1992). Inequality Reexamined, Clarendon Press.

Sen, A. (2004). "Capabilities, Lists, and Public Reason: Continuing the Conversation." Feminist Economics 10(3): 77-80.

Sen, A. K. (1976). "Poverty: An Ordinal Approach to Measurement." Econometrica 44(2): 219-231.

Sharifi, A. and M. van Herwijnen (2001). Spatial Decision Support Systems. Enschede, International Institute for Geoinformation Science and Earth Observation (ITC).

Shortridge, A. (2007). "Practical limits of Moran's autocorrelation index for raster class maps." Computers, Environment and Urban Systems 31(3): 362-371.

Siegel, J. I., A. N. Licht, et al. (2011). "Egalitarianism and international investment." Journal of Financial Economics 102(3): 621-642.

Siler, W. and J. J. Buckley (2005). Fuzzy Expert Systems and Fuzzy Reasoning, Wiley.

Simon, H. A. (1960). The new science of management decision, PrenticeHall. 
Sivanandam, S. N., S. Sumathi, et al. (2006). Introduction to Fuzzy Logic using MATLAB, Springer.

Sjahrir, B. S., K. Kis-Katos, et al. (2014). "Administrative Overspending in Indonesian Districts: The Role of Local Politics." World Development 59: 166-183.

Slinko, I. (2003). The Impact of Fiscal Decentralization on the Budget Revenue Inequality among Municipalities and Growth of Russian, EERC Research Network, Russia and CIS.

Smith, D. M. (1977). Human Geography: A Welfare Approach. London, Edward Arnold.

Smith, D. M. (1994). Geography and Social Justice: Social Justice in a Changing World, Wiley.

Smith, L. l. (2004). "The murky waters of the second wave of neoliberalism: corporatization as a service delivery model in Cape Town." Geoforum 35(3): 375-393.

Son, H. H. and N. Kakwani (2008). "Global Estimates of Pro-Poor Growth." World Development 36(6): 1048-1066.

Sovacool, B. K. (2013). "Expanding renewable energy access with pro-poor public private partnerships in the developing world." Energy Strategy Reviews 1(3): 181-192.

Stolt, R., P. Blomqvist, et al. (2011). "Privatization of social services: Quality differences in Swedish elderly care." Social Science \& Medicine 72(4): 560-567.

Subramanian, A. and S.-J. Wei (2007). "The WTO promotes trade, strongly but unevenly." Journal of International Economics 72(1): 151-175.

Sudgen, R. (2006). "What We Desire, What We Have Reason to Desire, Whatever We Might Desire: Mill and Sen on the Value of Opportunity." Utilitas 18(01): 33-51.

Tabuchi, T. (2014). "Historical trends of agglomeration to the capital region and new economic geography." Regional Science and Urban Economics 44(0): 50-59.

Takeru, S. and I. Hitoshi (2011). "MOLTS: Multinational Operators for Local Transport Services " Asian Transport Studies 1(3): 234-249.

Tang, C. S. and S. Zhou (2012). "Research advances in environmentally and socially sustainable operations." European Journal of Operational Research 223(3): 585-594.

Tebaldi, E. and R. Mohan (2010). "Institutions and Poverty." The Journal of Development Studies 46(6): 1047-1066.

Thornton, J. (2007). "Fiscal decentralization and economic growth reconsidered." Journal of Urban Economics 61(1): 64-70.

Tiffin, J. and C. Kissling (2007). Transport Communications: Understanding Global Networks Enabling Transport Services, Kogan Page. 
Till, J. (2013). "The broken middle: The space of the London riots." Cities 34(0): 71-74.

Toninelli, P. M. (2000). The Rise and Fall of State-Owned Enterprise in the Western World, Cambridge University Press.

TRB (2004). Design Speed, Operating Speed, and Posted Speed Practices. TRB's National Cooperative Highway Research Program (NCHRP) Report 504, Transportation Research Board of The National Academies

Tsai, Y.-H. (2005). "Quantifying Urban Form: Compactness versus 'Sprawl'." Urban Studies 42(1): 141-161.

Tsou, K.-W., Y.-T. Hung, et al. (2005). "An accessibility-based integrated measure of relative spatial equity in urban public facilities." Cities 22(6): 424-435.

Tsoukias, A. (1991). "Preference modeling as a reasoning process: A new way to face uncertainty in multiple criteria decision support systems." European Journal of Operational Research 55(3): 309318.

UNDP (2008). Malaysia measuring and monitoring poverty and inequality. Malaysia, United Nations Development Programme.

Utne, I. B., P. Hokstad, et al. (2011). "A method for risk modeling of interdependencies in critical infrastructures." Reliability Engineering \&amp; System Safety 96(6): 671-678.

van den Bergh, J. C. J. M. (2009). "The GDP paradox." Journal of Economic Psychology 30(2): 117-135.

Wang, F. and M. T. Arnold (2008). "Localized income inequality, concentrated disadvantage and homicide." Applied Geography 28(4): 259-270.

Wiegand, P. (1995). Geography 80(1): 93.

Williams, G. and R. Pagliari (2004). "A comparative analysis of the application and use of public service obligations in air transport within the EU." Transport Policy 11(1): 55-66.

Wismadi, A., M. Brussel, et al. (2012). "Effect of neighbouring village conditions and infrastructure interdependency on economic opportunity: A case study of the Yogyakarta region, Indonesia." Computers, Environment and Urban Systems 36(5): 371-385.

Wismadi, A., M. Zuidgeest, et al. (2013). "Spatial Preference Modelling for equitable infrastructure provision: an application of Sen's capability approach." Journal of Geographical Systems.

World Bank (2008). World Development Report 2008 - Agriculture for Development. Washington, D.C., The International Bank for Reconstruction and Development / The World Bank.

Xiang, W.-N. (2001). "Weighting-by-choosing: a weight elicitation method for map overlays." Landscape and Urban Planning 56(1-2): 61-73. 
Yager, R. R. (1992). "Second order structures in multi-criteria decision making." International Journal of Man-Machine Studies 36(4): 553570.

Yigitcanlar, T. and S. H. Lee (2014). "Korean ubiquitous-eco-city: A smartsustainable urban form or a branding hoax?" Technological Forecasting and Social Change 89: 100-114.

Yitzhaki, S. (2002). "Do we need a separate poverty measurement?" European Journal of Political Economy 18(1): 61-85.

Yu, Y., L. Zhang, et al. (2011). "On the determinants of public infrastructure spending in Chinese cities: A spatial econometric perspective." The Social Science Journal 48(3): 458-467.

Yuan, J.-H., J.-G. Kang, et al. (2008). "Energy consumption and economic growth: Evidence from China at both aggregated and disaggregated levels." Energy Economics 30(6): 3077-3094.

Zhang, P. and S. Peeta (2011). "A generalized modeling framework to analyze interdependencies among infrastructure systems." Transportation Research Part B: Methodological 45(3): 553-579.

Zhang, Y. (2014). "From State to Market: Private Participation in China's Urban Infrastructure Sectors, 1992-2008." World Development 64: 473-486. 


\section{Summary}

Resource allocation for infrastructure development is one of the central issues in many developing countries. Under conditions of limited budgets prevailing in those countries, resource allocation becomes more critical. The budget constraint problem increases the complexity of the decisionmaking mechanism that includes different policy objectives for development (Liang and Wey 2013). One classical policy trade-off is equity versus efficiency and growth (Castells and Solé-Ollé 2005).

In an infrastructure development context, a pro-poor policy's objective is to include equity principles in a resource allocation mechanism to provide opportunities for communities to join economic activities. The equity measure includes 'social equity' (striving for equity over different socioeconomic groups) and 'spatial equity' (striving for equity over space).

With regard to regional development, two possible approaches to promote the role of infrastructure and economic interaction are available, placebased policies and people-centred policies. These policy options have been detailed in the World Bank publication of the World Development Report (WDR) 2009.

Scientific discourse on place-based policies vs people-centred policies in the context of distributive welfare converges in an attempt to simultaneously address social and spatial equity. Therefore, this study's objective is to equip policy makers with an understanding of the implications of targeting both spatial and social equity in the local context and providing them with recommendations on where and when those policy options should be applied or combined.

Therefore, this thesis addresses issues of inequity in infrastructure resource allocation. This is done by, first conducting a thorough analysis of this problem by investigating whether the two policy options, place-based or people-centred, could distinctly result in effective resource allocation in infrastructure. Second, to further investigate those policy options, for each, a set of models and algorithms was developed to implement the policy into a formal and transparent resource allocation operation. Third, to analyze the effectiveness of each policy option, a framework for measuring the impact on spatial and social equity is provided, based on social welfare theories. Finally, with these three stages, we provide inputs to the possible development of a Spatial Decision Support Systems (SDSS) tool that could be used for infrastructure allocation in the Indonesian context. 
In the first investigation, we examined the effect of places and its spatial connection of infrastructure to the distribution of economic opportunities. Here, we developed and compared three models of infrastructure and economic interaction. The first model defines economic opportunity in a village as a function of available infrastructure within that village. The second model includes the effect of economic opportunity in neighbouring villages in addition to available infrastructure within the village. In the third model we include the interdependency of infrastructures as another factor affecting the potential level of economic development in the village.

Our comparison of these three connected concepts and associated models disclosed that both neighbourhood factors and infrastructure interdependency are critically important and should be included in the decision making process for allocating resources in infrastructure development. Therefore, the findings emphasize the importance of considering information on neighbouring areas and infrastructure interdependency in the implementation of a place-based policy for allocating resources for infrastructure development.

In an attempt to further examine the effectiveness of place-based policy, we developed a new approach to implement such a policy in a Spatial Decision Support System (SDSS). This approach is operationalized as the Preference Modelling (PM) component of the SDSS. PM provides a means to transform stakeholder value into priority and allocation. This is done by introducing Spatial Preference Modelling (SPM), which enables us to operationalize Place-based Policy in a DSS for allocating resources. In the comparison with the traditional Preference Model, we found that by considering the neighbouring unit differences, resource allocation with SPM performs better in addressing spatial equity issues.

To generalize our findings, we compared the agreement of place-based and people-centred policies on planning objectives and social justice, with reference to utilitarian and non-utilitarian welfare theories applied in infrastructure.

The comparison involves a case study presenting a resource allocation problem for infrastructure development that includes roads, electricity, telecommunication and fresh water infrastructure in the Special Region of Yogyakarta in Indonesia. The results confirm that Spatial Preference Modelling generally better satisfies both utilitarian and non-utilitarian welfare theory than the more traditional non-spatial Preference Modelling. The effectiveness of the preference modeling is also influenced by the level of development, the typology of infrastructure, and the initial contribution 
level of inequality. These findings could help both utilitarian as well as nonutilitarian infrastructure planners achieve a more equitable allocation of resources.

Learning from the nature of the effectiveness of "place-based" over "people-centred" policies for equitable infrastructure, we developed a decision support framework to recommend where and when "place-based" or "people-centred" policies for equitable infrastructure development should be applied. This framework synthesizes all of the findings into a decision support framework for Equity Based Resources LocationAllocation Simulation (EQLAS) for integrated infrastructure development.

The EQLAS is a framework to operationalize measures of well-being and equity in resource location-allocation modelling. It includes two types of preference modelling to operationalize both Place-based and Peoplecentred policies, evaluating their impacts and recommending which policy needs to be applied, as well as when and where, according to specific localities.

In conclusion, in addition to evaluating the impact of each policy option, this research also contributes in the provision of a new formal method to apply policy options into a resource allocation approach in a GIS-based Decision Support System. Hence, this research allows policy and decision makers to systematically address inequity by means of improving infrastructure performance toward equitable growth. 


\section{Samenvatting}

Toewijzing van middelen voor infrastructuurontwikkeling is een van de centrale thema's in veel ontwikkelingslanden. Juist in deze landen, met hun beperkte budgetten, wordt de toewijzing van middelen kritischer. Het probleem van deze beperkte budgetten verhoogt de complexiteit van het besluitvormingsproces dat verschillende beleidsdoelstellingen voor ontwikkeling moet verenigen (Liang en Wey 2013). Een klassieke wisselwerking tussen deze beleidsdoelstellingen is het bereiken van rechtvaardigheid ten opzichte van efficiëntie en groei (Castells en Solé-Ollé 2005).

In de context van infrastructuurontwikkeling is het doel van beleid dat gericht is op het arme deel van de bevolking om principes van rechtvaardigheid op te nemen in het toewijzen van middelen en zodoende de mogelijkheden voor gemeenschappen om zich economisch te ontwikkelen te vergroten. Deze rechtvaardigheidsbenadering omvat een begrip van sociale rechtvaardigheid (rechtvaardigheid in verdeling over verschillende inkomensgroepen) en ruimtelijke rechtvaardigheid (in de zin van het streven naar een gelijkwaardige ruimtelijke verdeling).

Met betrekking tot regionale ontwikkeling zijn er twee mogelijke benaderingen ter realisatie van de rol van infrastructuur in het vergroten van economische activiteit: ruimtelijk (plaatsgebonden) beleid en mensgericht (sociaal) beleid. Deze beleidsopties zijn beschreven in de het World Development Report van de Wereldbank (WDR, 2009).

Het wetenschappelijk debat over locatie gebaseerd beleid versus mensgericht beleid in het kader van de verdeling van rechtvaardigheid convergeert in een poging om tegelijkertijd ruimtelijke en sociale rechtvaardigheid te bewerkstelligen. Daarom is het doel van deze studie het voorzien van beleidsmakers van een goed begrip van het toepassen van locatiegericht en mensgericht beleid in de lokale context en hen te voorzien van aanbevelingen over waar en wanneer deze beleidsopties moeten worden toegepast of gecombineerd.

Daarom richt dit proefschrift zich op vraagstukken van ongelijkheid bij de toewijzing van middelen voor infrastructuurontwikkeling. Dit gebeurt door enerzijds een grondige probleemanalyse; onderzocht is of de twee beleidsopties (locatiegericht en mensgericht) leiden tot een meer effectieve toewijzing van middelen voor infrastructuur. Hierna zijn voor elk van deze beleidsopties modellen en algoritmen ontwikkeld om beleidsimplementatie in een meer formele procedure van toewijzing te 
realiseren. Ten derde wordt, om de effectiviteit van elke beleidsoptie te analyseren, een kader ontwikkeld voor het meten van de impact van toewijzing op ruimtelijke en sociale rechtvaardigheid. Deze meting is gebaseerd op theorieën van sociale rechtvaardigheid. Tenslotte geven we door middel van deze drie fasen input voor de mogelijke ontwikkeling van een ruimtelijk beslissingsondersteunend systeem dat kan worden gebruikt voor de toewijzing van infrastructuur in de context van Indonesië.

In het eerste deel van het onderzoek kijken we naar het effect van locatie en het ruimtelijke verband tussen infrastructuur en de verdeling van economische kansen. Met dit doel zijn 3 modellen ontwikkeld. Het eerste model beschouwt economische ontwikkeling als een functie van de beschikbare infrastructuur in een ruimtelijke eenheid (het dorpsniveau binnen het Indonesische administratieve systeem). Het tweede model kijkt ook naar de effecten van infrastructuur in de omliggende dorpen op de kwaliteit van de infrastructuur in het dorp zelf. In het derde model wordt ook gekeken naar de interactie tussen verschillende soorten infrastructuur.

Teneinde plaatsgebonden beleid verder te onderzoeken is een nieuwe aanpak ontwikkeld waarin de toewijzing van middelen wordt gedaan middels een ruimtelijk beslissingsondersteunend systeem. Hiermee wordt de effectiviteit van de twee benaderingen vergeleken. Het beslissingsondersteunend systeem vormt een middel om belanghebbenden te betrekken bij het bepalen van prioriteiten welke infrastructuur te ontwikkelen en welke middelen toe te wijzen. Dit wordt gedaan door de invoering van een ruimtelijk voorkeursmodel, dat ons in staat stelt om op basis van plaatsgebonden beleid middelen toe te wijzen. In de vergelijking tussen het meer traditionele niet-ruimtelijke en het ruimtelijke model blijkt dat het ruimtelijk model in staat is een betere verdeling van middelen te bewerkstelligen.

Om onze bevindingen te generaliseren, vergelijken we de overeenkomst van locatiegericht en mensgericht beleid met planningsdoelstellingen en sociale rechtvaardigheid, onder verwijzing naar de utilitaire en nietutilitaire welzijnstheorieën zoals deze worden toegepast in de infrastructuur.

Deze vergelijking betreft een studie naar de toewijzing van middelen voor de ontwikkeling van wegen, elektriciteit, telecommunicatie en zoet water in de regio Jogjakarta in Indonesië. De resultaten bevestigen dat ruimtelijke voorkeursmodellen in het algemeen beter voldoen aan zowel utilitaire als niet-utilitaire welzijnstheorie dan de meer traditionele niet-ruimtelijke voorkeursmodellen. De effectiviteit van de modellen wordt ook beïnvloed 
door het niveau van ontwikkeling, de typologie van de infrastructuur, en de eerste mate van ongelijkheid. Deze bevindingen kunnen zowel utilitaire als niet-utilitaire infrastructuur planners helpen om te komen tot een meer rechtvaardige verdeling van middelen.

Op basis van de effectiviteit van de locatiegerichte en mensgerichte aanpak ontwikkelen we een raamwerk voor een beslissingsondersteunend systeem, dat aanbevelingen omvat waar en wanneer welke aanpak moet worden toegepast. Dit raamwerk combineert alle bevindingen in een beslissingsondersteunend systeem voor geïntegreerde ontwikkeling van de infrastructuur, het zogenoemde EQLAS model.

Het EQLAS Model stelt ons in staat om maatregelen ter vergroting van welzijn en sociale en ruimtelijke rechtvaardigheid te operationaliseren in een locatie-allocatie model. Het omvat twee soorten voorkeursmodellen die kunnen omgaan met locatiegericht en mensgericht beleid, is in staat om effecten te bepalen en aanbevelingen te doen welk beleid dient te worden toegepast in welke locatie.

Tot slot, in aanvulling op mogelijkheid om de impact van beleidsopties te bepalen, draagt dit onderzoek ook bij aan de een nieuwe formele methode om verschillende beleidsopties toe te passen in een locatie-allocatie benadering in een op GIS gebaseerd beslissingsondersteunend systeem. Op deze manier stelt dit onderzoek beleidsmakers en beslissers in staat op een systematische manier onrechtvaardigheid te betrekken in het verbeteren van infrastructuur. 


\section{Biography}

Arif Wismadi was born on June 13, 1968 in Purbalingga. He obtained Bachelor's degree in architecture from Universitas Gadjah Mada, Yogyakarta, Indonesia in 1992, and then entered his professional career within multi disciplinary teams in a consulting engineer that focused on designing and planning public facilities and infrastructures. He started his teaching experience in Departement of Architecture, Faculty of Civil Engineering and Planning, Universitas Islam Indonesia in 1993. After 8 years of research and consulting activities, he joined an initiative to establish research center for transport and logistics which then in 2001 formally named as Center for

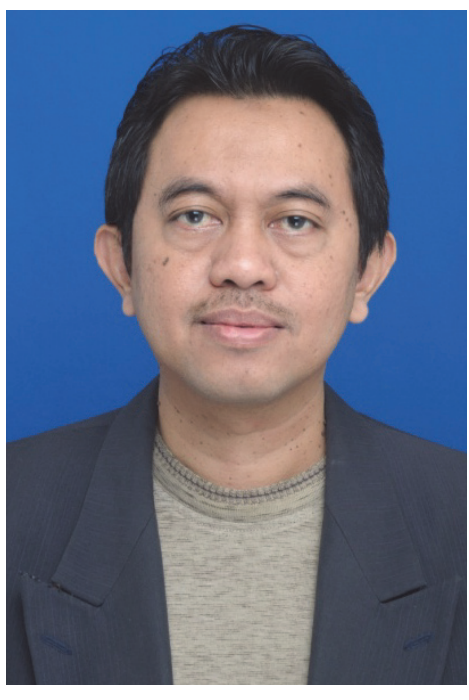
Transportation and Logistics Studies (PUSTRAL) in Universitas Gadjah Mada. To enhance the capacity to deal with information complexity in research, consultancy and advocacy service, with support of Stuned Scholarship, he studied Geo-Information Management in ITC, the Netherland and obtained MSc degree in 2003. Equipped with this knowledge, he expanded his professional carrier on various field of infrastructure planning and management. His 23 years consulting experiences include public sector reforms toward pro-competitive policy to promote growth, while securing the interest of vurnerable societies. This experience then became one of the triggering factors to join the initiative to establish a new Master Program on Management of Infrastructure and Community Development in Universitas Gadjah Mada (http://pipm.pasca.ugm.ac.id). The success of the proposal had opened his opportunity for pursuing PhD with support of Indonesia Facility (INDF) Project. During study period, beside served research and education activities for this new program, he also experienced in supervising, facilitating and hosting research in Indonesia for more than 30 students from ITC and other faculties in University of Twente. His interest on university-based and multidisciplinary research has continued to extend through networked organizations of regional association, international societies and scientific communities. Hence, beside perfoming $\mathrm{PhD}$ research he also served ITU, ADB, AusAID and World Bank, and had leadership positions at various projects of USAID, European Union, and ASEAN. All these exposures on the real world problems had been influencing the process and outcome of this $\mathrm{PhD}$ research. 


\section{ITC Dissertation List}

http://www.itc.nl/research/phd/phd graduates.aspx 